\title{
UTILIZAÇÃO DE ANÁLISES ECOTOXICOLÓGICAS NO APRIMORAMENTO DA AVALIAÇÃO DA QUALIDADE DA ÁGUA: APLICAÇÃO DO IVA - ÍNDICE DE QUALIDADE DA ÁGUA PARA A PROTEÇÃO DA VIDA AQUÁTICA
}

\section{MARIA DE LOURDES LORENZETTI}

\author{
Tese apresentada ao Departamento de \\ Saúde Ambiental da Faculdade de Saúde \\ Pública da Universidade de São Paulo \\ para obtenção do Grau de Doutor em \\ Saúde Pública. \\ Área de Concentração: Saúde Ambiental \\ Orientadora: Dra Denise Navas Pereira
}

São Paulo, SP 
Autorizo, exclusivamente para fins acadêmicos e cientificos, a reprodução total ou parcial desta tese, por processos fotocopiadores.

Assinatura 


\section{AGRADECIMENTOS}

Quero agradecer a muitas pessoas que me auxiliaram na realização deste trabalho.

Mas quero, antes de tudo, dedicar esta tese à minha orientadora de todas as horas, Denise Navas Pereira.

Dificil é traduzir neste espaço o importante papel de coadjuvante que esta querida amiga, mais que uma orientadora, prestou durante todas as etapas desta tese. Discutiu a concepção, auxiliou na elaboração, revisão, edição, e cobrou, cobrou, cobrou...mas sempre incentivando e com disponibilidade para colaborar. Quero agradecer sua paciência e o seu crédito na minha capacidade profissional.

Um dos objetivos ocultos deste trabalho foi ressaltar o trabalho de um grupo de profissionais dedicados e motivados pela crença de estarem fazendo algo pelo bem do meio ambiente e da saúde pública. Minha intenção foi apresentar, na introdução desta tese, um histórico, não completo, mas significativo, da importância deste grupo de profissionais que trouxe para o Brasil a Ecotoxicologia Aquática, e se esforçou para difundi-la em todo o país. Com eles convivi e aprendi, e foi principalmente com eles que contei para discutir, buscar informação, apoio e colaboração para esta tese. Somos todos autores dos índices para proteção da vida aquática apresentados aqui; este foi mais um dos valiosos trabalhos realizados em conjunto por este grupo, do qual orgulhosamente fiz parte. São eles os meus colegas da área de Hidrobiologia da CETESB, os mais antigos e os mais novos: Eduardo, Pedro, Rosalina, Valéria, Marta, Sandra, Márcia Aragão, Daniel, Maria do Carmo, Mara, Guiomar, Mônica, Rita, Márcia Janete e Milanelli.

Pude contar, durante a elaboração desta tese, com a ajuda pronta, eficiente e descompromissada de muitos colegas da CETESB, seja na elaboração dos mapas (Marisa, Marise e Ana), seja através de valiosas sugestões, além da cessão de dados e material para consulta (Nelson, Bevilacqua, Maria Inês). A todos o meu sincero e emocionado agradecimento.

Finalmente, agradeço ao Alcides, e ao Ettore, meu filho, pela compreensão e paciência ao prescindir da minha companhia nas muitas horas dedicadas a este trabalho. 


\section{RESUMO}

Lorenzetti ML. Utilização de análises ecotoxicológicas no aprimoramento da avaliação da qualidade da água: aplicação do IVA - Índice de Qualidade da Água para Proteção da Vida Aquática. São Paulo; 2001. [Tese de Doutorado Faculdade de Saúde Pública da USP].

Análises ecotoxicológicas têm sido utilizadas pela CETESB no monitoramento da qualidade das águas no Estado de São Paulo desde 1992, e foram recentemente incorporadas a um índice numérico, o IVA-Índice de Qualidade das Águas para Proteção da Vida Aquática. Foi avaliada a adequação do uso dessas análises como componentes de indices numéricos de qualidade de água para a proteção da vida aquática, a capacidade do IVA em complementar informações sobre a qualidade do ambiente aquático e identificar as causas de deterioração da qualidade da água. Para tanto, o IVA foi aplicado a uma bacia hidrográfica numa série histórica de dados, comparando-o ao IQA (Índice de Qualidade das Águas), adotado até o presente como índice genérico de qualidade das águas no Estado de São Paulo. O IVA é composto por dois índices: o IPMCA - Índice de Parâmetros Mínimos para Proteção das Comunidades Aquáticas e o IET - Índice de Estado Trófico. O IVA foi aplicado à bacia do rio Cubatão, nos cinco pontos da Rede de Monitoramento da Qualidade das Águas da CETESB localizadas nesta bacia, no período de 1995 a 2000 , e os resultados foram avaliados quanto aos indicadores de qualidade que influenciaram a sua classificação, a sensibilidade do IVA comparada ao IQA e a tendência observada em seis anos de dados. Foram detectadas condições piores da qualidade da água em praticamente todos os pontos de monitoramento, em relação ao IQA, muitas vezes devido à deteç̧ão de toxicidade a organismos aquáticos e/ou potencial de eutrofização. Os indicadores de qualidade que influenciaram na classificação das águas pelo IVA como Regular, Ruim e Péssima foram o IET no rio Cubatão a jusante do Canal de Fuga da Usina Hidrelétrica (44,7\%), no rio Mogi $(46,3 \%)$ e no rio Piaçaguera $(25,3 \%)$, a toxicidade no outro ponto do rio Cubatão $(39,5 \%)$ e no Canal de Fuga da Usina Hidrelétrica $(35,1 \%)$, o pH no rio Mogi $(17,6 \%)$, e o oxigênio dissolvido no rio Piaçaguera $(15,5 \%)$. Das substâncias tóxicas, destacaram-se fenóis e os metais cádmio, cobre, chumbo, cromo, mercúrio, níquel e zinco. A análise estatística não demonstrou qualquer tendência para os dados do IVA. A inclusão de análises ecotoxicológicas como componentes de um índice numérico permitiu uma avaliação mais fidedigna da qualidade da água para proteção da vida aquática; a integração do IET e do IPMCA na formação do IVA ampliou significativamente a capacidade deste índice para identificar as variáveis causadoras da deterioração da qualidade da água; o IVA permite a inclusão de outros indicadores para a avaliação de um determinado ambiente aquático, dentro do grupo de substâncias tóxicas do IPMCA. A aplicação do IVA na bacia do rio Cubatão mostrou que esse índice é mais adequado que o IQA para avaliar a qualidade das águas com fins de proteção da vida aquática. A divulgação pública do IVA constitui-se em uma rica e útil fonte de informações para fóruns regionais tomadores de decisão.

Descritores: Análises ecotoxicológicas, Índices de qualidade de água, Bacia do rio Cubatão. 


\section{SUMMARY}

Lorenzetti ML. The use of ecotoxicological analyses in the improvement of water quality evaluation: application of IVA - Water Quality Index for Protection of Aquatic Life. São Paulo; 2002. [Tese de Doutorado - Faculdade de Saúde Pública da USP].

The monitoring of the water quality in the State of São Paulo by using ecotoxicological analyses is a fact, and recently they were included in a numeric index, IVA - Water Quality Index for Protection of Aquatic Life. The use of ecotoxicological analyses as components of numeric indexes of water quality intended to protect aquatic communities was evaluated, also the IVA's ability to detect the state of quality of the aquatic environment and to identify the causes of deterioration of the water quality; the Index was also applied to a hidrographic basin through a historical series of data, comparing it to IQA, the Index of Water Quality. IVA is composed by two indexes: IPMCA - Index of Minimum Parameters for Protection of the Aquatic Communities, and IET - Index of Trophic State. IVA was applied to the Cubatão river basin, in the five (5) points where the water quality is monitored by the system of São Paulo State in this basin, from 1995 to 2000 , and the results were evaluated in relation to the parameters that influenced their classification, IVA's sensibility compared to IQA, and the observed tendency in six (6) years of data. Worse conditions of the water quality were detected in practically all the monitoring stations, in relation to IQA. The parameters that influenced the classification of the water quality for IVA as to Regular, Bad and Very Bad were IET in the Cubatão river downstream the Henry Borden outflow (44,7\%), in the Mogi river (46,3\%) and in the Piaçaguera river $(25,3 \%)$; the toxicity in the other station of the Cubatão river $(39,5 \%)$ and in the Henry Borden outflow $(35,1 \%)$; the $\mathrm{pH}$ in the Mogi river $(17,6 \%)$, and the dissolved oxygen in the Piaçaguera river $(15,5 \%)$. Of the toxic substances, the most important were phenols, cadmium, copper, lead, chromium, mercury, nickel and zinc. The statistical analysis didn't demonstrate any tendency for IVA's data. The inclusion of ecotoxicological analyses as components of a numeric index was a great progress, because it allowed a more trustworthy evaluation of the water quality related to the aquatic communities' protection. The integration of IET and of IPMCA in IVA's making of enlarged significantly the ability of this index to identify the variable that causes the deterioration of the water quality. IVA allows the inclusion of other significant parameters for the evaluation of an aquatic environment, in the component group of toxic substances of IPMCA. Concerning IVA's application in the Cubatão river basin, it was found that this index is more adapted for evaluation of the water quality for protection of the aquatic life than IQA. IVA's public notice is a rich and useful source of information for regional forums of decision makers.

Descriptors: Ecotoxicological analyses, Water quality indexes, Cubatão river basin. 


\section{ÍNDICE}

1. INTRODUÇÃO 1

2. OBJETIVOS 11

3. METODOLOGIA 12

3.1. IPMCA - Índice de Parâmetros Mínimos para

$\begin{array}{ll}\text { Proteção das Comunidades Aquáticas } & 12\end{array}$

3.2. IET - Índice do Estado Trófico 15

3.3. IVA - Índice para a Proteção da Vida Aquática $\quad 17$

3.4. Aplicação do IVA à bacia do rio Cubatão 18

4. RESULTADOS 24

5. DISCUSSÃO 41

5.1. Índices de qualidade de água $\quad 41$

5.2. Aplicação do IVA à bacia do rio Cubatão $\quad 50$

6. CONCLUSÕES E RECOMENDAÇÕES

7. REFERÊNCIAS BIBLIOGRÁFICAS

ANEXOS

Tabelas A1 a A30 - Resultados dos parâmetros analisados pela Rede de Monitoramento e cálculo do IVA.

Tabelas A31 a A35 - Parâmetros que influenciaram na qualidade das águas classificadas pelo IVA como Regular, Ruim e Péssima.

Tabelas A36 a A40 - Sumário da análise estatística da média móvel do IVA 


\section{LISTA DE TABELAS}

Tabela 1. Indicadores de qualidade componentes do IPMCA e suas ponderações, de acordo com os três níveis de qualidade

Tabela 2. Classificação do estado trófico, segundo o Índice de Carlson, modificado por Toledo et al. (1983)

Tabela 3. Representação das classes de qualidade com os valores de IVA

Tabela 4. Valores atribuídos às diferentes classes do IVA para a utilização em séries temporais

Tabela 5. Descrição dos pontos de amostragem na bacia do rio Cubatão (segundo CETESB, 2001 ${ }^{\mathrm{a}}$ )

Tabela 6. Médias anuais do IVA - Índice para Proteção da Vida Aquática, nos diferentes pontos de amostragem, no período de 1995 a 2000 


\section{LISTA DE FIGURAS}

Figura 1. Localização da área de estudo no litoral do Estado de São Paulo

Figura 2. Mapa representativo da região de estudo, com a localização dos pontos de amostragem de qualidade das águas

Figura 3. Ponto CUBA02700 - Indicadores de qualidade que influenciaram na qualidade das águas classificadas pelo IVA como Regular, Ruim e Péssima

Figura 4. Ponto CUBA03900 - Indicadores de qualidade que influenciaram na qualidade das águas classificadas pelo IVA como Regular, Ruim e Péssima

Figura 5. Ponto CFUG02900 - Indicadores de qualidade que influenciaram na qualidade das águas classificadas pelo IVA como Regular, Ruim e Péssima

Figura 6. Ponto MOGI02800 - Indicadores de qualidade que influenciaram na qualidade das águas classificadas pelo IVA como Regular, Ruim e Péssima

Figura 7. Ponto PIAC02700 - Indicadores de qualidade que influenciaram na qualidade das águas classificadas pelo IVA como Regular, Ruim e Péssima

Figura 8. Freqüências percentuais das classificações de qualidade da água obtidas para IQA e IVA, no ano de 1995

Figura 9. Freqüências percentuais das classificações de qualidade da água obtidas para IQA e IVA, no ano de 1996

Figura 10. Freqüências percentuais das classificações de qualidade da água obtidas para IQA e IVA, no ano de 1997

Figura 11. Freqüências percentuais das classificações de qualidade da água obtidas para IQA e IVA, no ano de 1998

Figura 12. Freqüências percentuais das classificações de qualidade da água obtidas para IQA e IVA, no ano de 1999

Figura 13. Freqüências percentuais das classificações de qualidade da água obtidas para IQA e IVA, no ano de 2000

Figura 14. Médias anuais das classificações de qualidade da água obtidas para o IVA no período de 1995 a 2000

Figura 15. Evolução da média móvel do IVA no ponto CUBA02700, no período de 1995 a 2000

Figura 16. Evolução da média móvel do IVA no ponto CUBA03900, no período de 1995 a 2000 
Figura 17. Evolução da média móvel do IVA no ponto CFUG02900, no período de 1995 a 2000

Figura 18. Evolução da média móvel do IVA no ponto MOGI02800, no período de 1995 a 2000

Figura 19. Evolução da média móvel do IVA no ponto PIAC02700, no período de 1995 a 2000

Figura 20. Evolução da média móvel do IQA no ponto CUBA02700, no período de 1991 a 2000

Figura 21. Evolução da média móvel do IQA no ponto CUBA03900, no período de 1991 a 2000

Figura 22. Evolução da média móvel do IQA no ponto CFUG02900, no período de 1991 a 2000

Figura 23. Evolução da média móvel do IQA no ponto MOGI02800, no período de 1991 a 2000

Figura 24. Evolução da média móvel do IQA no ponto PIAC02700, no período de 1991 a 2000 


\section{INTRODUÇÃO}

A preocupação do homem com a qualidade da água para seus diferentes usos não é nova. Por centenas de anos, os procedimentos para avaliação da qualidade de água foram baseados em cheiro, aparência e sabor. Nas últimas décadas, tem havido um grande progresso no sentido de partir de associações sensoriais para um maior conhecimento das características das águas, através da aplicação de avanços científicos na deteç̧ão e determinação analítica de seus elementos, possibilitando uma definição de sua adequação para usos específicos.

A relação da qualidade das águas com doenças, e consequentemente com as condições sanitárias, foi o grande impulsionador do desenvolvimento de exames bacteriológicos e a base científica para o estabelecimento de critérios de qualidade de água para a proteção da saúde pública. Posteriormente, um grande número de substâncias que podem estar presentes no meio aquático foi reconhecido como potencialmente causador de efeitos adversos, considerando outros usos, além do abastecimento público.

A evolução do conhecimento das características das águas e dos efeitos dos poluentes decorrentes da crescente interferência antrópica nos corpos d'água possibilitou o desenvolvimento de padrões e critérios de qualidade, refletidos tanto em legislações quanto em guias contendo recomendações e procedimentos para avaliar a qualidade dos recursos hídricos (USEPA, 1973). Esses padrões, estabelecidos em legislação, e os critérios propostos por diretrizes ("guidelines") de qualidade de água, estes freqüentemente reavaliados de acordo com os dados mais recentes do conhecimento científico, têm servido de referência para a avaliação da adequação das águas para diferentes usos.

A Organização Mundial da Saúde sugere três formas básicas de obtenção de dados de qualidade de água (OMS, apud ROBERTO \& ABREU, 1991):

- monitoramento

- vigilância, $\mathrm{e}$

- investigação

O monitoramento prevê o levantamento sistemático de dados em pontos selecionados, de modo a acompanhar a evolução das condições de qualidade da água ao longo do tempo, fornecendo séries temporais e espaciais.

A vigilância implica numa avaliação praticamente contínua da qualidade da água. Pretende detectar alterações instantâneas de modo a permitir providências imediatas para resolver ou contornar o problema, como, por exemplo, suspender uma captação para abastecimento público. Essa prática exige, normalmente, a utilização de equipamentos automáticos de medição.

A investigação é projetada para atender às necessidades de um estudo em particular. Normalmente, é feita em campanhas intensivas e de determinada duração. 
O monitoramento de qualidade das águas é um dos aspectos essenciais para a caracterização da qualidade dos recursos hídricos, e identificação de mudanças temporais e espaciais causadas pelas atividades humanas e fatores naturais. Deve, também, ser capaz de fornecer informações para o gerenciamento adequado dos recursos hídricos, garantindo que sejam tomadas decisões adequadas sobre as ações necessárias para prevenir ou mesmo remediar a degradação dos corpos d'água (INTERGOVERNMENTAL TASK FORCE ON MONITORING WATER QUALITY, 1992).

\section{Monitoramento da Qualidade das Águas no Estado de São Paulo}

No Estado de São Paulo, a CETESB - Companhia de Tecnologia de Saneamento Ambiental, criada através da Lei Estadual 118, de 29/06/73, recebeu a atribuição de "manter um sistema de informações e divulgar dados de interesse da engenharia sanitária e da poluição das águas, de forma a ensejar o aperfeiçoamento de métodos e processos para estudos e projetos, execução e manutenção de sistemas" (CETESB, 1996).

Em fins de 1974, a CETESB deu início à operação da Rede Básica de Monitoramento da Qualidade das Águas Interiores do Estado de São Paulo, com a seleção de 47 pontos de amostragem, sendo que, desde então, várias modificações foram introduzidas, com alteração de pontos de amostragem, freqüência de coletas e parâmetros determinados.

O programa de monitoramento da agência ambiental do Estado de São Paulo avalia 33 parâmetros físicos, químicos e microbiológicos, considerados mais representativos para a avaliação sistemática da qualidade das águas:

Temperatura da água

Temperatura do ar $\mathrm{pH}$

Oxigênio dissolvido (OD)

Demanda bioquímica de oxigênio (DBO)

Demanda química de oxigênio (DQO)

Coliformes totais

Coliformes fecais

Nitrogênio total

Nitrogênio nitrato

Nitrogênio nitrito

Nitrogênio amoniacal

Nitrogênio Kjeldahl total

Fósforo total

Ortofosfato solúvel

Residuo total

Resíduo não filtrável
Turbidez

Condutividade específica

Cor

Surfactantes

Fenol

Cloreto

Ferro total

Manganês

Bário

Cádmio

Chumbo

Cobre

Cromo total

Niquel

Mercúrio

Zinco

Os dados obtidos no monitoramento são comparados com os limites estabelecidos pela Resolução CONAMA 20/86 (CONAMA, 1986) ou pelo Decreto Estadual 
8468/76 (CETESB, 1994a), identificando, assim, os indicadores de qualidade que se apresentaram ou não em conformidade com esses limites.

Um dos instrumentos que tem sido utilizado para facilitar a interpretação das informações geradas pelo monitoramento é o IQA - Índice de Qualidade das Águas, adotado pela CETESB em 1978, e desenvolvido pela "National Sanitation Foundation", dos Estados Unidos. Esse índice incorpora 9 indicadores de qualidade escolhidos em uma pesquisa feita entre especialistas em qualidade de águas, em 1970, como os mais relevantes para a avaliação da qualidade das águas para abastecimento público. Foram estabelecidas curvas de variação da qualidade das águas de acordo com o estado ou a condição de cada parâmetro e, em função da concentração ou medida dos parâmetros, são obtidos valores das curvas médias de variação de qualidade. O IQA é determinado pelo produtório ponderado das qualidades de água correspondentes aos nove parâmetros selecionados: temperatura da amostra, $\mathrm{pH}$, oxigênio dissolvido, demanda bioquímica de oxigênio, coliformes fecais, nitrogênio total, fósforo total, resíduo total e turbidez (CETESB, 1978).

O cálculo do IQA resulta em um número que varia na faixa de 0 a 100 , e a qualidade da água bruta é classificada para o abastecimento público segundo o seguinte critério de qualidade (CETESB, 1996):

$\begin{array}{cll}80-100 & \Rightarrow & \text { ótima } \\ 52-79 & \Rightarrow & \text { boa } \\ 37-51 & \Rightarrow & \text { aceitável } \\ 20-36 & \Rightarrow & \text { ruim } \\ 0-19 & \Rightarrow & \text { péssima }\end{array}$

Para os elementos tóxicos analisados, que não são levados em conta no cálculo do IQA, até o ano de 1993 era adotado o IT - Índice de Toxicidade, uma variável binária que assumia o valor 0 (zero) caso um ou mais dos elementos tóxicos ultrapassasse os padrões estabelecidos para a classe 1 do CONAMA 20/86, ou valor 1 (um), caso esses elementos estivessem dentro dos limites permitidos. O conjunto de substâncias tóxicas considerados para o IT eram: bário, cádmio, chumbo, cobre, cromo total, estanho, mercúrio, zinco e fenol. Desta forma, a nota final de uma amostra de água extraída de um determinado ponto de amostragem era o resultado do produto do IQA pelo IT. Portanto, o resultado final do IQA, com a aplicação do Indice de Toxicidade, era dependente das concentrações máximas permissíveis de substâncias tóxicas fixadas nos padrões de qualidade das águas para cada classe de água estabelecida na legislação, e não se embasava em qualquer identificação de efeito tóxico a organismos aquáticos, que poderia ser verificado através de testes de toxicidade.

$\mathrm{Na}$ época em que em vários países estavam sendo elaborados critérios e padrões numéricos para uma série de substâncias, visando a proteção dos recursos hídricos para seus diferentes usos, dentre eles a preservação da vida aquática, as atividades em Toxicologia Aquática, o delineamento de seus princípios e, principalmente, sua aplicação no controle da poluição hídrica, estavam apenas se iniciando (MACEK, 1980; BUIKEMA et al., 1982 in BERTOLETTI, 1989). 
A Toxicologia Aquática é definida como o estudo dos efeitos de substâncias químicas manufaturadas e outros materiais antropogênicos e naturais nos organismos aquáticos, em vários níveis de organização, desde a sub-celular, organismos individuais, até comunidades e ecossistemas. Os efeitos podem causar tanto desvios positivos quanto negativos das circunstâncias previamente existentes, mas os focos principais da Toxicologia Aquática são os desvios considerados perigosos à natureza e os processos de recuperação da biota que podem ocorrer quando a exposição diminui (RAND, 1995).

Com os conhecimentos advindos dessa ciência, sabe-se hoje que os padrões e critérios estabelecidos, baseados na toxicidade de substâncias isoladas, podem não preservar, efetivamente, a qualidade de água necessária para a manutenção da vida aquática, já que as substâncias presentes em um corpo d'água podem sofrer transformações e interações que muitas vezes potenciam ou reduzem os efeitos adversos aos organismos aquáticos. Além disso, a biodisponibilidade das substâncias tóxicas é influenciada tanto por fatores inerentes aos contaminantes como também por fatores ambientais existentes. Dentre os fatores mais importantes pode-se citar a adsorção aos sólidos suspensos e sedimentos, formação de suspensão coloidal, complexação, volatilização, como também a relação entre área e volume de água, temperatura, vazão, $\mathrm{pH}$, tamanho da partícula do sedimento, etc. (RAND \& PETROCELLI, 1985).

Devido à complexidade e variabilidade de compostos orgânicos que podem estar presentes em efluentes domésticos e industriais, ou em um corpo hídrico, é recomendável que a caracterização das águas seja complementada. Neste sentido, associados ao controle e prevenção da poluição das águas, têm sido utilizados testes de toxicidade, por meio dos quais determina-se o potencial tóxico de um agente químico ou de uma mistura complexa, onde os efeitos desses poluentes são medidos através da resposta dos organismos vivos, ou seja, por meio de testes de toxicidade (ZAGATTO \& GHERARDI-GOLDSTEIN, 1991).

A aplicação de testes de toxicidade com organismos aquáticos em amostras de água superficial do Estado de São Paulo ajudou a esclarecer a limitação do uso do IQA Índice de Qualidade das Águas, e seu respectivo IT, como indicadores das condições da qualidade das águas para manutenção da vida aquática. Os resultados obtidos mostraram a necessidade da inclusão de outros indicadores biológicos na avaliação da qualidade das águas para proteção da vida aquática, já que o IQA visa, por princípio, caracterizar a qualidade da água utilizada para o consumo humano após tratamento convencional.

BERTOLETTI et al. (1989) verificaram a dificuldade de se prever ou explicar a toxicidade obtida para organismos aquáticos em função dos teores de agentes químicos isolados, determinados através de análises químicas, e concluiram que a utilização do IT, que se baseava unicamente nesses resultados de concentrações totais das substâncias químicas consideradas, podia não expressar as reais condiçð̃es de águas superficiais, visando a proteção da vida aquática. Ressaltaram também que a limitação desse índice residia em não considerar que, numa amostra de água 
superficial, a toxicidade pode ser conseqüência de vários fatores, destacando-se dentre eles a ação conjunta de baixas concentrações de agentes tóxicos, incluindo os não determinados quimicamente, e a biodisponibilidade desses agentes.

Em 1991, foi publicado o resultado da aplicação de testes de toxicidade aguda em amostras de vários pontos da Rede de Monitoramento da CETESB, durante o período de outubro de 1980 a janeiro de 1985. Dos 213 testes realizados com o microcrustáceo Daphnia similis, 22 apresentaram efeito tóxico agudo, indicando condições ambientais inadequadas à manutenção da vida aquática, mesmo em águas que estavam de acordo com os padrões numéricos previstos em lei (ZAGATTO \& GHERARDI-GOLDSTEIN, 1991). Essa constatação serviu de alerta para um problema de qualidade ambiental de corpos d'água receptores de despejos domésticos e industriais, mostrando que o programa de monitoramento realizado até o momento não era adequado para uma avaliação da qualidade das águas para todos os usos previstos na legislação, sendo o da proteção da fauna e flora aquáticas um dos mais nobres. Neste trabalho foi aplicado o teste com Daphnia similis, destinado à determinação de toxicidade aguda das águas. $O$ efeito agudo caracteriza-se por uma resposta severa e rápida a um estímulo, a qual se manifesta nos organismos aquáticos, em geral, num intervalo de 0 a 96 horas. Usualmente, o efeito observado é a letalidade ou alguma outra manifestação que a antecede, tal como o estado de imobilidade em alguns crustáceos (RAND \& PETROCELLI, 1985). Muitas amostras apresentaram indícios de toxicidade, ou seja, observou-se menos de $50 \%$ de imobilidade dos organismos teste na concentração mais elevada utilizada nos testes, de $90 \%$ da amostra de água. Este resultado revelou a necessidade de se utilizar testes mais sensíveis que permitissem detectar o efeito a níveis subletais.

Os testes de toxicidade aguda, usualmente definidos por sua curta duração ( 2 a 4 dias), envolvem um modelo experimental simples, tendem a ser menos custosos que os testes crônicos; consequentemente, a maioria dos dados toxicológicos existentes ainda se baseiam em respostas de testes de toxicidade aguda (BIRGE et al, in RAND, 1995). Durante um período, os efeitos crônicos eram freqüentemente extrapolados a partir dos resultados de testes agudos através de "fatores de segurança" ou "fatores de aplicação" (STEPHAN \& MOUNT, 1973; MOUNT, 1977; ANDERSON \& D'APOLLONIA, 1978; LAWS, 1981; CAIRNS, 1991 in COONEY, 1995). Portanto, estas extrapolações foram bastante utilizadas para o estabelecimento de padrões de qualidade de água para a proteção da vida aquática.

No entanto, a necessidade de uma avaliação mais acurada do potencial de risco de substâncias tóxicas à biota aquática requereu métodos mais empíricos para estudar os efeitos de substâncias tóxicas ao longo do processo reprodutivo como um todo. Assim, no período decorrido entre o meio da década de 60 e a década de 70 , o uso dos testes crônicos de ciclo de vida total com peixes e invertebrados aumentou, assim como também foram melhorados os métodos de cultivo desses animais em laboratório. A duração do tempo de exposição, a dificuldade de padronização, o custo dos testes crônicos de ciclo de vida total, e a necessidade estabelecida por legislação nos E.U.A. de uma avaliação rápida da toxicidade crônica de efluentes industriais, levaram à busca do desenvolvimento de testes crônicos de curta duração com uma maior diversidade de espécies de peixes e invertebrados. Investigadores da 
USEPA (U.S. Environmental Protection Agency) e outros (MOUNT \& NORBERG, 1984; NORBERG-KING \& MOUNT, 1985; BIRGE et al., 1985; USEPA, 1989) desenvolveram quatro testes de curto prazo ( $\leq 7$ dias de duração) como substitutos para os testes tradicionais para avaliar efeitos crônicos: dois testes de 7 dias com a espécie de peixe Pimephales promelas ("fathead minnows"), sendo um para avaliar sobrevivência e crescimento e o outro para sobrevivência e teratogenicidade; um teste de 7 dias com o microcrustáceo Ceriodaphnia dubia, avaliando sobrevivência e reprodução, e um teste de 4 dias de duração com a espécie de alga Selenastrum capricornutum, avaliando crescimento (COONEY, in RAND, 1995).

Paralelamente à aplicação do teste de toxicidade aguda com Daphnia similis em vários estudos, enfocando a toxicidade de efluentes industriais e seu potencial para causar efeitos nos corpos d'água receptores e em amostras de água de rios e reservatórios do Estado de São Paulo (GHERARDI-GOLDSTEIN et al., 1981), foi implantado, na área de Toxicologia Aquática da CETESB, a partir do procedimento padronizado pela USEPA (USEPA, 1989), o teste de toxicidade crônica com o microcrustáceo Ceriodaphnia dubia (CETESB, 1991). O efeito crônico traduz-se pela resposta a um estímulo que continua por longo tempo, normalmente por períodos que vão de $1 / 10$ do ciclo vital até a totalidade da vida do organismo. Esse efeito geralmente é observado quando concentrações de agentes tóxicos afetam uma ou várias funções biológicas dos organismos, como a reprodução, o crescimento, o comportamento, etc. (RAND \& PETROCELLI, 1985).

A partir de novembro de 1992, os testes de toxicidade crônica foram incluídos em alguns pontos da Rede de Monitoramento, seguindo uma tendência mundial de complementação da caracterização físico-química tradicional com análises ecotoxicológicas, permitindo identificar efeitos danosos de águas receptoras de efluentes industriais e domésticos complexos sobre a fauna aquática, através da resposta direta de organismos aquáticos indicadores (USEPA, 1985, 1986, 1991a; BERTOLETTI et al., 1989; EAGLESON et al., 1990; CARDWELL et al., 1993).

Em 1993, 33 pontos de monitoramento foram avaliados quanto à toxicidade das águas, concentrando-se basicamente nas bacias dos rios Paraíba do Sul, Piracicaba, Sorocaba e na Região Metropolitana de São Paulo. O número de pontos de monitoramento onde se realizou os testes com Ceriodaphnia dubia foi aumentando ao longo dos anos, sendo que, no ano de 2000 , os testes de toxicidade crônica com Ceriodaphnia dubia foram aplicados em amostras de água de 118 pontos da Rede de Monitoramento de Qualidade das Águas da CETESB, abrangendo todas as bacias hidrográficas do Estado de São Paulo. O teste de toxicidade crônica tem sido realizado em amostras de água de todos os pontos de monitoramento onde os níveis de oxigênio dissolvido mantêm-se acima de $4,0 \mathrm{mg} / \mathrm{L}$ e, para a caracterização dos efeitos detectados, utilizam-se as denominações agudo, crônico ou não tóxico (CETESB, 1993, 1994b, 1995, 1996, 1998a, b, 1999, 2000, 2001a).

A complexidade da análise dos dados gerados pela Rede de Monitoramento levou à busca de novos indicadores que facilitassem a interpretação dessas informações, que representassem uma avaliação mais refinada da qualidade das águas para seus múltiplos usos, que apresentassem uma informação condensada para o 
gerenciamento ambiental e que fossem de mais fácil compreensão para o público em geral.

Os dados obtidos como resultado da execução dos testes de toxicidade crônica com o microcrustáceo Ceriodaphnia dubia em amostras de água dos pontos da Rede de Monitoramento de Qualidade de Águas Interiores da CETESB propiciou o desenvolvimento de uma proposta de índice específico para avaliar a qualidade das águas para atender ao seu uso de proteção das comunidades aquáticas, previsto para corpos d'água enquadrados nas classes 1, 2 e 3 do Decreto Estadual 8468/76 (CETESB, 1994a) e nas classes especial, 1 e 2 da Resolução CONAMA 20/86 (CONAMA, 1986).

Uma primeira versão da proposta do índice, o IPCA (Índice para Preservação das Comunidades Aquáticas), foi apresentado à comunidade científica no XXVI Congresso da Sociedade Internacional de Limnologia (SIL), em 1995 (ZAGATTO et al., 1998b). Nesse índice, além das análises químicas convencionais, foi incluído o resultado do teste de toxicidade crônica com o microcrustáceo Ceriodaphnia dubia (ABNT, 1995), o qual pode detectar a presença, ausência, interações e a biodisponibilidade de substâncias em concentrações capazes de causar efeito tóxico sobre a reprodução e/ou sobrevivência dos organismos. Assim, a análise conjunta dos indicadores de qualidade físicos, químicos e ecotoxicológicos permitiu a determinação de um índice que indica a qualidade das águas com vistas à proteção das comunidades aquáticas.

A partir de discussões internas na CETESB sobre a amplitude do índice, o IPCA sofreu algumas alterações, e passou a ser denominado IPMCA - Índice de Qualidade das Águas com Parâmetros Mínimos para Preservação das Comunidades Aqquáticas, integrando dados físicos e químicos determinados rotineiramente pela Rede de Monitoramento de Qualidade das Águas da CETESB com os resultados dos testes de toxicidade crônica com organismos aquáticos. É importante ressaltar que tanto o IPCA quanto o IPMCA não contemplavam indicadores de qualidade que avaliassem a qualidade da água no que se refere ao processo de eutrofização.

Em agosto de 1998, a Secretaria do Meio Ambiente do Estado de São Paulo instituiu, através da Resolução SMA-65, grupos interinstitucionais de trabalho para rever, estudar e desenvolver um novo Índice Básico de Qualidade de Água com vistas aos seus usos múltiplos.

Os grupos de trabalho envolveram profissionais de várias instituições, tais como empresas de saneamento básico, universidades e institutos de pesquisa, envolvendo levantamentos de literatura nacional e internacional sobre $o$ assunto, bem como diversas reuniões de trabalho, além de simulações com dados já existentes da rede de monitoramento de qualidade das águas da CETESB.

O produto deste trabalho foi a proposta de criação de três índices individuais, sendo:

- IAP - Índice de Qualidade de Água Bruta para fins de Abastecimento Público 
- IVA - Índice para a Proteção da Vida Aquática e

- IB - Índice de Balneabilidade

O IAP destina-se a avaliar a qualidade da água bruta com vistas ao abastecimento público, e foi definido como o produto dos valores de IQA e da ponderação do teste de Ames para a avaliação de efeitos de mutagenicidade. Incorporou-se também outros indicadores de qualidade ao cálculo, como o potencial de formação de trihalometanos, metais pesados e substâncias que alteram as propriedades organolépticas da água. Dessa forma, criou-se um sub-índice, denominado ISTO Índice de Substâncias Tóxicas e Organolépticas, que contempla a presença dessas substâncias. O IAP é calculado, portanto, através do produto do IQA e o ISTO. A sua aplicação está sendo realizada em 28 pontos de amostragem da Rede de Monitoramento que são coincidentes com captações de água bruta para posterior abastecimento público.

O Índice de Balneabilidade (IB) foi aperfeiçoado através da Resolução CONAMA n ${ }^{\circ}$ 274 (CONAMA, 2000), que revisou os critérios de classificação das condições de balneabilidade das praias.

O IVA resultou de uma modificação do IPMCA (Índice de Qualidade das Águas com Parâmetros Mínimos para Preservação das Comunidades Aquáticas). Considerou-se que, para este índice ser capaz de identificar o enriquecimento do meio aquático por nutrientes, notadamente nitrogênio e fósforo, responsáveis pelo processo de eutrofização, seria necessário introduzir um novo componente. Decidiu-se utilizar o IET - Índice do Estado Trófico de Carlson modificado por TOLEDO et al (1983) e TOLEDO (1990), tornando assim o IVA, agora integrando o IPMCA e o IET, mais abrangente, pois fornece informações não só quanto à qualidade da água em termos ecotoxicológicos, como também sobre o seu grau de trofia (CETESB, 1999).

O IVA está sendo aplicado em águas coletadas em 118 pontos de amostragem de rios e reservatórios da Rede de Monitoramento da Qualidade das Águas da CETESB, nos quais são coletadas mensal ou bimestralmente amostras de água para análises físicas, químicas, bacteriológicas e ecotoxicológicas, totalizando, atualmente, 43 indicadores de qualidade.

Apesar de ser possível o cálculo do IVA para todos os pontos de monitoramento realizados pela CETESB, onde se aplica o teste de toxicidade crônica com o microcrustáceo Ceriodaphnia dubia, este trabalho irá abordar somente os resultados da Unidade de Gerenciamento de Recursos Hídricos (UGRHI)7 - Baixada Santista, mais especificamente da Bacia do rio Cubatão, no período de 1995 a 2000, onde são realizadas análises periódicas em cinco pontos de amostragem. Esse período de estudo foi escolhido devido à existência de resultados dos testes de toxicidade crônica em todos os pontos de amostragem da Rede de Monitoramento na bacia do rio Cubatão só a partir do ano de 1995, mesmo tendo sido iniciada sua aplicação no mês de novembro de 1992, em alguns pontos de amostragem, distribuídos em diferentes bacias hidrográficas do Estado de São Paulo. 
Esta bacia hidrográfica foi selecionada como estudo de caso pelo fato de se tratar de uma das áreas mais críticas em termos de degradação ambiental por poluição hídrica e atmosférica de origem industrial no Estado de São Paulo, apesar dos esforços envidados visando sua recuperação.

São muitos os estudos realizados na região, avaliando os impactos da poluição em águas, sedimentos e organismos aquáticos do estuário e baía de Santos (TOMMASI, 1979; CETESB, 1979, 1981) e posteriormente avaliação da contaminação e toxicidade a organismos aquáticos nos rios Perequê, Cubatão, Mogi, Perdido e Piaçaguera, em Cubatão (JOHNSCHER-FORNASARO \& ZAGATTO, 1985; CETESB, 1989). Estes levantamentos constataram o comprometimento do ambiente aquático em todos os locais estudados, apontando, como causas de degradação destes sistemas, a poluição de origem doméstica e industrial, responsável pela contaminação química e microbiológica, e as alterações físicas dos habitats, resultantes dos processos de erosão, assoreamento, aterros de canais e manguezais e intervenções no sistema de drenagem.

Os manguezais da região, que representam cerca de $43 \%$ dos $231 \mathrm{~km}^{2}$ de manguezais da costa paulista, também foram significativamente alterados. RODRIGUES \& ROQUETTI-HUMAYTÁ (1988) identificaram locais de elevada contaminação por metais pesados e bosques de mangue bastante alterados pela poluição, em levantamento realizado no período entre 1982 e 1984, abrangendo 33 pontos da Baixada Santista.

Em 1984, a CETESB deu início a um intensivo programa de controle da poluição do ar, das águas e do solo no polo industrial de Cubatão, destacando-se ações como implantação de sistemas de tratamento de efluentes industriais em todas as fábricas da região, resultando na acentuada redução da carga de poluentes para o sistema hídrico. A partir destas ações, foram observados alguns resultados de recuperação ambiental da região, como aumento de diversidade de aves e organismos aquáticos e a intensificação da pesca (CETESB, 2001b).

Apesar do grande esforço dispendido para o controle da poluição e melhoria da qualidade ambiental, alguns levantamentos posteriores, realizados principalmente na bacia do rio Cubatão, mostraram que a região permanecia impactada, indicando riscos de acumulação dos contaminantes nos organismos que estariam retornando ao ambiente em recuperação, expondo a população ribeirinha ao consumo de pescados comprometidos (CETESB, 1990a; EYSINK et al., 1991; VARGAS-BOLDRINI et al., 1991).

Estudos reveladores foram realizados na região enfocando o consumo de peixes. SANTOS FILHO et al. (1991) observaram que 46,13\% das famílias de seis bairros de Cubatão consumiam peixes e/ou outros organismos da região. Cerca de $42 \%$ das famílias entrevistadas consideraram os produtos dos rios de Cubatão impróprios para o consumo e $54 \%$ concordaram com a afirmação de que o consumo de peixes da região poderia causar efeitos à saúde. GUTBERLET (1996) destacou que a pesca no rio Cubatão e nos manguezais da região era evitada pela população local, pois a maioria dos peixes apresentava a pele manchada, eram cegos e tinham sabor 
intragável. Além da pesca, a coleta de siris, caranguejos e mexilhões nos manguezais também representa uma atividade econômica importante para a população de menor poder aquisitivo.

Com o prosseguimento das ações de controle da poluição na década de 90 , era de se esperar uma redução na exposição da fauna local $\mathrm{e}$, conseqüentemente, de seus consumidores (especialmente pescadores locais), aos contaminantes. Levantamentos mais recentes, no entanto, apontam a persistência de poluentes na região, potencialmente disponiveis à biota aquática e pondo em risco a saúde pública e o equilíbrio ecológico dos ecossistemas aquáticos da região (PRÓSPERI et al., 1998; CETESB, 2001).

Levantamentos amplos como muitos dos citados acima demandam tempo, têm um custo elevado e geram uma infinidade de informações muitas vezes de difícil interpretação. A aplicação de um índice de qualidade de água tem como finalidade básica o fornecimento de informações de fácil compreensão para a população, além de ser uma ferramenta útil para o gerenciamento ambiental. Vale ressaltar que, na composição de índices de qualidade de água, são selecionadas algumas variáveis consideradas representativas e confiáveis para a obtenção de um diagnóstico rápido da qualidade de corpos d'água. A existência de uma rede de monitoramento de qualidade das águas, como a que a CETESB opera no Estado de São Paulo, contendo 43 indicadores de qualidade, torna possível o cálculo de vários índices de qualidade, com custo reduzido. Deve-se considerar, além disso, que esse índice reflete uma condição instantânea do ambiente aquático, e que estão sendo envidados esforços no sentido de se aprimorar ainda mais a avaliação da qualidade, considerando outros compartimentos do ambiente aquático (sedimento e biota).

A utilização do IVA - Índice para Proteção da Vida Aquática, cuja finalidade é avaliar a capacidade desses corpos d'água para a manutenção e sobrevivência de comunidades aquáticas, através da análise de dados físicos, químicos e biológicos selecionados, em uma análise envolvendo seis anos de dados na bacia do rio Cubatão, poderá contribuir na avaliação de sua capacidade de detectar o estado de degradação do ambiente em estudo $\mathrm{e}$, através da análise individual de seus componentes, diagnosticar as causas de deterioração da qualidade das águas e direcionar esforços para ações corretivas. 


\section{OBJETIVOS}

- Avaliar a capacidade do IVA - Índice de Qualidade para Proteção da Vida Aquática, como instrumento para avaliação da qualidade do ambiente aquático e identificação das causas de deterioração da qualidade da água para a manutenção e sobrevivência da biota aquática.

- Aplicar o IVA a uma bacia hidrográfica, considerando uma série histórica de dados, de maneira a identificar se esse índice representa um aprimoramento na avaliação dos corpos d'água, quanto à sua capacidade de manutenção e sobrevivência da vida aquática, comparando-o com o IQA - Índice de Qualidade das Águas, utilizado pela CETESB desde 1978 como um índice genérico de qualidade das águas. 


\section{METODOLOGIA}

Neste trabalho foram utilizados resultados de determinações fĩsicas, químicas e biológicas da Rede de Monitoramento da Qualidade das Águas, publicados nos Relatórios de Qualidade das Águas da CETESB nos períodos de 1995 a 2000, dos quais foram selecionados os dados de interesse para cálculo dos índices IPMCA, IET e IVA.

O IVA - Índice de Proteção da Vida Aquática, é composto por dois índices: IPMCA - Índice de Parâmetros Mínimos para Proteção das Comunidades Aquáticas e IET Índice do Estado Trófico. A composição de cada um destes índices e sua integração, resultando em diferentes classes de qualidade de água, está descrita a seguir:

\subsection{IPMCA - Índice de Parâmetros Mínimos para Proteção das Comunidades Aquáticas}

O índice é composto por dois grupos de indicadores de qualidade:

- grupo de substâncias tóxicas (cobre, zinco, chumbo, cromo, mercúrio, níquel, cádmio, surfactantes e fenóis)

- grupo de indicadores de qualidade essenciais (oxigênio dissolvido, $\mathrm{pH}$ e toxicidade).

No grupo de substâncias tóxicas, foram incluídos os indicadores de qualidade que são atualmente determinados pela Rede de Monitoramento de Qualidade das Águas Interiores do Estado de São Paulo, e que identificam o nível de contaminação por substâncias potencialmente danosas para as comunidades aquáticas. Nesse grupo, poderão ser inclú́dos novos indicadores de qualidade que venham a ser considerados importantes para a caracterização da qualidade das águas, mesmo regionalmente.

O grupo de indicadores de qualidade essenciais é composto por indicadores de qualidade considerados determinantes para a manutenção da vida aquática, e que podem ser facilmente alterados com a introdução de poluentes na água, como o $\mathrm{pH}$ e o oxigênio dissolvido. A inclusão do indicador toxicidade se justifica pelo fato de o teste de toxicidade crônica com Ceriodaphnia dubia ser capaz de detectar a presença, interações e a biodisponibilidade de substâncias em concentrações capazes de causar efeitos tóxicos sobre a reprodução e/ou sobrevivência dos organismos, substâncias estas que podem ou não estar contempladas no grupo de substâncias tóxicas avaliadas.

Para cada indicador de qualidade incluído no IPMCA, foram estabelecidos três diferentes níveis de qualidade, para os quais foram feitas as ponderações numéricas 1,2 e 3. Esses diferentes niveis são apresentados na Tabela 1 , sendo que os de ponderação 1 correspondem a padrões de qualidade de água estabelecidos pela Resolução CONAMA $n^{\circ}$ 20/86 (CONAMA, 1986). Os níveis relativos às ponderações 2 e 3 foram obtidos das diretrizes americanas (USEPA, 1991b) e legislação francesa (CODE PERMANENT: ENVIRONNEMENT ET NUISANCES, 
1986), as quais estabelecem limites máximos permissíveis de substâncias químicas na água, para evitar efeitos crônicos e agudos à biota aquática.

Esses níveis refletem as seguintes condições de qualidade de água:

- Nível A: águas com características necessárias para manter a sobrevivência e a reprodução dos organismos aquáticos. Atende aos padrões de qualidade para as classes Especial, 1 e 2 da Resolução CONAMA 20/86 (ponderação 1).

- Nivel B: águas com características necessárias para a sobrevivência dos organismos aquáticos, porém a reprodução pode ser afetada a longo prazo (ponderação 2).

- Nível C: águas com características que podem comprometer a sobrevivência dos organismos aquáticos (ponderação 3).

Tabela 1 - Indicadores de qualidade componentes do IPMCA e suas ponderações, de acordo com os três níveis de qualidade (Nível $\mathrm{A}=$ padrões de qualidade de água da Legislação CONAMA $\mathrm{n}^{\circ}$ 20/86; níveis $\mathrm{B}$ e $\mathrm{C}=$ Limites obtidos das diretrizes americanas e legislação francesa)

\begin{tabular}{|c|c|c|c|c|}
\hline & & Níveis & Faixa de variação & Ponderação \\
\hline \multirow[b]{2}{*}{$\begin{array}{c}\text { Indicadores de } \\
\text { Qualidade } \\
\text { Essenciais }\end{array}$} & $\mathrm{OD}(\mathrm{mg} / \mathrm{L})$ & $\begin{array}{l}\mathrm{A} \\
\mathrm{B} \\
\mathrm{C}\end{array}$ & $\begin{array}{l}>5 \\
3 \text { a } 5 \\
<3 \\
\end{array}$ & $\begin{array}{l}1 \\
2 \\
3 \\
\end{array}$ \\
\hline & $\mathrm{pH}$ & $\begin{array}{l}\mathrm{A} \\
\mathrm{B} \\
\mathrm{C}\end{array}$ & $\begin{array}{l}6-9 \\
5 \text { a } 6 \text { e } 9 \text { a } 9,5 \\
<5 \text { e }>9,5\end{array}$ & $\begin{array}{l}1 \\
2 \\
3\end{array}$ \\
\hline (IQE) & Toxicidade & $\begin{array}{l}\mathrm{A} \\
\mathrm{B} \\
\mathrm{C}\end{array}$ & \begin{tabular}{|l|} 
Não tóxico \\
Efeito crônico \\
Efeito agudo \\
\end{tabular} & $\begin{array}{l} \\
2 \\
3 \\
\end{array}$ \\
\hline \multirow[b]{3}{*}{ Substâncias } & Cádmio (mg/L) & $\begin{array}{l}\text { A } \\
\text { B } \\
\text { C }\end{array}$ & $\begin{array}{l}<0,001 \\
0,001 \text { a } 0,005 \\
>0,005\end{array}$ & $\begin{array}{l}1 \\
2 \\
3 \\
\end{array}$ \\
\hline & Cromo $(\mathrm{mg} / \mathrm{L})$ & $\begin{array}{l}\text { A } \\
\text { B } \\
\text { C }\end{array}$ & $\begin{array}{l}<0,05 \\
0,05 \text { a l } \\
>1\end{array}$ & $\begin{array}{l}1 \\
2 \\
3 \\
\end{array}$ \\
\hline & Cobre $(\mathrm{mg} / \mathrm{L})$ & $\begin{array}{l}\mathrm{A} \\
\mathrm{B} \\
\mathrm{C}\end{array}$ & \begin{tabular}{|l|}
$<0,02$ \\
$0,02 \mathrm{a} 0,05$ \\
$>0,05$ \\
\end{tabular} & $\begin{array}{l}1 \\
2 \\
3 \\
\end{array}$ \\
\hline \multirow[t]{6}{*}{ Tóxicas } & Chumbo (mg/L) & $\begin{array}{l}\mathrm{A} \\
\mathrm{B} \\
\mathrm{C}\end{array}$ & $\begin{array}{l}<0,03 \\
0,03 \text { a } 0,08 \\
>0,08 \\
\end{array}$ & $\begin{array}{l}1 \\
2 \\
3 \\
\end{array}$ \\
\hline & Mercúrio (mg/L) & $\begin{array}{l}\text { A } \\
\text { B } \\
\text { C }\end{array}$ & $\begin{array}{l}<0,0002 \\
0,0002 \text { a } 0,001 \\
>0,001\end{array}$ & $\begin{array}{l}1 \\
2 \\
3\end{array}$ \\
\hline & Niquel $(\mathbf{m g} / \mathrm{L})$ & $\begin{array}{l}\mathrm{A} \\
\mathrm{B} \\
\mathrm{C}\end{array}$ & \begin{tabular}{|l|}
$<0,025$ \\
0,025 a 0,16 \\
$>0,16$ \\
\end{tabular} & $\begin{array}{l}1 \\
2 \\
3 \\
\end{array}$ \\
\hline & Fenol $(\mathrm{mg} / \mathrm{L})$ & $\begin{array}{l}\text { A } \\
\text { B } \\
\text { C }\end{array}$ & $\begin{array}{l}<0,001 \\
0,001 \text { a } 0,05 \\
>0,05\end{array}$ & $\begin{array}{l}1 \\
2 \\
3\end{array}$ \\
\hline & Surfactantes $(\mathrm{mg} / \mathrm{L})$ & $\begin{array}{l}\mathrm{A} \\
\mathrm{B} \\
\mathrm{C}\end{array}$ & $\begin{array}{l}<0,5 \\
0,5 \text { a } 1 \\
>1 \\
\end{array}$ & $\begin{array}{l}1 \\
2 \\
3 \\
\end{array}$ \\
\hline & Zinco $(\mathrm{mg} / \mathrm{L})$ & $\begin{array}{l}\mathrm{A} \\
\mathrm{B} \\
\mathrm{C}\end{array}$ & $\begin{array}{l}<0,18 \\
0,18 \text { a } 1 \\
>1\end{array}$ & $\begin{array}{l}1 \\
2 \\
3 \\
\end{array}$ \\
\hline
\end{tabular}




\section{Cálculo do IPMCA}

Dadas as ponderações para os indicadores de qualidade determinados em uma amostra de água, o IPMCA é calculado da seguinte forma:

IPMCA = IQE X ST, onde:

- IQE = valor da maior ponderação do grupo de indicadores de qualidade essenciais.

- $\mathbf{S T}=$ valor médio das três maiores ponderações do grupo de substâncias tóxicas. Este valor é um número inteiro, com o seguinte critério de arredondamento: valores menores que 0,5 são arredondados para baixo e valores maiores ou iguais a 0,5 são arredondados para cima.

O valor do IPMCA pode variar de 1 a 9 , sendo subdividido em quatro níveis de qualidade, classificando as águas para proteção da vida aquática:

\begin{tabular}{cc}
\hline PPMCA & Qualidade da água \\
\hline 1 & Boa \\
2 & Regular \\
3 e 4 & Ruim \\
$>6$ & Péssima \\
\hline
\end{tabular}

Algumas considerações sobre os valores adotados, que identificam a qualidade das águas, podem ser elaboradas:

Valor do IPMCA = 1 (qualidade de água: Boa): Todos os indicadores de qualidade essenciais devem ter, no máximo, ponderação 1. Para o grupo de substâncias tóxicas, admite-se que apenas um dos indicadores de qualidade tenha a ponderação 2, ou seja, ultrapasse o padrão de qualidade de água estabelecido pela Resolução CONAMA 20/86. Esse critério foi adotado considerando-se que, mesmo que uma das substâncias tóxicas esteja acima do padrão de qualidade de água, ela não está disponível para causar efeitos adversos aos organismos aquáticos, visto que o teste de toxicidade não evidenciou qualquer tipo de efeito tóxico.

Valor do IPMCA = 2 (qualidade de água: Regular): Admite-se que um dos três indicadores de qualidade essenciais tenha ponderação de, no máximo, 2, desde que a média das ponderações do grupo de substâncias tóxicas seja 1 . No caso de ponderação 2 para a média do grupo de substâncias tóxicas, os indicadores de qualidade essenciais devem ter ponderação 1 . 
Valor do IPMCA = 3 e 4 (qualidade de água: Ruim): Quando qualquer um dos indicadores de qualidade essenciais atingir a ponderação 3 , desde que o grupo de substâncias tóxicas apresente ponderação 1; ou ponderação 2 para os indicadores de qualidade essenciais e valor médio 2 para o grupo de substâncias tóxicas; ou ponderação 1 para o grupo de indicadores de qualidade essenciais e valor 3 para o de substâncias tóxicas.

Valor do IPMCA $=>6$ (qualidade de água: Péssima): Quando um dos três indicadores de qualidade essenciais tiver ponderação de, no máximo, 2 e que a média das ponderações do grupo de substâncias tóxicas for de, no mínimo, 3, ou 3 para o grupo dos indicadores de qualidade essenciais e média igual ou maior que 2 para o grupo de substâncias tóxicas.

\subsection{IET - Índice do Estado Trófico}

$O$ Índice do Estado Trófico tem por finalidade classificar corpos d'água em diferentes graus de trofia, ou seja, avaliar a qualidade da água quanto ao enriquecimento por nutrientes e seu efeito relacionado ao crescimento excessivo de algas.

O Índice do Estado Trófico adotado foi o índice clássico introduzido por Carlson modificado por TOLEDO et al. (1983) e TOLEDO (1990), que, baseando-se em dados de diferentes reservatórios do Estado de São Paulo e através de método estatístico fundamentado em análise de regressão linear, alterou as expressões originais para adequá-las a ambientes subtropicais, utilizando os indicadores de qualidade transparência, fósforo total, ortofosfato e clorofila-a.

O Índice do Estado Trófico utilizado no cálculo do IVA é composto apenas pelo Índice do Estado Trófico para o fósforo - IET(P), e o Índice do Estado Trófico para a clorofila-a - IET(CL). Não foi considerado o IET para transparência devido a inconsistências encontradas com resultados de diversos ambientes, decorrentes da presença de sólidos em suspensão. Este tipo de ocorrência é particularmente significativa em ambientes lóticos.

Portanto, os IETs para fósforo e clorofila são definidos como:

$$
\begin{aligned}
& \operatorname{IET}(\mathrm{P})=10\{6-[\ln (80,32 / \mathrm{P}) / \ln 2]\} \quad \text { (equação 1) } \\
& \operatorname{IET}(\mathrm{CL})=10\{6-[(2,04-0,695 \ln \mathrm{CL}) / \ln 2]\} \quad \text { (equação 2) }
\end{aligned}
$$

onde:

- $\mathrm{P}=$ concentração de fósforo total medida à superfície da água, em $\mu \mathrm{g} / \mathrm{L}$

- $\mathrm{CL}=$ concentração de clorofila-a medida à superfície da água, em $\mu \mathrm{g} / \mathrm{L}$

- $\ln =$ logaritmo natural

A expressão final deste índice é a seguinte : 


$$
\operatorname{IET}=[\operatorname{IET}(\mathrm{P})+\operatorname{IET}(\mathrm{CL})] / 2 \quad \text { (equação } 3)
$$

onde:

- IET é a média aritmética simples dos índices relativos ao fósforo total e à clorofila-a.

No caso de não haver resultados para o fósforo total ou para a clorofila-a, o índice será calculado com o indicador de qualidade disponível e considerado equivalente ao IET, devendo, apenas, constar uma observação junto ao resultado, informando que apenas um dos indicadores foi utilizado.

De acordo com os diferentes valores de IET, as águas podem ser classificadas como: oligotrófica, mesotrófica, eutrófica e hipereutrófica, para as quais são dados valores de classes de IET de 1 a 4 (Tabela 2).

Tabela 2 - Classificação do estado trófico, segundo o Índice de Carlson, modificado por TOLEDO et al. (1983).

\begin{tabular}{c|c|c}
\hline Critério & Estado Trófico & Classes do IET \\
\hline IET $\leq 44$ & Oligotrófico & 1 \\
\hline $44<$ IET $\leq 54$ & Mesotrófico & 2 \\
\hline $54<$ IET $\leq 74$ & Eutrófico & 3 \\
\hline IET $>74$ & Hipereutrófico & 4 \\
\hline
\end{tabular}

A classificação acima descrita do estado trófico reflete as seguintes condições de qualidade da água para lagos e reservatórios (corpos lênticos) (CETESB, 2001a):

- Oligotróficos: corpos de água limpos, de baixa produtividade primária, em que não ocorrem interferências indesejáveis sobre os usos da água.

- Mesotróficos: corpos de água com produtividade primária intermediária, com possíveis implicações sobre a qualidade da água, mas em níveis aceitáveis, na maioria dos casos.

- Eutróficos: corpos de água com alta produtividade primária em relação às condições naturais, de baixa transparência, em geral afetados por atividades antrópicas, em que ocorrem alterações indesejáveis na qualidade da água e interferências nos seus múltiplos usos.

- Hipereutróficos: corpos de água afetados significativamente pelas elevadas concentrações de matéria orgânica e nutrientes, com comprometimento acentuado nos seus usos, podendo inclusive estarem associados a episódios de mortandade de peixes e causar conseqüências indesejáveis sobre as atividades pecuárias nas regiões ribeirinhas. 


\subsection{IVA - Índice para a Proteção da Vida Aquática}

Como já salientado, o IPMCA e o IET compõem o IVA. Para se estabelecer a ponderação mais adequada entre os componentes do IVA, foram analisados os resultados obtidos em simulações e dados de campo, os quais foram interpretados com base no significado de cada componente dos índices. A primeira tentativa em estabelecer o IVA foi através do cálculo do valor médio entre o IPMCA e o IET, ou seja, IVA $=($ IPMCA + IET $) / 2$. Observou-se que a classificação obtida através desse modelo, em alguns pontos, não condizia com a qualidade do corpo d'água, de acordo com o conhecimento prévio dos técnicos envolvidos, sendo em alguns casos demasiadamente rigorosa. Percebeu-se então que a discrepância encontrada estava ligada aos pesos para os níveis de trofia meso e eutrófico. Foram então testadas outras fórmulas de composição do IVA, chegando-se à conclusão que o IPMCA deveria ter um peso maior que o IET, já que a ponderação atribuída ao efeito crônico de uma amostra não poderia ter a mesma importância atribuída ao nível mesotrófico, isso porque o estado mesotrófico não indica necessariamente uma deterioração do ambiente aquático. Com relação à deteç̧ão de efeito crônico em uma água natural, pode-se afirmar que as populações aquáticas podem estar sofrendo efeitos subletais, como por exemplo, alteração na sua reprodução, crescimento, comportamento ou mesmo na sua sobrevivência. Depois de vários cálculos, atribuindo-se diferentes pesos ao IPMCA, e tomando-se como base os dados das amostras da Rede de Monitoramento, optou-se por aplicar um peso $20 \%$ maior ao IPMCA e somar esse valor ao IET, de modo a corrigir a distorção acima descrita (ZAGATTO et al.,1999).

Assim, foi definido que o IVA deve ser calculado segundo a expressão:

$$
I V A=(I P M C A \times 1,2)+\operatorname{IET} \quad \text { (equação 4) }
$$

$\mathrm{Na}$ ausência do valor do IET, para efeito dos cálculos, o mesmo será igual à unidade (1).

$\mathrm{O}$ índice descreve cinco classificações de qualidade, que se encontram relacionadas a seguir, e estão representadas na Tabela 3.

$\begin{array}{ll}\text { Qualidade Ótima } & I V A=2,2 \\ \text { Qualidade Boa } & I V A=3,2 \\ \text { Qualidade Regular } & 3,4 \leq I V A \leq 4,4 \\ \text { Qualidade Ruim } & 4,6 \leq I V A \leq 6,8 \\ \text { Qualidade Péssima } & \text { IVA }>7,6\end{array}$


Tabela 3 - Representação das classes de qualidade com os valores de IVA

IPMCA

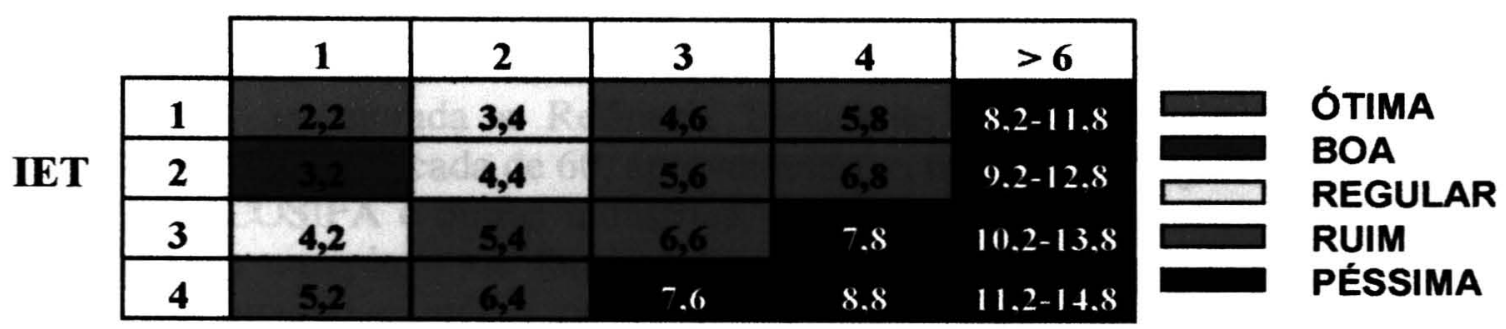

Para a síntese dos dados de um período, como a apresentação de um relatório anual, calcula-se a média dos resultados mensais de cada ponto, sendo atribuídos valores para cada classe de cores (ótima $=1$, boa $=2$, regular $=3$, ruim $=4$, péssima $=5$ ), conforme apresentado na Tabela 4. A média é arredondada, sendo considerada a classe de melhor qualidade até a metade de cada intervalo. Exemplo: classes: Ótima $\leq 1,5$, Boa $\leq 2,5$, Regular $\leq 3,5$, Ruim $\leq 4,5$, Péssima $>4,5$.

Tabela 4 - Valores atribuídos às diferentes classes do IVA para a utilização em séries temporais.

\section{IPMCA}

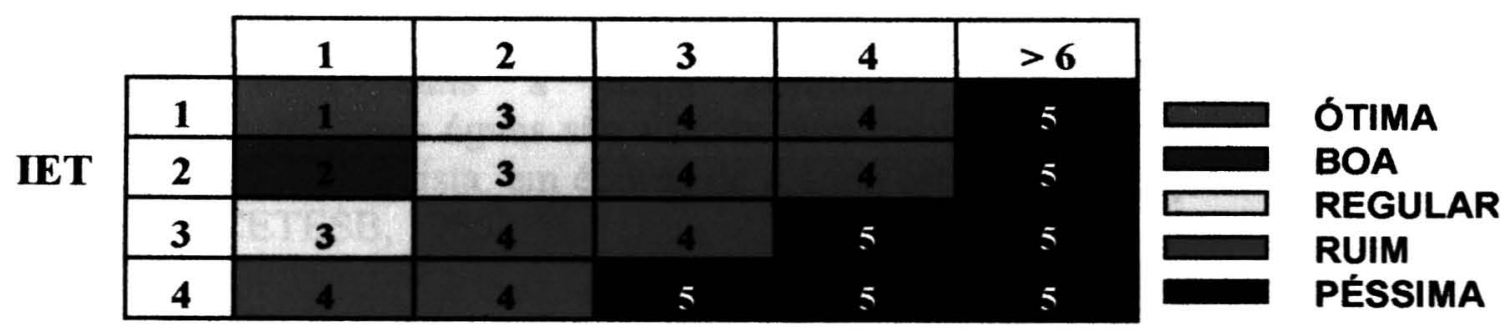

\subsection{Aplicação do IVA à Bacia do Rio Cubatão}

A área de estudo está localizada no litoral do Estado de São Paulo, conforme apresentado na Figura 1.

A bacia do rio Cubatão deságua no estuário de Santos. Seus rios, cujas nascentes estão localizadas na Serra do Mar, apresentam um regime torrencial na área serrana (CETESB, 1989), e um regime fluvial na Baixada Santista. Esta bacia tem uma área aproximada de $27000 \mathrm{~km}^{2}$, a qual corresponde a $11 \%$ da superficie do Estado de São Paulo. 
Historicamente, o rio Cubatão teve um importante papel no desenvolvimento sócioeconômico da região, devido à boa qualidade e abundância da água e à sua localização estratégica - entre a cidade de São Paulo e o porto de Santos, tendo também sido um fator determinante na decisão de se instalar um pólo industrial no município.

Em 1955, foi inaugurada a Refinaria Presidente Bernardes, da PETROBRÁS (CETESB, 1986). Na década de 60, aproveitando os insumos na região, instalaram-se a siderúrgica COSIPA e outras indústrias, petroquímicas. Entre 1970 e 1976, foi a vez de todo o complexo de fertilizantes. Em 1985, a Baixada contava com 23 indústrias de grande e médio porte, abrigando 111 fábricas distintas (CETESB, 1990a).

A industrialização desordenada e as condições meteorológicas e topográficas inadequadas para a dispersão de poluentes aero-dispersos, levaram a diversos problemas de degradação ambiental, notadamente a da mata de encostas da Serra do Mar. Com o advento das indústrias, os corpos d'água da região também receberam uma grande carga poluidora devido ao lançamento de efluentes industriais sem tratamento adequado, o que resultou em praticamente eliminação da vida aquática e restrição das atividades recreativas da população local. $O$ crescimento urbano desordenado também conduziu ao agravamento do problema, devido à proximidade entre as indústrias e as zonas habitadas, aumentando os riscos ligados à liberação acidental de poluentes.

Além de poluição originária na própria região, os esgotos de São Paulo, lançados no rio Tietê e revertidos à represa Billings através do rio Pinheiros, eram turbinados na Usina Henry Borden, sendo descarregados, pelos canais de fuga, no rio Cubatão, aumentando ainda mais a carga poluidora recebida por essa bacia. Excepcionalmente, essas águas são usadas para complementação do abastecimento de água da Baixada Santista, em épocas de grande estiagem e/ou quando do aumento da demanda (CETESB, 1985).

Vários planos de ação para controle da poluição e recuperação ambiental vêm sendo desenvolvidos na região e, desde 1977, a CETESB vem monitorando regularmente as águas da bacia do rio Cubatão.

A Rede de Monitoramento da CETESB possui cinco pontos de amostragem para avaliação da qualidade das águas na bacia do rio Cubatão, sendo dois pontos no rio Cubatão, um ponto no Canal de Fuga 2 da Usina Henry Borden, um no rio Mogi e um no rio Piaçaguera. Na Tabela 5 são apresentados os códigos dos pontos, os corpos d'água e a localização dos pontos de amostragem, segundo CETESB (2001a). A localização dos pontos de amostragem é apresentada em mapa esquemático da região (Fig. 2). 


\section{LOCALIZAÇÃO DA ÁREA DE ESTUDO}

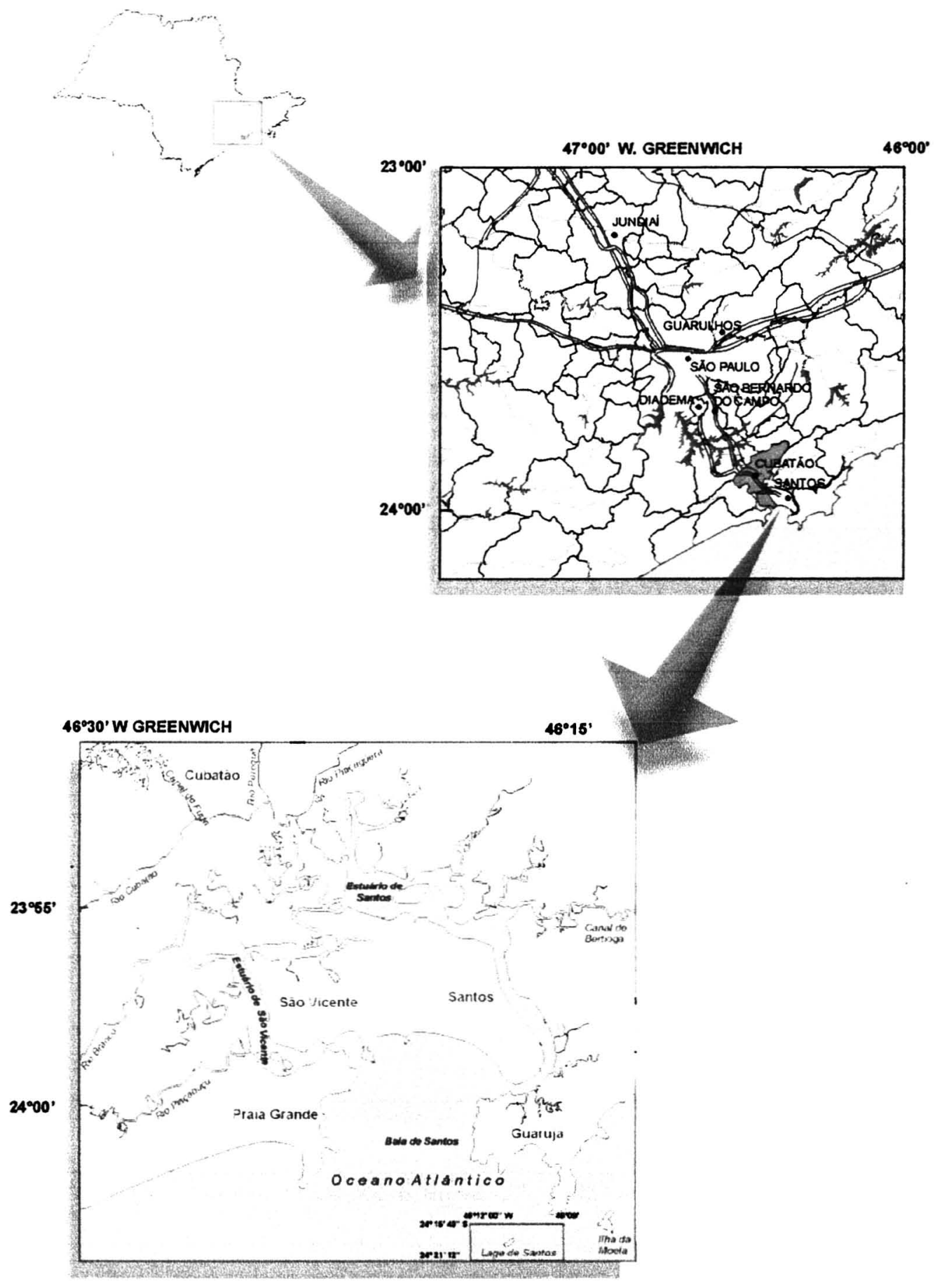

Figura 1 - Localização da área de estudo no litoral do Estado de São Paulo 


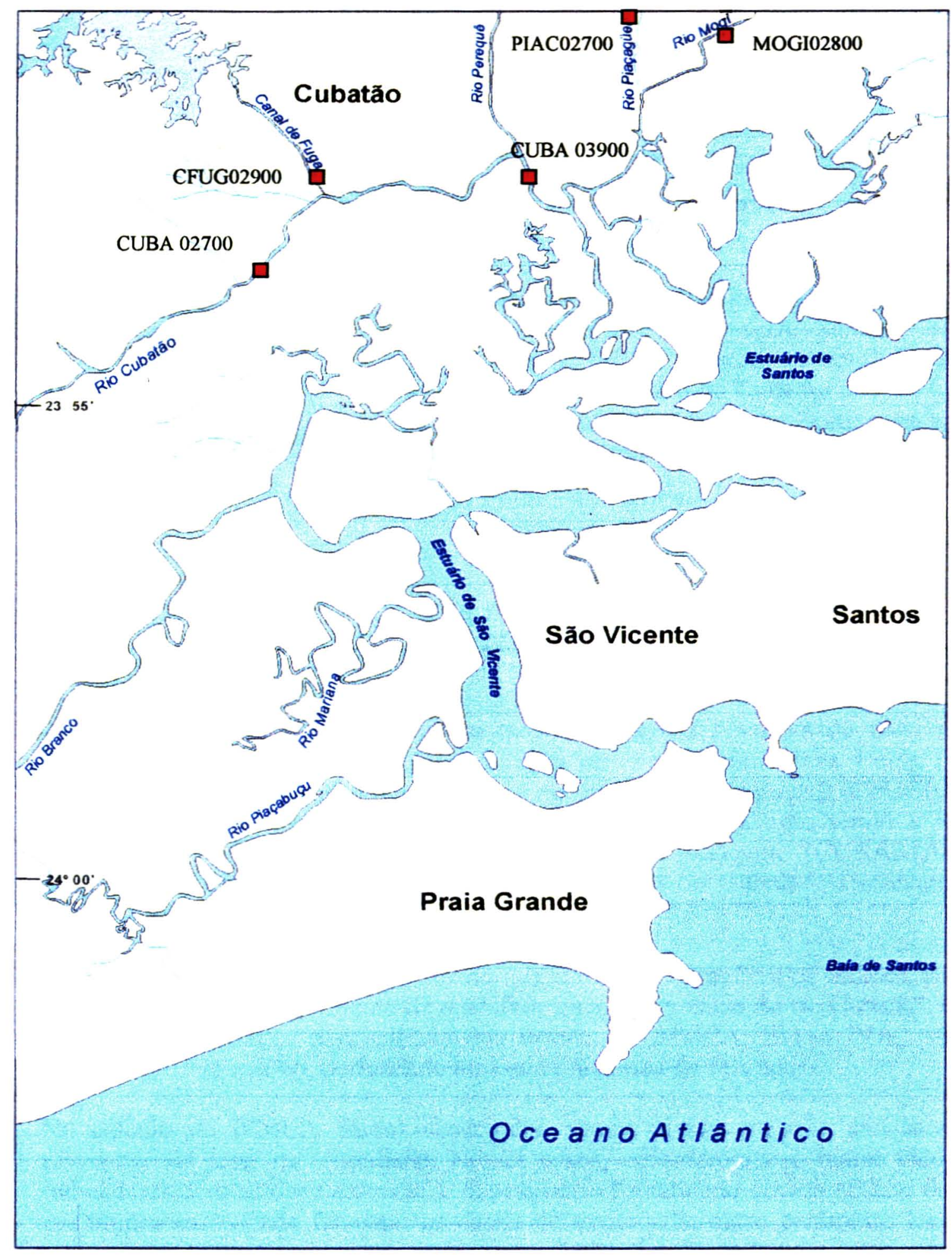

Legenda: — Corpos d'água $\square$ Pontos de monitoramento

Figura 2 - Mapa representativo da região de estudo, com a localização dos pontos de amostragem de qualidade das águas 
Tabela 5 - Descrição dos pontos de amostragem na bacia do rio Cubatão (segundo CETESB, 2001a).

\begin{tabular}{l|l|l}
\hline $\begin{array}{c}\text { Ponto de } \\
\text { amostragem }\end{array}$ & Corpo de água & \multicolumn{1}{c}{ Localização } \\
\hline CUBA02700 & Rio Cubatão & $\begin{array}{l}\text { Ponte Preta, em frente à antiga Estação de } \\
\text { Tratamento de Água do rio Cubatão }\end{array}$ \\
\hline CUBA03900 & Rio Cubatão & $\begin{array}{l}\text { Ponte na estrada de ferro Santos-Jundiaí, } \\
\text { cerca de 1.5 km a jusante da confluência do } \\
\text { rio Perequê com o rio Cubatão }\end{array}$ \\
\hline CFUG02900 & Canal de Fuga 2 & $\begin{array}{l}\text { Usina Hidroelétrica Henry Borden, na saída } \\
\text { da turbina da Usina Externa }\end{array}$ \\
\hline MOGI02800 & Rio Mogi & $\begin{array}{l}\text { Ponte na rodovia Piaçaguera, que liga } \\
\text { Cubatão ao Guarujá }\end{array}$ \\
\hline Rio Piaçaguera & $\begin{array}{l}\text { Ponte localizada na área da COSIPA, } \\
\text { continuação da Rua 3, Vila Parisi, 300 m a } \\
\text { jusante da Indústria Adubos Trevo }\end{array}$ \\
\hline
\end{tabular}

O rio Cubatão tem por característica receber as águas advindas do reservatório Billings, após serem utilizadas para geração de energia elétrica na Usina Henry Borden, localizada na Baixada Santista. As águas do Canal de Fuga 2 (CFUG02900) são oriundas do reservatório Billings, após utilização na Usina, sendo a seguir aduzidas ao rio Cubatão. Um dos pontos de amostragem (CUBA02700) é coincidente com a captação de água da SABESP no rio Cubatão, a montante do Canal de Fuga.

Todos os resultados dos indicadores de qualidade que compõem os índices, para os cinco pontos de monitoramento de qualidade da água na bacia do rio Cubatão, foram tabulados e utilizados para cálculo dos valores de IPMCA, IET e IVA, para o período de 1995 a 2000, perfazendo uma série histórica de seis anos.

No cálculo do IPMCA foram observados alguns meses em que não havia os resultados do teste de toxicidade. Nesses casos, considerou-se o maior valor dos indicadores de qualidade essenciais. Esse critério foi adotado devido ao fato de que, em muitos casos onde faltavam os dados de toxicidade, outro parâmetro essencial $(\mathrm{OD}$ ou $\mathrm{pH})$ já mostrava valores maiores que 2 e/ou 3, indicando uma deterioração da qualidade da água. Se esses dados fossem desconsiderados, devido à ausência de um dos componentes do índice (no caso a toxicidade), a classificação da qualidade daquela amostra de água estaria sendo superestimada.

No cálculo do IET foram considerados os resultados da concentração de fósforo total, já que nenhuma determinação de clorofila-a foi realizada nos pontos em estudo. Essa situação já havia sido prevista no desenvolvimento do índice, pois ainda não 
havia condições de realizar essa análise em todos os pontos da rede de monitoramento.

Como o IQA - Índice de Qualidade das Águas - tem sido, desde 1978, utilizado pela CETESB como indicador da qualidade das águas, o resultado deste índice está sendo também considerado na análise dos dados, em todos os pontos de monitoramento da bacia do rio Cubatão, no período selecionado neste estudo, para fins de comparação da sensibilidade dos índices como indicadores da qualidade das águas para preservação da vida aquática.

Para cada ponto de monitoramento foram calculadas as médias anuais do Índice para Proteção da Vida Aquática (IVA), assim como foi analisada a freqüência de ocorrência dos indicadores de qualidade que influenciaram na qualidade das águas classificadas pelo IVA como Regular, Ruim e Péssima, considerando-se os seis anos de dados.

Foi realizada uma análise de tendência do IVA para cada ponto de amostragem, com o objetivo de verificar o comportamento da qualidade da água na região em estudo no período de 1995 a 2000 . Foi escolhido o mesmo método estatístico utilizado para análise temporal de tendências do IQA, aplicado pela CETESB para os resultados deste índice desde 1996 (CETESB, 1998a). Para tanto, os dados mensais do IVA foram inicialmente ajustados através do cálculo da média móvel dos 12 meses anteriores. Com o intuito de se obter uma melhor interpretação dos dados, foram utilizados os valores da ponderação do IVA, por se tratarem de números puros, ao invés dos valores finais do índice, que são apresentados dentro de faixas de qualidade. Considerou-se que o uso das faixas de qualidade pode resultar em perda de informação, uma vez que valores diferentes podem cair numa mesma faixa de classificação de qualidade. Vale ressaltar que as faixas de qualidade têm uma função importante na apresentação do indice, pois resumem a informação que se pretende divulgar, porém seu uso em estudos de tendência não é adequado.

A análise de consistência estatística das tendências foi verificada aplicando-se a metodologia de análise de séries temporais de Box \& Jenkins, através do ajuste de modelos auto-regressivos, que faz uso do teste " $t$ de Student" para verificar o nível de significância obtido. Foi adotado o nível de significância de $10 \%$. Quando o teste resulta significante, admite-se que existe uma tendência definida na evolução do índice, que poderá ser positiva, indicando uma tendência de melhora na qualidade, ou negativa, indicando uma tendência de piora na qualidade da água. No caso em que o teste resulte não significante, considera-se sem tendência, mostrando uma condição estável ou de pequena variação da qualidade da água. 


\section{RESULTADOS}

Os resultados dos indicadores de qualidade determinados pela Rede de Monitoramento da Qualidade das Águas da CETESB, utilizados no cálculo dos índices IPMCA, IET e IVA, as ponderações de cada um dos indicadores e o resultado do cálculo dos índices, para cada ponto de monitoramento e ano de estudo, são apresentados nas tabelas A1 a A30, no Anexo. Estas tabelas também contêm informações de campo no momento das coletas de água, como a ocorrência de chuvas nas últimas 24 horas anteriores à coleta, coloração e temperatura da água, e temperatura do ar, assim como o resultado do IQA.

Os dados constantes destas tabelas serviram como base para diversas análises dos resultados, descritas a seguir.

Os indicadores de qualidade que influenciaram na qualidade das águas classificadas pelo IVA como Regular, Ruim e Péssima, considerando todos os resultados do índice no período total de estudo, são apresentados em tabelas e gráficos de freqüência nas Tabelas A31 a A35 (Anexo) e Figuras 3 a 7.

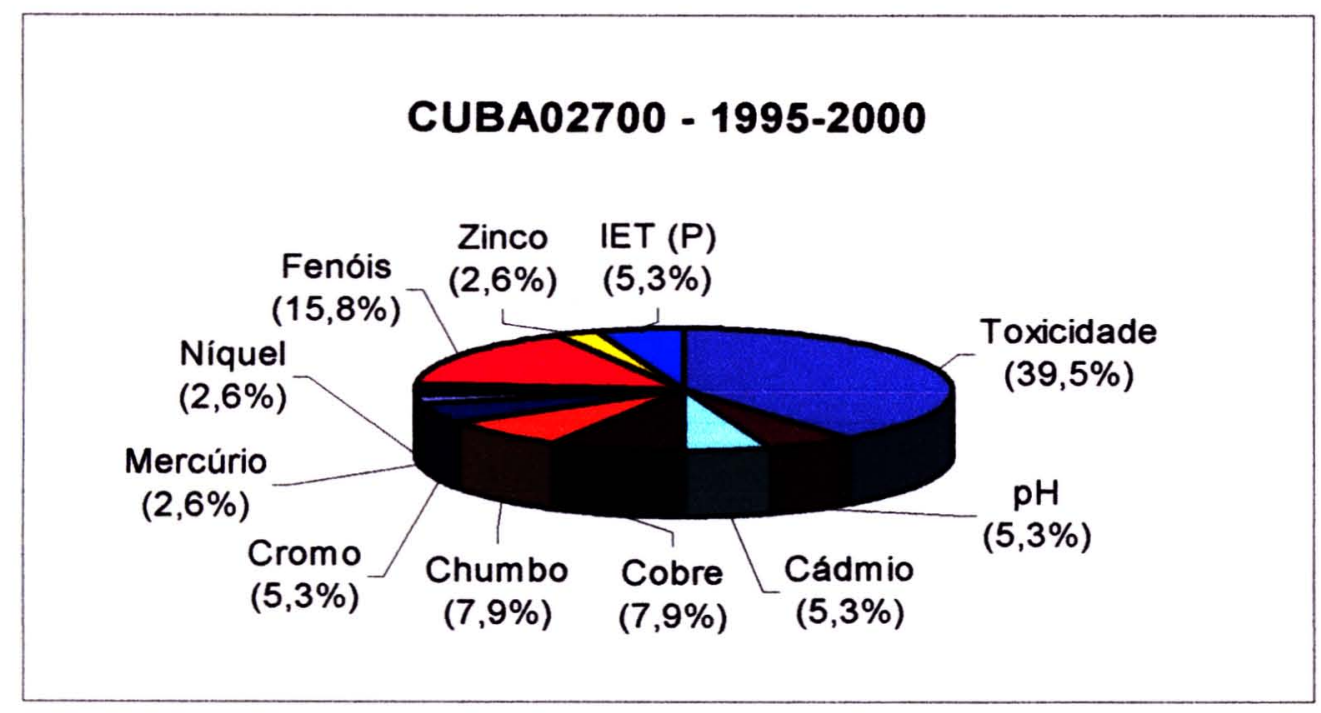

Figura 3 - Ponto CUBA02700 - Indicadores de qualidade que influenciaram na qualidade das águas classificadas pelo IVA como Regular, Ruim e Péssima. 


\section{CUBA03900- 1995-2000}

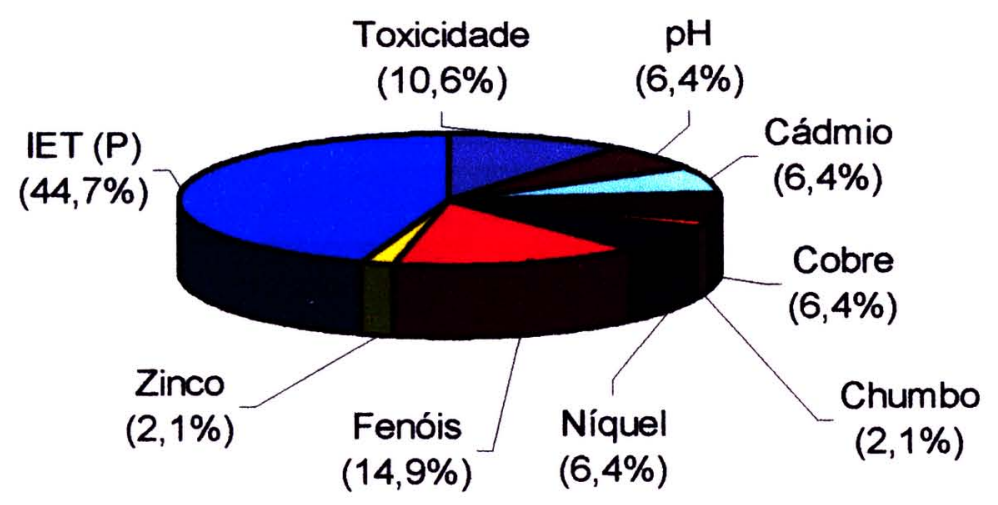

Figura 4 - Ponto CUBA03900 - Indicadores de qualidade que influenciaram na qualidade das águas classificadas pelo IVA como Regular, Ruim e Péssima.

\section{CFUG02900 -1995-2000}

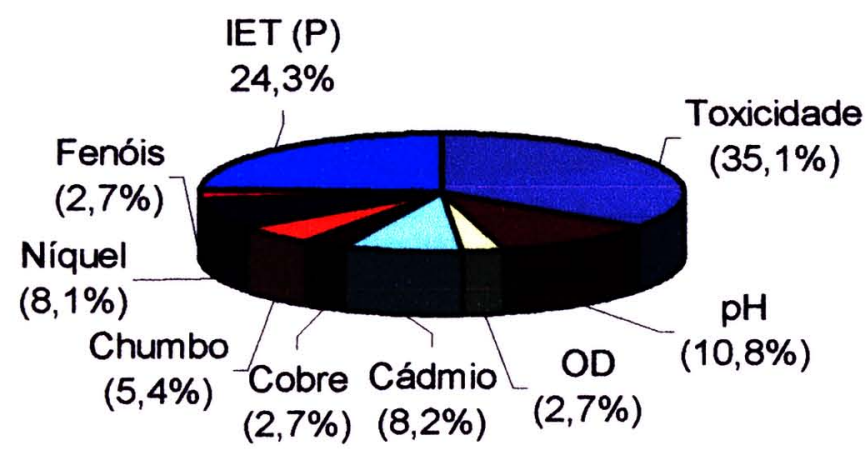

Figura 5 - Ponto CFUG02900 - Indicadores de qualidade que influenciaram na qualidade das águas classificadas pelo IVA como Regular, Ruim e Péssima. 


\section{MOGI02800 - 1995- 2000}

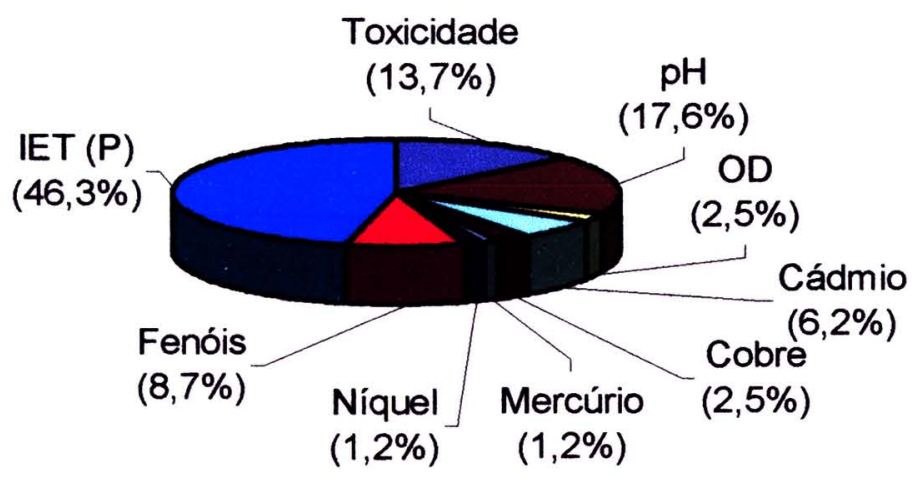

Figura 6 - Ponto MOGI02800 - Indicadores de qualidade que influenciaram na qualidade das águas classificadas pelo IVA como Regular, Ruim e Péssima.

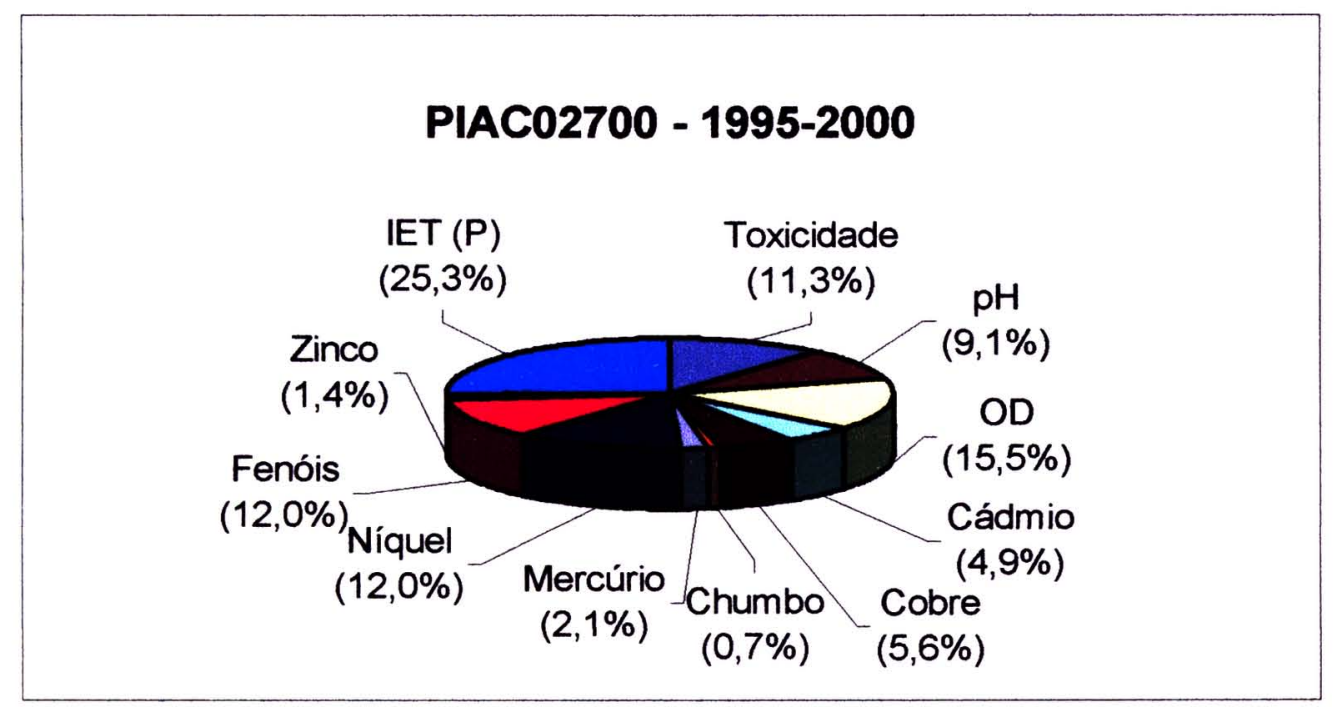

Figura 7 - Ponto PIAC02700 - Indicadores de qualidade que influenciaram na qualidade das águas classificadas pelo IVA como Regular, Ruim e Péssima.

De maneira geral, observa-se que o IET, calculado a partir da concentração de fósforo total, teve maior influência na classificação do IVA nos pontos CUBA03900 $(44,7 \%)$, MOGI02800 (46,3\%) e PIAC02700 (25,3\%), além de se mostrar também como segundo fator responsável pela classificação do IVA no ponto CFUG02900, com $24,3 \%$ de influência. A toxicidade foi o parâmetro de maior influência nos 
pontos CUBA02700 (39,5\%) e CFUG02900 (35,1\%), apresentando a segunda maior frequência no ponto PIAC02700 (11,3\%). O pH foi um dos parâmetros mais significativos para a classificação do IVA no ponto MOGI02800, com freqüência de $17,6 \%$, o mesmo ocorrendo com o OD, no ponto PIAC02700 $(15,5 \%)$. Em relação às substâncias tóxicas, vale destacar a influência do níquel e fenóis, no ponto PIAC02700, ambos com freqüência de 12,0\%, e os fenóis nos pontos do rio Cubatão: CUBA02700 (15,8\%) e CUBA03900 (14,9\%). Os metais cádmio, cobre, chumbo, cromo, mercúrio e zinco também mostraram influência na classificação do IVA, porém com freqüências mais baixas, na maioria dos pontos de monitoramento.

Os mapas esquemáticos da UGRHI 7 - Baixada Santista, identificando os pontos de amostragem, foram utilizados para apresentar os resultados de IVA e IQA, em forma de gráfico, mostrando a freqüência percentual de ocorrência de cada classificação de qualidade das águas, de acordo com os índices considerados, em cada ano de estudo (Figuras 8 a 13).

Os gráficos mostram que, de uma maneira geral, na aplicação do IVA detectou-se condições piores de qualidade da água em quase todos os pontos, em relação ao IQA. Em todos os pontos de monitoramento considerados, no período de estudo, o IQA detectou qualidade Péssima somente no ponto PIAC02700, nos anos de 1995 (10\%) e 1997 (17\%), enquanto o IVA classificou a água nesta faixa de qualidade no mesmo ponto de monitoramento com uma freqüência alta, em todos os anos de estudo. Observa-se também que o IQA apresentou qualidade Boa e Ótima nos pontos CFUG02900 e CUBA02700 em todos os anos estudados, sendo que o IVA resultou em classificação que variou de Ótima a Ruim. Nos pontos PIAC02700 e MOGI02800, a aplicação do IVA resultou, em todos os anos considerados, em uma classificação de qualidade da água nas faixas de Ruim a Péssima, enquanto o IQA apresentou maior porcentagem na faixa de qualidade Aceitável. No ponto CUBA03900 houve maior concordância nas classificaçőes de qualidade da água calculadas de acordo com o IQA e IVA, variando de Ótima a Ruim, porém com uma maior tendência do IQA à classificação de qualidade Boa, enquanto o IVA classificou as águas, na maior parte do estudo, com qualidade Regular e Ruim.

Na Tabela 7 são resumidos os resultados dos valores médios anuais do IVA, nos diferentes pontos de amostragem, no período de 1995 a 2000.

Tabela 7 - Médias anuais do IVA - Índice para Proteção da Vida Aquática, nos diferentes pontos de amostragem, no período de 1995 a 2000.

\begin{tabular}{|c|c|c|c|c|c|c|}
\hline \multirow[b]{2}{*}{ PONTOS } & \multicolumn{6}{|c|}{ ANOS } \\
\hline & 1995 & 1996 & 1997 & 1998 & 1999 & 2000 \\
\hline CFUG 02900 & 3 & 2 & 3 & 3 & 3 & 3 \\
\hline CUBA 02700 & 3 & 3 & 2 & 3 & 2 & 2 \\
\hline CUBA 03900 & 3 & 4 & 3 & 4 & 4 & 2 \\
\hline PIAC 02700 & 4 & 5 & 5 & 5 & 4 & 5 \\
\hline MOGI 02800 & 4 & 4 & 4 & 4 & 4 & 4 \\
\hline
\end{tabular}




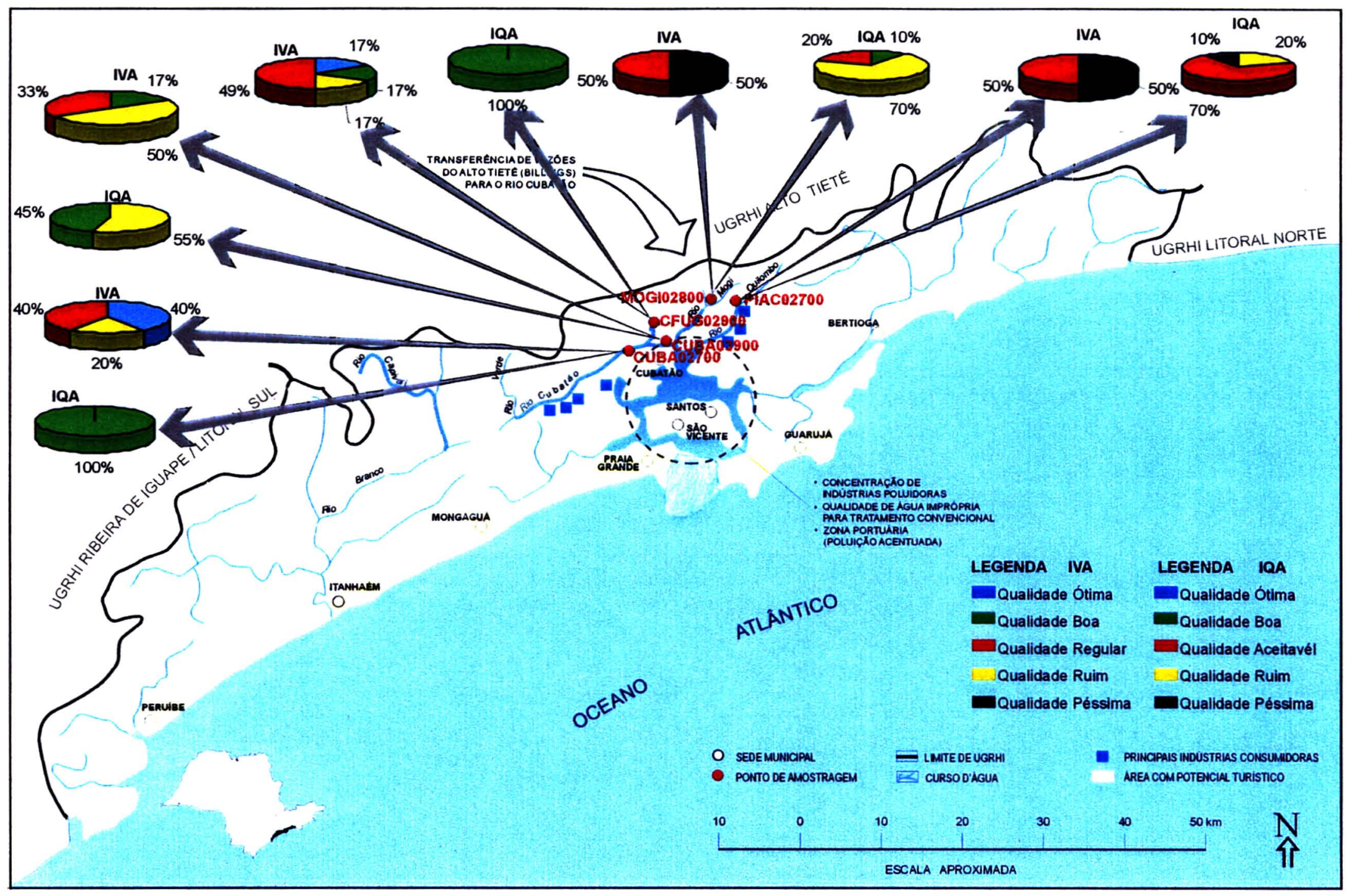

Figura 8 - Freqüências percentuais das classificações de qualidade da água obtidas para IQA e IVA, no ano de 1995 


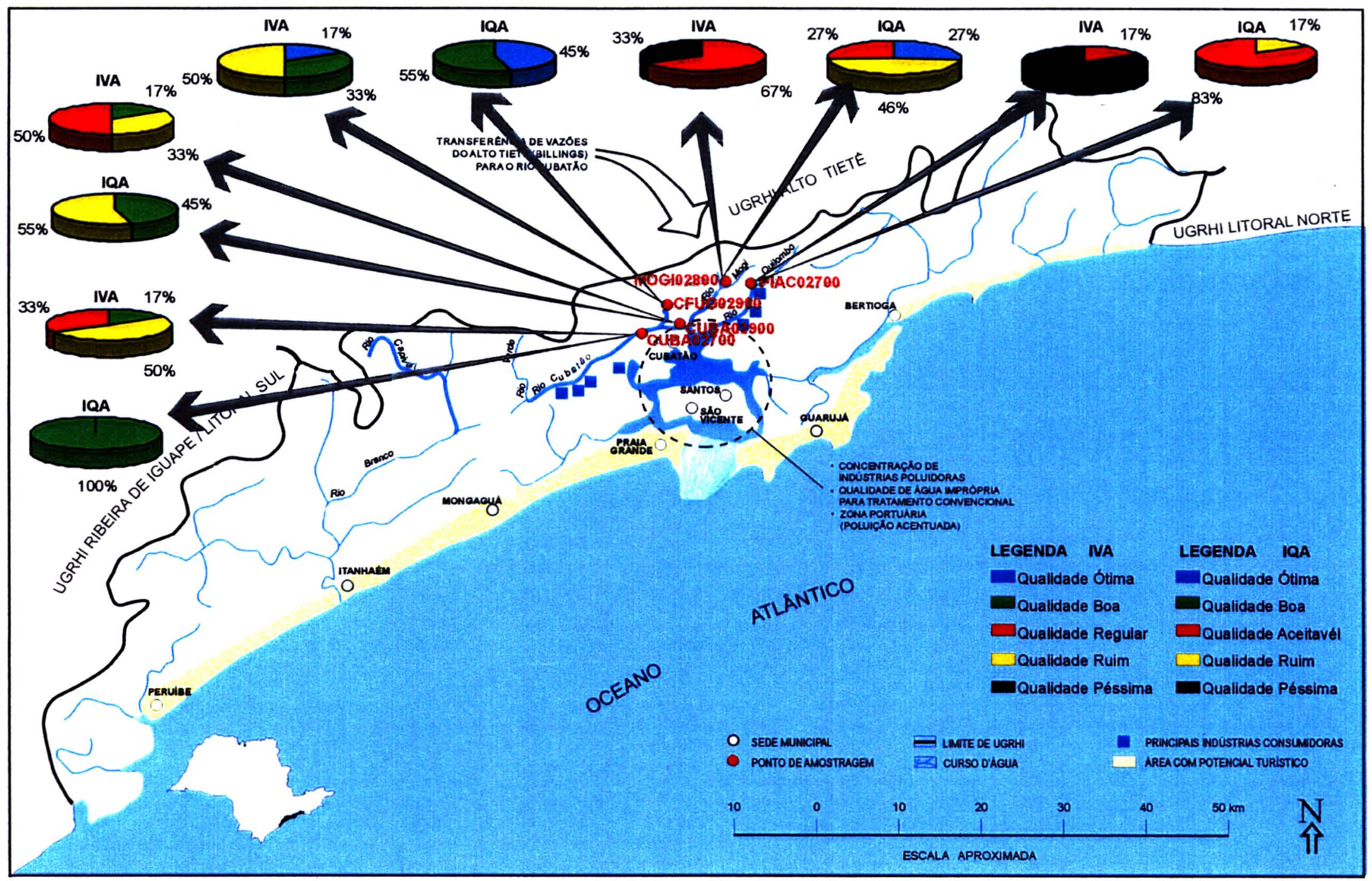

Figura 9 - Freqüências percentuais das classificações de qualidade da água obtidas para IQA e IVA, no ano de 1996 


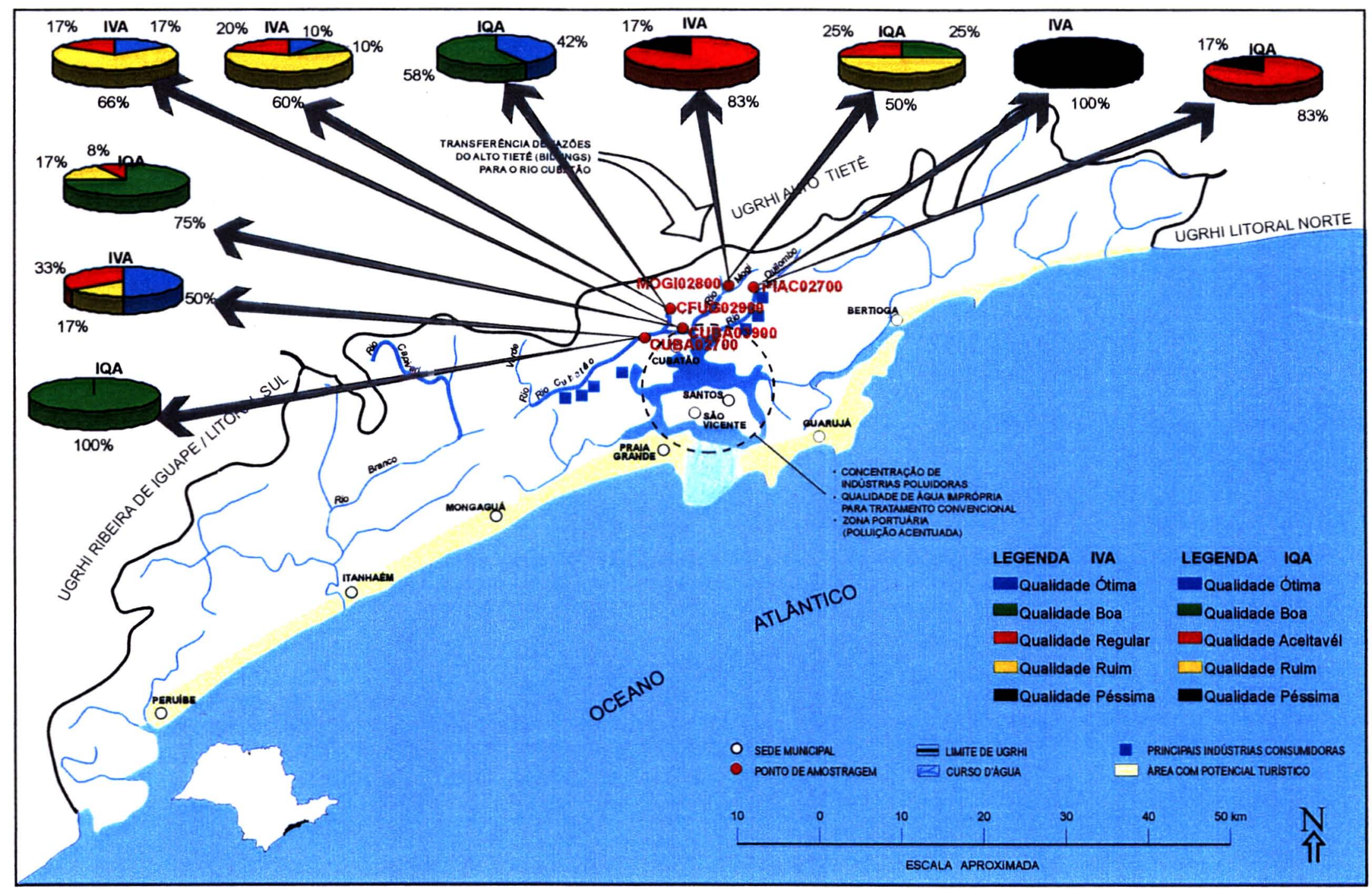

Figura 10 - Freqüências percentuais das classificações de qualidade da água obtidas para IQA e IVA, no ano de 1997. 


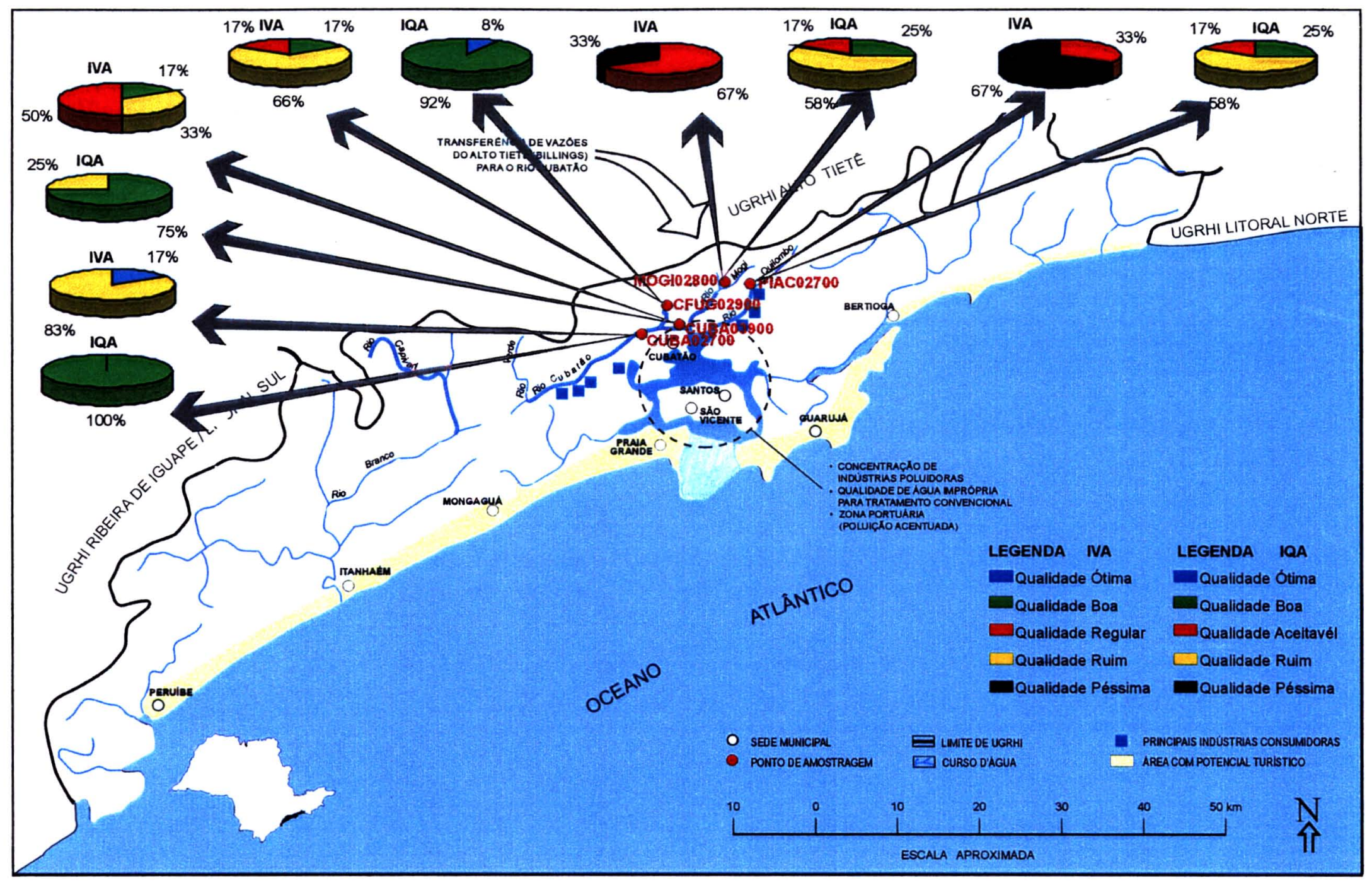

Figura 11 - Freqüências percentuais das classificações de qualidade da água obtidas para IQA e IVA, no ano de 1998 


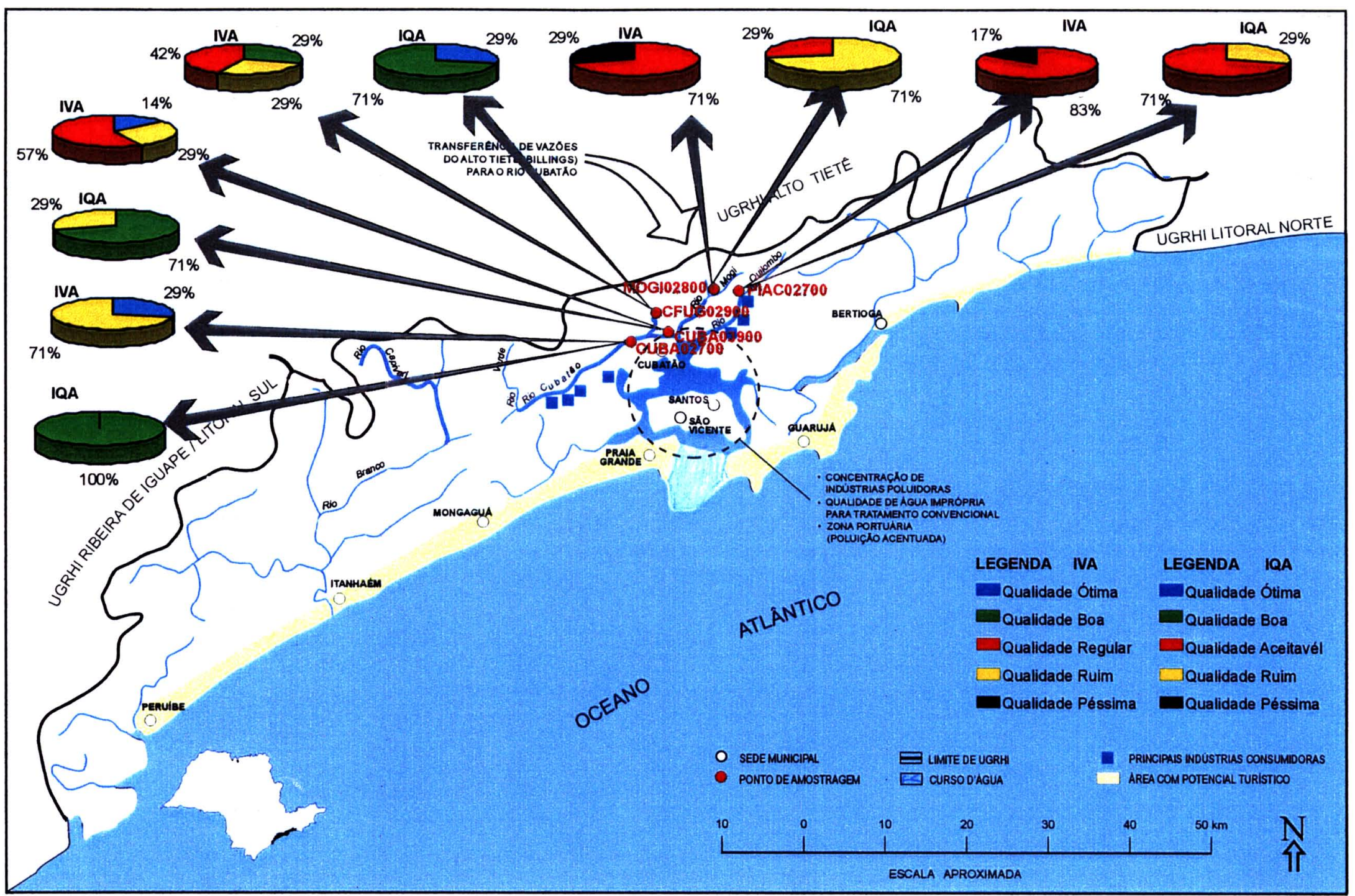

Figura 12 - Freqüências percentuais das classificações de qualidade da água obtidas para IQA e IVA, no ano de 1999 


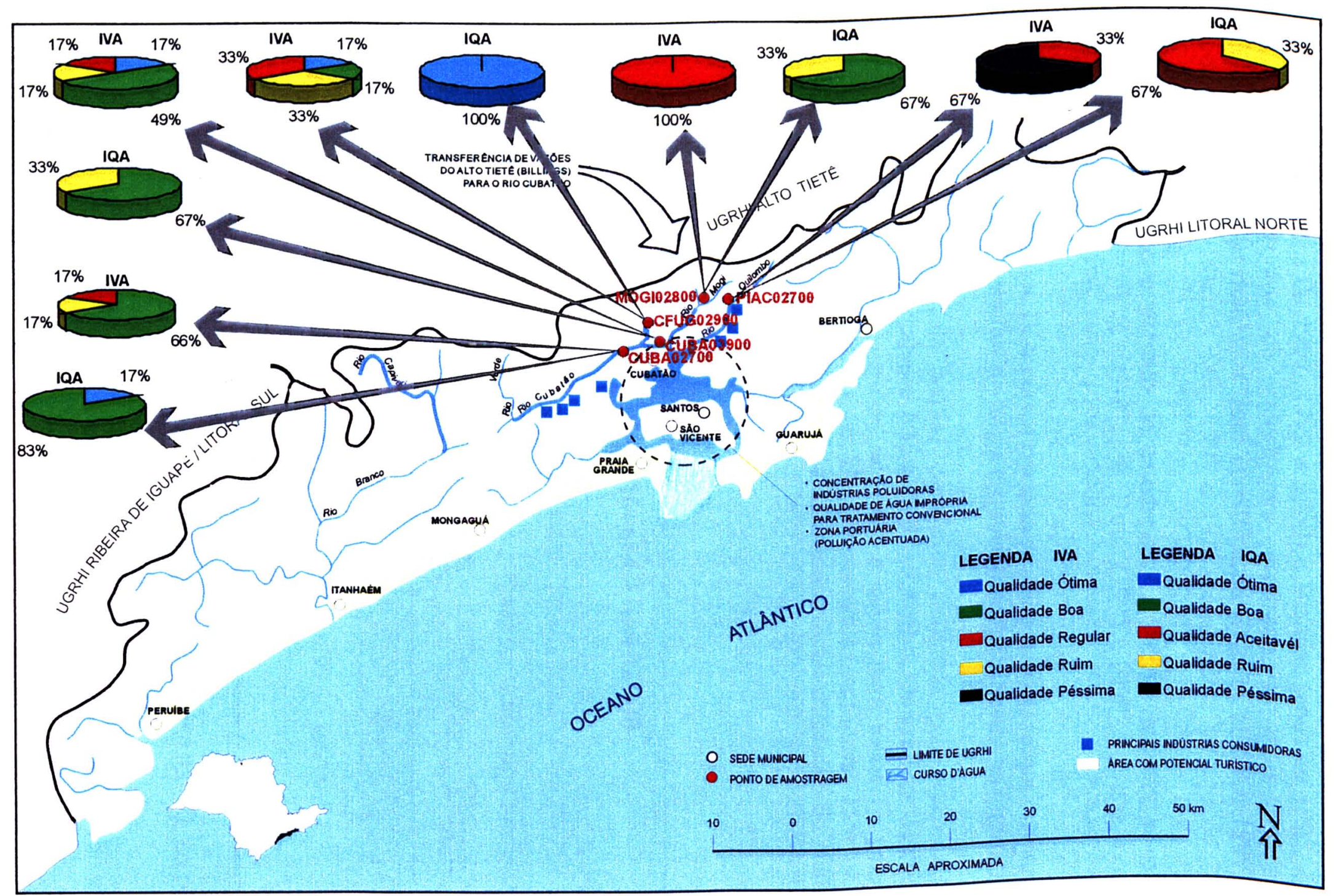

Figura 13 - Freqüências percentuais das classificações de qualidade da água, obtidas para IQA e IVA, no ano de 2000 
As médias do IVA mostram predominância da classificação Regular no ponto CFUG02900 em todos os anos de estudo, com exceção do ano de 1996, que mostrou uma qualidade Boa. No ponto CUBA02700 observou-se igual número de classificações Boa (anos de 1997, 1999 e 2000) e Regular (anos de 1995, 1996 e 1998). Os outros pontos de amostragem mostraram-se mais impactados: CUBA03900 apresentou dois anos com classificação Regular (1995 e 1997), três anos com classificação Ruim (1996, 1998 e 1999), e somente no ano de 2000 a média do IVA mostrou classificação Boa; MOGI02800 apresentou classificação Ruim ao longo de todo o período de estudo; e PIAC02700 mostrou-se o mais problemático, com dois anos de classificação Ruim (1995 e 1999) e quatro anos com classificação Péssima (1996, 1997, 1998 e 2000).

Os resultados das médias de IVA para o período de 1995 a 2000 foram condensados em gráficos, e estão apresentados no mapa esquemático apresentado na Figura 14.

O sumário dos resultados da análise estatística realizada para verificação de tendência do IVA consta das tabelas A36 a A40, no Anexo. Os gráficos de evolução da média móvel do IVA no período de 1995 a 2000, para todos os pontos de monitoramento da bacia do rio Cubatão, são apresentados nas Figuras 15 a 19. Estes gráficos permitem verificar a tendência dos resultados de classificação da qualidade, obtidos com a aplicação do índice.

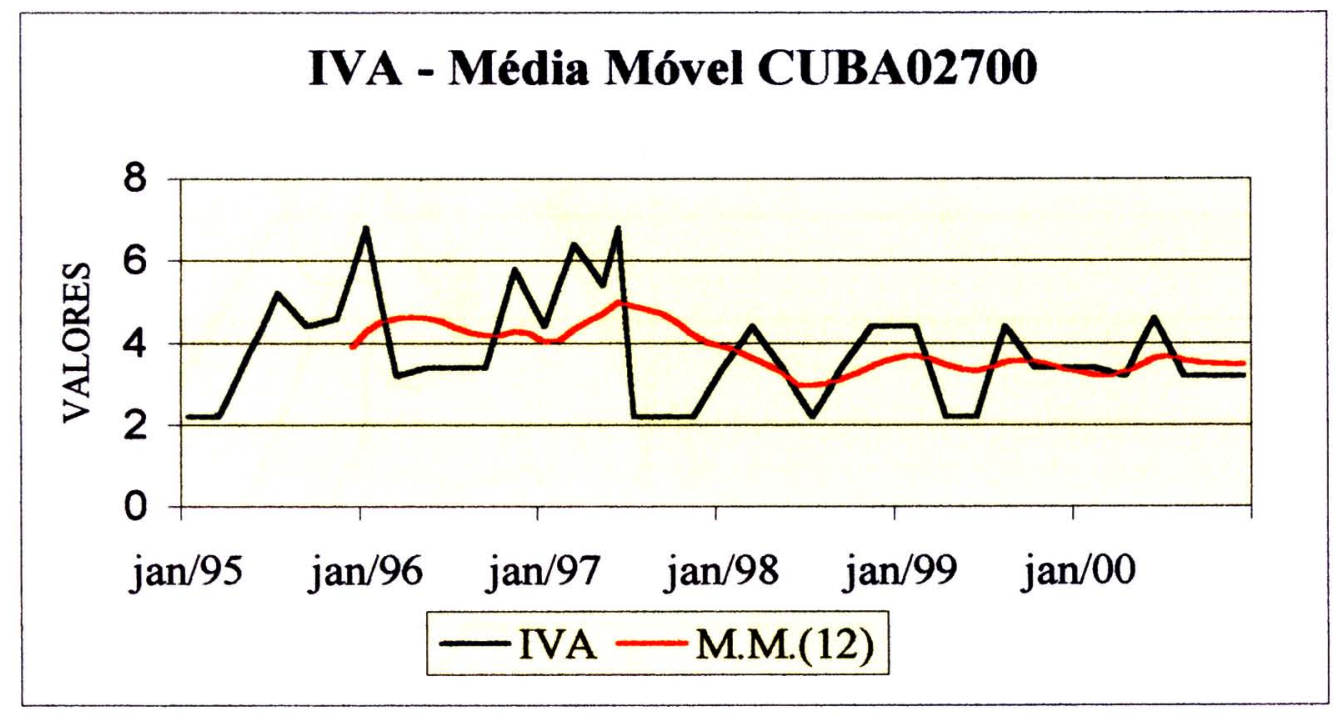

Figura 15 - Evolução da média móvel do IVA no ponto CUBA02700, no período de 1995 a 2000. 


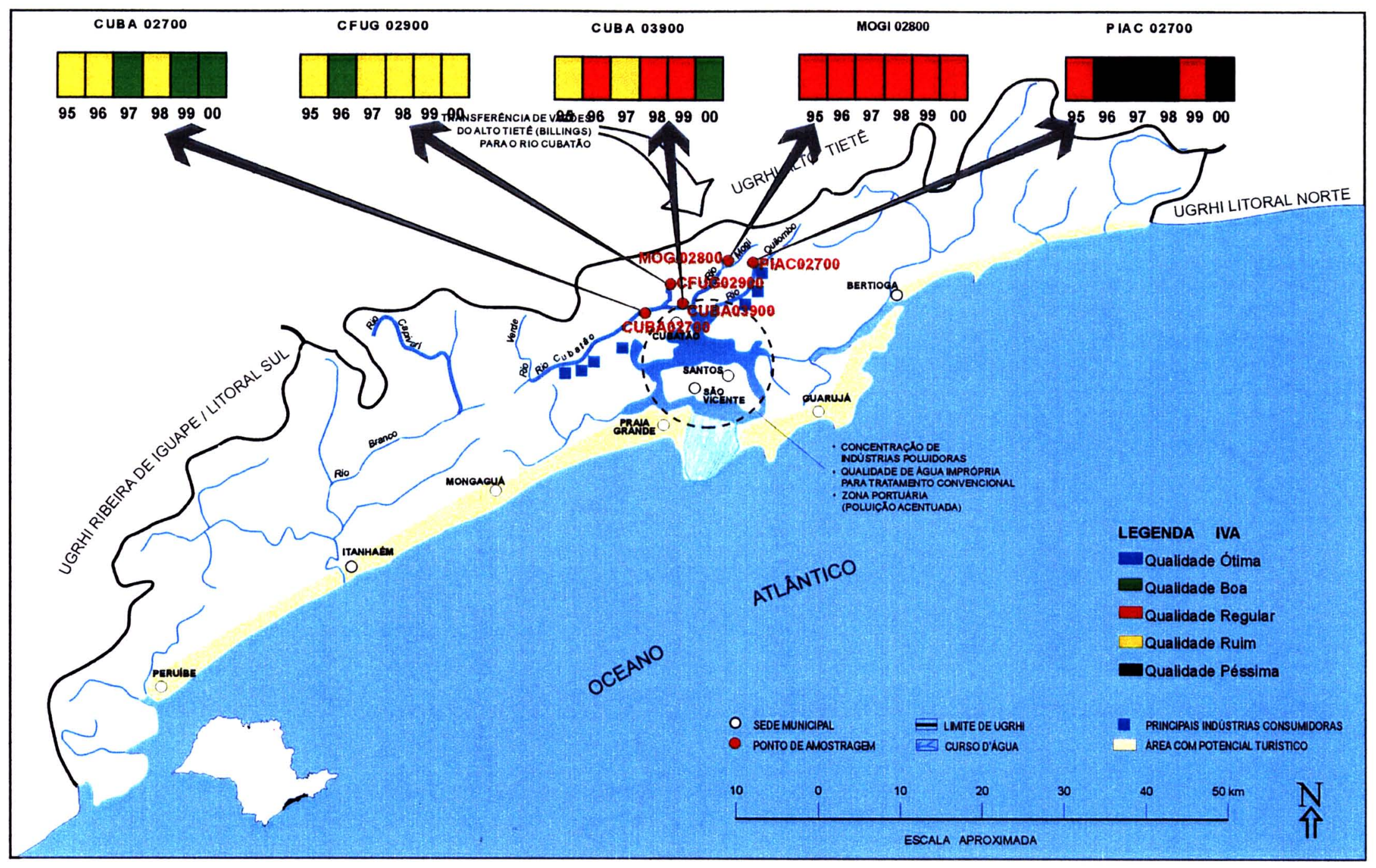

Figura 14 - Médias anuais das classificações de qualidade da água obtidas para o IVA no período de 1995 a 2000 


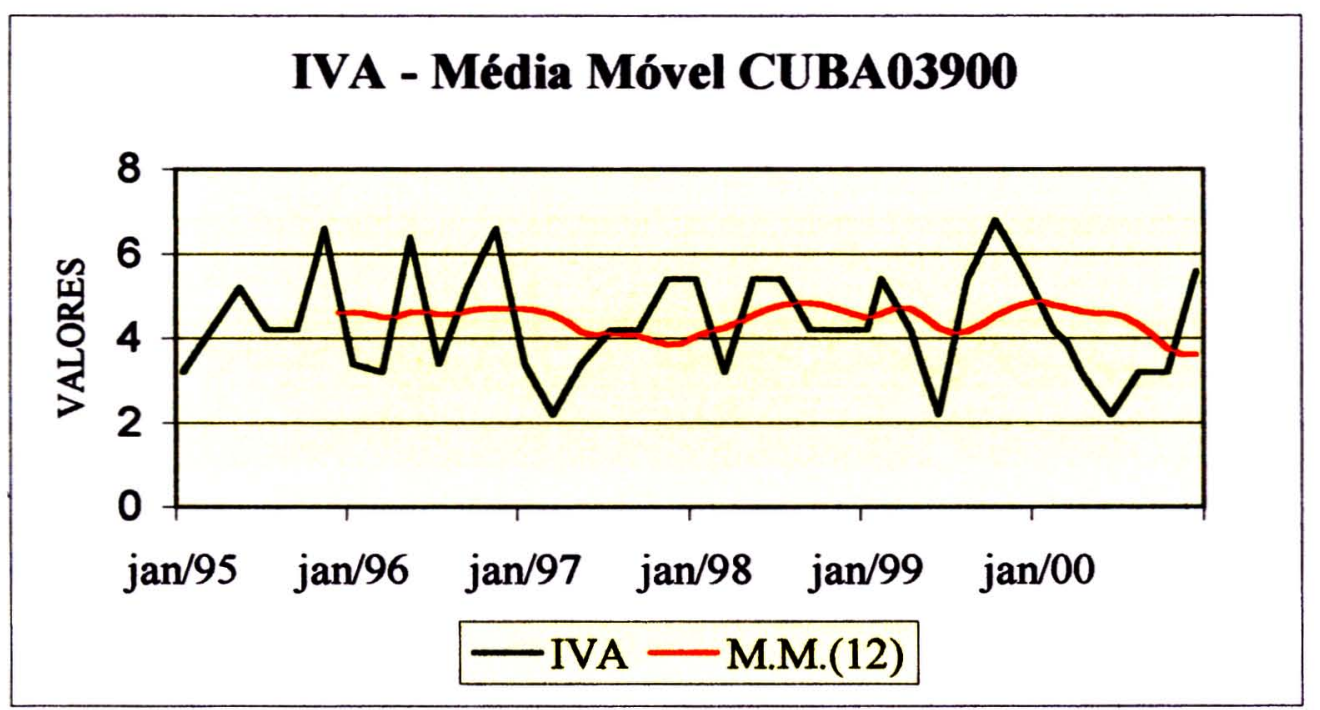

Figura 16 - Evolução da média móvel do IVA no ponto CUBA03900, no período de 1995 a 2000.

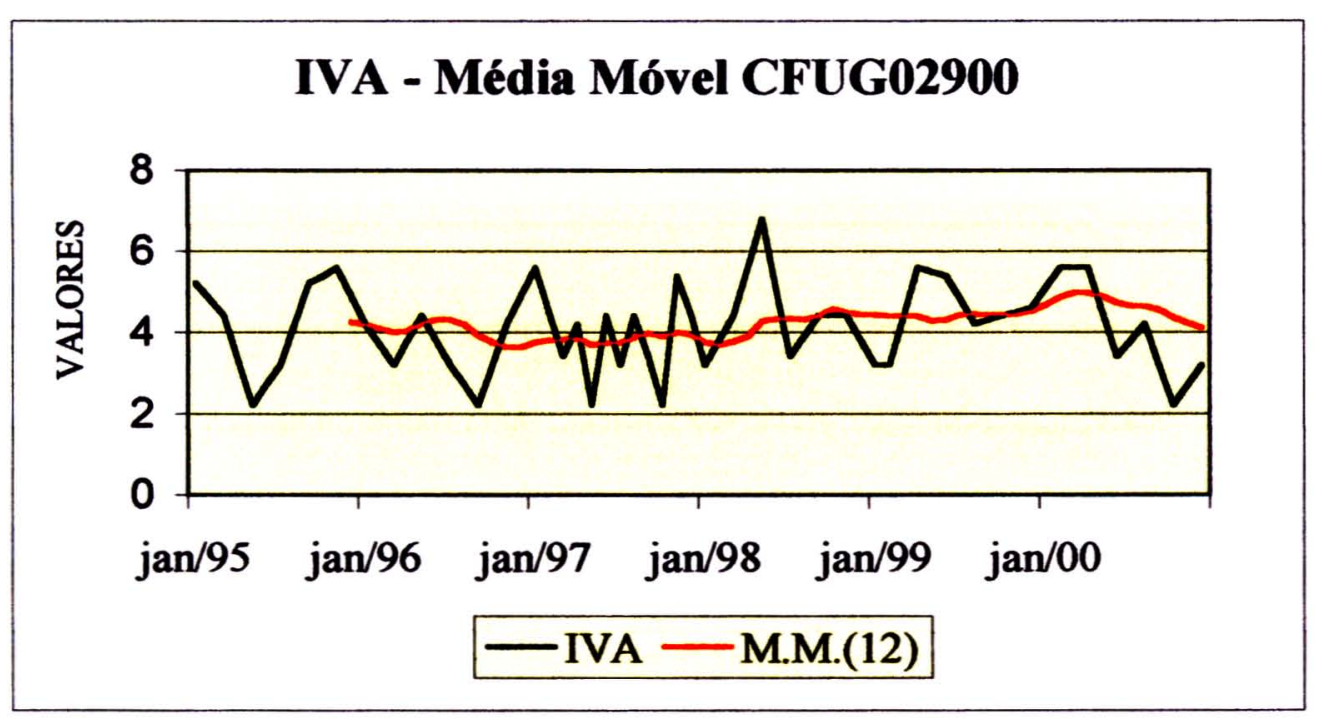

Figura 17 - Evolução da média móvel do IVA no ponto CFUG02900, no período de 1995 a 2000. 


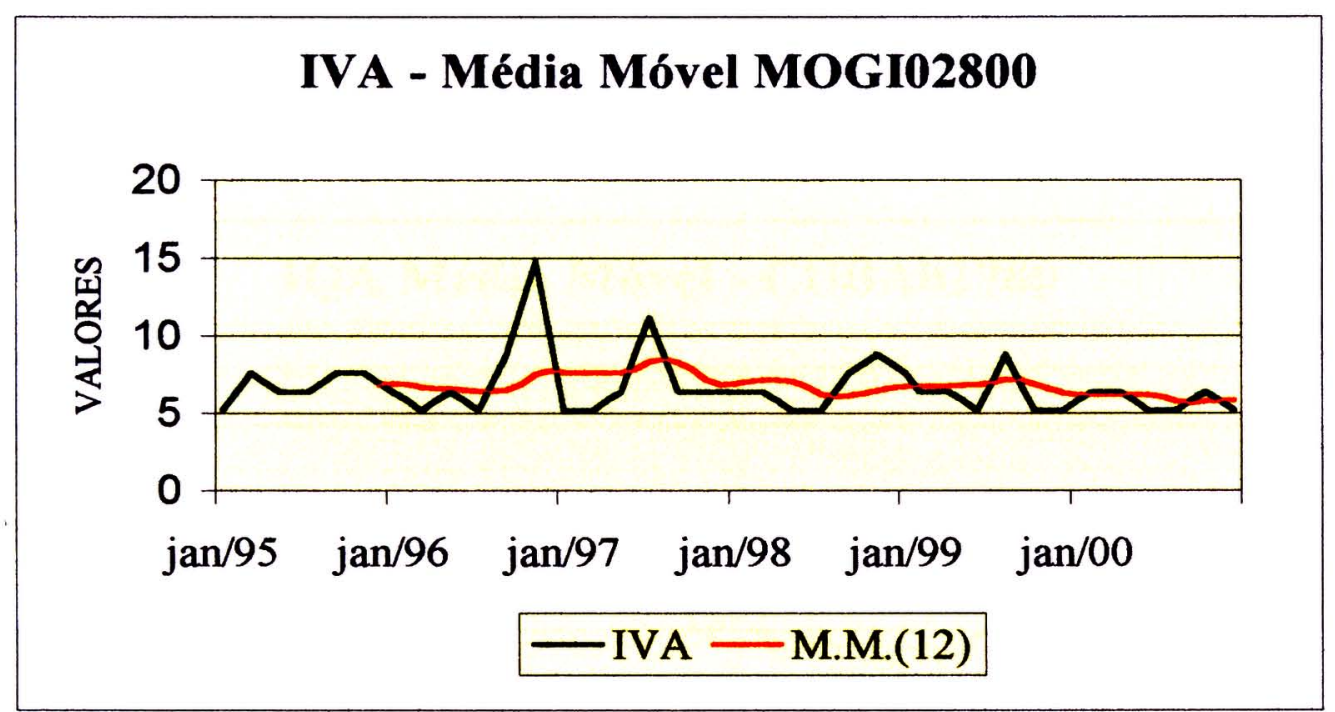

Figura 18 - Evolução da média móvel do IVA no ponto MOGI02800, no período de 1995 a 2000.

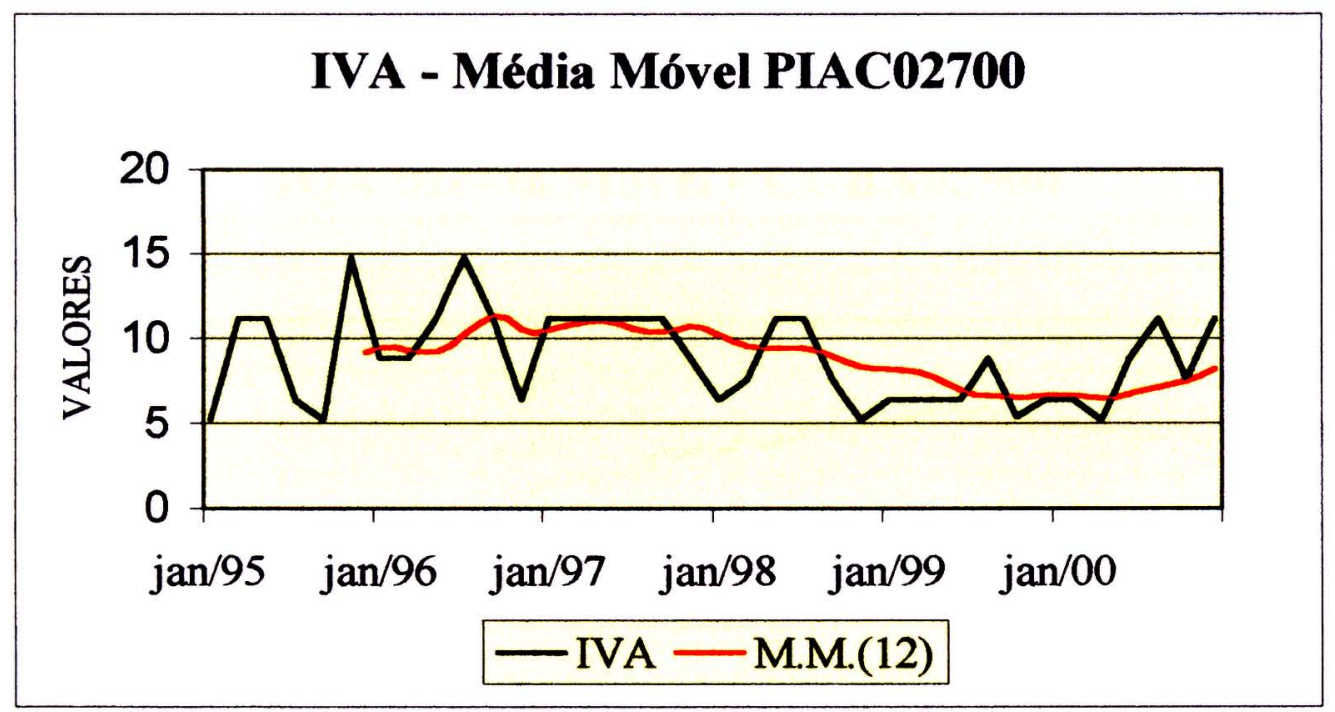

Figura 19 - Evolução da média móvel do IVA no ponto PIAC02700, no período de 1995 a 2000

$\mathrm{Na}$ análise de tendência do IVA, verificou-se que a aplicação do teste "t de Student" resultou não significante para os dados de IVA no período de 1995 a 2000 , em todos os pontos de monitoramento da bacia do rio Cubatão. Os gráficos de evolução de média móvel apresentados refletem o resultado obtido. 
Para fins de comparação, apresenta-se, a seguir, os gráficos de evolução da média móvel do IQA - Índice de Qualidade das Águas, no período de 1991 a 2000 (Figuras 20 a 24).

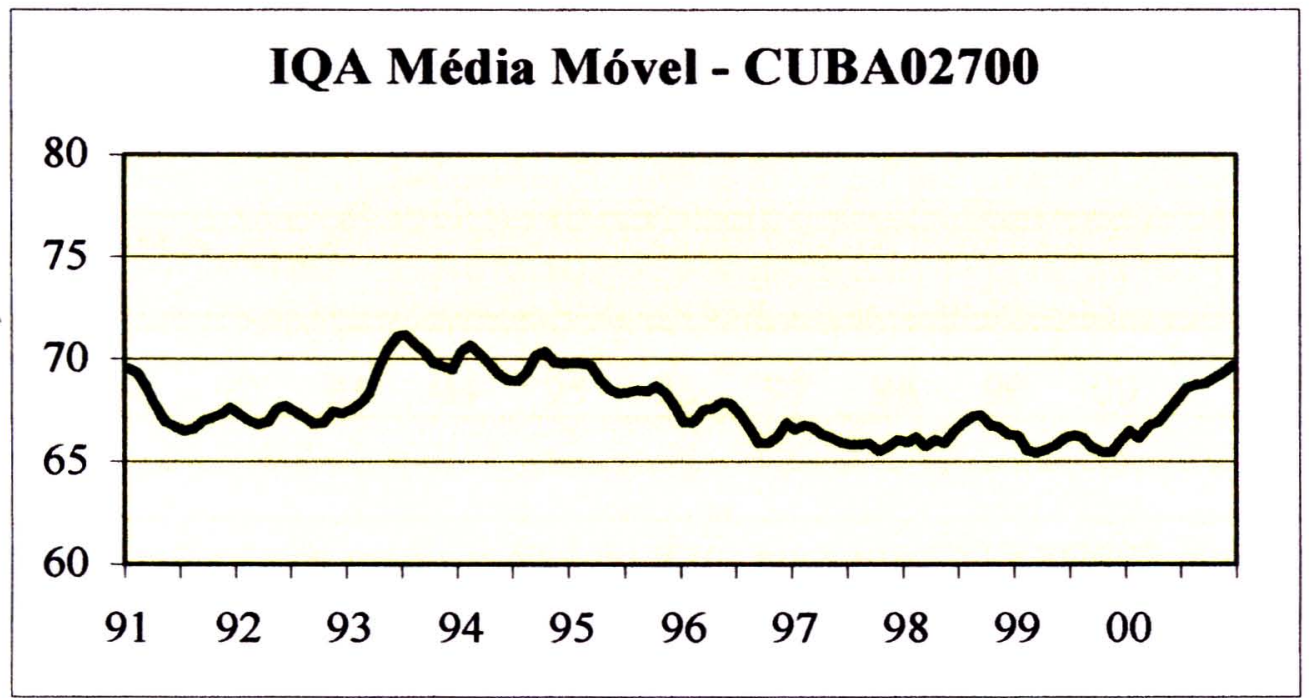

Figura 20 - Evolução da média móvel do IQA, no ponto CUBA02700, no período de 1991 a 2000.

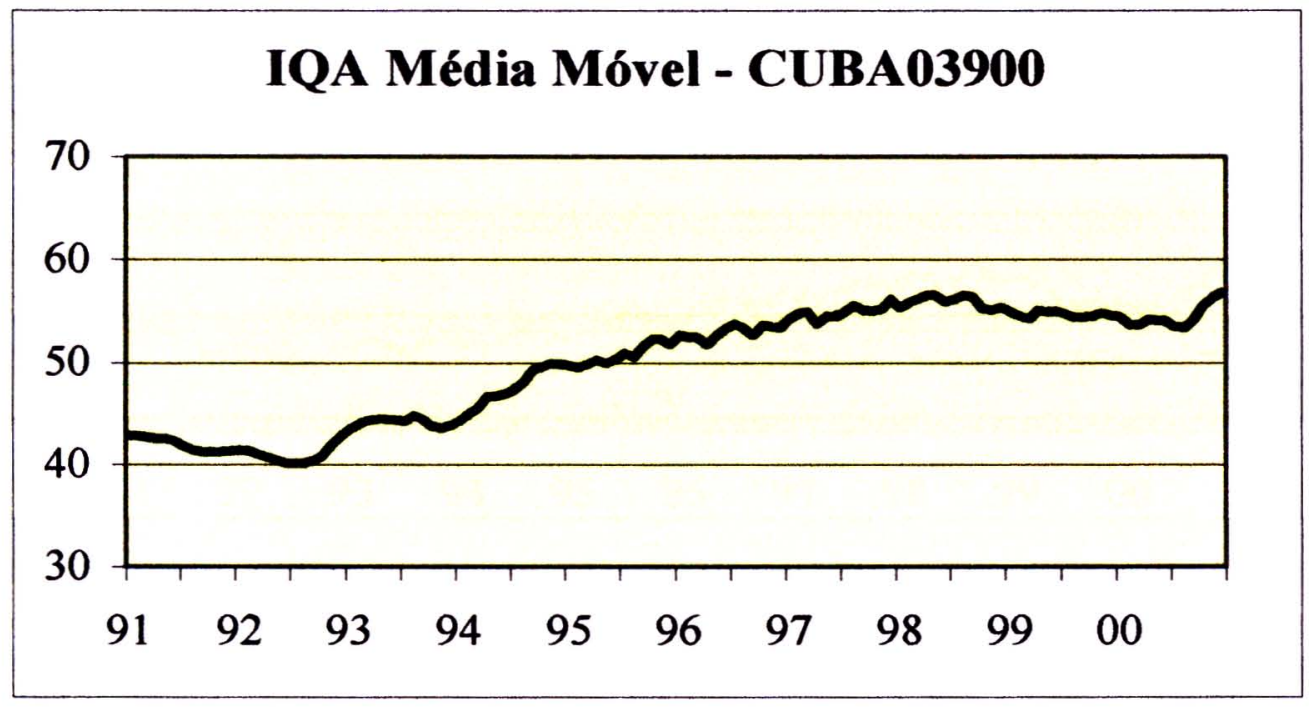

Figura 21 - Evolução da média móvel do IQA, no ponto CUBA03900, no período de 1991 a 2000. 


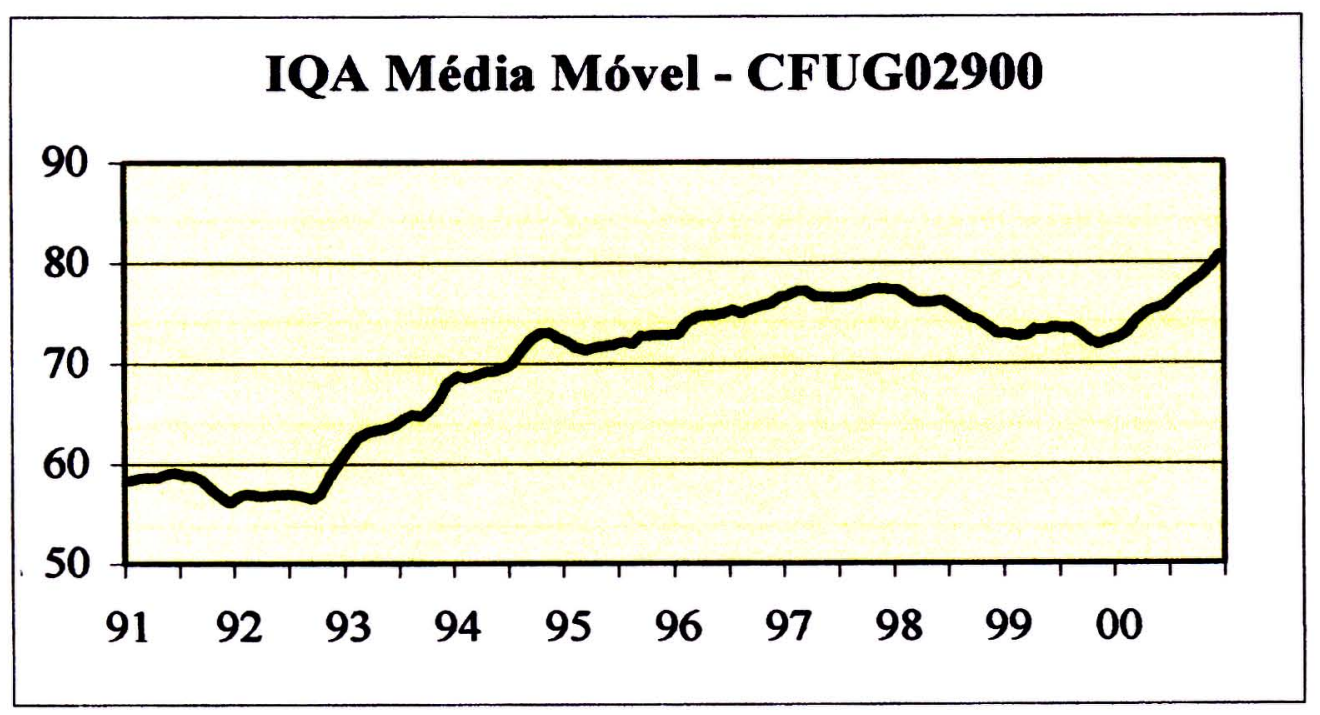

Figura 22 - Evolução da média móvel do IQA, no ponto CFUG02900, no período de 1991 a 2000.

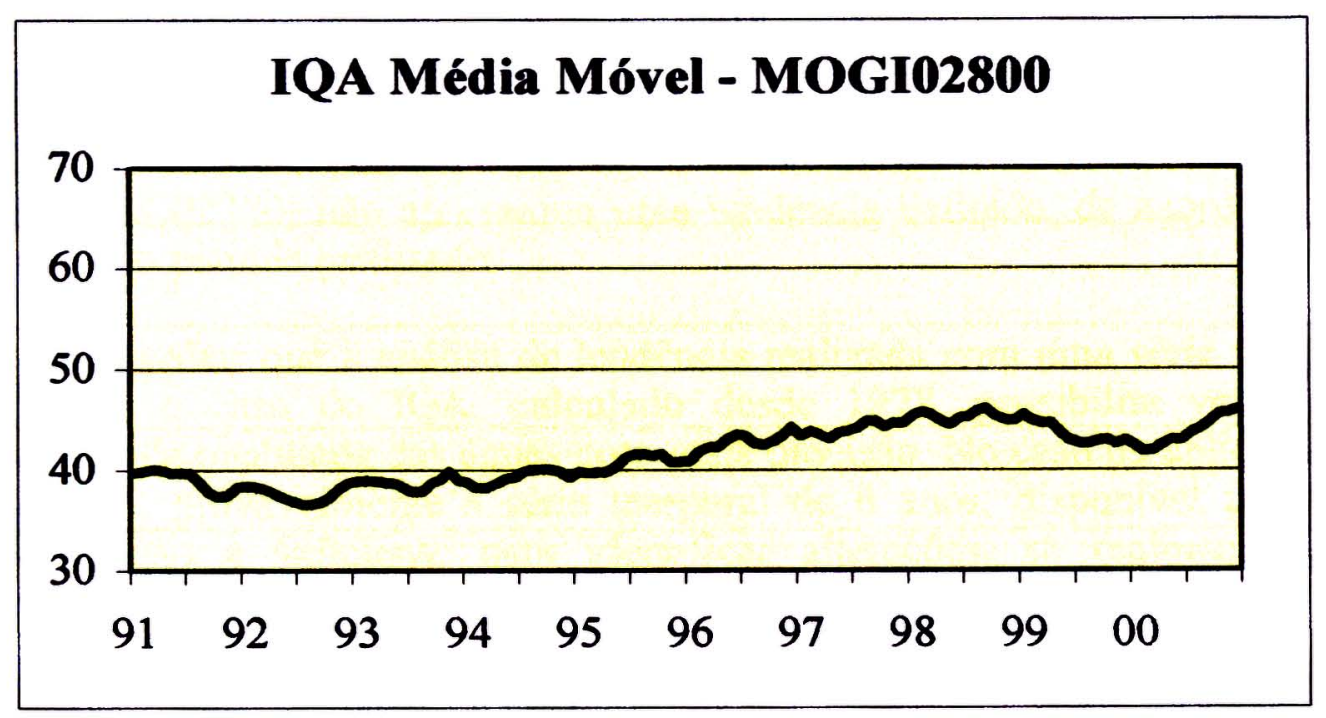

Figura 23 - Evolução da média móvel do IQA, no ponto MOGI02800, no período de 1991 a 2000. 


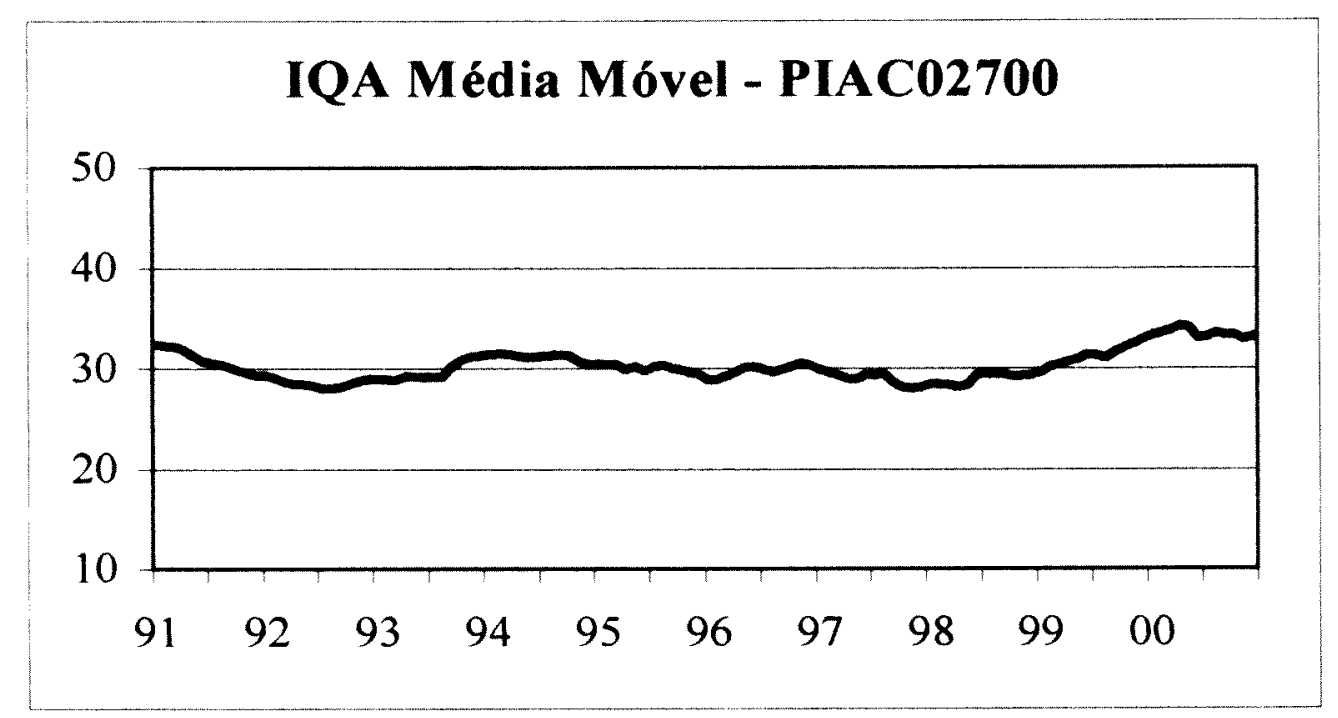

Figura 24 - Evolução da média móvel do IQA, no ponto PIAC02700, no período de 1991 a 2000.

Observa-se que, para os pontos de monitoramento do rio Cubatão, o IQA apresenta uma tendência de piora no ponto CUBA02700 até o ano de 1999, recuperando a qualidade no ano de 2000. Já no ponto CUBA03900 observa-se uma melhora da qualidade a partir do ano de 1993. Essa melhora está diretamente relacionada com as melhores condições de qualidade das águas provenientes do reservatório Billings, por meio do Canal de Fuga (CFUG02900), que também apresentaram uma tendência de melhora de qualidade. A qualidade das águas do rio Mogi (MOGI02800) e do rio Piaçaguera (PIAC02700) não apresentou uma tendência definida, de acordo com o IQA, ao longo do período analisado.

É importante ressaltar que a análise de tendência realizada com uma série temporal maior, como é o caso do IQA, calculado desde 1978, possibilita verificar o comportamento da qualidade das águas com mais precisão. No caso da aplicação do método ao IVA, provavelmente a série temporal de 6 anos, disponível para este estudo, ainda não é suficiente para identificar alterações, se realmente estão ocorrendo, do perfil da qualidade da água para preservação da vida aquática. 


\section{DISCUSSÃO}

\section{1. Índices de Qualidade das Águas}

A disponibilidade de água é cada vez mais uma preocupação da sociedade contemporânea. A consciência de que esse recurso essencial para qualquer ser vivo está sendo utilizado de maneira inadequada, resultando no risco de, a curto ou médio prazo, não ser capaz de prover seus diferentes usos, tem levado a população a procurar informações sobre a qualidade da água da qual depende, e buscar, junto às autoridades competentes, soluções para a melhoria de sua qualidade de vida.

Sabe-se que a degradação da qualidade da água se dá através de várias fontes, dentre as quais se destacam os efluentes domésticos, os efluentes industriais, o deflúvio superficial urbano e o deflúvio superficial agrícola, estando portanto associada ao tipo de uso e ocupação do solo (CETESB, 1996). Substâncias tóxicas (metais pesados, substâncias orgânicas) lançadas nos sistemas aquáticos, geralmente resultantes de processos industriais, têm sido historicamente as grandes responsáveis pela degradação dos ambientes aquáticos. Os resíduos líquidos decorrentes da disposição inadequada de lixo doméstico e industrial lançados diretamente nos corpos d'água ou transportados indiretamente pela chuva merecem especial destaque, pois resultam no agravamento da qualidade da água, ameaçando a biota aquática e também os organismos terrestres, incluindo o homem.

Embora os ecossistemas aquáticos sejam adaptáveis a uma variedade de mecanismos físicos, químicos e biológicos através dos quais substâncias tóxicas podem ser assimiladas sem implicações sérias para a biota endêmica, quando contaminantes químicos atingem níveis acima da capacidade assimilativa dos corpos d'água receptores, eles podem afetar a sobrevivência, o crescimento, a reprodução ou o comportamento dos organismos (ANDERSON \& D'APOLLONIA, 1978 in COONEY, 1995).

As águas superficiais e subterrâneas constituem um recurso natural de grande importância, cuja qualidade deve ser preservada, tendo em vista sua rentabilidade econômica e suas principais utilizações: abastecimento público, irrigação, lazer e aquacultura (FONTOURA, 1985 in PELÁEZ-RODRÍGUEZ, 2000).

Mas como se avalia a qualidade da água, e como essas informações são tratadas e reportadas à população?

MEYBECK \& HELMER (1992) consideram que a qualidade de um ambiente aquático pode ser definida: a) segundo a presença de substâncias inorgânicas ou orgânicas em diferentes concentrações e especiações e b) segundo a composição e estrutura da biota aquática presente no corpo d'água. A qualidade do ambiente aquático mostra variações temporais e espaciais em decorrência de processos internos e externos ao corpo d'água.

O monitoramento é uma medida sistemática de variáveis e processos ao longo do tempo relacionados a um problema específico (SPELLEBERG, 1991 in RAND, 
1995). O monitoramento ambiental inclui observações e medidas de indicadores de qualidade biológicos, químicos e físicos seguindo um planejamento e metodologias comparáveis. O objetivo do monitoramento é coletar dados suficientes para avaliar a qualidade de um ambiente (ar, água e solo).

O monitoramento da qualidade da água é um meio de se avaliar as condições dos recursos hídricos e prover uma base de informações para planos efetivos que promovam o uso inteligente e o gerenciamento adequado desta fonte vital. A necessidade de dados de qualidade da água corretos e atualizados que dêem suporte a ações e programas de gerenciamento dos recursos é amplamente reconhecida. Através de um monitoramento efetivo, pode-se responder questões críticas sobre as condições da qualidade da água, determinar a efetividade das ações de controle e programas de gerenciamento, focalizar recursos disponíveis para um beneficio máximo, identificar problemas, necessidades e oportunidades, e desenvolver novas ações, procedimentos, e programas.

O monitoramento da qualidade da água tem sido definido como uma atividade integrada para a avaliação das características físicas, químicas e biológicas da água em relação à saúde humana, condições ecológicas, e determinados usos (INTERGOVERNMENTAL TASK FORCE ON MONITORING WATER QUALITY, 1992).

Em 1970, BROWN et al. destacaram, em seu trabalho intitulado "A water quality index - do we dare?", que milhões de dólares eram gastos para o controle da poluição da água realizado nos municípios e indústrias americanas, porém nenhuma provisão ainda havia sido feita para manter o público informado, em termos simples e compreensíveis, do resultado deste esforço e investimento na melhoria da qualidade da água. Destacaram também que "todos falam sobre qualidade da água, ou até mais sobre a falta dela, no entanto poucos param um momento para pensar como isto está sendo medido. Agências federais, estaduais e locais coletam dados em uma miríade de parâmetros individuais, os quais terminam em volumosos arquivos ou, ocasionalmente, são publicados em brochuras - em uma forma difícil de digerir e assimilar. O que é claramente necessário é um padrão de comparação de qualidade da água que leve em consideração os parâmetros mais significativos".

Uma das mais desanimadoras expectativas encaradas por cientistas de qualidade da água é como tornar dados freqüentemente complexos de qualidade de água em informação de fácil compreensão e utilidade para não cientistas, como por exemplo, tomadores de decisão, planejadores e o público em geral (SMITH, 1989).

$\mathrm{Na}$ tentativa de simplificar o conteúdo da informação dos dados, foram envidados esforços para produzir um único (ou talvez uns poucos) número(s) que fosse $(\mathrm{m})$ capaz(es) de integrar de alguma maneira uma coleção de dados. Tais números são chamados de índices de qualidade de água (SMITH, 1990).

Os índices de qualidade de água propostos desde a década de 70 consideram parâmetros físicos e químicos similares, sendo a principal diferença dentre eles a forma estatística de integrar e interpretar essas variáveis. ZAGATTO et al. (1999) 
levantaram índices de qualidade de água propostos e em utilização, identificando os parâmetros neles considerados:

\begin{tabular}{|l|l|}
\hline \multicolumn{1}{|c|}{ Indicadores de Qualidade } & \multicolumn{1}{|c|}{ Fonte } \\
\hline $\begin{array}{l}\text { pH, OD, condutividade, coliformes, cloretos, alcalinidade, } \\
\text { substâncias extraidas com clorofórmio }\end{array}$ & Horton (1965) \\
\hline $\begin{array}{l}\text { pH, OD, coliformes fecais, DBO, nitrato, fosfato, temperatura, } \\
\text { turbidez, sólidos totais }\end{array}$ & Brown et al.(1970) \\
\hline $\begin{array}{l}\text { pH, OD, carbono orgânico dissolvido, sólidos em suspensão, } \\
\text { amônia, nitrato, cloreto, ferro, manganês, surfactantes. }\end{array}$ & Prati et al. (1971) \\
\hline OD, DBO, N-amoniacal, sólidos em suspensão. & Ross (1977) \\
\hline $\begin{array}{l}\text { pH, OD, N-amoniacal, N-total, coliformes, fosfato, sólidos em } \\
\text { suspensão, condutividade, temperatura }\end{array}$ & Bolton et al. (1978) \\
$\begin{array}{l}\text { pH, OD, DBO, N-amoniacal, nitrato, coliformes, fosfato, sólidos } \\
\text { em suspensão, metais, temperatura, hidrocarbonetos, pesticidas, } \\
\text { fenóis, cianetos. }\end{array}$ & House \& Ellis (1987) \\
\hline $\begin{array}{l}\text { pH, OD, DBO, temperatura, amônia, nitrato, sólidos em } \\
\text { suspensão, cloreto. }\end{array}$ & Tyson \& House (1989) \\
\hline $\begin{array}{l}\text { pH, OD, sólidos em suspensão, turbidez, temperatura, } \\
\text { coliformes. }\end{array}$ & Smith (1990) \\
\hline $\begin{array}{l}\text { pH, OD, DBO, coliformes, N-amoniacal, P-total, resíduo total, } \\
\text { turbidez, temperatura }\end{array}$ & CETESB (1993) \\
\hline
\end{tabular}

Os mesmos autores ressaltam também que os índices propostos não abordam aspectos básicos da Ecotoxicologia Aquática. Milhares de substâncias potencialmente tóxicas são lançadas no ambiente e a maioria dos índices existentes não contemplam sequer as substâncias mais comuns. No trabalho de HOUSE \& ELLIS (1987), embora tenham sido considerados diferentes grupos de substâncias tóxicas, o resultado do índice não foi satisfatório devido à metodologia de cálculo escolhida, a qual resulta na atenuação/diluição dos valores das variáveis, quando interpretados conjuntamente.

Desde o início do controle de qualidade das águas, os padrões numéricos, e os parâmetros físicos, químicos e bacteriológicos serviram de referência para avaliar o nível de degradação dos corpos hídricos. Questiona-se, no entanto, a forma de combinação desses indicadores de qualidade para expressar um índice para proteção da vida aquática. Mesmo que se tenha uma noção de quais parâmetros poderiam ser usados para esse índice, sabe-se hoje que existe uma infinidade de substâncias tóxicas e que tornar-se-ia técnica e economicamente inviável uma análise completa do ponto de vista físico-químico. Além disso, as interações entre diferentes substâncias dificilmente poderiam ser avaliadas através dessas análises (BERTOLETTI et al., 1989; ZAGATTO \& GHERARDI-GOLDSTEIN, 1991).

Para identificar e controlar o lançamento de substâncias tóxicas nos sistemas aquáticos é importante a utilização de testes de toxicidade em laboratório. Com base nos resultados destes testes, seja em nível agudo ou crônico, avalia-se o risco de um efeito deletério nos sistemas aquáticos naturais. Deste modo, os testes de toxicidade são instrumentos iniciais, que proporcionam os dados qualitativos e quantitativos sobre os efeitos adversos ou tóxicos de diversas substâncias aos organismos 
aquáticos, e que podem ser então utilizados para avaliar o potencial, ou o grau de dano, a um ecossistema aquático.

Efeitos adversos nos ecossistemas aquáticos podem resultar da exposição a uma substância tóxica que causa diretamente a morte de um organismo (efeito agudo) ou produz efeitos subletais na habilidade dos organismos em se desenvolverem, crescerem e reproduzirem no ecossistema (efeitos crônicos) (COONEY, 1995).

O Laboratório de Toxicologia Aquática da CETESB tem trabalhado com testes de toxicidade desde 1978 , inicialmente dentro de um programa de padronização com substâncias químicas isoladas, efluentes, detergentes e pesticidas, segundo o método padronizado pela ISO (1975), com várias espécies de peixes e invertebrados (NAVAS-PEREIRA et al., 1987). Outros trabalhos enfocaram a toxicidade de efluentes industriais e seu potencial para causar efeito nos corpos receptores, abrangendo cerca de 300 efluentes líquidos, de diversas atividades industriais (CETESB, 1987a, b; BERTOLETTI, 1990), e a toxicidade da água de vários rios do Estado de São Paulo (GHERARDI-GOLSTEIN et al., 1981; ZAGATTO \& GHERARDI-GOLDSTEIN, 1991; CETESB, 1992). Estes trabalhos avaliaram a toxicidade aguda das amostras, com várias espécies de peixes (Brachydanio rerio, Poecilia reticulata e Hemigrammus marginatus), os microcrustáceos Daphnia magna e Daphnia similis, e as algas Chlorella vulgaris e Scenedesmus quadricauda.

O desenvolvimento do teste de toxicidade crônica com Ceriodaphnia dubia (CETESB, 1991), a partir de metodologia proposta pela EPA (USEPA, 1989), proporcionou a introdução deste teste na Rede de Monitoramento de Qualidade das Águas da CETESB. Através dessa análise, foi possível identificar corpos d'água que, apesar de atenderem aos padrões de qualidade de água estabelecidos pela legislação, causavam toxicidade aguda ou crônica a organismos aquáticos.

Os dados gerados pela Rede de Monitoramento da Qualidade das Águas, aos quais foram adicionados os dados de toxicidade, permitiram o desenvolvimento do IPCA, um novo índice de qualidade de água que tinha como objetivo a proteção das comunidades aquáticas, um dos usos da água contemplados na Resolução Federal CONAMA n ${ }^{\circ}$ 20/86 e regulamento da Lei 997/76 do Estado de São Paulo, aprovado pelo Decreto 8468/76 (CETESB, 1982, 1994a). O IPCA considerava uma série de substâncias potencialmente tóxicas para os organismos aquáticos, e incorporava $o$ resultado do teste de toxicidade crônica com Ceriodaphnia dubia.

Este índice foi o primeiro avanço na avaliação da qualidade da água com vistas à proteção da vida aquática; mas ainda havia o problema da não inclusão de parâmetros capazes de avaliar a qualidade da água quanto ao seu grau de eutrofização, limitação esta já apontada quando da sua primeira apresentação à comunidade científica, no XXVI Congresso da Sociedade Internacional de Limnologia, em 1995 (ZAGATTO et al., 1998b).

O processo de eutrofização consiste no enriquecimento das águas por nutrientes, sendo que um dos resultados mais comuns é o crescimento de plantas aquáticas, que podem ser tanto as que se movimentam livremente na água, como é o caso das 
comunidades fitoplanctônicas, representadas principalmente pelas algas, quanto as plantas flutuantes, como, por exemplo, os conhecidos aguapés. O desenvolvimento excessivo das plantas aquáticas (floração) não é função exclusivamente da presença de nutrientes na água, mas é controlado também por fatores físicos ambientais naturais, entre os quais se destacam a transparência, a temperatura da água, bem como o regime hidráulico do corpo d'água.

Em níveis baixos, a eutrofização pode ser benéfica, pois aumenta a produtividade dos corpos hídricos, ou seja, a sua capacidade de manutenção da vida aquática. Em níveis elevados, contudo, passa a prejudicar os usos da água, através de interferências variadas, como as estéticas e recreacionais, ocasionadas pelo acúmulo de algas na superficie da água e pelos maus odores gerados na decomposição da matéria orgânica, a depleção do oxigênio no período noturno causando mortandade de peixes, entupimento de filtros de estações de tratamento de água, ou desenvolvimento de algas do grupo das cianoficeas, que podem ser potencialmente tóxicas a animais e causar problemas à saúde humana, no caso de ingestão acidental.

A crescente utilização de fertilizantes é um dos fatores que tem incrementado o processo de eutrofização nos últimos anos em todo o mundo, contribuição esta que se soma àquela advinda dos esgotos domésticos e industriais que são usualmente lançados às águas sem o devido tratamento. Nesse sentido, vale destacar os detergentes em pó como fontes importantes de fósforo, que têm como destino final os mananciais (CETESB, 2001a).

O desenvolvimento do IVA - Índice para Proteção da Vida Aquática, integrando resultados de análises químicas, testes de toxicidade, e o Índice de Estado Trófico, que por sua vez utiliza dados obtidos para clorofila-a (segundo norma CETESB, $1990 \mathrm{~b})$ e fósforo total, veio preencher a lacuna existente quanto aos fatores causadores da eutrofização em corpos d'água.

O IVA tem o objetivo de proporcionar a avaliação da qualidade das águas para fins de proteção da vida aquática (fauna e flora em geral), diferenciado, portanto, de um índice para avaliação da água para o consumo humano e recreação de contato primário. A proteção das comunidades aquáticas está prevista para corpos d'água enquadrados nas classes 1, 2 e 3 do regulamento da Lei 997/76 aprovado pelo Decreto Estadual 8468/76, e nas classes especial, 1 e 2 da Resolução CONAMA $20 / 86$, sendo portanto pertinente sua aplicação somente para esses ambientes.

Uma primeira aplicação do IVA foi feita por ZAGATTO et al. (1999), utilizando dados selecionados da Rede de Monitoramento da CETESB, em 17 pontos de amostragem do rio Tietê, desde sua cabeceira até sua foz, e dos reservatórios da Região Metropolitana de São Paulo. Os autores consideraram o IVA útil para identificar pontos críticos referentes à qualidade das águas para proteção da vida aquática, e capaz de diagnosticar as causas da deterioração da qualidade das águas, através da análise dos vários componentes do índice. Assim, observou-se que a qualidade das águas do rio Tietê apresenta-se ruim no seu trecho inicial, sendo a concentração de oxigênio dissolvido a responsável por esta classificação. $\mathrm{Na}$ região da Grande São Paulo até a cidade de Tietê, a qualidade das águas mostrou-se 
péssima, verificando-se uma pequena melhora após receber as águas do rio Sorocaba, e voltando a apresentar qualidade péssima no ponto de amostragem localizado na entrada do reservatório de Barra Bonita. A presença de substâncias tóxicas (toxicidade, metais e fenol) e baixas concentrações de OD foram considerados os responsáveis pela qualidade péssima das águas. No reservatório de Barra Bonita obteve-se qualidade regular, até a barragem de Promissão, em função de nutrientes, OD e toxicidade crônica, passando a apresentar qualidade boa até a confluência com o rio Paraná.

Na Região Metropolitana de São Paulo, o IVA classificou as águas dos reservatórios Billings, Taiaçupeba e Jundiaí como de qualidade ruim, identificando a toxicidade $\mathrm{e}$ eutrofização como os componentes que mais influenciaram neste resultado; e as águas do reservatório Guarapiranga, braços do Rio da Pedras e do Rio Grande com qualidade regular, apresentando toxicidade crônica, metais pesados e principalmente eutrofização.

PELÁEZ-RODRIGUEZ et al. (2000) aplicaram também o IVA em estudo que avaliou a qualidade da água do rio Monjolinho e do ribeirão do Feijão, localizados na bacia hidrográfica do rio Jacaré-Guaçu, no Estado de São Paulo. Neste trabalho, a qualidade da água dos rios foi analisada em relação à concentração de metais pesados, estado trófico e toxicidade, além do IVA, como integrador das respostas obtidas para os diferentes parâmetros. Os resultados revelaram que as concentrações dos metais pesados foram, em geral, baixas, e as concentraçð̃es de fósforo variaram de médias a altas, caracterizando condições de mesotrofia e hipereutrofia. Verificouse a ocorrência de toxicidade crônica em quatro das localidades analisadas. A aplicação do IVA permitiu classificar a bacia do alto Jacaré-Guaçu como de qualidade regular em um ponto (representando $3 \%$ da drenagem da bacia), de qualidade ruim em 12 pontos (representando $85 \%$ da bacia) e de qualidade péssima em um ponto (representando aproximadamente $12 \%$ da drenagem total da bacia). Esses resultados identificaram a necessidade urgente de medidas de controle e recuperação da bacia, que se constitui em um importante recurso hídrico para o município de São Carlos, respondendo por $60 \%$ do volume de água captado para o abastecimento público. Os autores consideraram que o IVA representa uma ferramenta útil, que integra e expressa de uma forma clara diferentes informações sobre a qualidade da água em uma bacia hidrográfica, servindo, dessa forma, para informar ao público em geral, subsidiar atividades educativas e, principalmente, para o gerenciamento ambiental.

É importante observar que PELÁEZ- RODRIGUEZ et al. (2000) aplicaram o IVA utilizando os mesmos componentes e parâmetros propostos por ZAGATTO et al. (1999). Cabe aqui ressaltar que, desde o desenvolvimento do IPCA, e na sua seqüência de aprimoramento, o IPMCA e o IVA, buscou-se manter uma característica importante dos índices: a possibilidade de inclusão, dentro do componente grupo de substâncias tóxicas IPMCA, de tantos indicadores de qualidade quantos fossem considerados necessários e significativos para uma avaliação adequada do ambiente aquático em estudo. Os parâmetros incluídos inicialmente no IPMCA, e utilizados até o momento pela CETESB e neste trabalho, são os analisados pela Rede de Monitoramento da Qualidade das Águas, mas nada impede que sejam 
complementados e/ou substituídos por outros, a partir do momento em que um diagnóstico ambiental de uma região permita identificar substâncias potencialmente tóxicas que possam estar comprometendo a qualidade das águas. Para tanto, as informações essenciais são os limites máximos permissíveis destas substâncias químicas na água, para evitar efeitos crônicos e agudos à biota aquática, que possibilitarão o estabelecimento dos três níveis de qualidade, para os quais são feitas as ponderações numéricas 1,2 e 3 . De acordo com a proposta do IPMCA, esses níveis refletem as seguintes condições de qualidade de água:

- Nível A: águas com características necessárias para manter a sobrevivência e a reprodução dos organismos aquáticos (ponderação 1).

- Nível B: águas com características necessárias para a sobrevivência dos organismos aquáticos, porém a reprodução pode ser afetada a longo prazo (ponderação 2).

- Nível C: águas com características que podem comprometer a sobrevivência dos organismos aquáticos (ponderação 3).

Considerando-se os princípios da Toxicologia Aquática, pode-se afirmar que no nível A o limite permissível a ser considerado é o de não efeito, no nível B deve-se buscar o limite permissível para evitar efeitos crônicos, e no nível C, o limite a ser considerado deverá ser o que previne efeitos agudos a organismos aquáticos.

Uma perspectiva interessante e exequível, e que poderia trazer resultados mais concretos em termos de diagnósticos ambientais, seria a regionalização do monitoramento de qualidade das águas. A identificação de características regionais, como uso do solo, uso e disponibilidade de água, principais atividades industriais, e outras informaçðes, serviria como base para estabelecimento dos parâmetros mais adequados a serem analisados em cada região ou bacia hidrográfica. Esse procedimento poderia reverter na melhor utilização dos dados gerados pelo monitoramento, no sentido de identificar questões críticas sobre as condiçð̃es da qualidade da água, determinar a efetividade das ações de controle e programas de gerenciamento, destinar recursos disponíveis para um beneficio máximo, identificar problemas, necessidades e oportunidades, e desenvolver novas ações, procedimentos, e programas regionais.

O monitoramento regionalizado, conjugado a uma adequada divulgação pública dos resultados obtidos, como a utilização de um índice como o IVA - Indice para Proteção da Vida Aquática, constitui-se em uma rica e útil fonte de informaçð̃es para fóruns regionais tomadores de decisão, como os Comitês de Bacia Hidrográfica, consórcios de municipios, fóruns de desenvolvimento regional.

O aprimoramento contínuo de um indice de qualidade é uma tarefa importante para aqueles que trabalham com qualidade das águas. Torna-se importante salientar, no entanto, que o IVA é uma ferramenta para diagnosticar a qualidade da amostra de água apenas no momento de sua coleta, caracterizando-se como uma medida instantânea da contaminação e do grau de trofia das águas, e que a integridade de um ambiente deve ser avaliada através da densidade e diversidade das suas comunidades aquáticas. Assim, um levantamento das comunidades aquáticas de um determinado 
ecossistema, aliado às análises físicas, químicas e ecotoxicológicas, deverá, necessariamente, complementar as informações desse índice.

Nesse sentido, recomenda-se, no monitoramento da qualidade das águas, o uso de comunidades aquáticas, tais como: fitoplanctônica, perifítica, zooplanctônica, bentônica e de peixes. Cada uma destas comunidades responde de forma distinta aos impactos, diferindo no seu grau de sensibilidade e nos tempos de resposta e de recuperação. Como exemplos de indicação de desequilíbrio ambiental, podem ser citados: florações de algas em decorrência do aumento de eutrofização, aparecimento de estruturas de resistência nos organismos zooplanctônicos como resposta a condições ambientais desfavoráveis, dominância de espécies tolerantes e desaparecimento de espécies bentônicas e perifíticas sensíveis, devido à poluição doméstica e industrial, e mortandade de peixes provocada pelo lançamento de substâncias tóxicas e alterações bruscas da qualidade da água.

Como parte dos resultados da revisão e desenvolvimento de novos índices de qualidade de água, decorrentes da Resolução SMA-65, de 1998, foi proposto o desenvolvimento de índices de comunidades (fitoplâncton, perifiton, zooplâncton, bentos e peixes), que seriam complementares ao IVA, sendo apresentados separadamente, e mostrando classes de qualidade que indicariam o estado do ecossistema avaliado.

Uma questão central para a Toxicologia Aquática é o monitoramento biológico ou biomonitoramento, ou seja, o uso regular e sistemático de organismos vivos para avaliar mudanças no ambiente ou qualidade da água (CAIRNS \& VAN DER SCHALIE, 1982 in RAND, 1995).

Trabalhos de revisão têm apontado para a limitação da visão de qualidade das águas em programas de monitoramento que empregam exclusivamente índices físicos e químicos, e apontam para a necessidade de se aplicar medidas biológicas para a obtenção de uma abordagem mais ecossistêmica (PRAT et al., 1986). Atualmente parece haver um consenso de que é necessário fundir as duas investigações, de forma a se obter não apenas as causas da degradação, mas também seus efeitos sobre os ecossistemas aquáticos. A necessidade de se compor vários parâmetros para a obtenção de dados capazes de melhor satisfazer a indicação de medidas de controle também tem sido largamente apontada (LUCEY, 1987; WALLEY \& JUDD, 1993; NEWMAN et al., 1992, ambos apud PRAT et al., 1997).

A importância da conservação dos recursos biológicos e da detecção de alterações ambientais reforçou a necessidade de desenvolvimento e emprego de ferramentas biológicas nos programas de monitoramento. Indicadores biológicos (espécies indicadoras de determinada condição ambiental) e índices (índice saprobiótico, índice de diversidade, entre outros), foram determinados para avaliar a qualidade da água, especialmente quando podem detectar ou até mesmo antecipar os efeitos negativos da poluição, e usados para proteção das espécies e das características tróficas (GHETTI \& RAVERA, 1994; NAVAS-PEREIRA \& HENRIQUEMARCELINO, 1996). 
Em vários países da Europa, os estudos de composição das comunidades, proporção de espécies indicadoras ou avaliação da bioacumulação de contaminantes são acompanhados de ensaios ecotoxicológicos (GHETTI \& RAVERA, 1994). Como uma única avaliação não é capaz de representar por completo todo o ambiente, geralmente mais de uma comunidade é avaliada em programas de monitoramento, que podem incluir plâncton, perifiton, bentos e a ictiofauna.

A CETESB tem caminhado nessa linha, dispendendo esforços no sentido de desenvolver, em conjunto com profissionais de outras instituições que formam o Grupo Técnico de Comunidades (resultado da Resolução SMA-65/98), os índices de comunidades, que deverão ser propostos para complementar o monitoramento, depois de uma fase de simulação com dados disponíveis. Após seu aprimoramento e validação, deverão ser elaborados protocolos específicos para cada comunidade e para cada tipo de ambiente, que delinearão desde a metodologia de coleta até a de tratamento final dos dados.

Os resultados obtidos no projeto "Estudo de melhoria dos atuais sistemas de avaliação da qualidade das águas superficiais das diferentes UGRHIs do Estado de São Paulo - atividade Biomonitoramento de Reservatórios", que englobou análise de fitoplâncton, zooplâncton e bentos (CETESB, no prelo (a)) já estão sendo utilizados para a validação de algumas propostas de índices para estas comunidades. Especificamente para fitoplâncton, estes dados estão sendo utilizados com o objetivo de identificar espécies fitoplanctônicas indicadoras da qualidade do ambiente, além da validação de um índice para fitoplâncton (Maria do Carmo Carvalho, comunicação pessoal).

Outra perspectiva animadora na área de monitoramento de qualidade ambiental utilizando análises de comunidades, e que parece ser uma tendência em vários países, é o desenvolvimento de protocolos e índices de simples utilização que podem ser aplicados para avaliações rápidas e de baixo custo por não especialistas. Dentre eles pode-se citar o projeto de desenvolvimento de um índice de diatomáceas que deverá ser disponibilizado para professores secundários e alunos universitários (PRYGIEL \& COSTE, 1996), os protocolos de bioavaliação rápida para uso em rios e córregos da EPA (USEPA, 1996, BARBOUR et al., 1997) e os protocolos que estão sendo desenvolvidos pela CETESB na região da cabeceira do rio Atibaia, SP, em parceria com o Departamento de Ecologia do Instituto de Biociências da USP (CETESB, no prelo (b)). Este projeto piloto tem também como objetivo levantar informações integradas para complementar o projeto "Entre Serras e Águas", implantado pela Secretaria do Meio Ambiente do Estado de São Paulo, com a finalidade de elaborar um plano de desenvolvimento sustentável para a área de influência da duplicação da Rodovia Fernão Dias.

Essas iniciativas proporcionam, além de um treinamento específico para interessados na área, um aumento da consciência ambiental do público envolvido, seja ele composto por alunos, profissionais de outras áreas, membros de comunidades ribeirinhas, já que estarão realmente envolvidos na avaliação da qualidade do corpo d'água, e poderão propor ações visando preservar ou recuperar esses recursos naturais. Existe educação ambiental mais eficiente que essa? 


\subsection{Aplicação do IVA à bacia do rio Cubatão}

Desde a inclusão dos resultados das análises ecotoxicológicas nos Relatórios de Qualidade das Águas da CETESB, o IVA, um dos novos índices de qualidade de água propostos (CETESB, 1999), pode ser calculado para os 118 pontos de monitoramento do Estado de São Paulo onde são realizados os testes de toxicidade crônica com Ceriodaphnia dubia.

Recentemente a CETESB enviou a vários especialistas de diferentes instituições um documento expondo a aplicação dos novos índices (IAP e IVA) com dados do ano de 1999, para análise e contribuições sobre a sua adequação e aplicabilidade na avaliação da qualidade das águas para abastecimento público (IAP) e proteção da vida aquática (IVA) (CETESB, comunicação pessoal). Até o momento, no entanto, não foi realizada uma análise do comportamento do IVA considerando uma série histórica.de dados.

Neste trabalho, os resultados dos parâmetros da Rede de Monitoramento na bacia do rio Cubatão (UGRHI 7 - Baixada Santista) foram utilizados para calcular o IVA no período de 1995 a 2000, permitindo verificar sua capacidade de detectar o estado de degradação do ambiente em estudo $e$, através da análise individual de seus componentes, diagnosticar as principais causas da deterioração da qualidade das águas na região.

Como já citado, a bacia do rio Cubatão é foro de interesse para estudo, pois abriga um dos maiores complexos industriais do país, sua localização topográfica é peculiar, e tem um longo e triste histórico de degradação ambiental, tendo sido considerada uma das áreas mais críticas do Estado de São Paulo, em termos de poluição hídrica e atmosférica de origem industrial.

A aplicação do IVA nos cinco pontos de monitoramento de qualidade de água localizados nesta bacia resultou, em praticamente todos os locais amostrados, em classificações de qualidade inferiores àquelas obtidas pelo cálculo do IQA. Esses resultados mostram que os indicadores que fazem parte do IVA são mais sensíveis para detectar a degradação da qualidade da água, quando o objetivo é a proteção da vida aquática.

Os indicadores que tiveram maior peso na classificação dos corpos d'água da bacia em faixas piores de qualidade, em comparação com o IQA, foram a toxicidade a organismos aquáticos e o potencial de eutrofização, medido pelo IET. Em relação à toxicidade, pode-se destacar alguns exemplos onde se observa claramente sua influência no resultado do IVA: no ponto CUBA03900, no mês de dezembro de 2000, a detecção de toxicidade aguda foi determinante para a classificação da água como de qualidade Ruim para a proteção da vida aquática, enquanto o IQA apontou qualidade boa; no ponto CFUG02900, no meses de abril de 1999, fevereiro e abril de 2000 , novamente a deteç̧ão de toxicidade aguda na amostra de água resultou em classificação do IVA Ruim, enquanto o IQA classificou as águas nas faixas de qualidade Boa e Ótima. O mesmo ocorreu no ponto MOGI02800, no mês de julho 
de 1997, quando foi detectada toxicidade aguda e concentrações de algumas substâncias tóxicas acima do padrão de qualidade, resultando em IVA na faixa de qualidade Péssima, com o IQA indicando qualidade Aceitável. Já a influência de valores elevados do IET para a classificação em faixas de qualidade inferiores do IVA, indicando alto potencial de eutrofização das águas (na faixa de hipereutrófico), foi bastante significativa nos pontos CUBA03900, em alguns meses dos anos de 1995 e 1996 (classificação do IVA Ruim), e principalmente nos pontos MOGI02800 e PIAC02700, em todo o período de análise abordado neste estudo (classificação do IVA Ruim e Péssima). Vale destacar que no ponto CUBA03900, o IQA classificou as águas nesse período como Aceitável e Boa, e no ponto MOGI02800 nas faixas de Boa e Aceitável, com alguns meses na faixa de qualidade Ruim.

Os dois índices mostraram que os pontos localizados no rio Mogi e no rio Piaçaguera são os mais impactados pela poluição na bacia, porém o IVA apresentou uma maior porcentagem de classificação na faixa de qualidade ruim e péssima.

O IQA mostrou uma melhor qualidade de água nos pontos localizados no Canal de Fuga da Usina Hidrelétrica Henry Borden CFUG02900) e no rio Cubatão, tanto no ponto localizado a jusante do Canal de Fuga (CUBA03900), quanto no ponto localizado junto à captação de água da SABESP, a montante do Canal de Fuga (CUBA02700). As águas destes pontos foram classificadas pelo IQA nas faixas de Ótima a Boa, com alguns eventos de classificação Ruim no ponto CUBA03900. Os pontos que o IVA classificou como de melhor qualidade na bacia foram CUBA02700 e CFUG02900, com médias anuais variando de classificação regular a boa. Já no ponto CUBA03900, apesar de haver uma maior concordância entre os indices, com variação de qualidade nas faixas de Ótima a Ruim, a média anual do IVA resultou em uma maior porcentagem de qualidade Ruim, o que o diferencia dos outros dois pontos citados, evidenciando uma maior deterioração da qualidade de suas águas para a manutenção e conservação da vida aquática.

É interessante observar os resultados das análises de tendência realizados com os dois índices. Os dois pontos de monitoramento que recebem águas advindas do reservatório Billings (CFUG02900 e CUBA03900) mostraram uma clara tendência de melhora quando foi realizada a análise da média móvel de 10 anos de dados do IQA, a partir do ano de 1993. Este resultado evidencia que o reservatório Billings iniciou um processo de recuperação da qualidade desde que, em 1992, passou a receber um menor aporte das águas poluídas provenientes dos rios Pinheiros e Tietê, em decorrência da Resolução Conjunta SMA/SES n 3, de 04/09/92. Esta Resolução autoriza o bombeamento das águas do Canal do Pinheiros somente em condições específicas, principalmente quando há riscos de enchentes na Região Metropolitana de São Paulo (CETESB, 2001a). Já o ponto CUBA02700, localizado a montante do Canal de Fuga, e que portanto não sofre influência das águas do Reservatório Billings, apresentava, até ao ano de 1999, uma tendência de piora da qualidade de suas águas, de acordo com o IQA, com uma melhora de qualidade no ano de 2000 (CETESB 2000, 2001a).

A mesma análise estatística, aplicada aos dados do IVA, considerando um período de seis anos, não identificou uma tendência significante da qualidade de água, 
mostrando uma condição estável ou de pequena variação da qualidade da água para proteção da vida aquática.

Analisando os indicadores de qualidade que mais influenciaram a classificação do IVA como Regular, Ruim e Péssima, podemos observar que há coincidência dos indicadores que foram determinantes para as classificações obtidas nos pontos CUBA03900 e CFUG02900, ou seja, os influenciados pelas águas do reservatório Billings: IET(P), toxicidade, $\mathrm{pH}$, fenóis e os metais cádmio, cobre, chumbo, níquel e zinco. O IET teve uma das maiores porcentagens de influência na classificação do IVA nos dois pontos, porém o grande diferencial foi observado em relação à toxicidade, que foi detectada com uma porcentagem bem maior nas águas do Canal de Fuga $-35,1 \%$, contra $10,6 \%$ no rio Cubatão a jusante do canal. A toxicidade provavelmente é devida a poluentes que ainda persistem na água e no sedimento do reservatório. Outra forte possibilidade é a presença de algas cianoficeas potencialmente tóxicas, encontradas com frequência no reservatório Billings (AMARAL FILHO et al., 1999). Uma das espécies identificadas foi Cylindrospermopsis raciborskii, que apresentou toxicidade ao microcrustáceo Daphnia similis, em teste realizado com duas cepas isoladas do braço Taquacetuba, do reservatório Billings (ZAGATTO, 1998). O autor observou ainda que as cepas desta alga causaram inibição da reprodução e diminuição da taxa de sobrevivência do microcrustáceo Ceriodaphnia dubia. BURATINI (2000) também encontrou uma correlação entre a toxicidade a Ceriodaphnia dubia e o material em suspensão de amostras de água da represa Billings contendo cianofíceas das espécies Microcystis aeruginosa e Cylindrospermopsis raciborskii. A autora constatou que, após remoção do material em suspensão da amostra de água por filtração em pré-filtro AP20, houve redução ou eliminação da toxicidade em $86 \%$ das amostras onde essa toxicidade foi inicialmente detectada.

O resultado do IET também pode indicar que grandes quantidades de fósforo foram acumuladas ao longo de anos no sedimento do reservatório e que, ao serem liberadas, provocam o enriquecimento da coluna d'água por nutrientes, caracterizando o processo de eutrofização. Vale ressaltar a alta freqüência de florações de algas que têm acontecido no reservatório, decorrente deste processo (AMARAL FILHO et al., 1999; CETESB, 2000, 2001a).

Deve-se destacar que o ponto CUBA02700 foi, de todos os locais estudados na região, o que apresentou maior porcentagem de toxicidade a organismos aquáticos $(39,5 \%)$. As águas deste ponto de monitoramento apresentaram concentrações acima dos limites permissíveis para mercúrio e cromo, o que não foi observado no outro ponto do rio Cubatão, localizado a jusante - CUBA03900). Além disso, apresentou uma maior porcentagem de influência para a classificação do IVA para o parâmetro chumbo (7,9\% contra $2,1 \%$ no ponto CUBA03900). Apesar de algumas indicações de possíveis causas da toxicidade observada nas águas deste ponto, sabe-se da dificuldade de se prever ou explicar a toxicidade obtida para organismos aquáticos em função das concentrações de agentes químicos isolados, determinados através de análises químicas (BERTOLETTI, 1989). De acordo com CETESB (2000), o ponto CUBA02700 não sofre a influência de ações realizadas em outras bacias, apresenta toxicidade crônica, contaminação bacteriológica, bem como tendência de piora dos 
parâmetros sanitários. Esta constatação leva à recomendação de que suas fontes de contaminação sejam melhor investigadas, e sejam aplicadas ações de controle, no sentido de se reverter a situação atual, uma vez que o rio Cubatão é um importante manancial de abastecimento público para a região.

O que parece ser característico da contaminação presente no rio Cubatão são fenóis, que apresentaram uma razoável influência no resultado do IVA, tanto no ponto a montante $(15,8 \%)$ quanto no ponto a jusante $(14,9 \%)$ do Canal de Fuga. Este ponto de monitoramento mostrou somente $2,7 \%$ de influência dos fenóis na classificação do índice, o que confirma não haver influência das águas do reservatório Billings na contaminação por estas substâncias.

Com relação aos fenóis, vale destacar que os limites existentes na legislação brasileira, tanto a nível estadual como federal, são bastante restritivos no que se refere à qualidade das águas para proteção da vida aquática, em comparação com dados disponíveis na literatura (USEPA, 1991b; CANADA, 1995). Entretanto, considerou-se necessário manter tais limites de fenol, uma vez que prevalece a preocupação com a manutenção das qualidades estéticas da água para abastecimento público.

Em relação ao rio Cubatão, o recente estudo da contaminação realizado pela CETESB na região (CETESB, 2001b) mostrou que, em comparação a estudos anteriores (CETESB, 1981, 1990a), há indicação de uma redução dos níveis de concentração de cobre, hexaclorobenzeno e BHC presentes na fase solúvel do sedimento, porém não houve alteração das concentrações de cádmio, chumbo, e zinco no compartimento água. Este levantamento mostrou ainda que os níveis de cádmio e níquel encontrados nos rios de Cubatão são capazes de causar efeito tóxico à biota, além de identificar níveis elevados do pesticida organoclorado endosulfan $B$, indicando uma possível fonte de contaminação ainda presente na região. $O$ sedimento foi o compartimento que apresentou a maior variedade de contaminantes, bem como a maior frequência de deteç̧ão, em comparação com a água e os organismos. As áreas que apresentam as maiores concentrações de contaminantes localizam-se próximas às fontes de poluição. Os dois pontos amostrados neste estudo no rio Cubatão apresentaram concentrações altas de cádmio, cromo, níquel, PCBs e PAHs. Em relação à contaminação dos organismos, verificou-se que as zonas de maior bioacumulação foram a bacia do rio Cubatão e o estuário de Santos, locais em que foram observados, em termos gerais, os maiores valores nos sedimentos, o que sugere ser este compartimento uma importante fonte de contaminação para os organismos aquáticos. Vale ressaltar que, apesar dos peixes e siris coletados nos rios de Cubatão terem apresentado, de uma maneira geral, uma redução da contaminação por cádmio, chumbo, mercúrio, zinco, hexaclorobenzeno, e pesticidas organoclorados em relação a estudos anteriores, foram observadas altas concentrações de cobre e níquel em siris do rio Cubatão, chegando algumas amostras a ultrapassar os limites recomendáveis para consumo humano (CETESB, 2001b).

Os rios Mogi e Piaçaguera apresentaram, ao longo de todo o período de estudo, classificações de qualidade de água para preservação da vida aquática variando de Ruim a Péssima, segundo o IVA, sendo que o corpo d'água mais problemático 
quanto à deterioração da qualidade da água é sem dúvida o rio Piaçaguera, que se mostrou com qualidade Péssima em quatro dos seis anos de estudo, considerando a média do IVA.

No rio Mogi, o parâmetro que mais influenciou na qualidade das águas classificadas como Regular, Ruim e Péssima pelo IVA foi o IET (calculado através da concentração de fósforo total), com uma porcentagem de $46,3 \%$ de ocorrência de níveis com classificação eutrófica e hipereutrófica. Além do IET, destacaram-se a toxicidade $(13,7 \%)$, o pH $(17,6 \%)$ e os fenóis $(8,7 \%)$.

A presença de indústrias de fertilizantes no rio Mogi tem causado problemas de contaminação já identificados nos primeiros trabalhos realizados por técnicos da CETESB na região. ZAGATTO et al. (1987) verificaram que as águas do rio Mogi apresentaram alta toxicidade a Daphnia similis em todos os pontos de amostragem a jusante do lançamento destas indústrias, enquanto que nos pontos de amostragem a montante das mesmas não foi verificado efeito tóxico a esse organismo aquático. As amostras de água no ponto anterior ao lançamento dos efluentes apresentavam baixas concentrações de fósforo, nitrogênio e fluoreto, e $\mathrm{pH}$ em torno de 6,0 , enquanto as amostras de água coletadas após o despejo de indústrias de fertilizantes apresentavam concentrações até 1.000 vezes mais elevadas dessas substâncias, com valores de $\mathrm{pH}$ baixo, variando na faixa de 3,8 a 5,2 . Neste estudo foi utilizado também o teste de toxicidade com a alga Chlorella vulgaris, realizado em amostra de água do rio Mogi. Foi observado um baixo crescimento algáceo, que considerou-se ser devido ao baixo $\mathrm{pH}$ (em torno de 4,0), efeito este confirmado após o acerto do $\mathrm{pH}$ para 7,0, quando foi observado o efeito contrário, ou seja, um alto crescimento algáceo estimulado pelos elevados níveis de nutrientes. Esta avaliação mostrou o grande potencial de impacto do lançamento destes efluentes sem tratamento adequado no corpo d'água, pois os níveis de nitrogênio e fósforo encontrados nas amostras de água foram elevados o suficiente para agravar o estado de eutrofização das águas, principalmente quando o $\mathrm{pH}$ destas fosse normalizado, cessando seu efeito inibidor do crescimento algáceo. Em trabalho realizado por JOHNSCHER-FORNASARO \& ZAGATTO (1985), utilizando a comunidade bentônica como indicadora de qualidade, verificouse que amostras de sedimento do rio Mogi apresentavam somente "taxa" tolerantes à poluição orgânica, indicando degradação ambiental.

As concentrações de fósforo total encontradas no rio Mogi durante o período de 1995 a 2000 ainda são bastante elevadas, evidenciando que as ações de controle realizadas na região, que envolveram em grande parte a exigência de tratamento de efluentes industriais e conseqüente redução de substâncias tóxicas e nutrientes lançados nos corpos d'água, necessitam de um maior rigor, principalmente no que se refere ao controle de nitrogênio amoniacal e fósforo total (CETESB, 1996, 1998a, b, 1999, 2000, 2001a).

O rio Piaçaguera, como já observado, é o que apresenta piores condições de qualidade para preservação da vida aquática. Durante todo o período de estudo, as águas deste corpo d'água apresentaram classificação Ruim e Péssima para o IVA. Mesmo o IQA, que se mostrou muito menos sensível que o IVA, mostrou uma classificação no máximo Boa, em três meses no ano de 1998, apresentando, no 
restante do período de estudo, classificações variando de Regular a Ruim, com alguns eventos de qualidade Péssima. $\mathrm{Na}$ análise dos parâmetros que influenciaram a classificação obtida para o IVA destacaram-se os parâmetros IET $(25,3 \%$ de influência), oxigênio dissolvido (15,5\%), fenóis e níquel $(12 \%)$, toxicidade $(11,3 \%)$ e pH $(9,1 \%)$, além de cádmio, cobre, mercúrio, zinco e chumbo, com freqüências menores de influência no resultado do IVA. Os relatórios de qualidade das águas da CETESB já citados apontam o problema da presença de indústrias de fertilizantes situadas às margens deste rio, como também acontece com o rio Mogi, bem como de outras indústrias químicas, responsáveis pelo lançamento de fósforo e outras substâncias nas águas do rio. Aponta-se também para o problema da vazão do rio Piaçaguera, que possui uma vazão média menor que $1,0 \mathrm{~m}^{3} / \mathrm{s}$, enquanto o rio Mogi apresenta uma vazão média de aproximadamente $3,0 \mathrm{~m}^{3} / \mathrm{s}$, o que torna a situação de degradação do rio Piaçaguera muito mais crítica em função da sua baixa capacidade de diluição dos poluentes que recebe.

Vários estudos têm mostrado os problemas de contaminação do rio Piaçaguera. No levantamento realizado por VARGAS-BOLDRINI et al.(1990) foram identificados níveis de chumbo, $\mathrm{BHC}$, lindane e fenol que ultrapassavam os limites de preservação da vida aquática, sendo que o sedimento deste rio foi classificado como moderadamente poluído por arsênio e zinco. ZAGATTO et al. (1987) detectaram toxicidade alta ao microcrustáceo Daphnia similis em amostras de água do rio Piaçaguera, observando também altos teores de zinco, cádmio, chumbo, níquel e ferro. No estudo efetuado por JOHNSCHER-FORNASARO \& ZAGATTO (1985), também foi observada uma séria poluição orgânica, denunciada pela alta densidade de organismos bentônicos tolerantes a este tipo de poluição.

No levantamento realizado pela CETESB em 1999 (CETESB, 2001b), verificou-se que o rio Piaçaguera apresenta contaminação preocupante por arsênio, dioxinas e furanos e principalmente clorofórmio, que atingiu concentrações na água de até dez vezes o limite estabelecido pelo Canadá para ambientes de água doce. Este poluente também foi detectado no estuário de São Vicente e no rio Perequê, reforçando a necessidade de reavaliar as fontes deste poluente nestes locais. Os sedimentos do rio Piaçaguera apresentaram altas concentrações de PAHs, arsênio, cádmio, níquel, cobre, dioxinas e furanos. Considerou-se que esta contaminação é devida ao fato desse rio receber efluentes e águas de drenagem contaminadas de indústrias de fertilizantes e da região do Vale do Mogi e da Vila Parisi.

A aplicação do IVA na bacia do rio Cubatão mostrou que este índice é mais adequado que o IQA para avaliação da qualidade das águas para proteção da vida aquática, já que seus componentes, principalmente o que identifica o grau de trofia das águas (IET), a toxicidade, $\mathrm{pH}$ e $\mathrm{OD}$, além das substâncias tóxicas, foram de grande utilidade na identificação das causas da degradação da qualidade das águas nesta bacia hidrográfica. O parâmetro IET se destacou por esta ser uma bacia cujas águas recebem uma grande contribuição de nutrientes, seja de origem industrial ou doméstica. A toxicidade também mostrou sua importância como componente do índice, já que foi capaz de identificar áreas de risco para a manutenção da vida aquática, sendo que um grande número de substâncias potencialmente tóxicas estão 
presentes nesta região, e muitas delas não são rotineiramente avaliadas nos programas de monitoramento da qualidade das águas.

Como discutido anteriormente, seria interessante elaborar um monitoramento de qualidade das águas regionalizado, levando-se em conta os principais contaminantes presentes no local de interesse. No caso da bacia do rio Cubatão, alguns poluentes identificados desde os primeiros estudos poderiam ser incluídos, como é o caso do arsênio e, mais atualmente, o clorofórmio, buscando-se os limites permissíveis para evitar efeitos agudos e crônicos, e fazendo então parte do componente "grupo das substâncias tóxicas" do IPMCA, dentro do IVA.

Outra observação que pode ser feita refere-se à divulgação pública dos resultados do IVA. Da mesma forma que se faz para o IQA e para o Índice de Balneabilidade, é interessante que, além da integração dos resultados mensais em um valor médio anual do IVA, as classificações mensais deste índice façam também parte dos documentos de divulgação da qualidade das águas, pois indicam as variações obtidas na aplicação do índice, devidas a comportamentos sazonais e até eventos de contaminação que poderão ser identificados posteriormente através da análise dos componentes individuais do indice. 


\section{CONCLUSÕES E RECOMENDAÇÕES}

Em relação aos índices de qualidade das águas, algumas conclusões deste estudo podem ser apresentadas:

- A integração do IET e do IPMCA na formação do IVA - Índice de Qualidade das Águas para Proteção da Vida Aquática, ampliou de maneira significativa a capacidade deste índice para identificar diferentes variáveis causadoras da deterioração da qualidade das águas. Assim, o IVA pode revelar a presença de substâncias em concentrações passíveis de causar efeito à biota aquática, através de seu efeito tóxico, além de avaliar o grau de trofia da água.

- O IVA permite a inclusão, dentro do componente "grupo de substâncias tóxicas" do IPMCA, de tantos indicadores de qualidade quantos forem considerados necessários e significativos para uma avaliação adequada do ambiente aquático escolhido para estudo. Para tanto, deve-se buscar os limites máximos permissíveis da substância a ser incluída que previnam qualquer tipo de efeito (efeitos crônicos e efeitos agudos) a organismos aquáticos, possibilitando o estabelecimento dos três níveis de qualidade considerados no IPMCA.

- O IVA, por utilizar os dados da Rede de Monitoramento de Qualidade das Águas da CETESB, se constitui em uma ferramenta para diagnosticar a qualidade da amostra de água apenas no momento de sua coleta, caracterizando-se como uma medida instantânea da contaminação e do grau de trofia das águas. Desta forma, é importante, para a avaliação da qualidade de um ecossistema, a obtenção de informações da diversidade e densidade das comunidades aquáticas que, aliadas às análises químicas e ecotoxicológicas, deverão complementar as informações fornecidas pelo índice.

- A regionalização do monitoramento da qualidade das águas poderia trazer resultados ainda mais práticos em termos de diagnósticos ambientais. Após a identificação de características regionais, como uso do solo, uso e disponibilidade da água, principais atividades industriais e fontes de poluição e outras informações, os parâmetros mais adequados para a bacia ou região seriam escolhidos. Este procedimento poderia reverter na melhor utilização dos dados gerados no monitoramento, no sentido de identificar questões críticas sobre as condições da qualidade da água, direcionar ações de controle e recursos, para um beneficio máximo.

- Uma perspectiva promissora na área de monitoramento ambiental é o desenvolvimento de protocolos e índices de simples utilização que podem ser aplicados para avaliações rápidas e de baixo custo por não especialistas. Esse tipo de iniciativa proporciona um aumento da consciência ambiental dos envolvidos, sejam eles profissionais de outras áreas, estudantes ou membros de comunidades ribeirinhas, que poderão propor ações visando preservar ou recuperar os recursos naturais. 
Com relação à aplicação do IVA na bacia do rio Cubatão, conclui-se que:

- A aplicação do IVA mostrou que este índice é mais adequado que o IQA para avaliação da qualidade das águas para proteção da vida aquática, já que seus componentes, principalmente o que identifica o grau de trofia das águas (IET), a toxicidade, $\mathrm{pH}$ e OD, além das substâncias tóxicas, foram de grande utilidade na identificação das causas da degradação da qualidade das águas nesta bacia hidrográfica.

- O rio Piaçaguera foi o que apresentou as piores condições de qualidade para preservação da vida aquática, segundo o IVA. Durante todo o período de estudo (1995 a 2000), suas águas apresentaram classificação Ruim e Péssima para o IVA. Os parâmetros que mais influenciaram a classificação do IVA neste corpo d'água foram o IET, o oxigênio dissolvido, fenóis, níquel, toxicidade e $\mathrm{pH}$.

- O rio Mogi também apresentou, ao longo de todo o período de estudo, classificações do IVA variando de Ruim a Péssima. O parâmetro que mais influenciou na qualidade das águas classificadas pelo IVA foi o IET (calculado através da concentração de fósforo total), com uma porcentagem de $46,3 \%$ de ocorrência de níveis com classificação eutrófica e hipereutrófica. Além do IET, destacaram-se a toxicidade $(13,7 \%)$, o pH $(17,6 \%)$ e os fenóis $(8,7 \%)$.

- A presença de indústrias de fertilizantes situadas às margens dos rios Mogi e Piaçaguera, bem como de outras indústrias químicas, responsáveis pelo lançamento de fósforo e outras substâncias nas águas destes rios, se apresenta como a grande responsável pela degradação da qualidade de suas águas.

- Os pontos de amostragem no rio Cubatão, localizados à montante (CUBA02700) e à jusante (CUBA03900) do Canal de Fuga da Usina Hidrelétrica Henry Borden (CFUG02900), apresentaram classificações do IVA variando de Ótima a Ruim, dependendo dos meses e dos anos considerados. As médias do IVA obtidas para os pontos CFUG02900 e CUBA02700 variaram na faixa de qualidade Regular e Boa, enquanto no ponto CUBA03900 observou-se um grau maior de deterioração da qualidade da água para a manutenção e proteção da vida aquática, resultando em médias anuais do IVA com qualidade Ruim em três dos seis anos considerados neste estudo.

- Os indicadores de qualidade que influenciaram a classificação do IVA como Regular, Ruim e Péssima foram coincidentes para os pontos CUBA03900 e CFUG02900, ambos influenciados pela qualidade da água do reservatório Billings: IET, toxicidade, $\mathrm{pH}$, fenóis e os metais cádmio, cobre, chumbo, níquel e zinco. O IET apresentou uma das maiores porcentagens de influência na classificação do IVA nos dois pontos, diferenciando-se porém na porcentagem referente à toxicidade, que foi detectada com maior frequência nas águas do Canal de Fuga da Usina Henry Borden. Considerou-se que tanto a toxicidade quanto o alto grau de trofia podem ser resultantes da contaminação das águas do Reservatório Billings que, apesar de estar em processo de recuperação, pode 
ainda conter certa quantidades de poluentes e nutrientes em suas águas e sedimentos, além da presença de algas tóxicas.

- O ponto CUBA02700 foi, de todos os locais estudados na região, o que apresentou a maior porcentagem de toxicidade a organismos aquáticos $(39,5 \%)$, além de ter sofrido influência dos parâmetros IET, fenóis, $\mathrm{pH}$, e os metais cádmio, cobre, chumbo, cromo, níquel, mercúrio e zinco. Este ponto não sofre a influência de ações realizadas em outras bacias, apresenta toxicidade crônica, contaminação bacteriológica, bem como tendência de piora dos parâmetros sanitários, o que exige uma melhor investigação das suas fontes de contaminação e ações de controle mais enérgicas, no sentido de se reverter a situação atual, uma vez que o rio Cubatão é um importante manancial de abastecimento público para a região.

- A análise estatística aplicada para os dados de IVA nos pontos de amostragem da bacia do rio Cubatão para identificação de tendências de qualidade das águas não mostrou resultado significante, indicando uma condição estável ou de pequena variação da qualidade da água para proteção da vida aquática.

- No caso da bacia do rio Cubatão, alguns poluentes identificados desde os primeiros estudos poderiam ser incluídos no monitoramento da qualidade das águas e no cálculo do IVA, como é o caso do arsênio e do clorofórmio, buscando-se os limites permissíveis para evitar efeitos agudos e crônicos, e fazendo então parte do componente "grupo das substâncias tóxicas" do IPMCA.

Dessa forma, recomenda-se:

- A regionalização do monitoramento da qualidade das águas, após identificação dos indicadores de qualidade mais significativos para uma bacia ou região, mesmo os decorrentes de poluição difusa. O monitoramento regionalizado, conjugado a uma adequada divulgação pública dos resultados obtidos, como a utilização de um índice como o IVA - Indice para Proteção da Vida Aquática, constitui-se em uma rica e útil fonte de informações para fóruns regionais tomadores de decisão, como os Comitês de Bacia Hidrográfica, consórcios de municípios, fóruns de desenvolvimento regional.

- O desenvolvimento de índices de comunidades (fitoplâncton, perifiton, zooplâncton, bentos e peixes) para complementação ao IVA no monitoramento da qualidade das águas. Cada uma destas comunidades responde de forma distinta aos impactos, diferindo no seu grau de sensibilidade e nos tempos de resposta e de recuperação, permitindo uma avaliação mais completa do grau de integridade de um ecossistema.

- A inclusão de alguns poluentes identificados desde os primeiros estudos na bacia do rio Cubatão, como é o caso do arsênio e, mais atualmente, o clorofórmio, buscando-se os limites permissíveis para evitar efeitos agudos e crônicos, 
fazendo então parte do componente IPMCA (grupo das substâncias tóxicas), dentro do IVA.

- A divulgação das classificações mensais obtidas para o IVA, além do valor médio anual, pois estas indicam as variações obtidas na aplicação do índice, devidas a comportamentos sazonais e até eventos de contaminação que poderão ser identificados posteriormente através da análise dos componentes individuais do índice. 


\section{REFERÊNCIAS BIBLIOGRÁFICAS}

ABNT - Associação Brasileira de Normas Técnicas. Água - Avaliação de toxicidade crônica, utilizando Ceriodaphnia dubia Richard, 1894 (Cladocera, Crustacea). NBR 13373. 1995. 14 p.

Amaral Filho G, Bevilacqua JE, Lamparelli CC et al. Monitoramento integrado. Bacias do Alto e Médio Tietê. Avaliação da qualidade da água, sedimento e peixes. Contrato SABESP 20/97. Relatório final. 1999. Vol. 1, 316 p; vol. 2, 146 p.

Barbour MT, Gerritsen J, Snyder BD, Stribling JB. Revision to rapid bioassessment protocols for use in streams and rivers: periphyton, benthic, macroinvertebrates and fish. EPA 841-D-97-002, 1997.

Bertoletti E, Gherardi-Goldstein E, Nipper MG. Toxicidade de águas superficiais na região da Grande São Paulo. Rev. Soc. Bras. Toxicol. 1989, 2 (2): 1-20.

Bertoletti E. Toxicidade e concentração de agentes tóxicos em efluentes industriais. Cienc. Cult. 1990, 43(3/4): 271-277.

Birge WJ, Black JA, Westerman AG. Short-term fish and amphibian tests for determining the effects of toxicant stress on early life stages and estimating chronic values for single compounds and complex effluents. Environ. Toxicol. Chem. 1985, 49: $807-821$.

Bolton PW, Currie JC, Tervet DJ, Welsh WT. An index to improve water quality classification. Wat. Pollut. Control 1978, 77(2): 271-280.

Brown RM, McClelland N, Deininger RA, Tozer RG. A water quality index - do we dare? Water \& Sewage Works 1970, October, 339-343.

Buratini SV. A relação da toxicidade das amostras de águas superficiais ao cladócero Ceriodaphnia dubia com a ocorrência de cianofíceas. Resumo apresentado no VI ECOTOX, São Carlos, SP. Setembro de 2000.

Canadá. Canadian Water Quality Guidelines. Canadian Council of Resource and Environment Ministers. March 1995.

Cardwell RD, Parkhurst BR, Warren-Hicks W, Volosin JS. Aquatic Ecological Risk. Water Environ. Technol., April 1993 : 47-51.

CETESB, São Paulo. Qualidade da águas interiores do Estado de São Paulo. São Paulo, CETESB, 1978. Relatório Técnico, 219 p.

CETESB, São Paulo. Poluição das águas no estuário e baia de Santos. São Paulo, CETESB, 1979. Relatório Técnico, vol. 1, 71 p. 
CETESB, São Paulo. Metais pesados na baía de Santos e estuários de Santos e São Vicente. São Paulo, CETESB, 1981. Relatório Técnico, 231 p.

CETESB, São Paulo. Legislação básica. Poluição Ambiental Estadual e Federal. São Paulo, CETESB. 1982. 75 p.

CETESB, São Paulo. Carta do Meio Ambiente: Baixada Santista. São Paulo, CETESB, 1985. 33p. + anexos.

CETESB, São Paulo. Avaliação da toxicidade das águas e sedimentos dos rios e efluentes industriais da região de Cubatão. São Paulo, CETESB, 1986. Relatório Técnico, 226 p.

CETESB, São Paulo. Avaliação da toxicidade de efluentes líquidos de algumas indústrias localizadas na Bacia do rio Piracicaba. São Paulo, CETESB, 1987a. Relatório Técnico, 8p.

CETESB, São Paulo. Avaliação da toxicidade de despejos industriais na região da Grande São Paulo. São Paulo, CETESB, 1987b. Relatório Técnico, 88p

CETESB, São Paulo. Avaliação preliminar da contaminação por metais pesados na água, sedimento e organismos aquáticos do rio Cubatão (SP). São Paulo, CETESB, 1989. Relatório Técnico, 28 p e anexos.

CETESB, São Paulo. Contaminantes na bacia do rio Cubatão e seus reflexos na biota aquática. São Paulo, CETESB, 1990a. Relatório Técnico, 81 p, anexos e mapas.

CETESB, São Paulo. Determinação de pigmentos fotossintetizantes: clorofila-a, b e c e feofitina-a. Norma Técnica 306. São Paulo, CETESB. 1990b. 22 p.

CETESB, São Paulo. Água - Avaliação da toxicidade crônica utilizando Ceriodaphnia dubia Richards, 1894 (Cladocera, Crustacea). Norma Técnica CETESB L5.022. Novembro de 1991. 25p.

CETESB, São Paulo. Estudo ecotoxicológico do rio Atibaia. São Paulo, CETESB, 1992. Relatório Técnico, $21 \mathrm{p}+$ anexos.

CETESB, São Paulo. Relatório de Qualidade das Águas Interiores do Estado de São Paulo - 1992. São Paulo, CETESB, 1993. Série Relatórios, 251p.

CETESB, São Paulo. Legislação Estadual - Controle da poluição ambiental Estado de São Paulo. São Paulo, CETESB, 1994a. Série Documentos, 262p.

CETESB, São Paulo. Relatório de Qualidade das Águas Interiores do Estado de São Paulo - 1993. São Paulo, CETESB. 1994b. Série Relatórios, 225p. 
CETESB, São Paulo. Relatório de Qualidade das Águas Interiores do Estado de São Paulo - 1994. São Paulo, CETESB. 1995. Série Relatórios, 269p.

CETESB, São Paulo. Relatório de Qualidade das Águas Interiores do Estado de São Paulo - 1995. São Paulo, CETESB. 1996. Série Relatórios, 285p.

CETESB, São Paulo. Relatório de Qualidade das Águas Interiores do Estado de São Paulo - 1996. São Paulo, CETESB. 1998a. Série Relatórios, 268p.

CETESB, São Paulo. Relatório de Qualidade das Águas Interiores do Estado de São Paulo - 1997. São Paulo, CETESB. 1998b. Série Relatórios, 289p.

CETESB, São Paulo. Relatório de Qualidade das Águas Interiores do Estado de São Paulo - 1998. São Paulo, CETESB. 1999. Série Relatórios, 371p.

CETESB, São Paulo. Relatório de Qualidade das Águas Interiores do Estado de São Paulo - 1999. São Paulo, CETESB. 2000. Série Relatórios, 391p.

CETESB, São Paulo. Relatório de Qualidade das Águas Interiores do Estado de São Paulo - 2000. São Paulo, CETESB. 2001a. Série Relatórios, 2v.; v. 1: 214p; v.2: $138 \mathrm{p}$.

CETESB, São Paulo. Sistema estuarino de Santos e São Vicente. São Paulo, CETESB, 2001b. Série Relatórios, 178 p.

CETESB, São Paulo. Estudo de melhoria dos atuais sistemas de avaliação da qualidade das águas superficiais das diferentes UGRHIs do Estado de São Paulo. São Paulo, CETESB, no prelo (a). Relatório Técnico.

CETESB, São Paulo. Uso de índices biológicos no biomonitoramento de ambientes aquáticos continentais - riachos e corredeiras na bacia hidrográfica do rio Atibaia. São Paulo, CETESB, no prelo (b). Relatório Técnico.

Code Permanent: Environnement et Nuisances. Éditions législatives et administratives. Paris, França, 1986. Vol.1 e 2, 1784 p.

CONAMA, Conselho Nacional do Meio Ambiente. Resolução CONAMA n' 20, de 18.06.86. D.O.U. de 30.07.86. In: Resoluções CONAMA 1984-86. Brasília, SEMA, p. 72-89.

CONAMA, Conselho Nacional do Meio Ambiente. Resolução CONAMA n* 274, de 29.11.2000. D.O.U de 25.01. 2001, Secão I, p. 23

Cooney JD. Freshwater tests. In: Rand GM. Fundamentals of Aquatic Toxicology:.effects, environmental fate, and risk assessment. Second Edition. GM Rand (ed.). Taylor and Francis Publishers, Washington. DC, 1995. P $71-102$. 
Eagleson KW, Lenat DL, Ausley LW, Winborne FB. Comparison of measured instream biological responses with responses predicted using the Ceriodaphnia dubia chronic toxicity test. Environ. Toxicol. Chem. 1990, 9: 1019-1028.

Eysink GGJ, Lamparelli MC, Vargas-Boldrini C, Martins MC. Contaminants in the Cubatão Riverbasin and its Estuary (SP, Brazil), relating to the Aquatic Biota. Part 1. Heavy Metals, Arsenic and Cyanide. $11^{\text {th }}$ Biennial International Estuarine Research Conference - San Francisco, USA. Session: Inputs and Cycling of Natural and Contaminant Materials in Estuaries. 1991.

Gherardi-Goldstein E, Fernícola NAGG, Zagatto PA, Bertoletti E, Araújo RPA, Moura $A C N$. Contribuição da toxicologia ambiental para o controle da poluição das águas. São Paulo, CETESB. 1981. 19 p. (Trabalho apresentado no Congresso Brasileiro de Engenharia Sanitária e Ambiental,.11. Fortaleza, 1981).

Ghetti PF \& Ravera O. European perspective on biological monitoring. In: Loeb SL \& A Spacie (eds.). Biological monitoring of aquatic systems. Florida CRC Press, 1994 , p. $31-46$.

Gutberlet J. Cubatão: Desenvolvimento, exclusão social e degradação ambiental. Editora da Universidade de São Paulo/FAPESP. 1996. 244 p.

Horton R. An index number system for rating water quality. Journal WPCF 1965, 37 (3): $300-306$.

House MA \& Ellis JB. The development of water quality indexes for operational management. Wat. Sci. Tech. 1987, 19 (9): 145 - 154.

Intergovernmental Task Force on Monitoring Water Quality. Ambient Water Quality Monitoring in the United States: First Year Review, Evaluation, and Recommendations 1992. Washington, D.C.

Johnscher-Fornasaro G \& Zagatto PA. Utilização da comunidade bentônica como indicador da qualidade de rios da região de Cubatão. Anais do $13^{\circ}$ Congresso Brasileiro de Engenharia Sanitária e Ambiental nº 105. 8p, 1985.

Lucey J. Biological monitoring of rivers and streams using macroinvertebrates, In: Richardson DHS (ed.). Biological indicators of pollution. Dublin, The Royal Irish Academy Press, 1987, p. 63 - 75.

Meybeck M \& Helmer R. An introduction to water quality. In: Chapman D. Water Quality Assessment. Cambridge, University Press. 1992.

Mount DI \& Norberg TJ. A seven-day life-cycle cladoceran toxicity test. Environ. Toxicol. Chem. 1984, 3: 425-434. 
Norberg-King TJ \& Mount DI. A new fathead minnow (Pimephales promelas) subchronic test. Environ. Toxicol. Chem. 1985, 4: 711 - 718.

Navas-Pereira D, Gherardi-Goldstein E, Zagatto PA, Sassi R. Bioensaios: um programa a serviço do controle da poluição. Resultados iniciais. Ambiente, Rev. CETESB de Tecnol. 1987, 1(1): 32 - 36.

Navas-Pereira D \& Henrique-Marcelino RM Aplicação de índices biológicos numéricos na avaliação da qualidade ambiental. Rev. Bras. Biol. 56 (2) : 441$450,1996$.

Peláez-Rodríguez $M$, Peret AM, Matsumara-Tundisi $T$, Rocha $O$. Análise da qualidade da água e aplicação do índice de proteção da vida aquática (IVA) em duas sub-bacias da bacia hidrográfica do rio Jacaré-Guaçu, p. 95 - 114. In: Espíndola ELG, Botta-Paschoal CMR, Rocha O, Bohrer MBC, Oliveira-Neto AL de (eds.), Ecotoxicologia: perspectivas para o século XXI. São Carlos, RiMa, 2000.

Prat N, Muñoz I, Gonzales G, Millet X. Comparación critica de dos indices de calidad de las aguas. ISQUA y Bill. Tecnologia del Agua, 1986, 31: 33 - 49.

Prat N, Munné T, Rieradevall M. La calidad ecológica de las aguas. In: Sem. Intern. sobre macroinvertebrados bentonicos como bioindicadores de calidad de agua. Anais. Cali, Colômbia, 1997.

Prati L, Pavanello R, Pesarin F. Assessment of surface water pollution. Water Research 1971, 5: $741-751$.

Prygiel J \& Coste M. Recent trends in monitoring French Rivers using algae, especially diatoms, p. $87-96$. In: Whitton BA, Rott $E$ (eds). Use of algae for monitoring rivers II. Institute für Botanik, Universität Innsbruck. 1996.

Prósperi V, Eysink GGJ, Saito LM. Avaliação do grau de contaminação do sedimento ao longo do canal de navegação do porto de Santos. São Paulo, CETESB, 1998. Relatório Técnico, 33p e anexos.

Rand GM \& Petrocelli SR. Fundamentals of Aquatic Toxicology. GM Rand and SR Petrocelli (eds). Hemisphere Publishing Corporation, Washington. 1985. $666 \mathrm{p}$.

Rand GM. Fundamentals of Aquatic Toxicology:.effects, environmental fate, and risk assessment. Second Edition. GM Rand (ed.). Taylor and Francis Publishers, Washington. DC, 1995. 1125p.

Roberto S, Abreu RM de. Utilidade dos indicadores da qualidade das águas. Ambiente, Rev. CETESB de Tecnol. 1991, 5 (1) : 47-51. 
Rodrigues FO \& Roquetti-Humaytá MH. Estudo dos manguezais da Baixada Santista. São Paulo, CETESB, 1988. Relatório Técnico, 70 p.

Ross SL. An index system for classifying river water quality. Wat. Pollut. Control. $1977,76(1): 113-121$.

Santos Filho E, Souza e Silva R, Sakuma AM, Scorsafava MA, Barreto HHC, Inomata ONK, Lemes VRR. Concentrações de metais pesados e pesticidas organoclorados em crianças residentes em bairros situados às margens dos rios do município de Cubatão (SP). Secretaria de Estado da Saúde. Centro de Vigilância Sanitária. Programa de Saúde e Meio Ambiente. Instituto Adolfo Lutz. 1991.

Smith DG. A new form of water quality index for rivers and streams. Wat. Sci. Tech. 1989, 21 (2): $123-127$.

Smith DG. A better water quality indexing system for rivers and streams. Wat. Res. 1990, 24 (10): $1237-1244$.

Tommasi LR. Considerações ecológicas sobre o sistema estuarino de Santos (SP). Tese de Livre-Docência. USP, Instituto Oceanográfico. 2v. 489p. 1979.

Tyson JM \& House MA. The application of water quality index to rivers management. Wat. Sci. Tech. 1989, 21: 1149-1159.

Toledo Jr AP, Talarico M, Chinez SJ, Agudo EG. A aplicação de modelos simplificados para avaliação de processo da eutrofização em lagos e reservatórios tropicais. XIX Congresso Interamericano de Engenharia Sanitária e Ambiental. Camboriú, Santa Catarina, 1983, 57p.

Toledo Jr. AP. Informe preliminar sobre os estudos para obtenção de um índice para avaliação simplificada do estado trófico de reservatórios de regiões quentes tropicais. São Paulo, CETESB, 1990. Relatório Técnico, 11p e anexos.

USEPA, United States Environmental Protection Agency. Water Quality Criteria 1972. USEPA Ecological Research Series, EPA-R3-73-033, March 1973, 594 p.

USEPA, United States Environmental Protection Agency. Validity of effluent and ambient toxicity tests for predicting biological impact, Scippo Creek, Circleville, Ohio. EPA/600/3-85/044. Washington, D.C., 1985. p.i.

USEPA, United States Environmental Protection Agency. Validity of effluent and ambient toxicity tests for predicting biological impact, Skeleton Creek, Enid, Oklahoma. EPA/600/8-86/002. Washington, D.C., 1986. p.i.

USEPA, United States Environmental Protection Agency. Short-term methods for estimating the chronic toxicity of effluents and receiving waters for 
freshwater organisms. USEPA, 1989 - Cincinnati, Ohio. EPA/600/4-89/001. $262 \mathrm{P}$.

USEPA, United States Environmental Protection Agency. Technical support document for water quality-based toxics control. USEPA, 1991a. - Office of Water. EPA/505/2-90/001. Washington, D.C., 1991. 145p.

USEPA, United States Environmental Protection Agency. Water Quality Criteria Summary. USEPA, 1991b. Office of Science and Technology, Washington, D.C., $1991 b$.

USEPA, United States Environmental Protection Agency. Biological criteria: Technical guidance for streams and small rivers. USEPA, Office of Water. Washington, D.C., 1996.

Vargas-Boldrini C, Eysink GGJ, Lamparelli MC, Martins MC. Contaminants in the Cubatão River basin and its Estuary (SP, Brazil), relating to the Aquatic Biota. Part 2. Organic Compounds. $11^{\text {th }}$ Biennial International Estuarine Research Conference, San Francisco, USA. Session: Inputs and Cycling of Natural and Contaminant Materials in estuaries. November 1991.

Zagatto PA, Gherardi-Goldstein E, Bertoletti E, Lombardi CC, Martins MHRB, Ramos MLLC. Bioassays with aquatic organisms: toxicity of water and sediments from Cubatão river basin. Wat. Sci. Tech. 1987, 19 (11): 95 - 106.

Zagatto PA \& Gherardi-Goldstein E. Toxicidade em águas do Estado de São Paulo. Ambiente, Rev. CETESB de Tecnol. 1991, 5 (1): 13-20.

Zagatto PA. Toxicidade da alga Cylindrospermopsis raciborskii isolada do Reservatório Billings, Braço Taquacetuba. CETESB, São Paulo. Relatório Técnico. 1998. $23 \mathrm{p}+$ anexos.

Zagatto PA, Lorenzetti ML, Perez LSN, Menegon Jr. N, Buratini SV. Proposal for a new water quality index. Verh. Internat. Verein. Limnol. 1998, 26: 2449-2451.

Zagatto PA, Lorenzetti ML, Lamparelli MC, Salvador MEP, Menegon Jr. N, Bertoletti E. Aperfeiçoamento de um índice de qualidade de águas. Acta Limnol. Bras. 1999, 11 (2): $111-126$. 
ANEXO 
LEGENDAS PARA AS TABELAS A1 a A30

\section{Legenda IQA}

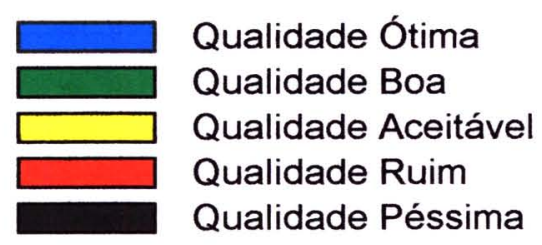

\section{Legenda IPMCA}

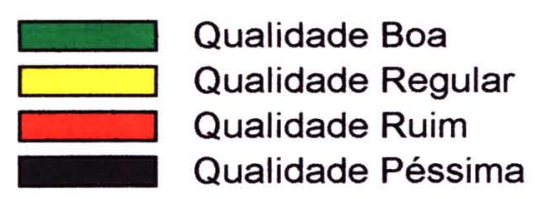

\section{Legenda IVA}

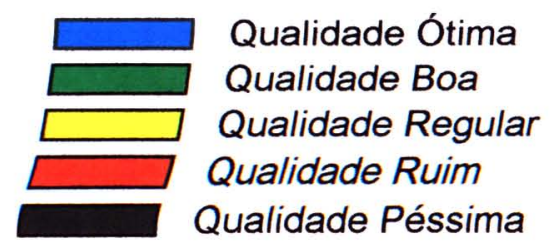


Tabela A1 - Resultados dos parâmetros analisados pela Rede de Monitoramento e cálculo do IVA no ponto CUBA02700, no ano de 1995

ANO: 1985

PONTO dE COLETA: RIO CUBATÃO, PONTE PRETA, EM FRENTE À ANTIGA ESTAÇÃO dE TRATAMENTO dE ÁGUA DO RIO CUBATÃO.

CODICO DO PONTO DE COLETA: CUBA02700

CLASSE: 2

\begin{tabular}{|c|c|c|c|c|c|c|c|c|c|c|c|c|}
\hline DADOS DE CUALIDADE & $\operatorname{dan}$ & Fev & Mar & Abr & Mal & Jun & Jul & Ano & Set & Out & Nov & Dez \\
\hline CHUVAS (últimas 24 horas) & Sim & Sim & Sim & Náo & Sim & Nâo & Năo & Nao & Sim & Sim & NaO & Nao \\
\hline COLORACAO DAS AGUAS & Verde & Limpida & Tunve & Verde & Limpida & Verde & Tunva & Limpida & Amarela & Verde & Cinza & Turva \\
\hline
\end{tabular}

\begin{tabular}{|c|c|c|c|c|c|c|c|c|c|c|c|c|}
\hline TEMPERATURA DO AR ( C) & 29 & 28 & 27 & 27 & 26 & 24 & 20 & 23 & 24 & 26 & 24 & 27 \\
\hline TEMPERATURA DA ÁGUA ( C) & 24 & 21 & 23 & 20 & 23 & 20 & 17 & 18 & 21 & 23 & 20 & 20 \\
\hline $\mathrm{pH}$ & 6,5 & 7,0 & 5,6 & 7,3 & 6,0 & 7,0 & 6,0 & 5,9 & 7,0 & 7,1 & 7,0 & 7,0 \\
\hline OXIGÉNIO DISSOLVIDO (mgO $/ \mathrm{L})$ & 7,7 & 7,6 & 8,4 & 7,8 & 7,3 & 8,4 & 8,7 & 8,6 & 8,5 & 8,5 & 8,0 & 8,0 \\
\hline FÓSFORO TOTAL (mgPR) & 0,020 & 0,045 & 0,020 & 0,005 & & 0,010 & 4,620 & 0,045 & 0,041 & 0,018 & 0,015 & 0,060 \\
\hline SURFACTANTES (mgl) & 0,01 & & 0,06 & & 0,05 & & 0,14 & & 0,06 & & $<0,02$ & \\
\hline \multicolumn{13}{|l|}{ ALUMINIO $(\mathrm{mg} / \mathrm{l})$} \\
\hline BÁRIO (mgl) & $<0,02$ & & $<0,02$ & & $<0,02$ & & $<0,02$ & & $<0,02$ & & $<0,02$ & \\
\hline CÁDMIO (mg/) & $<0,001$ & & $<0,001$ & & $<0,001$ & & $<0,001$ & & $<0,001$ & & 0,006 & \\
\hline CHUMBO (mgl) & $<0,05$ & & $<0,05$ & & $<0,05$ & & $<0,05$ & & $<0,05$ & & $<0,05$ & \\
\hline COBRE (mgh) & $<0,002$ & & $<0,002$ & & 0,01 & & $<0,004$ & & $<0,004$ & & 0,07 & \\
\hline CROMO TOTAL (mg/l) & $<0,05$ & & $<0,05$ & & $<0,05$ & & $<0,05$ & & $<0,05$ & & $<0,05$ & \\
\hline NIQQUEL (mgl) & $<0,002$ & & 0,004 & & 0,030 & & $<0,01$ & & $<0,01$ & & 0,010 & \\
\hline MERCÚRIO (mg/l) & & & & & & & & & & & $<0,0001$ & \\
\hline ZINCO (mgl) & 0,01 & & 0,002 & & 0,03 & & 0,05 & & $<0,01$ & & $<0,01$ & \\
\hline FENÓIS (mgl) & $<0,001$ & & 0,002 & & $<0,001$ & & 0,001 & & $<0,001$ & & $<0,001$ & \\
\hline \multicolumn{13}{|l|}{ PARAMETROS HIDROBIOLOOOICC } \\
\hline \multicolumn{13}{|l|}{ CLOROFILA-a $(\mu g /)$} \\
\hline TESTE DE TOXICIDADE CRÓNICA & Nelo Tóxic & & Näo Toxico & & Nấo Tóxico & & & & Crónico & & Năo Tóxico & \\
\hline
\end{tabular}

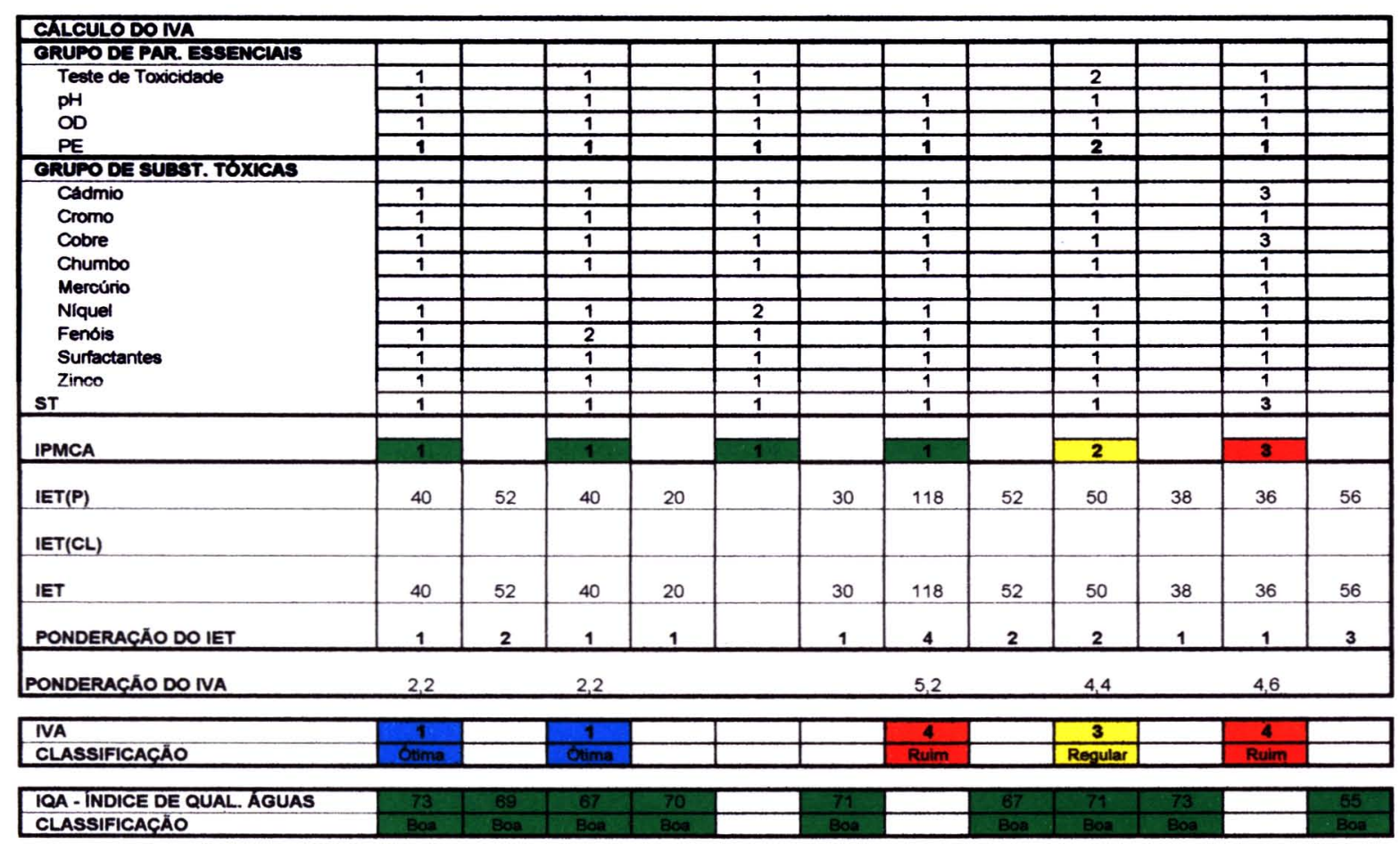


Tabela A2 - Resultados dos parâmetros analisados pela Rede de Monitoramento e cálculo do IVA no ponto CUBA02700, no ano de 1996

\section{ANO: 1996}

PONTO de COLETA: RIO CUBATÃo, PONTE PRETA, EM FRENTE À ANTIGA ESTAÇÃo de TRATAMENTO de ÁGUA do RIO CUBATÃo.

CODICO DO PONTO DE COLETA: CUBAO2700

CLASSE: 2

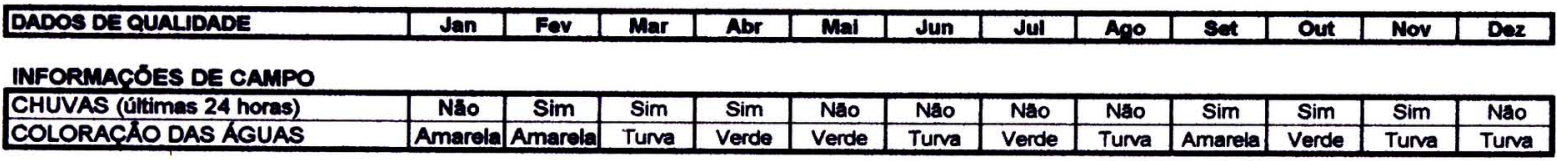

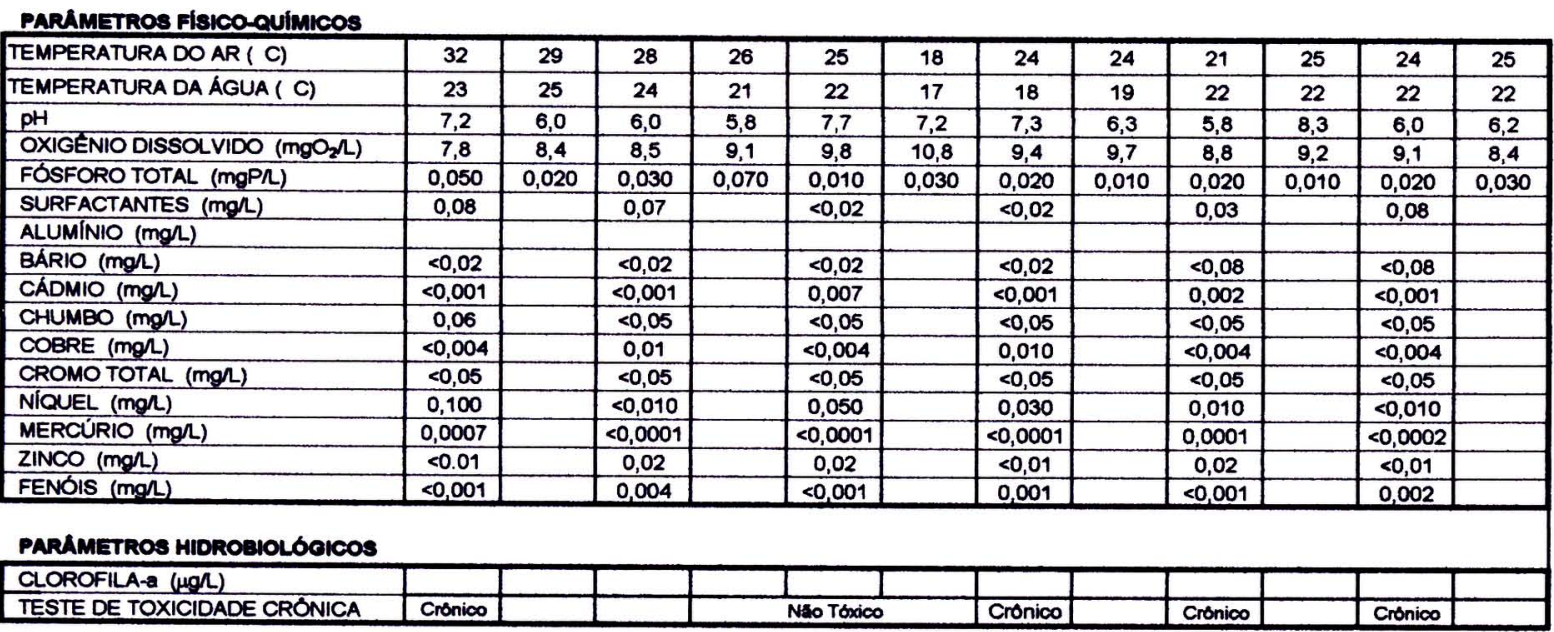

\begin{tabular}{|c|c|c|c|c|c|c|c|c|c|c|c|c|}
\hline \multirow{2}{*}{\multicolumn{13}{|c|}{$\begin{array}{l}\text { CALCULODONA } \\
\text { ORUPO DE PAR. ESSTICIAIS }\end{array}$}} \\
\hline & & & & & & & & & & & & \\
\hline \multirow{5}{*}{$\begin{array}{l}\text { Teste de Toxicidade } \\
\text { PH } \\
\text { OD } \\
\text { PE } \\
\text { ORUPO DE SUSST. TOXICAS }\end{array}$} & 2 & & & & 1 & & 2 & & 2 & & 2 & \\
\hline & 1 & & 1 & & 1 & & 1 & & 1 & & 1 & \\
\hline & 1 & & 1 & & 1 & & 1 & & 1 & & 1 & \\
\hline & 2 & & 1 & & 1 & & 2 & & 2 & & 2 & \\
\hline & & & & & & & & & & & & \\
\hline \multirow{10}{*}{$\begin{array}{l}\text { Cádmio } \\
\text { Cromo } \\
\text { Cobre } \\
\text { Chumbo } \\
\text { Mercúrio } \\
\text { Niquel } \\
\text { Fenois } \\
\text { Surfactantes } \\
\text { Zinco } \\
\text { st } \\
\end{array}$} & 1 & & 1 & & 3 & & 1 & & 2 & & 1 & \\
\hline & 1 & & 1 & & 1 & & 1 & & 1 & & 1 & \\
\hline & 1 & & 1 & & 1 & & 1 & & 1 & & 3 & \\
\hline & 2 & & 1 & & 1 & & 1 & & 1 & & 1 & \\
\hline & 2 & & 1 & & 1 & & 1 & & 1 & & 1 & \\
\hline & 1 & & 1 & & 2 & & 1 & & 1 & & 1 & \\
\hline & 1 & & 2 & & 1 & & 1 & & 1 & & 2 & \\
\hline & 1 & & 1 & & 1 & & 1 & & 1 & & 1 & \\
\hline & 1 & & 1 & & 1 & & 1 & & 1 & & 1 & \\
\hline & 2 & & 1 & & 2 & & 1 & & 1 & & 2 & \\
\hline IPMCA & 4 & & 1 & & 2 & & 2 & & 2 & & 4 & \\
\hline IET(P) & 53 & 40 & 46 & 58 & 30 & 46 & 40 & 30 & 40 & 30 & 40 & 46 \\
\hline \multicolumn{13}{|l|}{ IET(CL) } \\
\hline IET & 53 & 40 & 46 & 58 & 30 & 46 & 40 & 30 & 40 & 30 & 40 & 46 \\
\hline PONDERACEÃO DO IET & 2 & 1 & 2 & 3 & 1 & 2 & 1 & 1 & 1 & 1 & 1 & 2 \\
\hline PONDERACCAOO DO IVA & 6,8 & & 3,2 & & 3,4 & & 3,4 & & 3,4 & & 5.8 & \\
\hline IVA & 4 & & 2 & & 3 & & 3 & & 3 & & 4 & \\
\hline CLASSIFICACCĀO & Ruim & & Boa & & Reqular & & Regular & & Regular & & Ruim & \\
\hline IQA - INDICE DE QUAL. AGUAS & 61 & 86 & 86 & 59 & 71 & & 68 & 61 & 68 & 72 & 68 & 75 \\
\hline CLASSIFICAC¿ĀO & Boa & Boa & Boa & $\mathrm{Boa}$ & Boa & & Boa & Boa & Boa & Boa & Boa & 308 \\
\hline
\end{tabular}


Tabela A3 - Resultados dos parâmetros analisados pela Rede de Monitoramento e cálculo do IVA no ponto CUBA02700, no ano de 1997.

\section{ANO: 1997}

PONTO dE COLETA: RIO CUBATÁo, PONTE PRETA, EM FRENTE À ANTIGA ESTAÇÃo dE TRATAMENTO dE ÁGUA do RIO CUBATÃo

CÓDIGO DO PONTO DE COLETA: CUBA02700

CLASSE: 2

\begin{tabular}{|c|c|c|c|c|c|c|c|c|c|c|c|c|}
\hline DADOS DE QUALIDADE & Jan & Fev & Mar & Abr & Mai & Jun & Jul & Ago & Set & Out & Nov & Dez \\
\hline & & & & & & & & & & & & \\
\hline $\begin{array}{l}\text { CHUVAS (ültimas } 24 \text { horas) } \\
\text { COLORACAO DAS AGUAS }\end{array}$ & Nảo & Não & $\begin{array}{c}\text { Năo } \\
\text { Amarela }\end{array}$ & $\begin{array}{l}\text { Sim } \\
\text { Tura }\end{array}$ & $\begin{array}{l}\text { Nâo } \\
\text { Tutva }\end{array}$ & Sim & $\begin{array}{l}\text { Nao } \\
\text { Tuma }\end{array}$ & \begin{tabular}{|c|} 
Sim \\
Amarela \\
\end{tabular} & $\begin{array}{l}\text { Náo } \\
\text { Turaa }\end{array}$ & $\begin{array}{l}\text { Sim } \\
\text { Turva }\end{array}$ & $\begin{array}{l}\text { Nao } \\
\text { Turva }\end{array}$ & \begin{tabular}{|l} 
Năo \\
Amarele
\end{tabular} \\
\hline
\end{tabular}

PARÁMETROS FISICOQQUIMICOS

\begin{tabular}{|c|c|c|c|c|c|c|c|c|c|c|c|c|}
\hline TEMPERATURA DO AR ( C) & 26 & 27 & 27 & 25 & 27 & 23 & 24 & 26 & 27 & 23 & 26 & 26 \\
\hline TEMPERATURA DA ÁGUA ( C) & 21 & 24 & 23 & 24 & 21 & 19 & 18 & 19 & 19 & 21 & 22 & 21 \\
\hline OXIGÉNIO DISSOLVIDO ( $\left.\mathrm{mgO}_{2} / \mathrm{L}\right)$ & 8,1 & 8,2 & 8,1 & 8,9 & 8,1 & 6,5 & 8,2 & 10,1 & 7,0 & 5,8 & 6,5 & 6,3 \\
\hline SURFACTANTES (mg/) & 0,04 & & 0,02 & & 0,07 & & 0,06 & & $<0,02$ & & $<0,02$ & \\
\hline \multicolumn{13}{|l|}{ ALUMINIO (mg/L) } \\
\hline BÁRIO (mg/L) & $<0,08$ & & $<0,08$ & & $<0,08$ & & $<0,08$ & & $<0,08$ & & $<0,08$ & \\
\hline CÁDMIO (mg/l) & $<0,001$ & & $<0,001$ & & $<0,001$ & & $<0,001$ & & $<0,001$ & & $<0,001$ & \\
\hline CROMO TOTAL (mg/l) & $<0,05$ & & $<0,05$ & & $<0,05$ & & $<0,05$ & & $<0,05$ & & $<0,05$ & \\
\hline NIQUEL (mgl) & $<0,010$ & & $<0,010$ & & $<0,010$ & & $<0,010$ & & $<0,010$ & & 0,020 & \\
\hline MERCÚRIO (mg/l) & $<0,0002$ & & $<0,0002$ & & $<0,0002$ & & $<0,0002$ & & $<0,0002$ & & $<0,0002$ & \\
\hline ZINCO (mg/l) & $<0.01$ & & $<0.01$ & & 0,23 & & $<0,01$ & & $<0.01$ & & 0,02 & \\
\hline FENÓIS (mgl) & 0,003 & & $<0,001$ & & 0,002 & & 0,002 & & $<0,001$ & & 0,028 & \\
\hline
\end{tabular}

FENÓIS (mgl

\section{PARÁMETROS HIDROBIOLOGICOS}

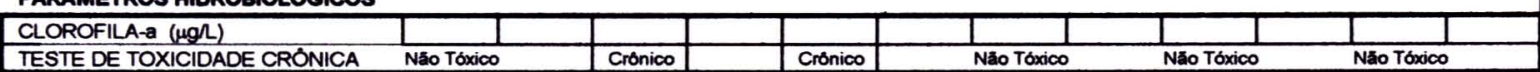

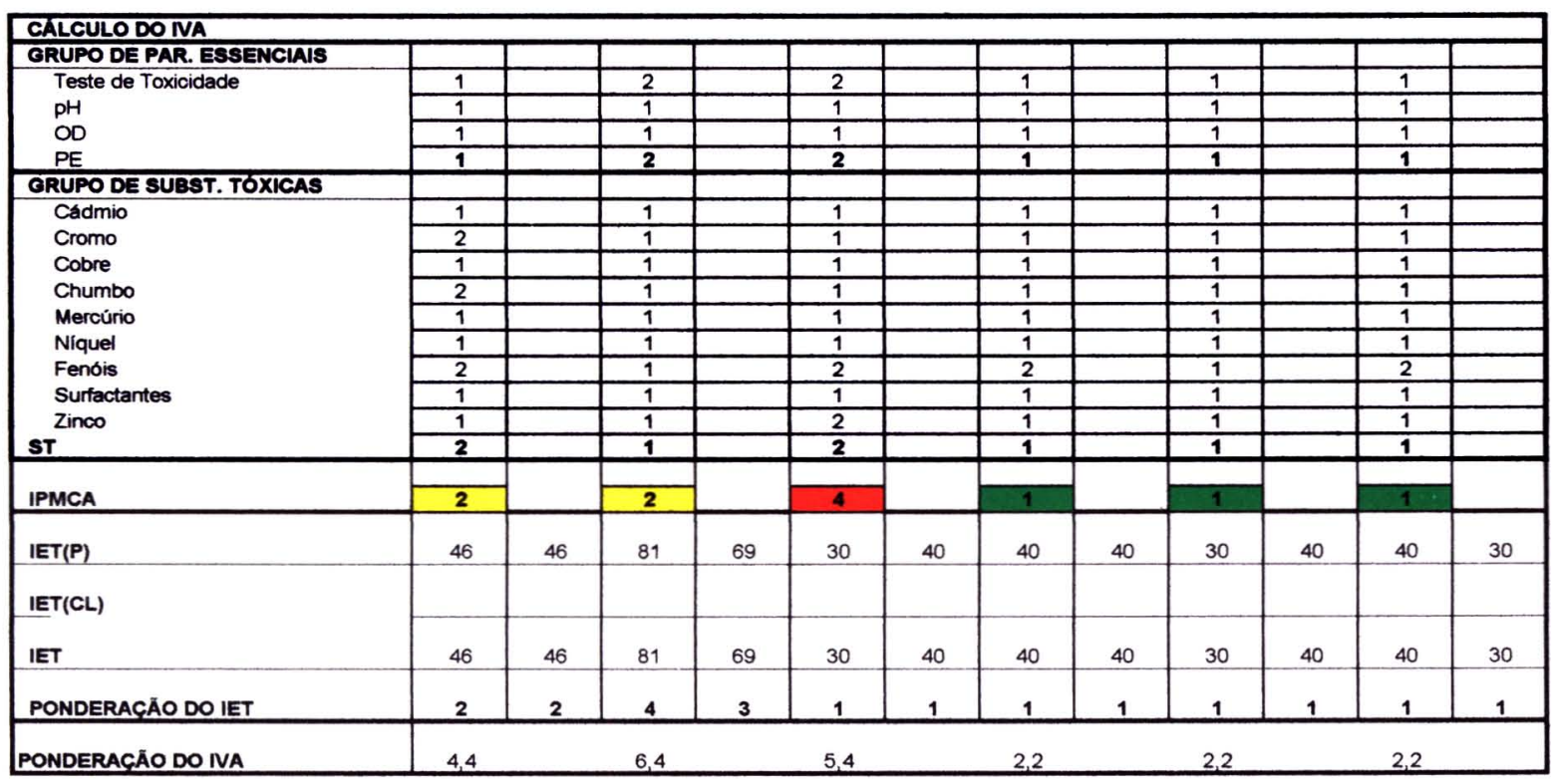

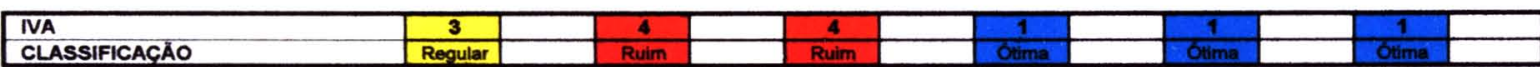

IQA - INDICE DE QUAL. ÁGUAS

CLASSIFICAC̨ĀO 
Tabela A4 - Resultados dos parâmetros analisados pela Rede de Monitoramento e cálculo do IVA no ponto CUBA02700, no ano de 1998.

ANO: 1998

PONTO DE COLETA: RIO CUBATÃO, PONTE PRETA, EM FRENTE Ȧ ANTIGA ESTAÇÃO DE TRATAMENTO DE ÁGUA DO RIO CUBATÃO

CÓDIGO DO PONTO DE COLETA: CUBA02700

CLASSE: 2

\begin{tabular}{|l|l|l|l|l|l|l|l|l|l|l|l|l|}
\hline DADOS DE QUALIDADE & Jan & Fev & Mar & Abr & Mal & Jun & Jul & Ago & Set & Out & Nov & Dez \\
\hline
\end{tabular}

INFORMACŌES DE CAMPO

\begin{tabular}{|l|l|l|l|l|l|l|l|l|l|l|l|l|}
\hline CHUVAS (ǘtimas 24 horas) & Năo & Năo & Sim & Năo & Sim & Năo & Năo & Năo & Sim & Sim & Nào & Năo \\
\hline
\end{tabular}

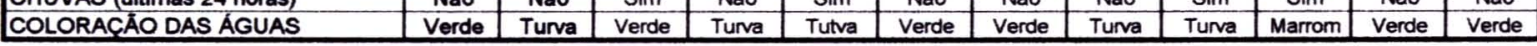

PARÂMETROS FísıCO-QUimicos

\begin{tabular}{|c|c|c|c|c|c|c|c|c|c|c|c|c|}
\hline TEMPERATURA DO AR ( C) & 28 & 32 & $\overline{34}$ & 30 & 21 & 26 & 26 & 21 & 24 & 21 & 25 & 27 \\
\hline OXIGÉNIO DISSOLVIDO ( $\left.\mathrm{mgO}_{2} / \mathrm{l}\right)$ & 5,6 & 6,5 & 8,0 & 5,8 & 6,4 & 6,5 & 6,4 & 5,1 & 6,8 & 6,4 & 5,8 & 5,2 \\
\hline FÓSFORO TOTAL (mgPM) & 0,020 & 0,020 & 0,050 & $<0,020$ & $<0,020$ & 0,020 & 0,020 & 0,030 & $<0,020$ & 0,040 & 0,030 & 0,020 \\
\hline ALUMINIO (mg/l) & $<0,2$ & & 2,62 & & 0,61 & & 0,24 & & 0,33 & & 0,22 & \\
\hline BÁRIO (mg/L) & $<0,08$ & & & & & & & & $<0,08$ & & $<0,08$ & \\
\hline CÁDMIO (mg/L) & $<0,001$ & & $<0,001$ & & $<0,001$ & & $<0,001$ & & $<0,001$ & & $<0,001$ & \\
\hline CROMO TOTAL (mg/L) & $<0,05$ & & $<0,01$ & & $<0,01$ & & $<0,01$ & & $<0,01$ & & 0,01 & \\
\hline NÍQUEL (mg/L) & $<0,010$ & & $<0,020$ & & $<0,020$ & & $<0,020$ & & $<0,020$ & & $<0,020$ & \\
\hline MERCÚRIO (mgl) & $<0,0002$ & & $<0,1000$ & & & & $<0,0002$ & & $<0,0002$ & & $<0,0002$ & \\
\hline ZINCO (mg/L) & $<0.01$ & & 0,04 & & $<0,01$ & & 0,01 & & 0,02 & & 0,01 & \\
\hline FENÓIS (mg/L) & 0,010 & & 0,006 & & $<0,001$ & & $<0,001$ & & $<0,001$ & & $<0,001$ & \\
\hline
\end{tabular}

\begin{tabular}{|c|c|c|c|c|c|c|c|c|c|c|c|c|}
\hline \multirow{2}{*}{\multicolumn{13}{|c|}{\begin{tabular}{|l|} 
CALCULODOIVA \\
GRUPODEPAR ESSENCIAIS
\end{tabular}}} \\
\hline & \\
\hline \multirow{4}{*}{$\begin{array}{l}\text { Teste de Toxicidade } \\
\text { PH } \\
\text { OD } \\
\text { PE }\end{array}$} & 1 & & 2 & & 2 & & 1 & & 2 & & 2 & \\
\hline & 1 & & 1 & & $\frac{2}{1}$ & & 1 & & 1 & & 1 & \\
\hline & 1 & & 1 & & 1 & & 1 & & 1 & & 1 & \\
\hline & 1 & & 2 & & 2 & & $\frac{1}{1}$ & & 2 & & 2 & \\
\hline \multicolumn{13}{|c|}{ GRUPO DE SUBST. TOXICAS } \\
\hline \multirow{10}{*}{$\begin{array}{l}\text { Cádmio } \\
\text { Cromo } \\
\text { Cobre } \\
\text { Chumbo } \\
\text { Mercúrio } \\
\text { Niquel } \\
\text { Fenois } \\
\text { Surfactantes } \\
\text { Zinco } \\
\text { si }\end{array}$} & 1 & & 1 & & 1 & & 1 & & 1 & & 1 & \\
\hline & $\frac{1}{2}$ & & $\frac{1}{1}$ & & $\frac{1}{1}$ & & $\frac{1}{1}$ & & $\frac{1}{1}$ & & 1 & \\
\hline & 1 & & 1 & & 1 & & 1 & & 1 & & 1 & \\
\hline & $\frac{1}{1}$ & & $\frac{1}{1}$ & & $\frac{1}{1}$ & & $\frac{1}{1}$ & & $\frac{1}{1}$ & & $\frac{1}{1}$ & \\
\hline & 1 & & 1 & & & & 1 & & 1 & & 1 & \\
\hline & 1 & & 1 & & 1 & & 1 & & 1 & & 1 & \\
\hline & $\frac{1}{2}$ & & $\frac{1}{2}$ & & $\frac{1}{1}$ & & $\frac{1}{1}$ & & $\frac{1}{1}$ & & $\frac{1}{1}$ & \\
\hline & 1 & & 1 & & 1 & & 1 & & 1 & & 1 & \\
\hline & 1 & & 1 & & 1 & & 1 & & 1 & & 1 & \\
\hline & 2 & & 1 & & 1 & & 1 & & 1 & & 1 & \\
\hline IPMCA & 2 & & 2 & & 2 & & 1 & & 2 & & 2 & \\
\hline IET(P) & 40 & 40 & 53 & 40 & 40 & 40 & 40 & 46 & 40 & 50 & 46 & 40 \\
\hline \multicolumn{13}{|l|}{ IET(CL) } \\
\hline IET & 40 & 40 & 53 & 40 & 40 & 40 & 40 & 46 & 40 & 50 & 46 & 40 \\
\hline PONDERAÇÃO DOIET & 1 & 1 & 2 & 1 & 1 & 1 & 1 & 2 & 1 & 2 & 2 & 1 \\
\hline PONDERAC.ÃO DO IVA & 3,4 & & 4.4 & & 3,4 & & 2,2 & & 3,4 & & 4,4 & \\
\hline
\end{tabular}

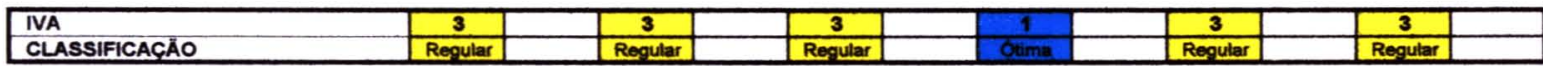

IQA - INDICE DE QUAL. AGUAS CLASSIFICACÃO 
Tabela A5 - Resultados dos parâmetros analisados pela Rede de Monitoramento e cálculo do IVA no ponto CUBA02700, no ano de 1999

ANO: 1898

PONTO dE COLETA: RIO CUBATÁ, PONTE PRETA, EM FRENTE A ANTIGA ESTAÇÃo dE TRATAMENTO dE ÁGUA DO RIO CUBATÃo. CODICO DO PONTO DE COLETA: CUBN02700

CLASSE: 2

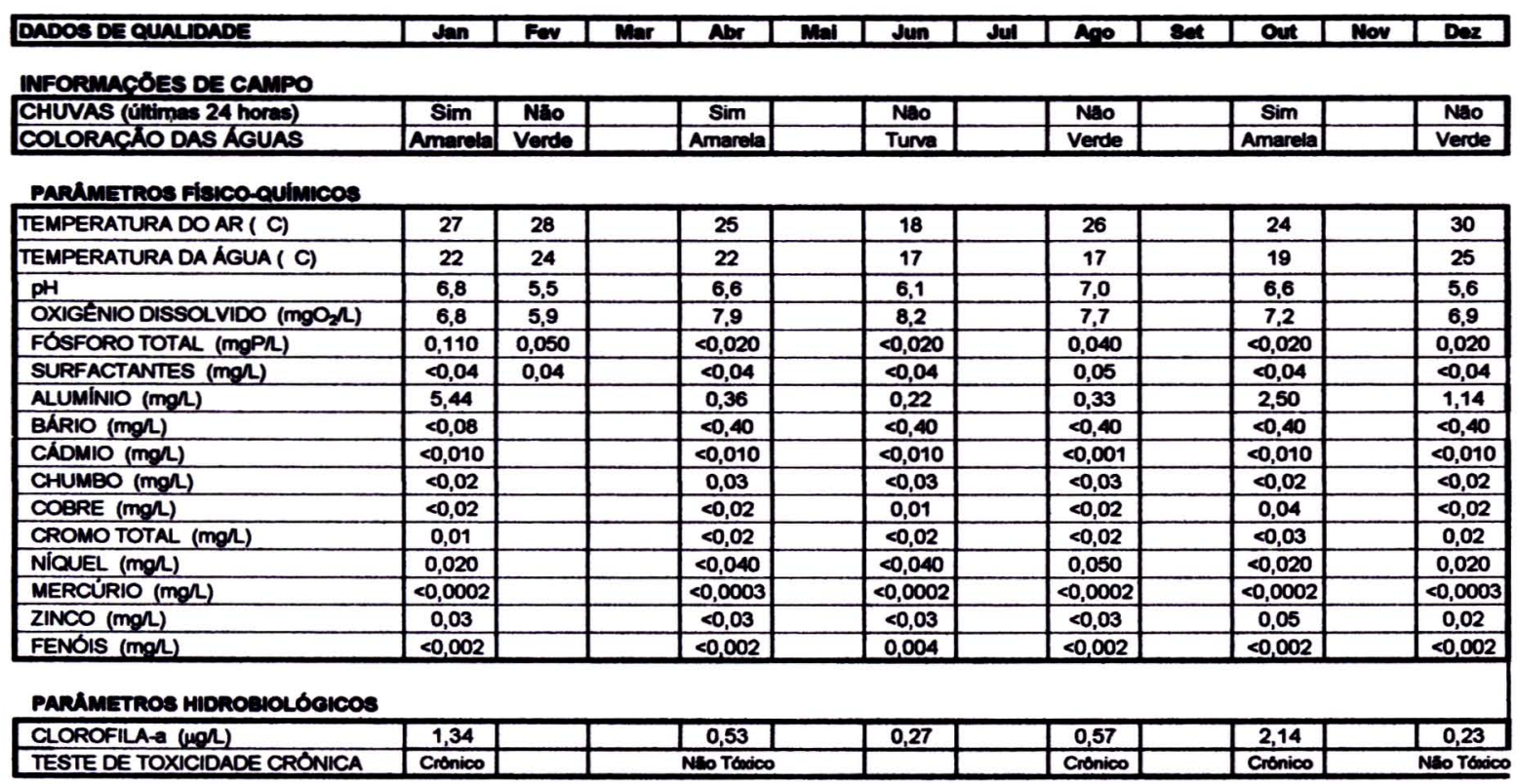

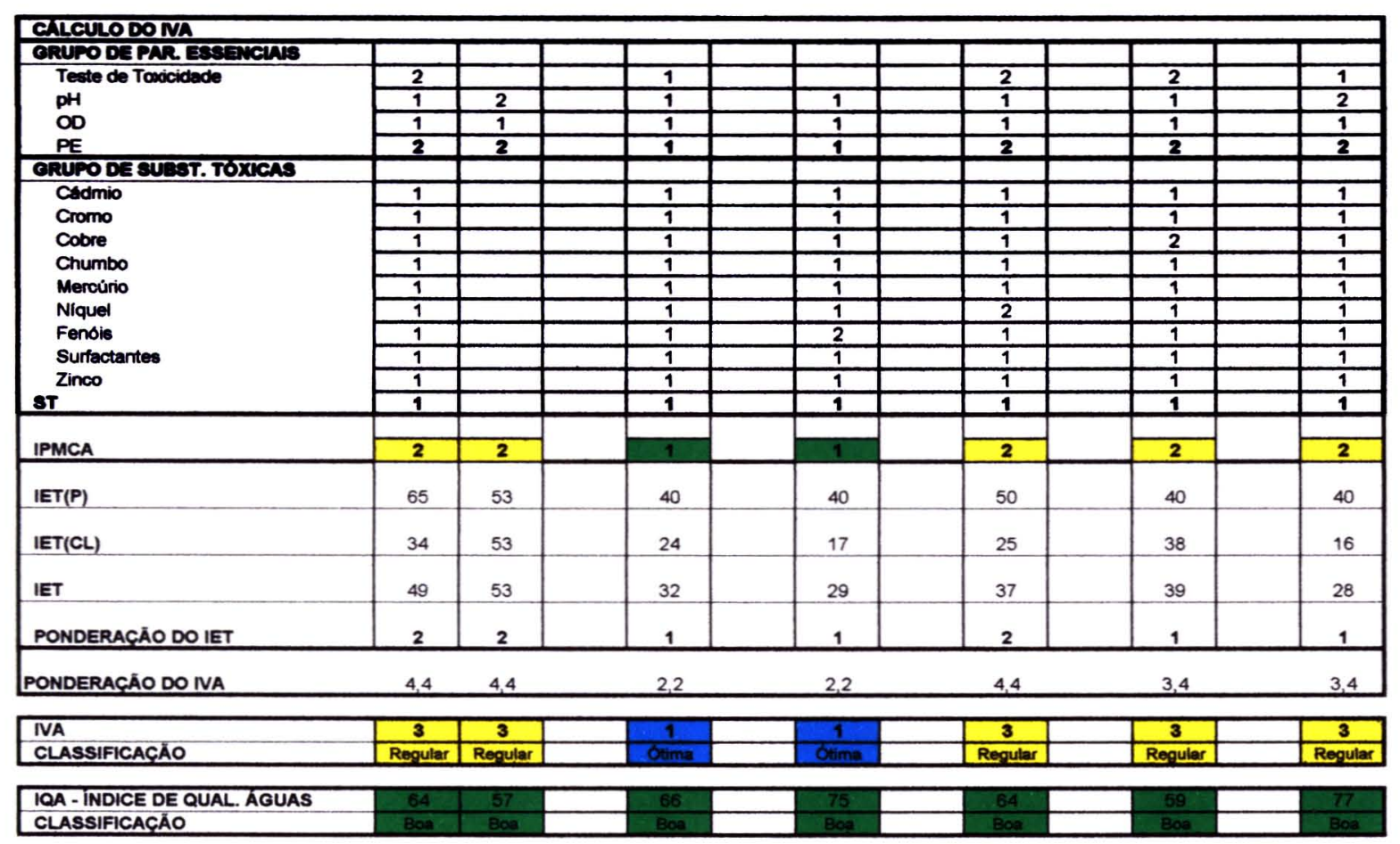


Tabela A6 - Resultados dos parâmetros analisados pela Rede de Monitoramento e cálculo do IVA no ponto CUBA02700, no ano de 2000.

\section{ANO: 2000}

PONTO dE COLETA: RIO CUBATÁO, PONTE PRETA, EM FRENTE A ANTIGA ESTAÇAO DE TRATAMENTO DE ÁGUA DO RIO CUBATÃo.

CODIGO DO PONTO DE COLETA: CUBA02700

CLASSE: 2

\begin{tabular}{|c|c|c|c|c|c|c|c|c|c|c|c|c|}
\hline DADOS DE QUALIDADE & $\operatorname{Jan}$ & Fov & Mar & Abr & Mal & Jun & Jul & Ano & set & Out & Nov & Dez \\
\hline & & & & & & & & & & & & \\
\hline CHUVAS (últimas 24 horas) & & Sim & & Nao & & NaO & & Năo & & Nao & & $\mathrm{NaO}$ \\
\hline COLORACAO DAS AGUAS & & Turve & & Amarela & & Tuna & & Verde & & Turva & & Verde \\
\hline
\end{tabular}

PARAMETROOS FISICOCUIMICOS

\begin{tabular}{|c|c|c|c|c|c|c|}
\hline TEMPERATURA DO AR ( C) & 27 & 28 & 22 & 26 & 26 & 30 \\
\hline TEMPERATURA DA ÁGUA ( C) & 21 & 22 & 18 & 21 & 23 & 25 \\
\hline $\mathrm{pH}$ & 6,6 & 8,0 & 7,4 & 7,6 & 7,0 & 7,0 \\
\hline OXIGÉNIO DISSOLVIDO (mgO $/$ L) & 6,9 & 5,5 & 7,0 & 6,4 & 5,4 & 7,0 \\
\hline SURFACTANTES (mg/) & 0,02 & 0,02 & 0,06 & 0,04 & 0,08 & $<0,03$ \\
\hline ALUMÍNIO (mg/l) & 0,92 & 0,91 & $<0,01$ & 1,30 & $<0,10$ & $<0,10$ \\
\hline BÁRIO (mgl) & $<0,40$ & $<0,40$ & $<0,08$ & $<0,08$ & $<0,40$ & $<0,08$ \\
\hline COBRE (mg/l) & $<0,02$ & $<0,02$ & 0,03 & $<0,02$ & 0,04 & 0,04 \\
\hline CROMO TOTAL (mg/l) & $<0,01$ & $<0,01$ & 0,05 & $<0,01$ & $<0,01$ & $<0,01$ \\
\hline NIQQUEL (mg/l) & $<0,020$ & $<0,020$ & $<0,020$ & $<0,020$ & $<0,020$ & $<0,020$ \\
\hline MERCÚRIO (mgl) & $<0,0003$ & $<0,0003$ & $<0,0003$ & $<0,0010$ & $<0,0010$ & $<0,0010$ \\
\hline ZINCO (mgh) & 0,14 & $<0,02$ & $<0,02$ & $<0,02$ & \begin{tabular}{|l|}
0,03 \\
\end{tabular} & $<0,02$ \\
\hline FENÓIS (mgl) & $<0,002$ & 0,002 & 0,007 & $<0,002$ & $<0,002$ & $<0,002$ \\
\hline
\end{tabular}

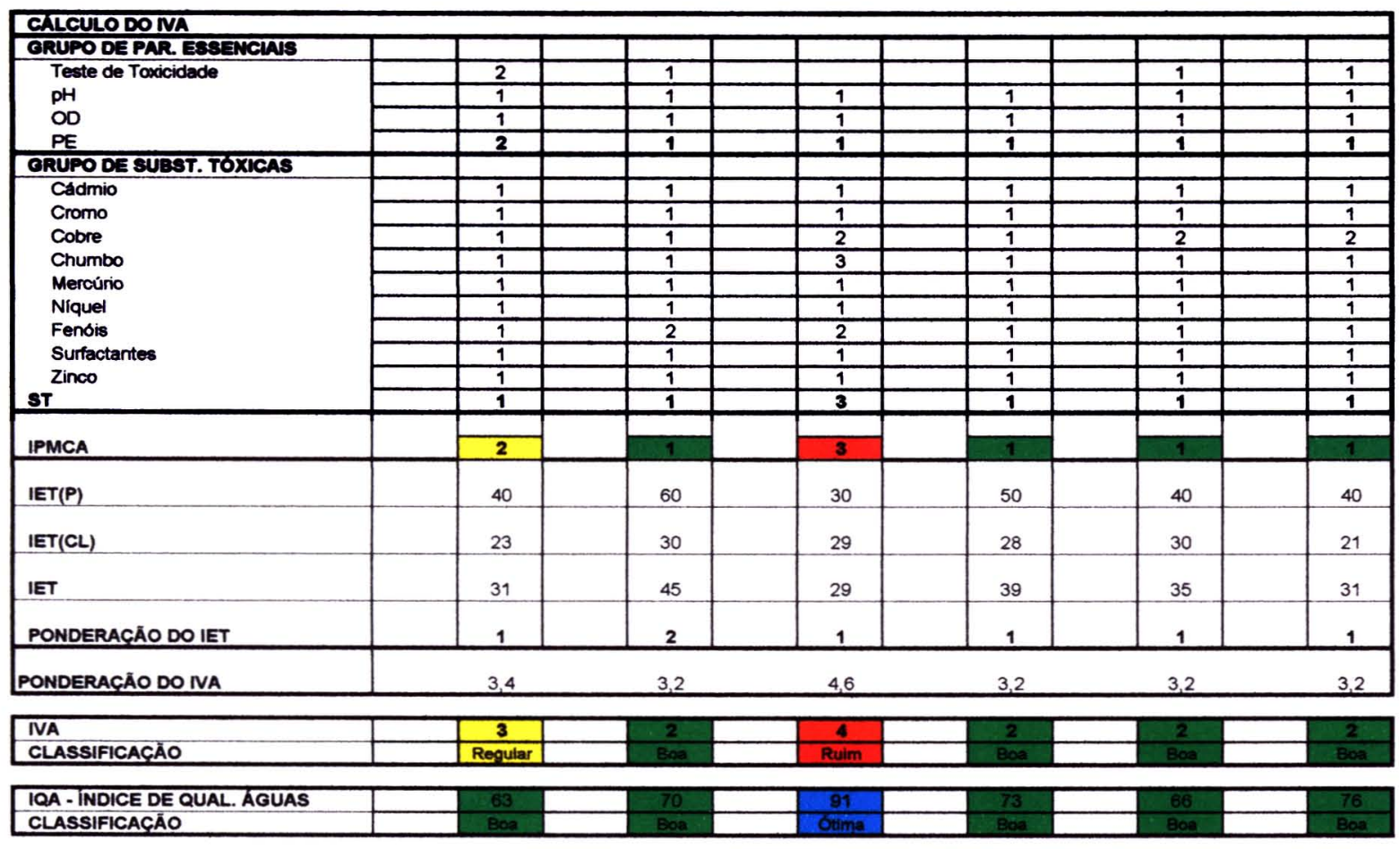


Tabela A7 - Resultados dos parâmetros analisados pela Rede de Monitoramento e cálculo do IVA no ponto CUBA03900, no ano de 1995.

ANO: 1995

PONTO DE COLETA: RIO CUBATÃO, PONTE DA ESTRADA DE FERRO SANTOS - JUNDIAİ, 1,5 Km A JUSANTE DA CONFL. DO RIO PEREQUÉ COM O RIO CUBATĀO

CÓDIBO DO PONTO DE COLETA: CUBA03900

CLASSE: 3

\begin{tabular}{|c|c|c|c|c|c|c|c|c|c|c|c|c|}
\hline DADOS DE QUALIDADE & Jan & Fev & Mar & Abr & Mal & Jun & Jul & A.0 & Set & Out & Nov & $\overline{D e z}$ \\
\hline & & & & & & & & & & & & \\
\hline CHUVAS (ûttimas 24 hora: & Sim & $\operatorname{sim}$ & $\operatorname{sim}$ & Náo & $\operatorname{sim}$ & Nao & Năo & Nao & Sim & Sim & Năo & Năo \\
\hline COLORACAO DAS AGUAS & Verde & Limpida & Amarela & Verde & Limpida & Verde & Turva & Limpida & Verde & Verde & Cinza & Turva \\
\hline
\end{tabular}

\section{PARÁMETROS FISICOQQUIMICOS}

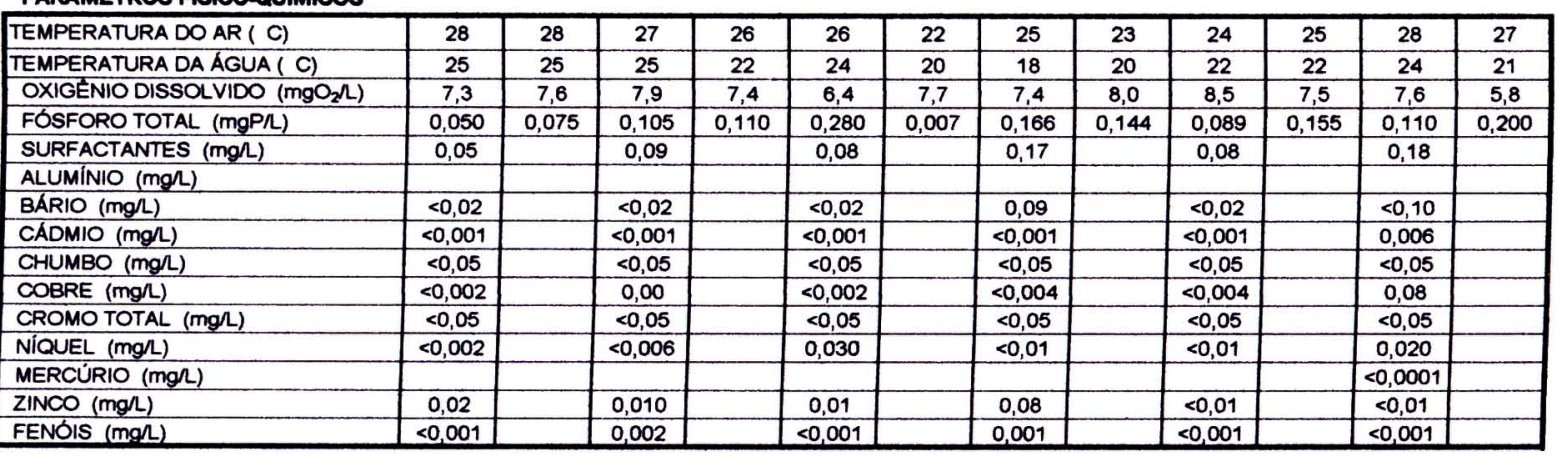

PARAMETROS HIDROBIOLOGICOS

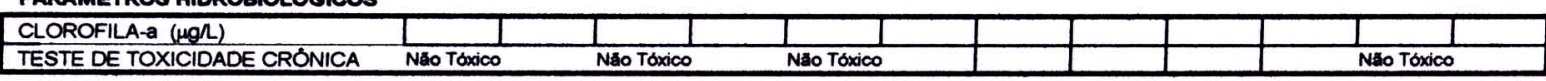

\begin{tabular}{|c|c|c|c|c|c|c|c|c|c|c|c|c|}
\hline \multirow{2}{*}{\multicolumn{13}{|c|}{$\begin{array}{l}\text { CALCULO DOIVA } \\
\text { GRUPO DE PAR. ESSENCIAIS }\end{array}$}} \\
\hline & 1 & & 1 & & & & & & & & & \\
\hline \multirow{3}{*}{$\begin{array}{l}\text { Teste de Toxicidade } \\
\mathrm{PH} \\
\mathrm{OD} \\
\mathrm{PE}\end{array}$} & $\frac{1}{1}$ & & $\frac{7}{1}$ & & $\frac{1}{1}$ & & 1 & & 1 & & $\frac{1}{1}$ & \\
\hline & 1 & & 1 & & 1 & & 1 & & $\frac{1}{1}$ & & $\frac{7}{1}$ & \\
\hline & 1 & & 1 & & 1 & & 1 & & 1 & & 1 & \\
\hline \multicolumn{13}{|c|}{ GRUPO DE SUBST. TOXICAS } \\
\hline \multirow{9}{*}{$\begin{array}{l}\text { Cadmio } \\
\text { Cromo } \\
\text { Cobre } \\
\text { Chumbo } \\
\text { Mercurio } \\
\text { Niquel } \\
\text { Fenóis } \\
\text { Surtactantes } \\
\text { Zinco } \\
\text { ST }\end{array}$} & 1 & & 1 & & 1 & & 1 & & 1 & & 3 & \\
\hline & 1 & & 1 & & 1 & & 1 & & 1 & & 1 & \\
\hline & 1 & & 1 & & 1 & & 1 & & 1 & & 3 & \\
\hline & 1 & & 1 & & 1 & & 1 & & 1 & & 1 & \\
\hline & & & & & & & & & & & 1 & \\
\hline & 1 & & 1 & & 2 & & 1 & & 1 & & 1 & \\
\hline & 1 & & 2 & & 1 & & 1 & & 1 & & 1 & \\
\hline & 1 & & 1 & & 1 & & 9 & & 1 & & 1 & \\
\hline & $\frac{1}{1}$ & & 1 & & 1 & & 1 & & 1 & & $\frac{1}{2}$ & \\
\hline \multicolumn{13}{|l|}{ IPMCA } \\
\hline & & & & & & & & & & & & \\
\hline IET(P) & 53 & 59 & 64 & 65 & 78 & 25 & 70 & 68 & 61 & 69 & 65 & 73 \\
\hline \multicolumn{13}{|l|}{$\operatorname{IET}(\mathrm{CL})$} \\
\hline IET & 53 & 59 & 64 & 65 & 78 & 25 & 70 & 68 & 61 & 69 & 65 & 73 \\
\hline PONDERACÁO DO IET & 2 & 3 & 3 & 3 & 4 & 1 & 3 & 3 & 3 & 3 & 3 & 3 \\
\hline PONDERACÃO DO IVA & 3,2 & & 4,2 & & 5,2 & & 4,2 & & 4,2 & & 6,6 & \\
\hline
\end{tabular}

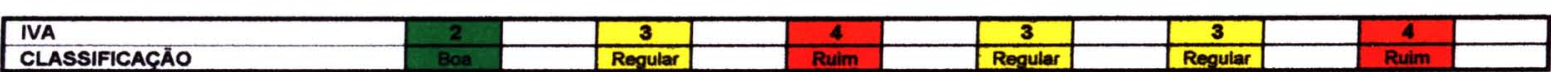

\begin{tabular}{|c|c|c|c|c|c|c|c|c|c|c|c|}
\hline IQA - INDICE DE QUAL. AGUAS & 50 & 49 & 56 & 61 & 44 & 56 & 54 & 48 & 62 & 46 & 41 \\
\hline
\end{tabular}


Tabela A8 - Resultados dos parâmetros analisados pela Rede de Monitoramento e cálculo do IVA no ponto CUBA03900, no ano de 1996.

ANO: 1996

PONTO dE COLETA: RIO CUBATÃO, PONTE DA ESTRADA DE FERRO SANTOS - JUNDIAI, 1,5 KM A JUSANTE DA CONFL. DO RIO PEREQUE COM O RIO CUBATÃO

CÓDIGO DO PONTO DE COLETA: CUBA03900

CLASSE: 3

\begin{tabular}{|c|c|c|c|c|c|c|c|c|c|c|c|c|}
\hline DADOS DE QUALIDADE & $\operatorname{Jan}$ & Fev & Mar & $\mathrm{Abr}$ & Mal & Jun & Jul & A9o & Set & Out & Nov & Dez \\
\hline CHUVAS (últimas 24 horas) & Năo & Sim & Sim & Sim & Năo & Năo & Năo & Năo & Sim & Sim & Sim & Nao \\
\hline COLORACÃO DAS AGUAS & Turva & Amarela & Cinza & Amarela & Cinza & Cinza & Verde & Tunva & Turva & Verde & Turva & Cinza \\
\hline
\end{tabular}

PARÂMETROS Físico-Quimicos

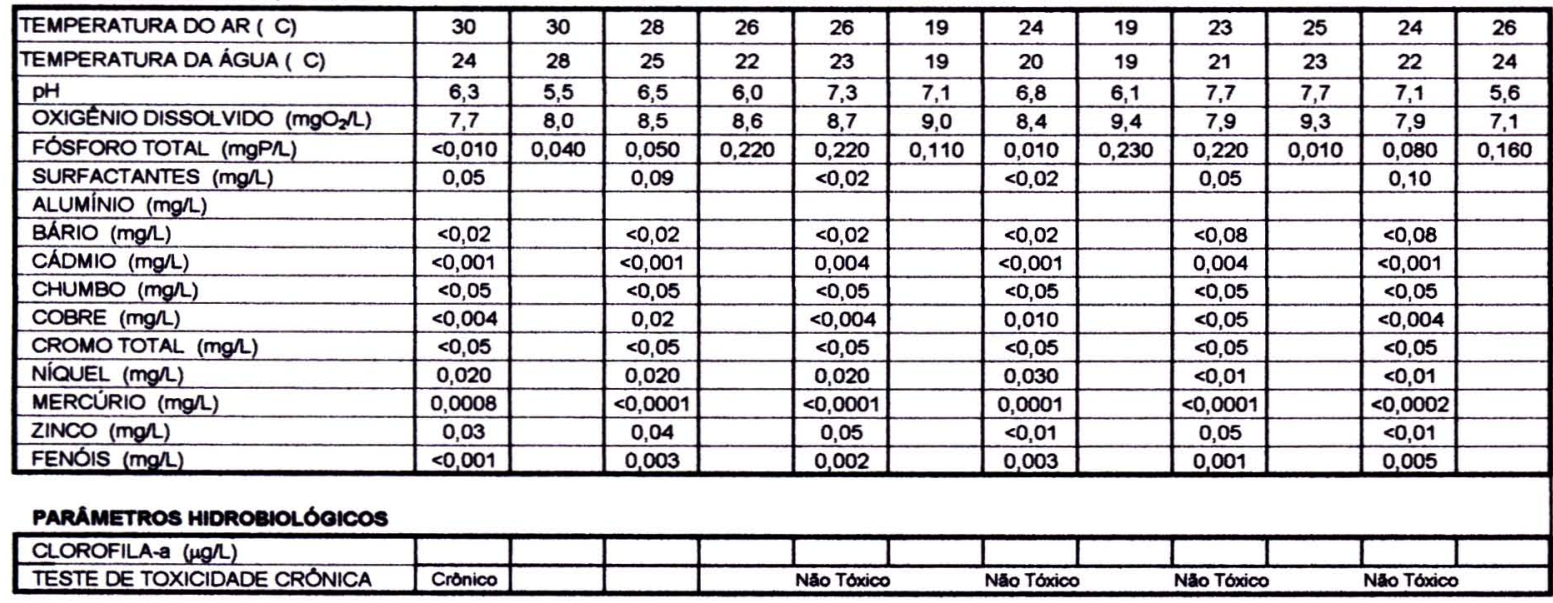

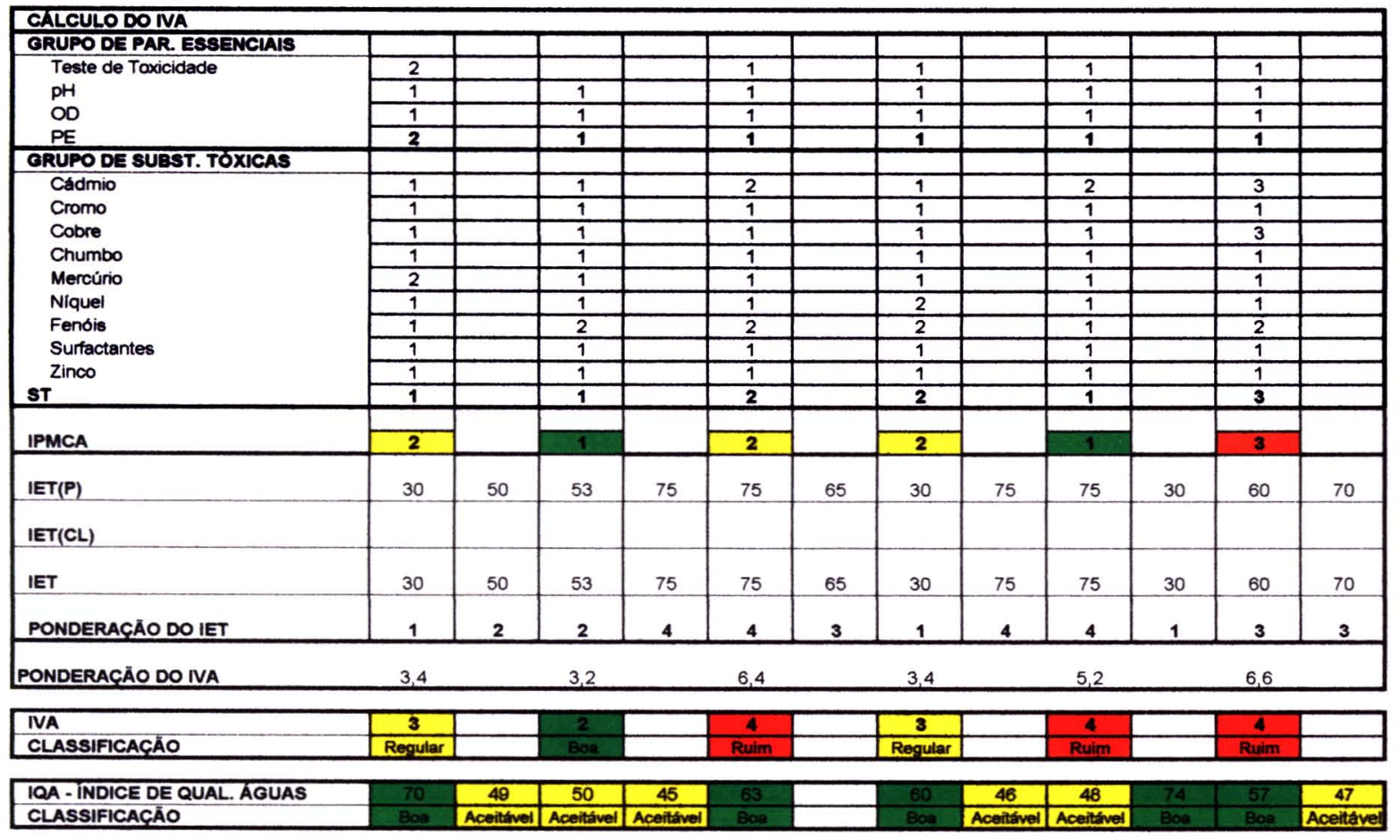


Tabela A9 - Resultados dos parâmetros analisados pela Rede de Monitoramento e cálculo do IVA no ponto CUBA03900, no ano de 1997.

\section{ANO: 1997}

PONTO DE COLETA: RIO CUBATÃO, PONTE DA ESTRADA DE FERRO SANTOS - JUNDIAİ, 1,5 Km A JUSANTE DA CONFL. DO RIO PEREQUÉ COM O RIO CUBATÃO

CÓDIGO DO PONTO DE COLETA: CUBA03900

CLASSE: 3

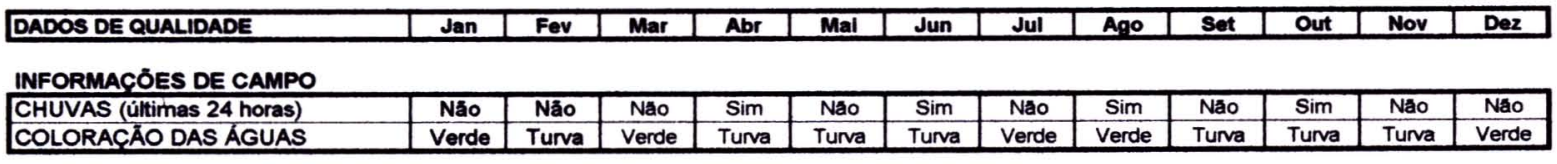

PARÁMETROS FísICO-QUIMICOS

\begin{tabular}{|c|c|c|c|c|c|c|c|c|c|c|c|c|}
\hline TEMPERATURA DO AR ( C) & 26 & 28 & 28 & 25 & 30 & 23 & 26 & 22 & 28 & 23 & 27 & 26 \\
\hline TEMPERATURA DA ÁGUA ( C) & 23 & 25 & 24 & 23 & 24 & 21 & 19 & 19 & 25 & 21 & 24 & 22 \\
\hline $\mathrm{pH}$ & 6,8 & 6,9 & 5,7 & 4,5 & 6,5 & 6,6 & 6,5 & 5,5 & 8,6 & 6,5 & 6,4 & 6,0 \\
\hline OXIGÉNIO DISSOLVIDO ( $\left.\mathrm{mgO}_{2} / \mathrm{L}\right)$ & 7,3 & 8,8 & 7,0 & 4,4 & 8,3 & 7,0 & 7,9 & 10,2 & 6,7 & 6,2 & 6,7 & 6,4 \\
\hline SURFACTANTES (mg/l) & 0,03 & & 0,02 & & 0,03 & & 0,09 & & 0,05 & & 0,14 & \\
\hline \multicolumn{13}{|l|}{ ALUMÍNIO (mg/L) } \\
\hline$B A ́ R I O(m g h)$ & $<0,08$ & & $<0,08$ & & $<0,08$ & & $<0,08$ & & $<0,08$ & & $<0,08$ & \\
\hline COBRE (mg/) & 0,01 & & $<0,004$ & & $<0,004$ & & $<0,004$ & & $<0,004$ & & $<0,004$ & \\
\hline CROMO TOTAL (mg/L) & $<0,05$ & & $<0,05$ & & $<0,05$ & & $<0,05$ & & $<0,05$ & & $<0,05$ & \\
\hline NIQUEL (mg/L) & $<0,010$ & & $<0,010$ & & $<0,010$ & & $<0,010$ & & $<0,010$ & & 0,060 & \\
\hline MERCÚRIO (mg/l) & $<0,0002$ & & $<0,0002$ & & $<0,0002$ & & $<0,0002$ & & $<0,0002$ & & $<0,0002$ & \\
\hline ZINCO (mg/) & 0,02 & & 0,01 & & 0,19 & & \begin{tabular}{|c|}
$<0,01$ \\
\end{tabular} & & $<0,01$ & & 0,02 & \\
\hline FENÓIS (mg/L) & $<0,001$ & & $<0,001$ & & 0,002 & & 0,002 & & $<0,004$ & & 0,003 & \\
\hline \multicolumn{13}{|l|}{ PARÂMETROS HIDROBIOLÓGICOS } \\
\hline
\end{tabular}

\begin{tabular}{|c|c|c|c|c|c|c|c|c|c|c|c|c|}
\hline \multicolumn{13}{|l|}{ CALCULODOIVA } \\
\hline \multicolumn{13}{|l|}{ GRUPO DE PAR. ESSENCIAIS } \\
\hline \multirow{4}{*}{$\begin{array}{l}\text { Teste de Toxicidade } \\
\mathrm{pH} \\
\mathrm{OD} \\
\mathrm{PE}\end{array}$} & 2 & & 1 & & 1 & & 1 & & 1 & & 1 & \\
\hline & 1 & & 9 & & 1 & & 1 & & 1 & & 1 & \\
\hline & 1 & & 1 & & 1 & & 1 & & 1 & & 1 & \\
\hline & 2 & & 1 & & 1 & & 1 & & 1 & & 1 & \\
\hline \multicolumn{13}{|l|}{ GRUPO DE SUBST. TOXICAS } \\
\hline \multirow{10}{*}{$\begin{array}{l}\text { Cádmio } \\
\text { Cromo } \\
\text { Cobre } \\
\text { Chumbo } \\
\text { Mercúrio } \\
\text { Niquel } \\
\text { Fenois } \\
\text { Surfactantes } \\
\text { Zinco } \\
\text { ST }\end{array}$} & 1 & & 1 & & 1 & & 1 & & 1 & & 1 & \\
\hline & 1 & & 1 & & 1 & & 1 & & 1 & & 1 & \\
\hline & 1 & & 1 & & 1 & & 1 & & 1 & & $\frac{1}{1}$ & \\
\hline & 1 & & 9 & & 1 & & 1 & & 1 & & 1 & \\
\hline & 1 & & 1 & & 1 & & 1 & & 1 & & 1 & \\
\hline & 1 & & 1 & & 1 & & 1 & & 1 & & 2 & \\
\hline & 1 & & 1 & & 2 & & 2 & & 1 & & 2 & \\
\hline & 1 & & 1 & & 1 & & 1 & & 1 & & 1 & \\
\hline & 1 & & 1 & & 2 & & 1 & & 1 & & 1 & \\
\hline & 1 & & 1 & & 2 & & 1 & & 9 & & 2 & \\
\hline IPMCA & 2 & & 1 & & 2 & & 1 & & 1 & & 2 & \\
\hline IET(P) & 40 & 40 & 30 & 85 & 30 & 50 & 56 & 46 & 56 & 69 & 69 & 30 \\
\hline \multicolumn{13}{|l|}{ IET(CL) } \\
\hline IET & 40 & 40 & 30 & 85 & 30 & 50 & 56 & 46 & 56 & 69 & 69 & 30 \\
\hline PONDERACCÃO DO IET & 1 & 1 & 1 & 4 & 1 & 2 & 3 & 2 & 3 & 3 & 3 & 1 \\
\hline PONDERACÃO DO IVA & 3,4 & & 2,2 & & 3,4 & & 4,2 & & 4.2 & & 5,4 & \\
\hline IVA & 3 & & 1 & & 3 & & $\overline{3}$ & & $\overline{3}$ & & 4 & \\
\hline CLASSIFICACĀO & Regular & & Osima & & Regular & & Regular & & Regular & & Ruim & \\
\hline IQA - INDICE DE QUAL. AGUAS & 72 & 62 & 60 & 34 & 61 & 55 & 65 & 63 & 52 & 43 & 48 & 83 \\
\hline CLASSIFICACÁO & Boa & Boa & $\mathrm{Bon}$ & Ruim & Boa & Boe & Boa & Boa & 802 & Aceitínel & Aceitível & $80 a$ \\
\hline
\end{tabular}


Tabela A10 - Resultados dos parâmetros analisados pela Rede de Monitoramento e cálculo do IVA no ponto CUBA03900, no ano de 1998.

\section{ANO: 1998}

PONTO DE COLETA: RIO CUBATĀO, PONTE DA ESTRADA DE FERRO SANTOS - JUNDIAÍ, 1,5 Km A JUSANTE DA CONFL. DO RIO PEREQUÉ COM O RIO CUBATÃO

CÓDIGO DO PONTO DE COLETA: CUBA03900

CLASSE: 3

\begin{tabular}{|c|c|c|c|c|c|c|c|c|c|c|c|c|}
\hline DADOS DE QUALIDADE & $\operatorname{Jan}$ & Fev & Mar & Abr & Mai & Jun & Jul & Ago & Set & Out & Nov & Dez \\
\hline INFO & & & & & & & & & & & & \\
\hline CHUVAS (últimas 24 horas) & Năo & Năo & Sim & Năo & Năo & Nâo & Năo & Năo & Sim & Sim & Năo & Năo \\
\hline COLORACÁO DAS AGUAS & Verde & Turva & Verde & Cinza & Verde & Verde & Verde & Turva & Turva & Marrom & Verde & Verde \\
\hline
\end{tabular}

\section{PARÂMETROS FISICO-QUIMICOS}

\begin{tabular}{|c|c|c|c|c|c|c|c|c|c|c|c|c|}
\hline TEMPERATURA DO AR ( C) & 29 & 35 & 32 & 30 & 26 & 26 & 27 & 24 & 28 & 20 & 25 & 26 \\
\hline TEMPERATURA DA ÁGUA ( C) & 25 & 29 & 25 & 25 & 22 & 22 & 23 & 21 & 22 & 19 & 22 & 22 \\
\hline $\mathrm{pH}$ & 5,5 & 7,8 & 6,0 & 6,8 & 6,8 & 6,8 & 6,5 & 8,5 & 6,4 & 5,4 & 6,0 & 5,8 \\
\hline OXIGÉNIO DISSOLVIDO (mgO & 5,5 & 5,6 & 5,9 & 5,4 & 6,0 & 6,6 & 5,9 & 6,5 & 7,3 & 5,8 & 5,4 & 5,4 \\
\hline FÓSFORO TOTAL (mgPR) & 0,110 & 0,020 & 0,040 & 0,100 & 0,070 & 0,030 & 0,090 & 0,150 & 0,190 & 0,100 & 0,070 & 0,030 \\
\hline SURFACTANTES $(\mathrm{mg} / \mathrm{l})$ & $<0,02$ & $<0,04$ & $<0,04$ & $<0,04$ & $<0,04$ & 0,05 & 0,05 & 0,06 & 0,28 & 0,06 & 0,04 & 0,05 \\
\hline ALUMINIO (mg/L) & $<0,20$ & & & & 1,90 & 0,84 & 0,84 & & & & 0,32 & \\
\hline BÁRIO (mg/L) & $<0,08$ & & & & & & & & & & $<0,08$ & \\
\hline CÁDMIO (mg/L) & $<0,001$ & & & & $<0,010$ & $<0,010$ & $<0,010$ & & & & $<0,010$ & \\
\hline CHUMBO (mg/l) & $<0,05$ & & & & 0,09 & 0,07 & 0,07 & & & & $<0,02$ & \\
\hline COBRE (mg/L) & $<0,004$ & & & & $<0,02$ & 0,02 & 0,02 & & & & $<0,02$ & \\
\hline CROMO TOTAL (mg/L) & $<0,05$ & & & & $<0,01$ & $<0,01$ & $<0,01$ & & & & $<0,01$ & \\
\hline NIQUEL (mg/L) & $<0,010$ & & & & $<0,020$ & $<0,020$ & $<0,020$ & & & & 0,030 & \\
\hline MERCÚRIO (mg/L) & $<0,0002$ & & & & & & $<0,0002$ & & & & $<0,0002$ & \\
\hline ZINCO (mg/L) & $<0,01$ & & & & $<0,01$ & 0,02 & 0,02 & & & & 0,05 & \\
\hline FENÓIS (mg/L) & 0,010 & & & & $<0,001$ & 0,001 & 0.001 & & & & $<0,001$ & \\
\hline
\end{tabular}

PARÂMETROS HIDROBIOLÓGICOS

CLOROFILA-a $(\mu g / L)$

TESTE DE TOXICIDADE CRÓNICA

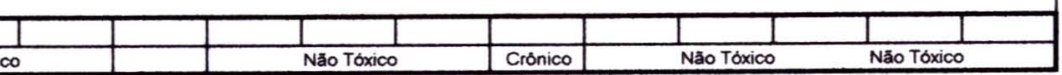

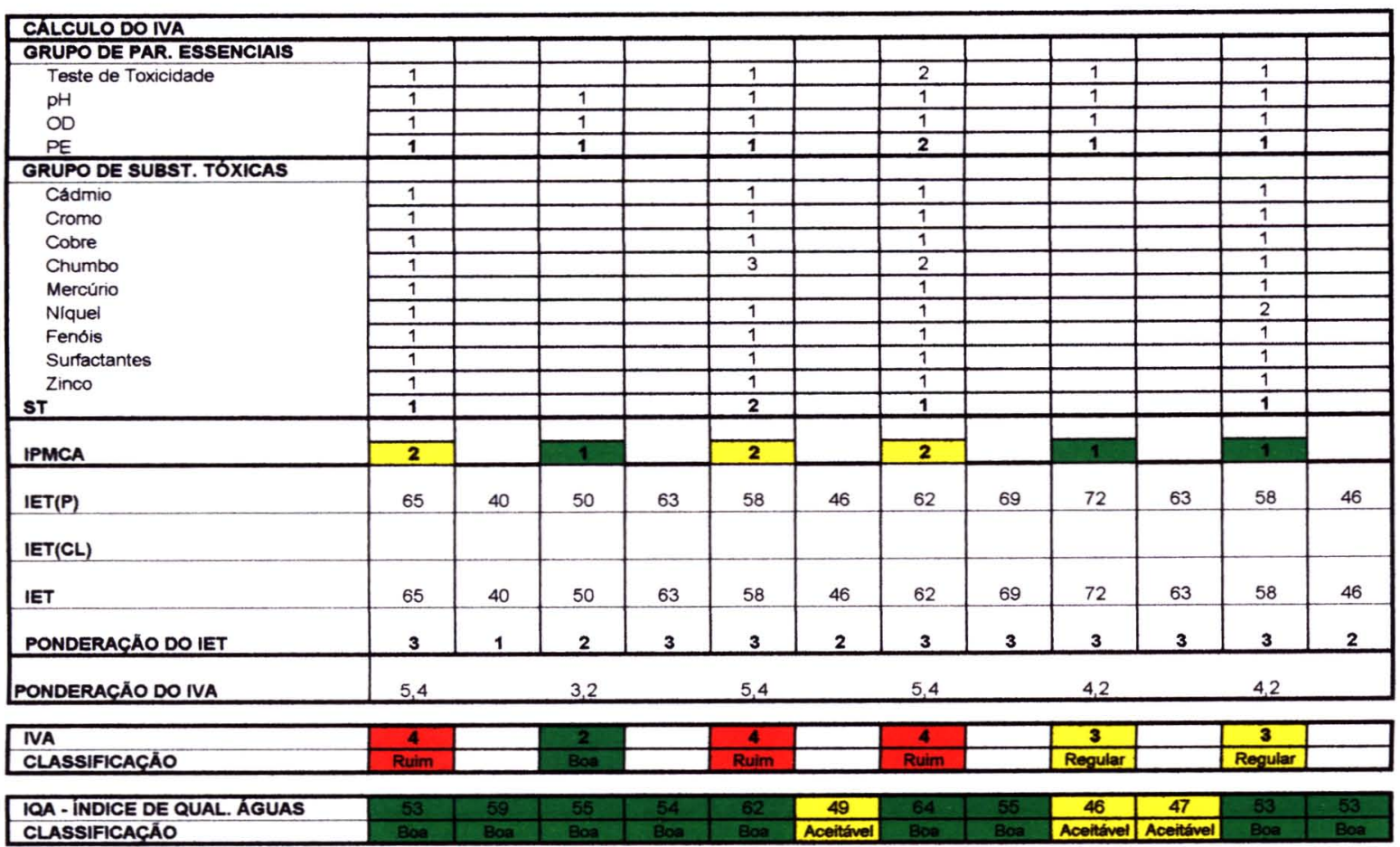


Tabela A11 - Resultados dos parâmetros analisados pela Rede de Monitoramento e cálculo do IVA no ponto CUBA03900, no ano de 1999.

ANO: 1998

PONTO dE COLETA: RIO CUBATÃO, PONTE DA ESTRADA DE FERRO SANTOS - JUNDIAÍ, 1,5 Km A JUSANTE DA CONFL. DO RIO PEREQUÉ COM O RIO CUBATAOO

CODIGO DO PONTO DE COLETA: CUBA03900

CLASSE: 3

\begin{tabular}{|c|c|c|c|c|c|c|c|c|c|c|c|c|}
\hline DADOS DE QUALIDADE & $\operatorname{Jan}$ & Fev & Mar & Abr & Mai & Jun & Jul & Ago & Set & Out & Nov & Dez \\
\hline 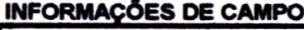 & & & & & & & & & & & & \\
\hline CHUVAS (últimas 24 horas) & Sim & Năo & & Sim & & $\mathrm{NaO}$ & & Nao & & Sim & & Nao \\
\hline COLORACĀO DAS ÁGUAS & Amarela & Cinza & & Cinza & & Turva & & Verde & & Verde & & Verde \\
\hline
\end{tabular}

PARÃMETROS FÍsICO-QuíMICOS

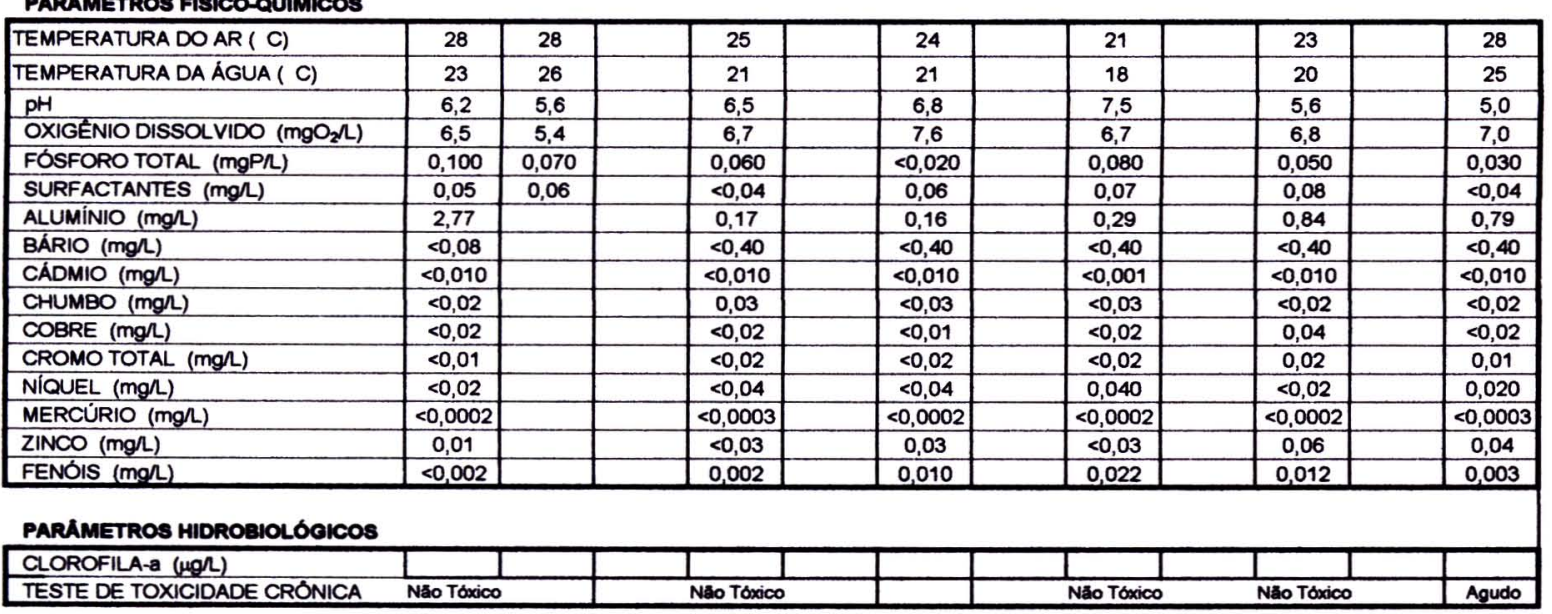

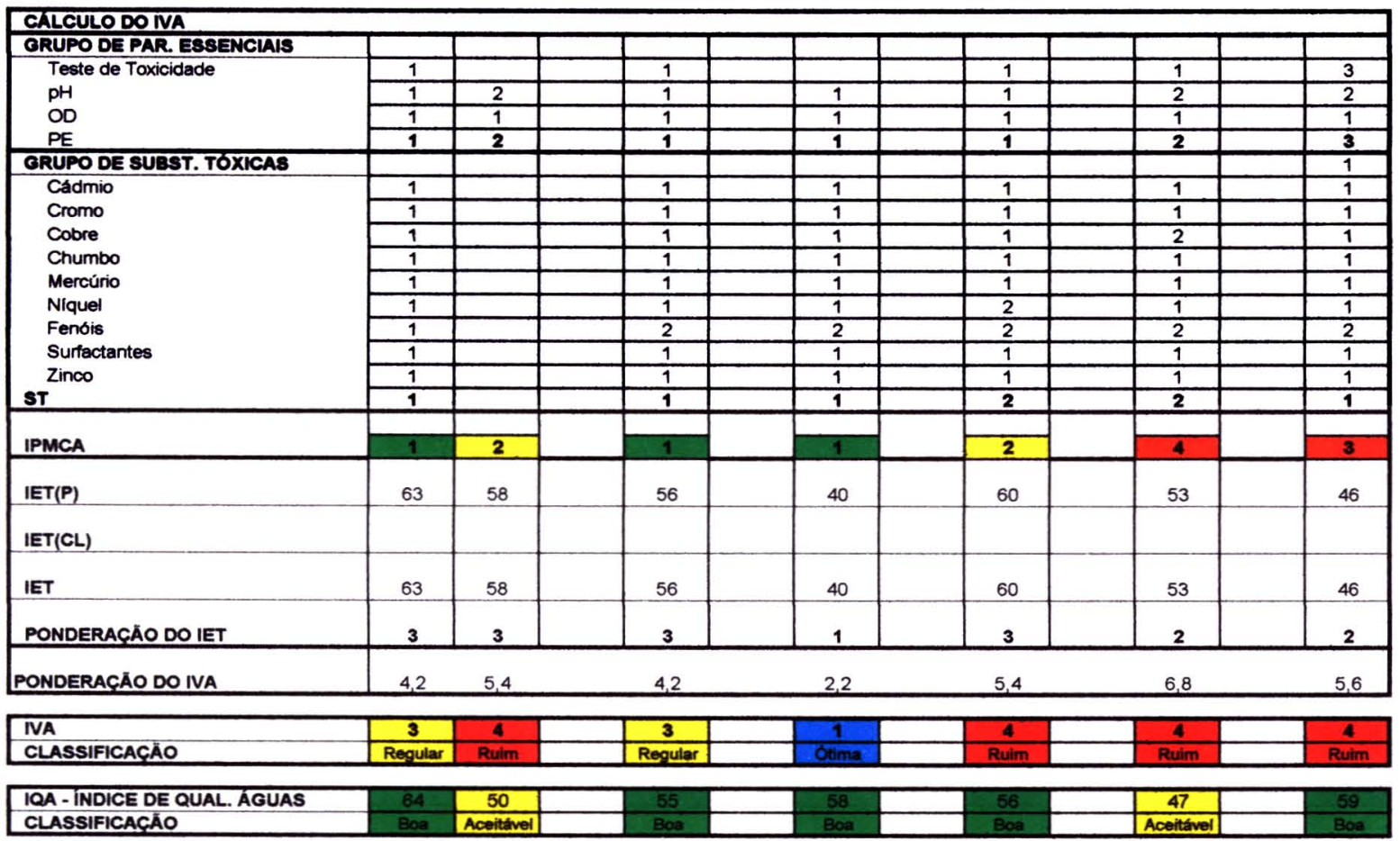


Tabela A12 - Resultados dos parâmetros analisados pela Rede de Monitoramento e cálculo do IVA no ponto CUBA 03900, no ano de 2000.

\section{ANO: 2000}

PONTO dE COLETA: RIO CUBATÃO, PONTE DA ESTRADA DE FERRO SANTOS - JUNDIAÍ, 1,5 Km A JUSANTE DA CONFL. DO RIO PEREQUE COM O RIO CUBATÃO

CODIGO DO PONTO DE COLETA: CUBA 03900

CLASSE: 3

\begin{tabular}{|c|c|c|c|c|c|c|c|c|c|c|c|c|}
\hline DADOS DE QUALIDADE & Jan & Fov & Mar & $\overline{A b r}$ & Mai & Jun & JuI & Ano & set & Out & Nov & Dez \\
\hline & & & & & & & & & & & & \\
\hline CHUVAS (ûtimas 24 horas) & & Sim & & Năo & & Năo & & Nao & & Nao & & Nâo \\
\hline COLORACAO DAS AGUAS & & Jermelha & & Verde & & Tuna & & Verde & & Turva & & Verde \\
\hline
\end{tabular}

\section{PARAMETROS FISICOQQUIMICOS}

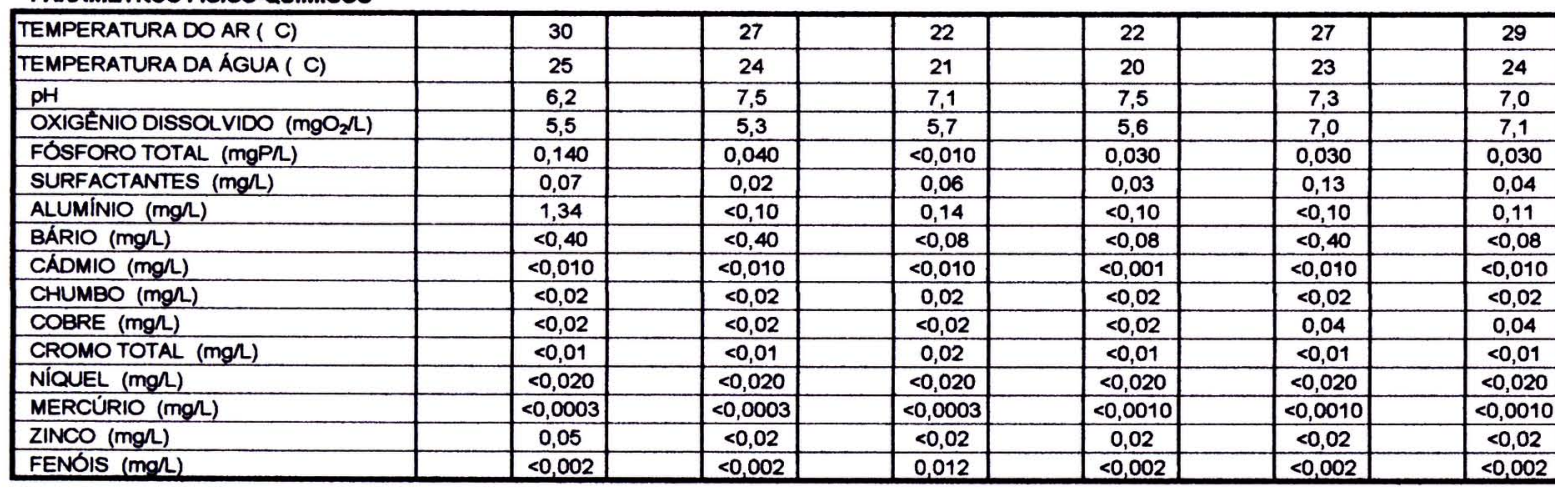

PARAMETROS HIDROBIOLOOOICOS

CLOROFILA G (HQL)

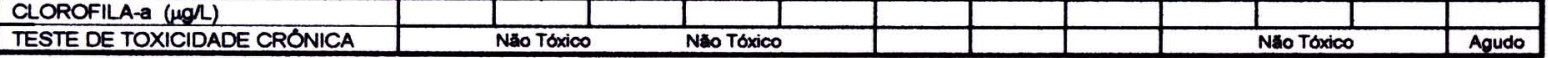

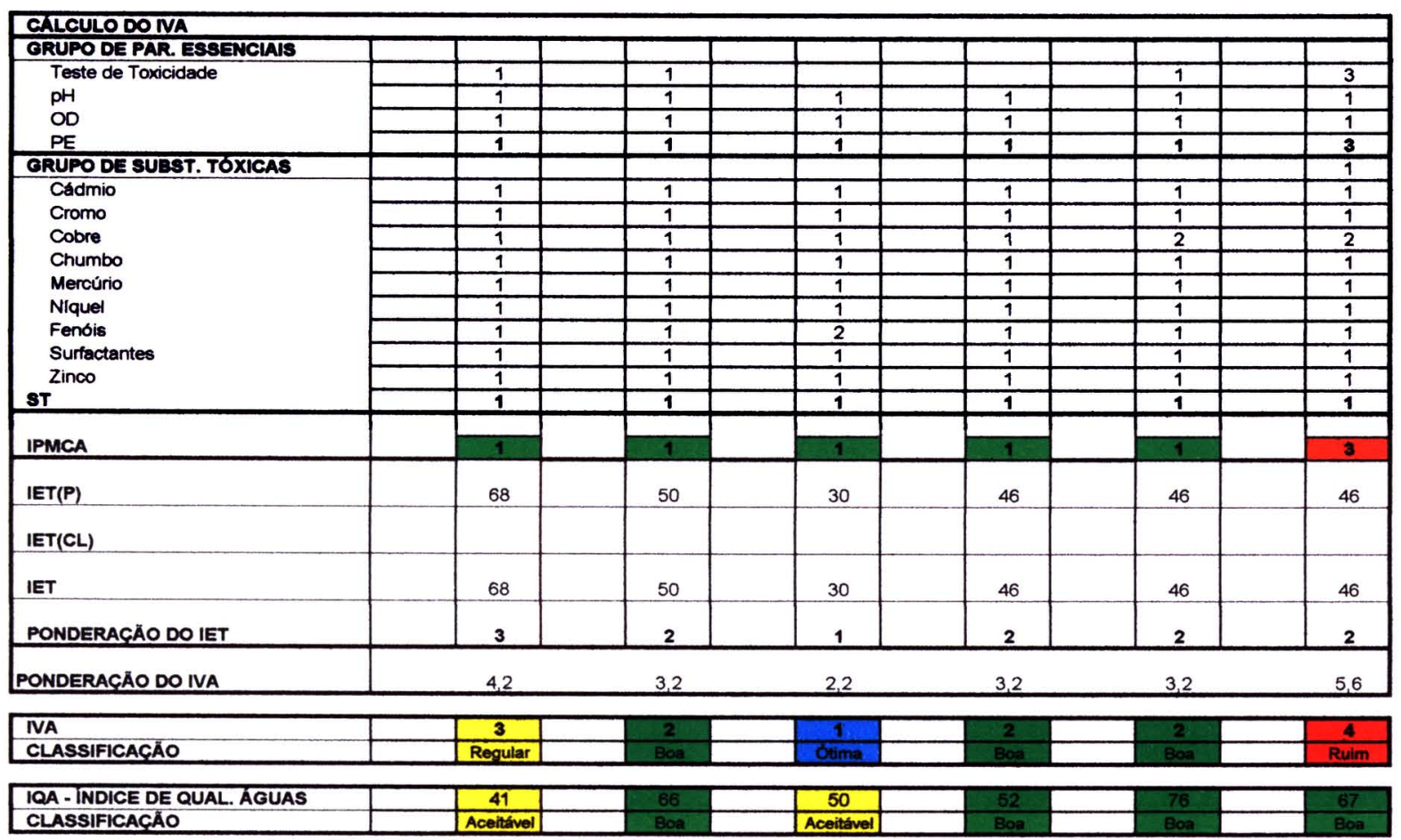


Tabela A13 - Resultados dos parâmetros analisados pela Rede de Monitoramento e cálculo do IVA no ponto CFUG02900, no ano de 1995.

\section{ANO: 1995}

PONTO dE COLETA: CANAL DE FUGA 2, USINA HIDRELÉTRICA HENRY BORDEN, NA SAIDA DA TURBINA DA USINA EXTERNA. CODIGO DO PONTO DE COLETA: CFUG02900

CLASSE: 2

\begin{tabular}{|c|c|c|c|c|c|c|c|c|c|c|c|c|}
\hline DADOS DE QUALIDADE & Jan & Fev & Mar & $\overline{\mathrm{Abr}}$ & Mai & Jun & JuI & Ago & Set & Out & Nov & Dez \\
\hline CHUVAS (últimas 2 & Sim & Sim & Sim & Năo & Sim & Năo & Nao & Nao & sim & Sim & Sim & Nao \\
\hline COLORACAOO DAS ÁGUAS & Verde & Limpida & Tuna & Verde & Limpida & Verde & Turva & Limpida & Verde & Verde & Tuna & Verde \\
\hline
\end{tabular}

\section{PARÂMETROS FISICO-QUimicos}

\begin{tabular}{|c|c|c|c|c|c|c|c|c|c|c|c|c|}
\hline TEMPERATURA DO AR ( C) & 29 & 30 & 26 & 26 & 26 & 23 & 21 & 20 & 24 & 25 & 30 & 27 \\
\hline TEMPERATURA DA ÁGUA ( C) & 24 & 25 & 24 & 21 & 24 & 19 & 16 & 18 & 20 & 20 & 22 & 21 \\
\hline $\mathrm{pH}$ & 7,0 & 6,0 & 5,4 & 7,0 & 6,3 & 6,8 & 6,8 & 6,7 & 7,0 & 7,6 & 7,5 & 6,0 \\
\hline OXIGÉNIO DISSOLVIDO (mgO & 8,0 & 8,0 & 8,0 & 7,7 & 8,0 & 9,0 & 8,9 & 8,6 & 8,5 & 9,0 & 9,1 & 8,7 \\
\hline FOSFORO TOTAL (mgPR) & 0,225 & 0,050 & 0,050 & 0,035 & 0,025 & 0,010 & 0,039 & 0,160 & 0,325 & 0,036 & 0,030 & 0,100 \\
\hline SURFACTANTES (mgl) & 0,04 & & 0,05 & & 0,04 & & 0,12 & & 0,07 & & 0,03 & \\
\hline \multicolumn{13}{|l|}{ ALUMINIO (mg/l) } \\
\hline BÁRIO (mgl) & $<0,02$ & & $<0,02$ & & $<0,02$ & & 0,09 & & $<0,02$ & & $<0,02$ & \\
\hline CÁDMIO (mg/L) & $<0,001$ & & $<0,001$ & & $<0,001$ & & $<0,001$ & & $<0,001$ & & 0,010 & \\
\hline CHUMBO (mgl) & $<0,05$ & & $<0,05$ & & $<0,05$ & & $<0,05$ & & $<0,05$ & & $<0,05$ & \\
\hline COBRE (mg/L) & $<0,002$ & & $<0,002$ & & 0,01 & & $<0,004$ & & $<0,004$ & & 0,07 & \\
\hline CROMO TOTAL (mg/l) & $<0,05$ & & $<0,05$ & & $<0,05$ & & $<0,05$ & & $<0,05$ & & $<0,05$ & \\
\hline NIQQUEL (mg/l) & 0,01 & & 0,010 & & 0,020 & & $<0,01$ & & $<0,01$ & & 0,020 & \\
\hline MERCÚRIO (mg/L) & & & & & & & & & & & 0,0001 & \\
\hline ZINCO (mg/L) & 0,01 & & $<0,001$ & & 0,004 & & 0,04 & & $<0,01$ & & $<0,01$ & \\
\hline FENÓIS (mgll) & $<0,001$ & & 0,001 & & $<0,001$ & & 0,001 & & 0,005 & & $<0,001$ & \\
\hline
\end{tabular}

FENOIS (mg/L)

PARAMETROS HIDROBIOLOGICOS

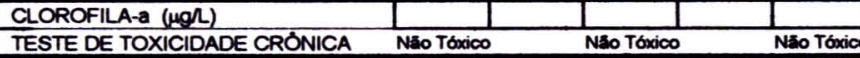

\begin{tabular}{|l|l|l|l|l|l|}
\hline CLOROFILA-a $(\mu \mathrm{g} / \mathrm{l})$ & & & & & \\
\hline TESTE DE TOXICIDADE CRÓNICA Náo Tóxico & Nåo Tóxico & Näo Tóxico \\
\hline
\end{tabular}

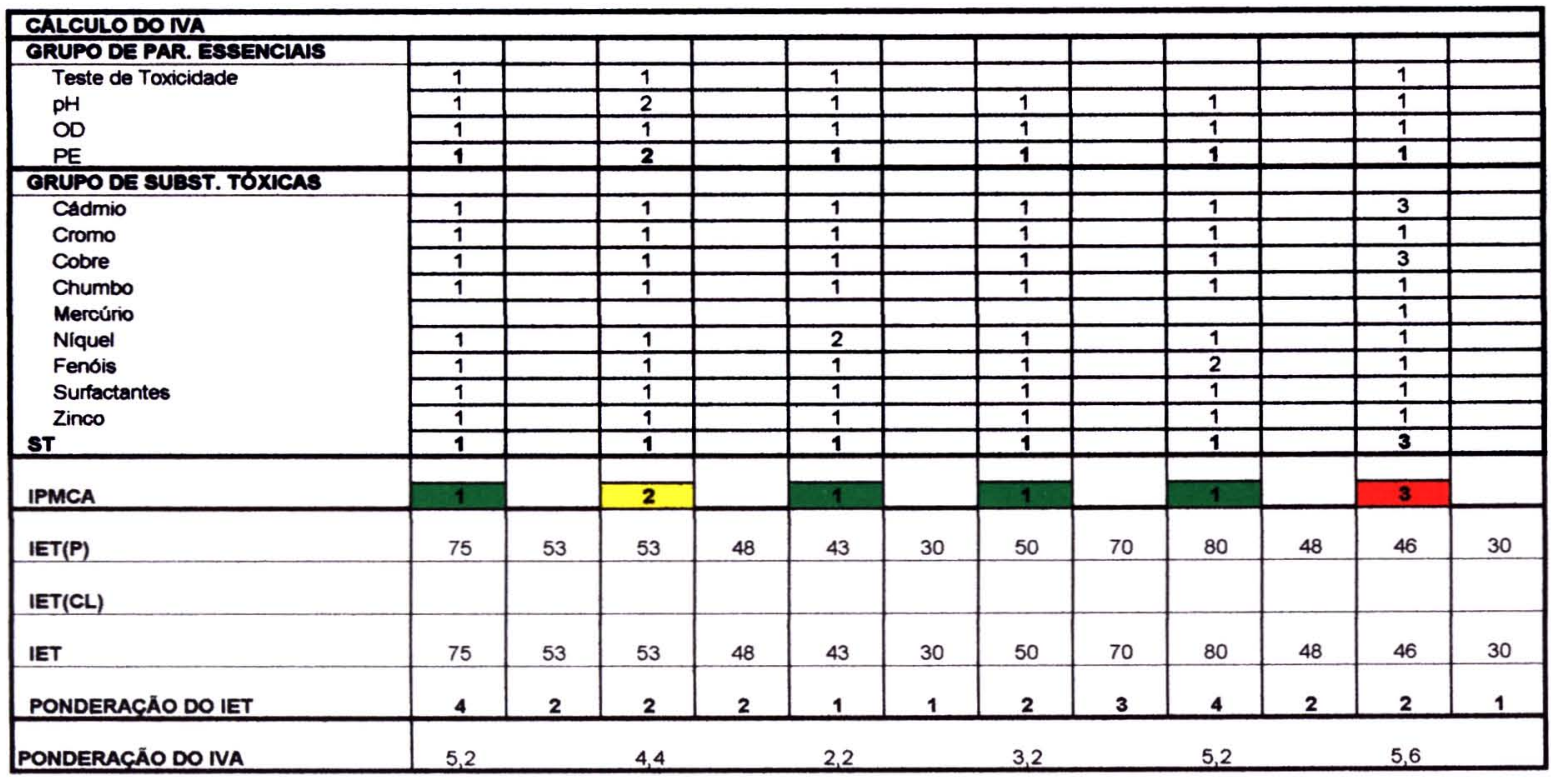

\begin{tabular}{|c|c|c|c|c|c|c|}
\hline IVA & $\overline{4}$ & $\overline{3}$ & 1 & 2 & 4 & 4 \\
\hline CLASSIFICAC,ĀO & Ruim & Reqular & Otima & Boa & Ruim & Ruim \\
\hline
\end{tabular}

IQA - INDICE DE QUAL. AGUAS

CLASSIFICACĀO 
Tabela A14 - Resultados dos parâmetros analisados pela Rede de Monitoramento e cálculo do IVA no ponto CFUG02900, no ano de 1996.

ANO: 1996

PONTO DE COLETA: CANAL DE FUgA 2, USINAHIDRELATRICA HENRY BORDEN, NA SAIDA DA TURBINA DA USINA EXTERNA. CODIGO DO PONTO DE COLETA: CFUC02900

CLASSE: 2

\begin{tabular}{|c|c|c|c|c|c|c|c|c|c|c|c|c|}
\hline DADOS DE QUALIDADE & Jan & Fev & Mar & Abr & Mal & Jun & Jul & A90 & Set & Out & Nov & Dez \\
\hline \multicolumn{13}{|l|}{ INFORMACÕES DE CAMPO } \\
\hline CHUVAS (últimas 24 horas) & Nåo & Sim & Sim & Sim & Nao & Năo & Năo & Nao & Sim & Sim & Sim & Nâo \\
\hline TEMPERATURA DO AR ( C) & 28 & 30 & 28 & 26 & 27 & 18 & 24 & 24 & 21 & 25 & 24 & 25 \\
\hline TEMPERATURA DA AGUA ( C) & 22 & 23 & 23 & 21 & 23 & 19 & 19 & 19 & 20 & 23 & 22 & 22 \\
\hline $\mathrm{pH}$ & 7,0 & 6,0 & 6,0 & 6,0 & 7,3 & 7,2 & 7,0 & 6,3 & 6,1 & 7,7 & 7,3 & 6,4 \\
\hline OXIGÉNIO DISSOLVIDO (mgO2/L) & 8,4 & 8,7 & 8,5 & 9,4 & 10,0 & 10,0 & 9,6 & 10,4 & 9,7 & 9,7 & 9,8 & 9,5 \\
\hline FÓSFORO TOTAL (mgPR) & 0,070 & 0,030 & 0,030 & 0,030 & 0,030 & 0,050 & 0,030 & 0,030 & 0,020 & 0,030 & 0,060 & 0,050 \\
\hline SURFACTANTES (mg/L) & 0,06 & & 0,09 & & $<0,02$ & & 0,04 & & 0,06 & & 0,07 & \\
\hline \multicolumn{13}{|l|}{ ALUMINIO (mgll) } \\
\hline BARIO (mg/l) & $<0,02$ & & $<0,02$ & & $<0,02$ & & $<0,02$ & & $<0,08$ & & $<0,08$ & \\
\hline CÁDMIO (mg/) & $<0,001$ & & $<0,001$ & & 0,002 & & $<0,001$ & & 0,004 & & $<0.001$ & \\
\hline CHUMBO (mgl) & $<0,05$ & & $<0,05$ & & $<0,05$ & & $<0,05$ & & $<0,05$ & & $<0,05$ & \\
\hline COBRE (mg/) & $<0,004$ & & 0,01 & & $<0,004$ & & 0,016 & & $<0,004$ & & $<0,004$ & \\
\hline CROMO TOTAL (mgll) & $<0,05$ & & $<0,05$ & & $<0,05$ & & $<0,05$ & & $<0,05$ & & $<0,05$ & \\
\hline NIQUEL (mg/l) & $<0,010$ & & $<0,010$ & & 0,030 & & 0,030 & & $<0,010$ & & $<0,010$ & \\
\hline MERCÚRIO (mg/L) & 0,0004 & & $<0,0001$ & & $<0,0001$ & & 0,0001 & & 0,0001 & & $<0,0002$ & \\
\hline ZINCO (mg/l) & $<0,01$ & & $<0,04$ & & 0,05 & & $<0,01$ & & 0,03 & & $<0,01$ & \\
\hline FENOIS (mgl) & $<0,001$ & & $<0,001$ & & $<0,001$ & & $<0,001$ & & $<0,001$ & & 0,002 & \\
\hline \multicolumn{13}{|l|}{ PARAMMETROS HIDROBIOLOGICOS } \\
\hline CLOROFILA-a $(\mu g / L)$ & & & & & & & & & & & & \\
\hline TESTE DE TOXICIDADE CRÓNICA & Nấ Tóxice & & & & Nắ Tóxico & & Nằ Tóxico & & Năo Tóxica & & Năo Tóxic & \\
\hline
\end{tabular}

\begin{tabular}{|c|c|c|c|c|c|c|c|c|c|c|c|c|}
\hline \multirow{2}{*}{\multicolumn{13}{|c|}{$\begin{array}{l}\text { CALCULO DOIVA } \\
\text { GRUPO DE PAR. ESSENCIAIS }\end{array}$}} \\
\hline & & & & & & & & & & & & \\
\hline \multirow{4}{*}{$\begin{array}{l}\text { Teste de Toxicidade } \\
\text { pH } \\
\text { OD } \\
\text { PE }\end{array}$} & 1 & & & & 1 & & 1 & & 1 & & 1 & \\
\hline & 1 & & 1 & & 1 & & 1 & & 1 & & 1 & \\
\hline & 1 & & 1 & & 1 & & 1 & & 1 & & 1 & \\
\hline & 1 & & 1 & & 1 & & 1 & & 1 & & 1 & \\
\hline \multicolumn{13}{|l|}{ GRUPO DE SUBST. TOXICAS } \\
\hline \multirow{10}{*}{$\begin{array}{l}\text { Cádmio } \\
\text { Cromo } \\
\text { Cobre } \\
\text { Chumbo } \\
\text { Mercúrio } \\
\text { Niquel } \\
\text { Fenois } \\
\text { Surfactantes } \\
\text { Zinco } \\
\text { sT } \\
\end{array}$} & 1 & & 1 & & 2 & & 1 & & 2 & & 1 & \\
\hline & 1 & & 1 & & 1 & & 1 & & 1 & & 1 & \\
\hline & 1 & & 1 & & 1 & & 1 & & 1 & & 1 & \\
\hline & 1 & & 1 & & 1 & & 1 & & 1 & & 1 & \\
\hline & 2 & & 1 & & 1 & & 1 & & 1 & & 1 & \\
\hline & 1 & & 1 & & 2 & & 2 & & 1 & & 1 & \\
\hline & 1 & & 1 & & 1 & & 1 & & 1 & & 2 & \\
\hline & 1 & & 1 & & 1 & & 1 & & 1 & & 1 & \\
\hline & 1 & & 1 & & 1 & & 1 & & 1 & & 1 & \\
\hline & 1 & & 1 & & 2 & & 1 & & 1 & & 1 & \\
\hline IPMCA & 1 & & 1 & & 2 & & 1 & & 1 & & 1 & \\
\hline IET(P) & 58 & 46 & 46 & 46 & 46 & 53 & 46 & 46 & 40 & 46 & 56 & 53 \\
\hline \multicolumn{13}{|l|}{ IET(CL) } \\
\hline IET & 58 & 46 & 46 & 46 & 46 & 53 & 46 & 46 & 40 & 46 & 56 & 53 \\
\hline PONDERACÃO DO IET & 3 & 2 & 2 & 2 & 2 & 2 & 2 & 2 & 1 & 2 & 3 & 2 \\
\hline PONDERACÃO DO IVA & 4,2 & & 3,2 & & 4,4 & & 3,2 & & 2,2 & & 4,2 & \\
\hline IVA & 3 & & 2 & & 3 & & 2 & & 1 & & $\overline{3}$ & \\
\hline CLASSIFICACÃO & Reqular & & Boa & & Regular & & Boa & & Otima & & Reqular & \\
\hline IQA - INDICE DE QUAL. AGUAS & 76 & 76 & 67 & 72 & 78 & & 83 & 81 & 88 & 82 & 80 & 75 \\
\hline CLASSIFICACĀOO & Boa & $\mathrm{Boa}$ & Boa & Boa & $\mathrm{Boa}$ & & Otima & Otima & Otima & Ótima & Dotima & $\mathrm{Boa}$ \\
\hline
\end{tabular}


Tabela A15 - Resultados dos parâmetros analisados pela Rede de Monitoramento e cálculo do IVA no ponto CFUG02900, no ano de 1997.

ANO: 1997

PONTO DE COLETA: CANAL DE FUGA 2, USINA HIDRELÉTRICA HENRY BORDEN, NA SAÍDA DA TURBINA DA USINA EXTERNA

CÓDICO DO PONTO DE COLETA: CFUG02900

CLASSE: 2

\begin{tabular}{|c|c|c|c|c|c|c|c|c|c|c|c|c|}
\hline DADOS DE QUALIDADE & $\operatorname{Jan}$ & Fev & Mar & $\mathrm{Abr}$ & Mal & Jun & Jul & Ano & Set & Out & Nov & Dez \\
\hline AMP & & & & & & & & & & & & \\
\hline CHUVAS (ültimas 24 horas) & Näo & Nåo & Nao & Sim & Nâo & Sim & Nao & Sim & Nao & Sim & Năo & Năo \\
\hline COLORACAO DAS ÁGUAS & Verde & Turva & Verde & Preta & Turva & Tuna & Preta & Verde & Tuna & Preta & Tuma & Verde \\
\hline
\end{tabular}

\begin{tabular}{|c|c|c|c|c|c|c|c|c|c|c|c|c|}
\hline TEMPERATURA DO AR ( C) & 26 & 27 & 29 & 25 & 30 & 23 & 25 & 26 & 28 & 23 & 26 & 26 \\
\hline TEMPERATURA DA ÁGUA ( C) & 22 & 24 & 23 & 23 & 22 & 20 & 19 & 21 & 21 & 21 & 21 & 22 \\
\hline $\mathrm{pH}$ & 6,8 & 6,9 & 7,0 & 5,0 & 6,5 & 6,7 & 6,5 & 5,5 & 7,6 & 6,5 & 7,2 & 6,5 \\
\hline OXIGENIO DISSOLVIDO $\left(\mathrm{mgO}_{2} \mathrm{~h}\right)$ & 8,7 & 9,8 & 8,4 & 8,4 & 8,8 & 7,0 & 7,8 & 10,7 & 7,3 & 5,9 & 7,8 & 6,6 \\
\hline FOSSFORO TOTAL (mgPR) & 0,030 & 0,010 & 0,020 & 0,060 & $<0,010$ & 0,040 & 0,040 & 0,050 & 0,020 & 0,020 & 0,090 & 0,040 \\
\hline SURFACTANTES (mgl) & 0,07 & & 0,02 & & $<0,02$ & & 0,05 & & 0,04 & & $<0,02$ & \\
\hline \multicolumn{13}{|l|}{ ALUMINIO (mg/) } \\
\hline BÁRIO (mgll) & $<0,08$ & & $<0,08$ & $<0,08$ & $<0,08$ & $<0,08$ & $<0,08$ & $<0,08$ & $<0,08$ & $<0,08$ & $<0,08$ & $<0,08$ \\
\hline CADMIO (mg/L) & $<0,001$ & & $<0,001$ & $<0,001$ & $<0,001$ & $<0,001$ & $<0,001$ & $<0,001$ & $<0,001$ & $<0,001$ & $<0,001$ & 0,008 \\
\hline CHUMBO (mgl) & $<0,05$ & & $<0,05$ & $<0,05$ & $<0,05$ & $<0,002$ & $<0,05$ & 0,003 & $<0,05$ & $<0,002$ & $<0,002$ & $<0,002$ \\
\hline COBRE (mg/l) & 0,01 & & $<0,004$ & 0,004 & 0,004 & $<0,004$ & $<0,004$ & $<0,004$ & $<0,004$ & $<0,004$ & $<0,004$ & $<0,004$ \\
\hline CROMO TOTAL (mgl) & $<0,05$ & & $<0,05$ & 0,002 & 0,002 & $<0,0005$ & $<0,05$ & $<0,0005$ & $<0,05$ & $<0,05$ & $<0,05$ & $<0,05$ \\
\hline NIQUEL (mgl) & $<0,010$ & & $<0,010$ & $<0,010$ & $<0,010$ & $<0,010$ & $<0,010$ & $<0,010$ & $<0,010$ & $<0,010$ & 0,020 & $<0,010$ \\
\hline MERCÚRIO (mg/) & $<0,0002$ & & $<0,0002$ & $<0,0002$ & $<0,0002$ & $<0,0001$ & $<0,0002$ & $<0,0001$ & 0,0001 & $<0,0001$ & $<0,0002$ & $<0,0001$ \\
\hline ZINCO (mg/L) & 0,01 & & $<0,01$ & $<0,01$ & 0,12 & $<0,01$ & $<0,01$ & $<0,01$ & $<0,01$ & 0,01 & 0,04 & 0,02 \\
\hline FENÓIS (mgl) & $<0,001$ & & $<0,001$ & & $<0,001$ & & $<0,001$ & & 0,004 & & $<0,001$ & $<0,001$ \\
\hline \multicolumn{13}{|l|}{ PARAMETROS HIDROBIOLOOOICOS } \\
\hline \multicolumn{13}{|l|}{ CLOROFILA-a $(\mu \mathrm{g} / \mathrm{L})$} \\
\hline TESTE DE TOXICIDADE CRÓNICA & Agudo & & Crónico & Nâo Tóxica & Năo Tóxica & Crónico & Nầ Tóxice & NGo Toxiced & Cronico & Näo Tóxice & Crónico & NEso Tóxico \\
\hline
\end{tabular}

\begin{tabular}{|c|c|c|c|c|c|c|c|c|c|c|c|c|}
\hline \multirow{2}{*}{\multicolumn{13}{|c|}{$\begin{array}{l}\text { CALCULO DOIVA } \\
\text { GRUPO DE PAR. ESSENCIAIS }\end{array}$}} \\
\hline & & & & & & & & & & & & \\
\hline \multirow{4}{*}{$\begin{array}{l}\text { Teste de Toxicidade } \\
\text { PH } \\
\text { OD } \\
\text { PE }\end{array}$} & 1 & & 2 & 1 & 1 & 2 & 1 & 1 & 2 & 1 & 2 & 1 \\
\hline & 3 & & 1 & 1 & 1 & 1 & 1 & 2 & 1 & 1 & 1 & 1 \\
\hline & 1 & & 1 & 1 & 1 & 1 & 1 & 1 & 1 & 1 & 1 & 1 \\
\hline & 3 & & 2 & 1 & 1 & 2 & 1 & 2 & 2 & 1 & 2 & 1 \\
\hline \multicolumn{13}{|c|}{ GRUPO DE SUBST. TOXICAS } \\
\hline \multirow{10}{*}{$\begin{array}{l}\text { Cadmio } \\
\text { Cromo } \\
\text { Cobre } \\
\text { Chumbo } \\
\text { Mercúrio } \\
\text { Niquel } \\
\text { Fenois } \\
\text { Surfactantes } \\
\text { Zinco } \\
\text { st }\end{array}$} & 1 & & 1 & 1 & 1 & 1 & 1 & 1 & 1 & 1 & 1 & 3 \\
\hline & 1 & & 1 & 1 & 9 & 1 & 1 & 1 & 1 & 1 & 1 & 1 \\
\hline & 1 & & 1 & 1 & 1 & 1 & 1 & 9 & 1 & 9 & 1 & 1 \\
\hline & 1 & & 9 & 1 & 9 & 1 & 1 & 1 & 1 & 1 & 1 & 1 \\
\hline & 1 & & 1 & 1 & 1 & 1 & 1 & 1 & 1 & 1 & 1 & 1 \\
\hline & 1 & & 1 & 1 & 1 & 1 & 1 & 1 & 1 & 1 & 1 & 1 \\
\hline & 1 & & 1 & & 9 & & 1 & & 2 & & 1 & 1 \\
\hline & 9 & & 9 & & 1 & & $\frac{1}{1}$ & & 1 & & 1 & \\
\hline & 1 & & 1 & 1 & 1 & 1 & 1 & 1 & 1 & 1 & 1 & 1 \\
\hline & 1 & & 1 & 1 & 1 & 1 & 1 & 1 & 1 & 1 & 1 & 2 \\
\hline IPMCA & 3 & & 2 & 1 & 1 & 2 & 1 & 2 & 2 & 1 & 2 & 2 \\
\hline IET(P) & 46 & 30 & 40 & 56 & 30 & 50 & 50 & 53 & 40 & 40 & 62 & 50 \\
\hline \multicolumn{13}{|l|}{ IET(CL) } \\
\hline IET & 46 & 30 & 40 & 56 & 30 & 50 & 50 & 53 & 40 & 40 & 62 & 50 \\
\hline PONDERAÇÃO DO IET & 2 & 1 & 1 & 3 & 1 & 2 & 2 & 2 & 1 & 1 & 3 & 2 \\
\hline PONDERACÃO DO IVA & 5,6 & & 3,4 & 4,2 & 2,2 & 4,4 & 3,2 & 4,4 & 3,4 & 2,2 & 5,4 & 4,4 \\
\hline
\end{tabular}

\begin{tabular}{|l|c|c|c|c|c|c|c|c|c|c|c|}
\hline IVA & 3 & 3 \\
CLASSIFICACAOAO & 4 & & 3 & 3 & 3 \\
\hline
\end{tabular}

IQA - INDICE DE QUAL. AGUAS

CLASSIFICACÃO 
Tabela A16 - Resultados dos parâmetros analisados pela Rede de Monitoramento e cálculo do IVA no ponto CFUG02900, no ano de 1998.

ANO: 1998

PONTO DE COLETA: CANAL DE FUGA 2, USINA HIDRELÉTRICA HENRY BORDEN, NA SAIDA DA TURBINA DA USINA EXTERNA. CÓDIGO DO PONTO DE COLETA: CFUG02900

CLASSE: 2

\begin{tabular}{|c|c|c|c|c|c|c|c|c|c|c|c|c|}
\hline DADOS DE QUALIDADE & Jan & Fev & Mar & Abr & Mal & Jun & Jul & Ano & Set & Out & Nov & Dez \\
\hline INFORMACOES DE CAMPO & & & & & & & & & & & & \\
\hline $\begin{array}{l}\text { CHUVAS (últimas } 24 \text { horas) } \\
\text { COLORAÇAO DAS AGUAS }\end{array}$ & $\begin{array}{l}\text { Năo } \\
\text { Verde }\end{array}$ & $\begin{array}{l}\text { Năo } \\
\text { Turva }\end{array}$ & Sim & $\frac{\text { Náo }}{\text { Turva }}$ & $\frac{\text { Sim }}{\text { Turva }}$ & Nao & $\begin{array}{l}\text { Năo } \\
\text { Verde }\end{array}$ & Náo & $\begin{array}{l}\text { Sim } \\
\text { Verde }\end{array}$ & $\begin{array}{c}\text { Sim } \\
\text { Verde }\end{array}$ & Nao & Nao \\
\hline
\end{tabular}

\begin{tabular}{|c|c|c|c|c|c|c|c|c|c|c|c|c|}
\hline TEMPERATURA DO AR ( C) & 31 & 33 & 34 & 28 & 21 & 26 & 26 & 21 & 23 & 21 & 25 & 26 \\
\hline TEMPERATURA DA ÁGUA ( C) & 26 & 27 & 26 & 22 & 21 & 24 & 22 & 19 & 19 & 19 & 21 & 22 \\
\hline $\mathrm{pH}$ & 6,0 & 6,9 & 5,4 & 7,1 & 7,5 & 6,5 & 6,5 & 8,1 & 6,4 & 6,6 & 6,5 & 5,5 \\
\hline OXIGÉNIO DISSOLVIDO (mgO & 6,4 & 6,1 & 4,1 & 6,1 & 6,8 & 6,8 & 5,7 & 5,9 & 7,2 & 6,5 & 6,0 & 5,1 \\
\hline FÓSFORO TOTAL (mgPR) & 0,050 & $<0,020$ & 0,030 & 0,360 & 0,030 & 0,030 & 0,020 & 0,070 & 0,050 & 0,040 & 0,050 & 0,030 \\
\hline SURFACTANTES (mgll) & $<0,02$ & & $<0,04$ & $<0,04$ & $<0,04$ & $<0,04$ & $<0,04$ & $<0,04$ & 0,05 & 0,05 & 0,05 & 0,04 \\
\hline ALUMINIO (mg/L) & $<0,10$ & $<0,10$ & $<0,10$ & & $<0,10$ & & 0,28 & & 0,12 & & 0,15 & \\
\hline BÁRIO (mg $/)$ & $<0,08$ & & & & & & & & $<0,08$ & & $<0,08$ & \\
\hline CÁDMIO (mg/L) & 0,002 & $<0,01$ & $<0,01$ & & $<0,01$ & & $<0,01$ & & $<0,01$ & & $<0,01$ & \\
\hline CHUMBO (mgl) & $<0,05$ & $<0,02$ & $<0,02$ & & 0,09 & & 0,03 & & $<0,02$ & & 0,02 & \\
\hline COBRE (mg/L) & $<0,004$ & 0,03 & $<0,02$ & & $<0,02$ & & 0,02 & & $<0,02$ & & $<0,02$ & \\
\hline CROMO TOTAL (mg/L) & $<0,05$ & $<0,01$ & $<0,01$ & & $<0,01$ & & $<0,01$ & & 0,02 & & $<0,01$ & \\
\hline NIQUEL (mg/l) & $<0,010$ & $<0,020$ & $<0,020$ & & $<0,020$ & & $<0,020$ & & $<0,020$ & & $<0,020$ & \\
\hline MERCÚRIO (mgl) & $<0,0001$ & $<0,0001$ & $<0,0001$ & & 0,1200 & & $<0,0002$ & & $<0,0002$ & & 0,0010 & \\
\hline ZINCO (mg/L) & $<0,01$ & 0,04 & $<0,03$ & & $<0,01$ & & $<0,01$ & & 0,01 & & 0,01 & \\
\hline FENÓIS (mg/L) & 0,001 & & 0,005 & & $<0,001$ & & $<0,001$ & & $<0,001$ & & 0.003 & \\
\hline \multicolumn{13}{|l|}{ PARAMETROS HIDROBIOLOOGICOS } \\
\hline \multicolumn{13}{|l|}{ CLOROFILA-a $(\mu g /)$} \\
\hline TESTE DE TOXICIDADE CRÓNICA & Nấ Toxico & & & & Crónico & & Crónico & & Crónico & & Crónico & \\
\hline
\end{tabular}

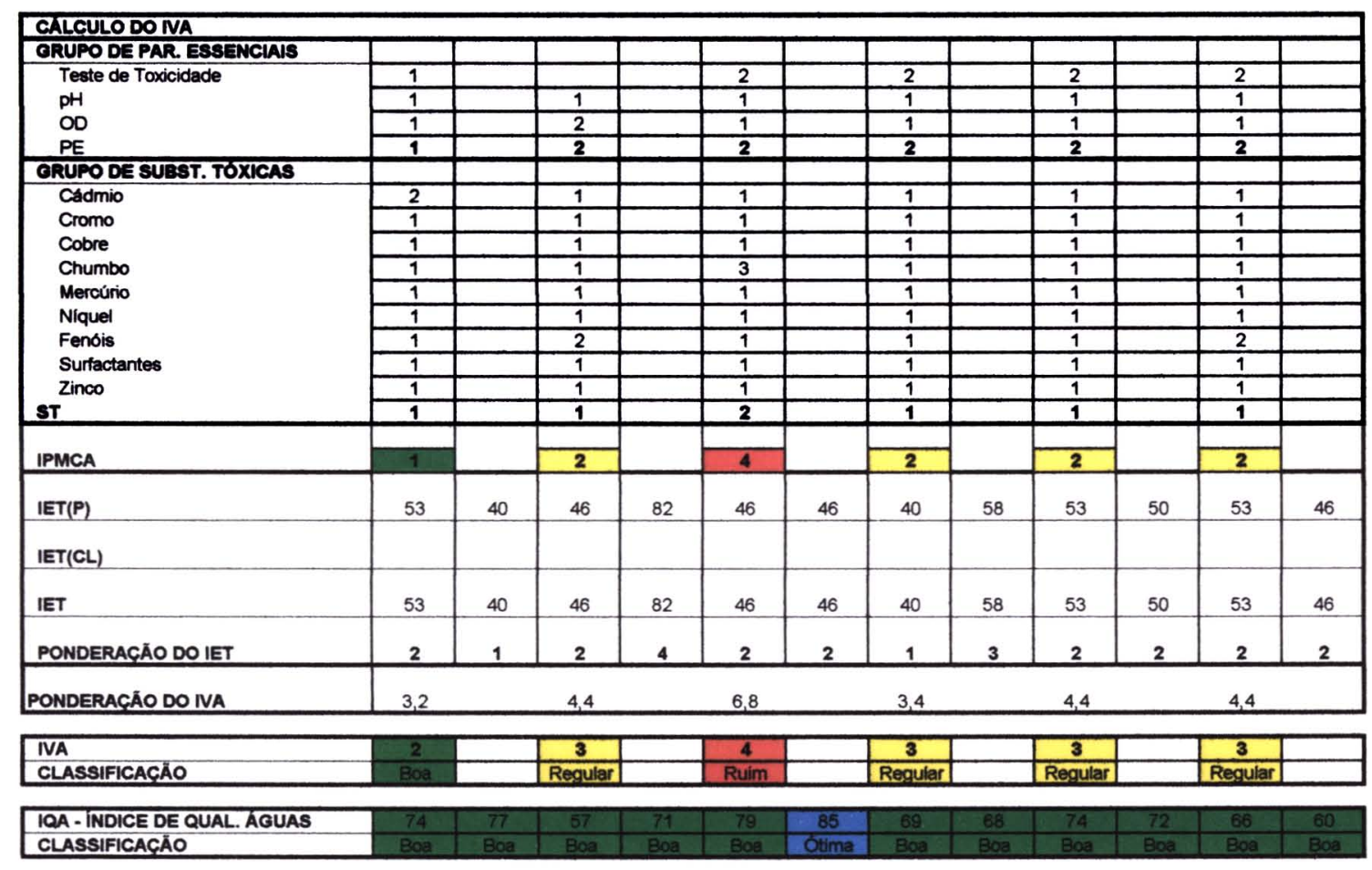


Tabela A17 - Resultados dos parâmetros analisados pela Rede de Monitoramento e cálculo do IVA no ponto CFUG02900, no ano de 1999.

\section{ANO: 1999}

PONTO DE COLETA: CANAL DE FUGA 2, USINA HIDRELÉTRICA HENRY BORDEN, NA SAIDA DA TURBINA DA USINA EXTERNA CÓDIGO DO PONTO DE COLETA: CFUC02900

CLASSE: 2

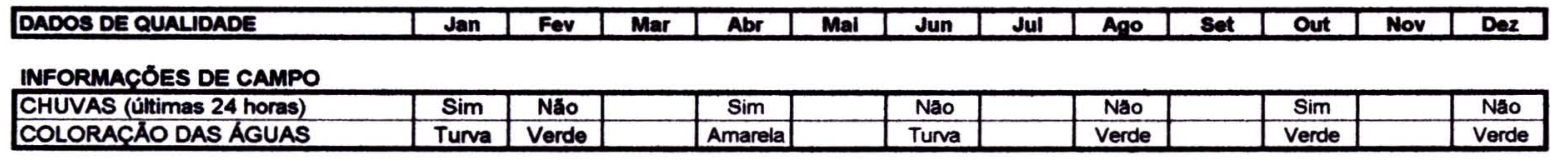

\begin{tabular}{|c|c|c|c|c|c|c|c|}
\hline TEMPERATURA DO AR ( C) & 27 & 29 & 25 & 20 & 25 & 23 & 30 \\
\hline $\mathrm{pH}$ & 6,6 & 6,0 & 6,7 & 7,0 & 6,0 & 7,0 & 5,5 \\
\hline FÓSFORO TOTAL (mgPR) & 0,050 & 0,040 & 0,030 & 0,120 & 0,060 & 0,040 & 0,020 \\
\hline SURFACTANTES (mg/l) & 0,04 & 0,06 & $<0,04$ & $<0,04$ & 0,07 & $<0,04$ & 0,04 \\
\hline ALUMINIO (mg/L) & 0,10 & 0,07 & $<0,06$ & 0,10 & 0,16 & $<0,10$ & 0,22 \\
\hline BÁRIO (mg/) & $<0,08$ & & $<0,40$ & $<0,40$ & $<0,40$ & $<0,40$ & $<0,40$ \\
\hline COBRE (mg/l) & $<0,02$ & & $<0,02$ & $<0,01$ & $<0,02$ & 0,03 & $<0,02$ \\
\hline CROMO TOTAL (mgl) & 0,01 & & $<0,02$ & $<0,02$ & $<0,02$ & 0,01 & 0,02 \\
\hline NIOUEL (mg/L) & $<0,020$ & & $<0,040$ & 0,040 & 0,040 & $<0,020$ & 0,020 \\
\hline MERCÚRIO (mg/l) & $<0,0002$ & & $<0,0003$ & $<0,0002$ & $<0,0002$ & $<0,00002$ & $<0,0003$ \\
\hline ZINCO (mg/L) & 0,29 & & $<0,03$ & $<0,03$ & $<0,03$ & 0,04 & 0,02 \\
\hline FENÓIS (mg/L) & $<0,002$ & & $<0,002$ & 0,003 & $<0,002$ & $<0,002$ & 0,004 \\
\hline
\end{tabular}

\begin{tabular}{|c|c|c|c|c|c|c|c|}
\hline \multirow{2}{*}{\multicolumn{8}{|c|}{$\begin{array}{l}\text { CALCULODOIVA } \\
\text { GRUPO DEPAR. ESSEMCIAIS }\end{array}$}} \\
\hline & & & & & & & \\
\hline \multirow{4}{*}{$\begin{array}{l}\text { Teste de Toxicidade } \\
\text { pH } \\
\text { OD } \\
\text { PE }\end{array}$} & 1 & & 3 & & 1 & 2 & 3 \\
\hline & 1 & 1 & 1 & 1 & 9 & 1 & 2 \\
\hline & 1 & 1 & 1 & 1 & 9 & 1 & 1 \\
\hline & 1 & 1 & 3 & 1 & 1 & 2 & 3 \\
\hline \multicolumn{8}{|l|}{ GRUPO DE SUBST. TOXICAS } \\
\hline \multirow{10}{*}{$\begin{array}{l}\text { Cádmio } \\
\text { Cromo } \\
\text { Cobre } \\
\text { Chumbo } \\
\text { Mercúrio } \\
\text { Niquel } \\
\text { Fendis } \\
\text { Surfactantes } \\
\text { Zinco } \\
\text { sT }\end{array}$} & 1 & & 1 & 1 & 1 & 1 & 1 \\
\hline & 1 & & 1 & 1 & 1 & 1 & 1 \\
\hline & 9 & & 1 & 1 & 1 & 2 & 1 \\
\hline & 1 & & 1 & 1 & 1 & 1 & 1 \\
\hline & 1 & & 1 & 1 & 1 & 1 & 1 \\
\hline & 1 & & 1 & 2 & 9 & 1 & 1 \\
\hline & 1 & & 1 & 2 & 2 & 1 & 2 \\
\hline & 1 & & 1 & 9 & 9 & 1 & 1 \\
\hline & 2 & & 1 & 1 & 1 & 1 & 1 \\
\hline & 1 & & 1 & 2 & 1 & 1 & 1 \\
\hline IPMCA & 1 & 1 & $\frac{3}{3}$ & 2 & 1 & 2 & $\sqrt{3}$ \\
\hline IET(P) & 53 & 50 & 46 & 66 & 56 & 50 & 40 \\
\hline \multicolumn{8}{|l|}{ IET(CL) } \\
\hline IET & 53 & 50 & 46 & 66 & 56 & 50 & 40 \\
\hline PONDERAÇÁO DO IET & 2 & 2 & 2 & 3 & 3 & 2 & 1 \\
\hline PONDERACĀO DO IVA & 3.2 & 3,2 & 5,6 & 5,4 & 4,2 & 4,4 & 4,6 \\
\hline IVA & 2 & 2 & 4 & $\frac{\pi}{4}$ & $\overline{3}$ & 3 & $\frac{4}{4}$ \\
\hline CLASSIFICACĀO & Boa & Boa & Ruim & Ruim & Reqular & Regular & Ruim \\
\hline IQA - INDICE DE QUAL. ÁGUAS & 79 & 71 & 76 & 82 & 72 & 63 & 80 \\
\hline CLASSIFICAC̨ĀO & Boa & Boa & Baa & Olima & $B 00$ & Boa & Otima \\
\hline
\end{tabular}


Tabela A18 - Resultados dos parâmetros analisados pela Rede de Monitoramento e cálculo do IVA no ponto CFUG02900, no ano de 2000.

\section{ANO: $\mathbf{2 0 0 0}$}

PONTO dE COLETA: CANAL DE FUGA 2, USINA HIDRELÉTRICA HENRY BORDEN, NA SAIDA DA TURBINA DA USINA EXTERNA.

CODICO DO PONTO DE COLETA: CFUG02900

CLASSE: 2

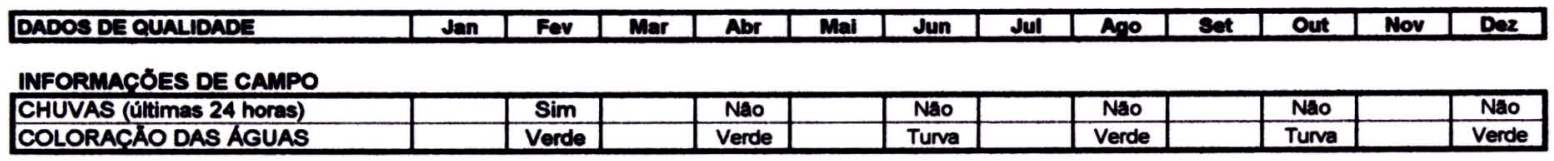

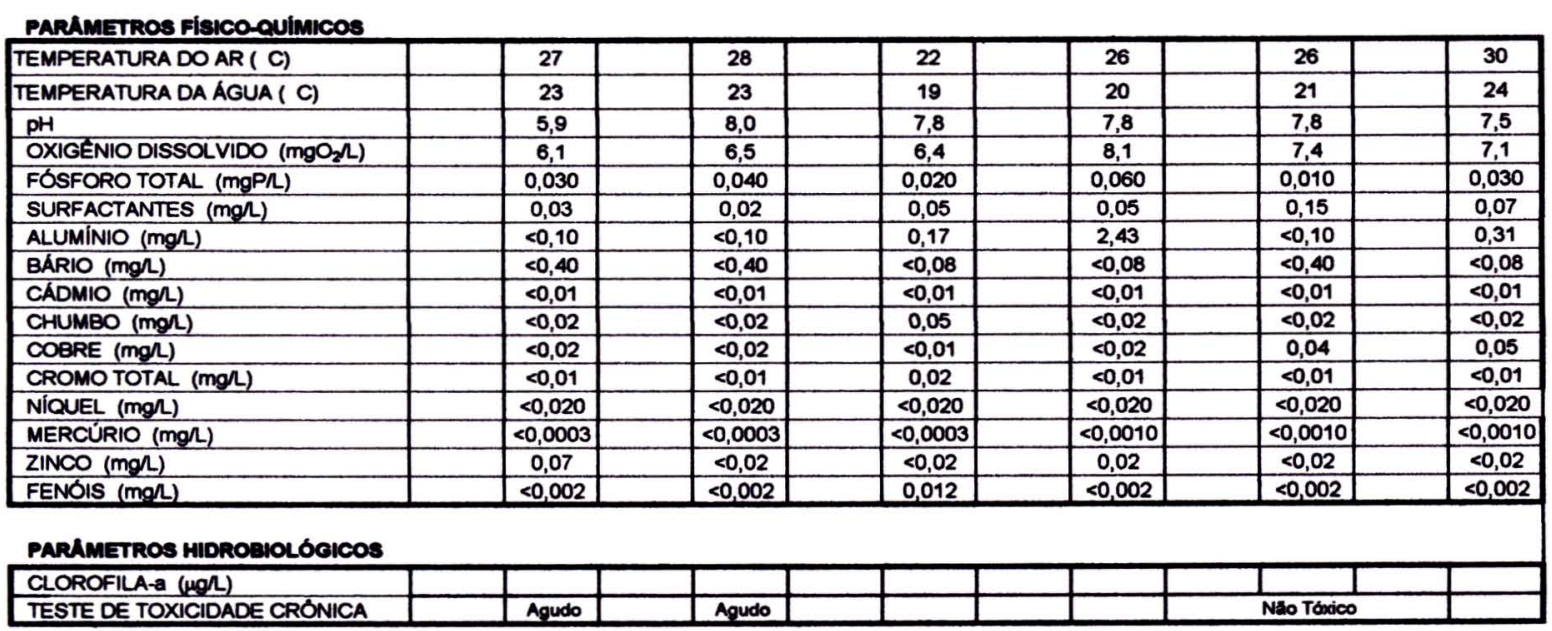

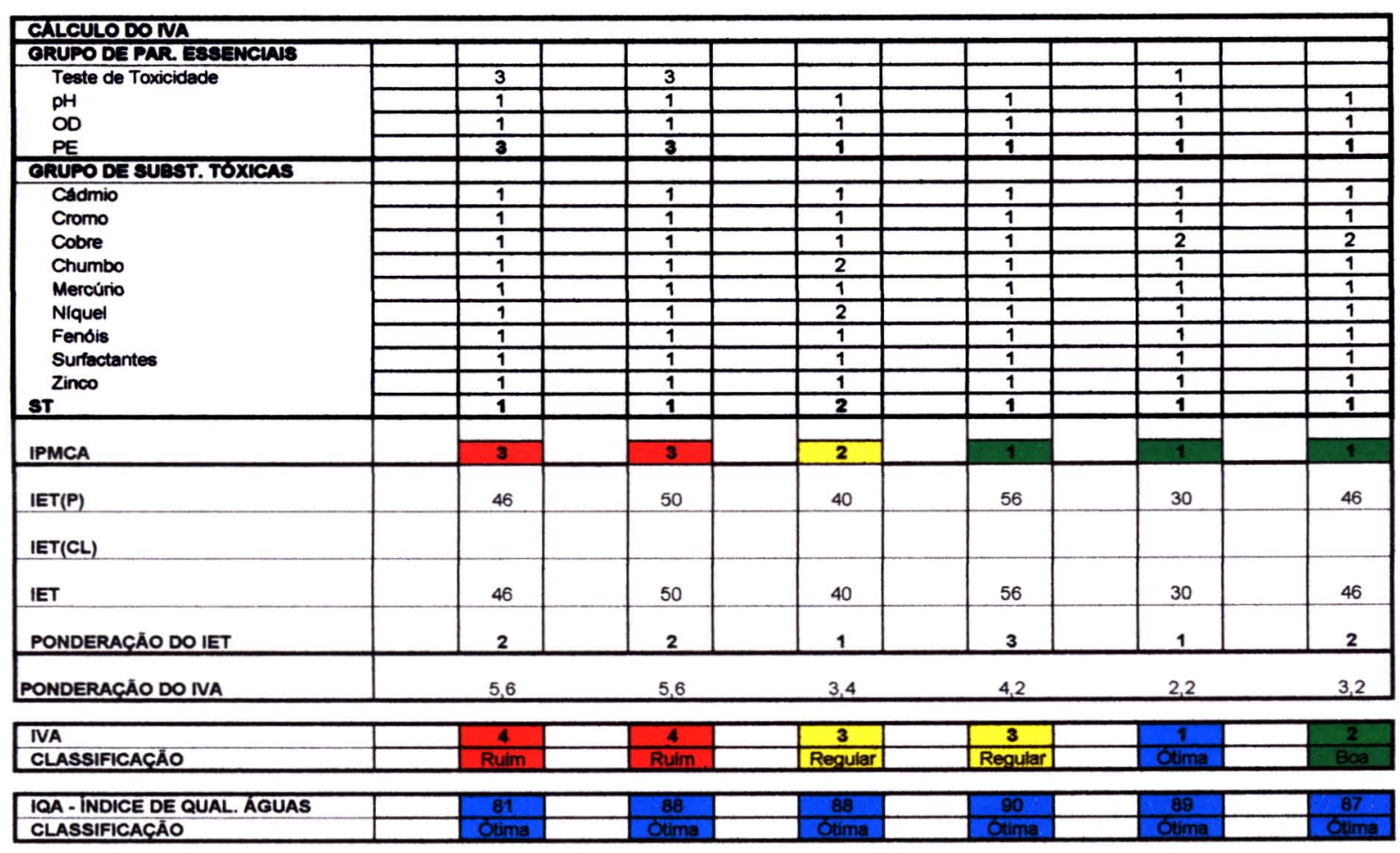


Tabela A19 - Resultados dos parâmetros analisados pela Rede de Monitoramento e cálculo do IVA no ponto MOGI02800, no ano de 1995.

\section{ANO: 1995}

PONTO DE COLETA: RIO MOGI, PONTE NA RODOVIA PIAÇAGUERA - GUARUJÁ, QUE LIGA CUBATÃo A GUARUJÁ

CODIBO DO PONTO DE COLETA: MOC102800

CLASSE: 2

\begin{tabular}{|c|c|c|c|c|c|c|c|c|c|c|c|c|}
\hline DADOS DE QUALIDADE & $\operatorname{Jan}$ & Fov & Mar & $\overline{A b r}$ & Mai & Jun & Jul & Ano & Set & Out & Nov & Dez \\
\hline \multicolumn{13}{|l|}{ INFORMACÓES DE CAMPO } \\
\hline CHUVAS (ültimas 24 horas) & Sim & $\operatorname{sim}$ & Sim & Nao & Sim & NaO & NaO & Nao & Sim & Sim & Sim & NaO \\
\hline COLORACAOO DAS ÁGUAS & Verde & Limpida & Turva & Verde & Limpida & Verde & Turva & Limpida & Verde & Verde & Tuna & Verde \\
\hline
\end{tabular}

PARAMETROS FISICO-QUIMICOS

\begin{tabular}{|c|c|c|c|c|c|c|c|c|c|c|c|c|}
\hline TEMPERATURA DO AR ( C) & 29 & 30 & 26 & 26 & 26 & 23 & 21 & 20 & 24 & 25 & 30 & 27 \\
\hline TEMPERATURA DA ÁGUA ( C) & 24 & 25 & 24 & 21 & 24 & 19 & 16 & 18 & 20 & 20 & 22 & 21 \\
\hline $\mathrm{pH}$ & 6,5 & 6,0 & 4,6 & 6,4 & 6,0 & 7,0 & 5,2 & 5,9 & 6,0 & 6,7 & 6,5 & 6,5 \\
\hline OXIGÉNIO DISSOLVIDO (mgO $\left.{ }_{2} \mathrm{~L}\right)$ & 7,6 & 7,1 & 7,8 & 7,0 & 6,0 & 7,4 & 7,0 & 6,9 & 6,9 & 7,3 & 6,6 & 6,0 \\
\hline FÓSFORO TOTAL (mgPR) & 0,455 & 3,000 & 10,000 & 5,700 & 0,850 & 0,394 & 4,320 & 2,740 & 2,020 & 1,030 & 1,300 & 3,130 \\
\hline SURFACTANTES (mgl) & 0,04 & & 0,05 & & 0,06 & & 0,14 & & 0,08 & & $<0,02$ & \\
\hline \multicolumn{13}{|l|}{ ALUMINIO (mgl) } \\
\hline BÁRIO (mg/L) & $<0,02$ & & $<0,02$ & & $<0,02$ & & 0,09 & & $<0,02$ & & $<0,02$ & \\
\hline CADMIO (mg/L) & $<0,001$ & & $<0,001$ & & 0,003 & & $<0,001$ & & $<0,001$ & & 0,008 & \\
\hline CHUMBO (mg/) & $<0,05$ & & $<0,05$ & & $<0,05$ & & $<0,05$ & & $<0,05$ & & $<0,05$ & \\
\hline COBRE (mgh) & $<0,002$ & & 0,002 & & 0,01 & & $<0,004$ & & $<0,004$ & & 0,07 & \\
\hline CROMO TOTAL (mgl) & $<0,05$ & & $<0,05$ & & $<0,05$ & & $<0,05$ & & $<0,05$ & & $<0,05$ & \\
\hline NIQUEL (mghl) & 0,02 & & 0,008 & & 0,020 & & $<0,01$ & & $<0,01$ & & 0,020 & \\
\hline MERCURIO (mg/l) & & & & & & & & & & & 0,0001 & \\
\hline ZINCO (mg/L) & 0,03 & & 0,020 & & 0,020 & & 0,06 & & $<0,01$ & & 0,10 & \\
\hline FENÓIS (mg/L) & $<0,001$ & & 0,001 & & 0,003 & & 0,002 & & $<0,001$ & & 0.005 & \\
\hline \multicolumn{13}{|l|}{ PARÁMETROS HIDROBIOLÓGICOS } \\
\hline \multicolumn{13}{|l|}{ CLOROFILA-a $(\mu g / 2)$} \\
\hline
\end{tabular}

\begin{tabular}{|c|c|c|c|c|c|c|c|c|c|c|c|c|}
\hline \multirow{2}{*}{\multicolumn{13}{|c|}{$\begin{array}{l}\text { CALCULODONA } \\
\text { CRUPODERAR }\end{array}$}} \\
\hline & & & & & & & & & & & & \\
\hline \multirow{4}{*}{$\begin{array}{l}\text { Teste de Toxicidade } \\
\text { pH } \\
\mathrm{OD} \\
\mathrm{PE}\end{array}$} & 1 & & 3 & & 1 & & & & 3 & & 1 & \\
\hline & 1 & & 3 & & 1 & & 2 & & 1 & & 1 & \\
\hline & 1 & & 1 & & 1 & & $\frac{2}{1}$ & & 1 & & 1 & \\
\hline & 1 & & 3 & & 1 & & 2 & & 3 & & 1 & \\
\hline \multicolumn{13}{|l|}{ GRUPO DE SUBST. TOXICAS } \\
\hline \multirow{10}{*}{$\begin{array}{l}\text { Cádmio } \\
\text { Cromo } \\
\text { Cobre } \\
\text { Chumbo } \\
\text { Mercúrio } \\
\text { Nlquel } \\
\text { Fenóis } \\
\text { Surfactentes } \\
\text { Zinco } \\
\text { sT }\end{array}$} & 1 & & 1 & & 2 & & 1 & & 1 & & 3 & \\
\hline & 1 & & 1 & & 1 & & 1 & & 1 & & $\frac{\pi}{1}$ & \\
\hline & 1 & & 1 & & 1 & & 9 & & 9 & & 3 & \\
\hline & 1 & & 1 & & 1 & & 1 & & 1 & & $\frac{1}{1}$ & \\
\hline & & & & & & & & & & & 1 & \\
\hline & 1 & & 1 & & 2 & & 1 & & 9 & & 1 & \\
\hline & 1 & & 1 & & $\frac{2}{2}$ & & 2 & & 2 & & 2 & \\
\hline & 1 & & 1 & & 1 & & $\frac{1}{1}$ & & 1 & & 1 & \\
\hline & 1 & & 1 & & 1 & & 1 & & 1 & & 1 & \\
\hline & 1 & & 1 & & 2 & & 1 & & 1 & & 3 & \\
\hline IPMCA & 1 & & 3 & & 2 & & 2 & & 3 & & $\frac{5}{3}$ & \\
\hline \multirow{2}{*}{$\begin{array}{l}\text { IET(P) } \\
\text { IET/CL) }\end{array}$} & 85 & 112 & 130 & 121 & 94 & 83 & 117 & 111 & 107 & 97 & 100 & 113 \\
\hline & \multicolumn{12}{|c|}{ IET(CL) } \\
\hline IET & 85 & 112 & 130 & 121 & 94 & 83 & 117 & 111 & 107 & 97 & 100 & 113 \\
\hline PONDERACCÁO DO IET & 4 & 4 & 4 & 4 & 4 & 4 & 4 & 4 & 4 & 4 & 4 & 4 \\
\hline PONDERACÃO DO IVA & 5,2 & & 7,6 & & 6,4 & & 6.4 & & 7,6 & & 7,6 & \\
\hline \multirow{2}{*}{\begin{tabular}{|l|} 
IVA \\
CLASSIFICACĀO \\
\end{tabular}} & 4 & & 5 & & 4 & & 4 & & 5 & & 5 & \\
\hline & Ruim & & & & Ruim & & Ruim & & & & & \\
\hline \multirow{2}{*}{$\begin{array}{l}\text { IOA-INDICE DE QUAL. AGUAS } \\
\text { CLASSIFICAC,ÁO }\end{array}$} & 51 & $\overline{38}$ & 48 & $\overline{41}$ & 45 & & $\overline{42}$ & $\overline{36}$ & & 49 & & \\
\hline & Aceit'́nvel & Aceitivel & Aceitituel & Acoitínel & Aceltínel & Bor & Aceitśnet & Ruim & Ruim & Aceituvel & & \\
\hline
\end{tabular}


Tabela A20 - Resultados dos parâmetros analisados pela Rede de Monitoramento e cálculo do IVA no ponto MOGI02800, no ano de 1996.

\section{ANO: 1996}

PONTO DE COLETA: RIO MOGI, PONTE NA RODOVIA PIAGGAGUERA - GUARUJÁ, QUE LIGA CUBATÃo A GUARUJÁ

CLASSE: 2

\begin{tabular}{|c|c|c|c|c|c|c|c|c|c|c|c|c|}
\hline DADOSDE QUALIDADE & $\operatorname{Jan}$ & Fev & Mar & Abr & Mal & Jun & Jul & Amo & Set & Out & Nov & Dez \\
\hline & & & & & & & & & & & & \\
\hline CHUVAS (Ûtimas 24 horas) & NaO & Sim & Sim & $\operatorname{sim}$ & Nao & Nao & $\mathrm{NaO}$ & $\mathrm{NaO}$ & Sim & Sim & Sim & Náo \\
\hline COLORACAO DAS AGUAS & Verde & Amarela & Verde & Turva & Cinza & Verde & Verde & Verde & Verde & Verde & Verde & Verde \\
\hline
\end{tabular}

PARAMETROS FISICO-Químicos

\begin{tabular}{|c|c|c|c|c|c|c|c|c|c|c|c|c|}
\hline TEMPERATURA DO AR ( C) & 30 & 29 & 29 & 26 & 27 & 19 & 23 & 20 & 23 & 25 & 24 & 26 \\
\hline TEMPERATURA DA ÁGUA ( c) & 24 & 24 & 24 & 21 & 23 & 19 & 19 & 19 & 21 & 24 & 22 & 23 \\
\hline pH & 6,2 & 6,5 & 6,0 & $\mathbf{5 , 5}$ & 6,8 & 6,8 & 6,5 & 5,6 & 5,6 & 7,2 & 5,3 & 6,0 \\
\hline OXIGÉNIO DISSOLVIDO (mgO $\left.{ }_{2} /\right)$ & 7,6 & 8,5 & 7,8 & 8,6 & 9,2 & 9,9 & 7,9 & 7,9 & 7,3 & 9,0 & 8,5 & 7,8 \\
\hline FÓSFORO TOTAL (mgPR) & 4,00 & 1,80 & 4,30 & 3,90 & 0,780 & 2,00 & 1,90 & 19,00 & 20,00 & 0,32 & 2,00 & 0,91 \\
\hline SURFACTANTES (mgl) & 0,06 & & 0,09 & & $<0,02$ & & 0,02 & & 0,19 & & 0,06 & \\
\hline \multicolumn{13}{|l|}{ ALUMINIO (mg/L) } \\
\hline BÁRIO (mg/) & $<0,02$ & & $<0,02$ & & $<0,02$ & & $<0,02$ & & $<0,08$ & & $<0,08$ & \\
\hline CADMIO (mgl) & $<0,001$ & & $<0,001$ & & 0,003 & & 0,008 & & 0,004 & & $<0,001$ & \\
\hline CHUMBO (mgl) & $<0,05$ & & $<0,05$ & & $<0,05$ & & $<0,05$ & & $<0,05$ & & $<0,05$ & \\
\hline COBRE (mgl) & $<0,004$ & & 0,02 & & $<0,004$ & & 0,019 & & $<0,004$ & & $<0,004$ & \\
\hline CROMO TOTAL (mgl) & $<0,05$ & & $<0,05$ & & $<0,05$ & & $<0,05$ & & $<0,05$ & & $<0,05$ & \\
\hline NIOUEL (mgl) & 0,010 & & $<0,010$ & & $<0,010$ & & $<0,030$ & & 0,020 & & $<0,010$ & \\
\hline MERCÚRIO (mgl) & 0,0006 & & $<0,0001$ & & $<0,0001$ & & $<0,0001$ & & 0,0002 & & 0,0002 & \\
\hline ZINCO (mg/l) & $<0,01$ & & 0,07 & & 0,04 & & 0,02 & & 0,05 & & $<0.01$ & \\
\hline FENÓIS (mol) & $<0,001$ & & 0.002 & & 0.004 & & 0.001 & & 0.034 & & 0,005 & \\
\hline \multicolumn{13}{|l|}{ CLOROFILA-a (ugl) } \\
\hline TESTE DE TOXICIDADE CRÓNICA & Cronico & & & & Nälo Tónico & & Nâ TOXXico & & Nto Toxice & & Agudo & \\
\hline
\end{tabular}

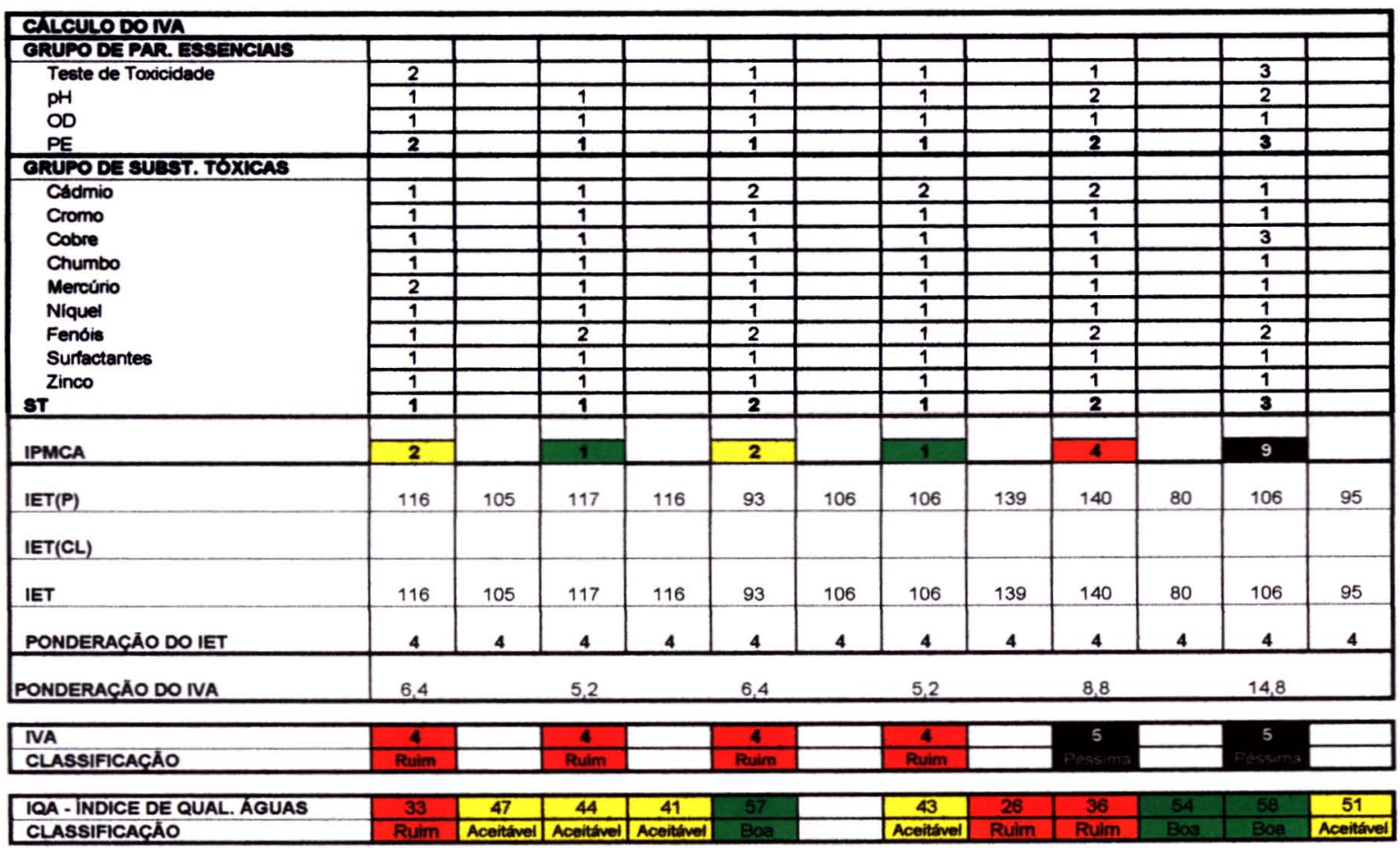


Tabela A21 - Resultados dos parâmetros analisados pela Rede de Monitoramento e cálculo do IVA no ponto MOGI02800, no ano de 1997.

ANO: 1997

PONTO DE COLETA: RIO MOGI, PONTE NA RODOVIA PIAÇAGUERA - GUARUUÁ, QUE LIGA CUBATAO A GUARUJÁ

CÓDIGO DO PONTO DE COLETA: MOG102800

CLASSE: 2

\begin{tabular}{|l|l|l|l|l|l|l|l|l|l|l|l|l|}
\hline DADOS DE QUALIDADE & Jan & Fev & Mar & Abr & Mai & Jun & Jul & Ago & Set & Out & Nov & Dez \\
\hline
\end{tabular}

INFORMACÕES DE CAMPO

\begin{tabular}{|c|c|c|c|c|c|c|c|c|c|c|c|c|}
\hline CHUVAS (ültimas 24 horas) & Năo & Näo & NaO & Sim & NaO & Sim & NaO & Sim & Năo & Sim & Nao & Năo \\
\hline$S A C$ & Verde & Verde & Verde & Verde & Verde & Verde & Verde & Verde & Cinza & Cinza & Verde & Verde \\
\hline
\end{tabular}

PARÁMETROS FISICOQOUIMICOS

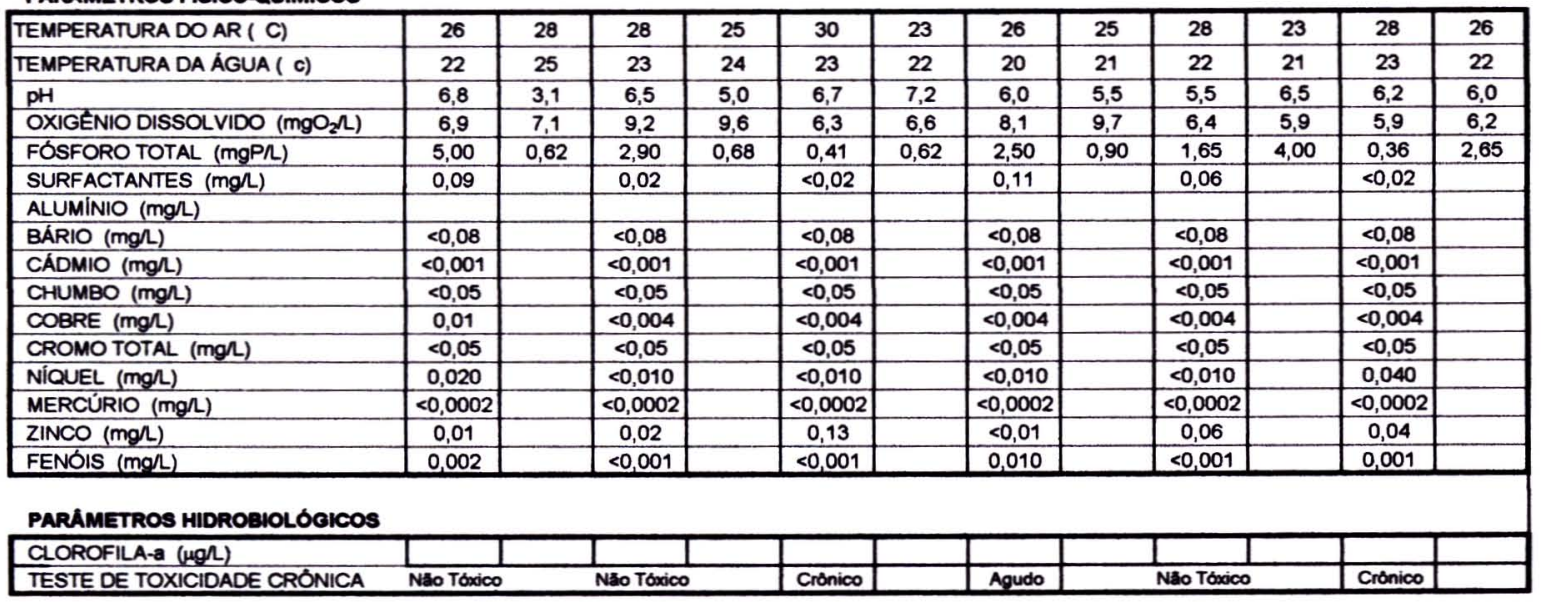

\begin{tabular}{|c|c|c|c|c|c|c|c|c|c|c|c|c|}
\hline \multicolumn{13}{|l|}{ CALCULODONA } \\
\hline \multicolumn{13}{|l|}{ GRUPODE PAR. ESSENCIAIS } \\
\hline \multirow{4}{*}{$\begin{array}{l}\text { Teste de Toxicidade } \\
\mathrm{pH} \\
\mathrm{OD} \\
\mathrm{PE}\end{array}$} & 1 & & 1 & & 2 & & 3 & & 1 & & 2 & \\
\hline & 1 & & 1 & & 1 & & 1 & & 2 & & 1 & \\
\hline & 1 & & 1 & & $\frac{1}{1}$ & & 1 & & 1 & & 1 & \\
\hline & 1 & & 1 & & 2 & & 3 & & 2 & & 2 & \\
\hline \multicolumn{13}{|l|}{ GRUPO DE SUBST. TOXICAS } \\
\hline \multicolumn{13}{|l|}{ Cádmio } \\
\hline \multirow{9}{*}{$\begin{array}{l}\text { Cromo } \\
\text { Cobre } \\
\text { Chumbo } \\
\text { Mercúrio } \\
\text { Niquel } \\
\text { Fenois } \\
\text { Surfactantes } \\
\text { Zinco } \\
\text { sT }\end{array}$} & 1 & & 1 & & 1 & & 1 & & 1 & & 1 & \\
\hline & 1 & & 1 & & 1 & & 1 & & 1 & & 1 & \\
\hline & 1 & & 1 & & 1 & & 1 & & 1 & & 1 & \\
\hline & 1 & & 1 & & 9 & & 1 & & 1 & & 1 & \\
\hline & 1 & & 1 & & 1 & & 1 & & 1 & & 2 & \\
\hline & 2 & & 1 & & 1 & & 2 & & 1 & & 1 & \\
\hline & 1 & & 1 & & 1 & & 1 & & 1 & & 1 & \\
\hline & 1 & & 1 & & 1 & & 1 & & 1 & & 1 & \\
\hline & 1 & & 1 & & 1 & & 2 & & 1 & & 1 & \\
\hline IPMCA & 1 & & 1 & & 2 & & 6 & & 2 & & 2 & \\
\hline IET(P) & 120 & 89 & 112 & 91 & 84 & 89 & 110 & 95 & 104 & 116 & 82 & 110 \\
\hline \multicolumn{13}{|l|}{ IET(CL) } \\
\hline IET & 120 & 89 & 112 & 91 & 84 & 89 & 110 & 95 & 104 & 116 & 82 & 110 \\
\hline PONDERACCĀO DO IET & 4 & 4 & 4 & 4 & 4 & 4 & 4 & 4 & 4 & 4 & 4 & 4 \\
\hline PONDERAC,ÃO DO IVA & 5.2 & & 5,2 & & 6,4 & & 11,2 & & 6,4 & & 6,4 & \\
\hline IVA & $\overline{4}$ & & 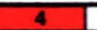 & & 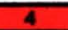 & & 5 & & 4 & & 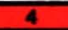 & \\
\hline CLASSIFICACĀO & Ruim & & Ruim & & Ruim & & $\sin 5$ & & Ruim & & Ruim & \\
\hline IQA - INDICE DE QUAL. AGUAS & 30 & 49 & 40 & 30 & 59 & 57 & $\overline{51}$ & 51 & 38 & 34 & 52 & 37 \\
\hline CLASSIFICACĀO & Ruim & Aceittavel & Aceitível & Ruim & Boa & $B \mathrm{Ba}$ & Aceitável & Aceitínel & Aceitível & Ruim & 800 & Aceit́tivel \\
\hline
\end{tabular}


Tabela A22 - Resultados dos parâmetros analisados pela Rede de Monitoramento e cálculo do IVA no ponto MOGI02800, no ano de 1998.

\section{ANO: 1998}

PONTO DE COLETA: RIO MOGI, PONTE NA RODOVIA PIAÇAGUERA - GUARUJÁ, QUE LIGA CUBATÃO A GUARUJÁ CODIBO DO PONTO DE COLETA: MOB102800

CLASSE: 2

\begin{tabular}{|c|c|c|c|c|c|c|c|c|c|c|c|c|}
\hline DADOS DE QUNLLIDADE & $\operatorname{Jan}$ & Fev & Mar & Abr & Mal & Jun & Jul & Ano & Set & Out & Nov & Dez \\
\hline & & & & & & & & & & & & \\
\hline CHUVAS (ütimas 24 horas) & NaOo & Năo & Sim & Nao & Sim & Nao & Nao & Nao & Sim & Sim & NaO & Nao \\
\hline COLORAČ̊ DAS ÁGUAS & Verde & Cinza & Verde & Cinza & Preta & Verde & Verde & Verde & Cinza & Tunva & Cinza & Verde \\
\hline
\end{tabular}

\begin{tabular}{|c|c|c|c|c|c|c|c|c|c|c|c|c|}
\hline TEMPERATURA DO AR ( C) & 31 & 34 & 32 & 32 & 24 & 26 & 26 & 24 & 24 & 21 & 25 & 27 \\
\hline TEMPERATURA DA ÁGUA ( C) & 25 & 29 & 26 & 25 & 23 & 23 & 23 & 25 & 18 & 22 & 23 & 23 \\
\hline pH & 5,5 & 6,8 & 5,5 & 6,4 & 6,6 & 7,0 & 6,8 & 3,6 & 3,4 & 3,7 & 5,7 & 5,0 \\
\hline OXIGÉNIO DISSOLVIDO (mgO $2 /$ ) & 4,9 & 5,5 & 4,7 & 5,9 & 6,1 & 6,4 & 5,1 & 4,9 & 5,8 & 5,7 & 5,7 & 4,9 \\
\hline FÓSFORO TOTAL (mgPR) & 0,40 & 3,00 & 4,00 & 24,00 & 12,00 & 0,460 & 0,920 & 1,20 & 3,00 & 1,44 & 0,50 & 0,40 \\
\hline SURFACTANTES (mg/L) & $<0,02$ & $<0,04$ & $<0,04$ & $<0,04$ & $<0,04$ & $<0,04$ & $<0,04$ & $<0,04$ & $<0,04$ & 0,05 & $<0,04$ & $<0,04$ \\
\hline ALUMINIO (mg/L) & 0,33 & & & & 2,45 & & 0,46 & & & & 1,52 & \\
\hline BÁRIO (mg/L) & $<0,08$ & & & & & & & & & & $<0,08$ & \\
\hline CÁDMIO (mg/L) & $<0,001$ & & & & $<0,01$ & & $<0,01$ & & & & $<0,01$ & \\
\hline CHUMBO (mgl) & $<0,05$ & & & & 0,07 & & 0,02 & & & & 0,03 & \\
\hline COBRE (mg/l) & $<0,004$ & & & & $<0,02$ & & 0,02 & & & & $<0,02$ & \\
\hline CROMO TOTAL (mgl) & $<0,05$ & & & & $<0,01$ & & $<0,01$ & & & & $<0,01$ & \\
\hline NIQUEL (mg/L) & $<0,010$ & & & & 0,020 & & 0,020 & & & & $<0,020$ & \\
\hline MERCÚRIO $(\mathrm{mg} / \mathrm{L})$ & $<0,0002$ & & & & $<0,0002$ & & $<0,0002$ & & & & 0,0020 & \\
\hline ZINCO (mg/L) & 0,03 & & & & 0,01 & & 0,03 & & & & 0,02 & \\
\hline FENÓIS (mg/L) & 0,010 & & & & $<0,001$ & & 0,010 & & & & $<0,001$ & \\
\hline \multicolumn{13}{|l|}{ CLOROFILA-a $(\mu g /)$} \\
\hline TESTE DE TOXICIDADE CRÓNICA & Năo Tóxico & & & & & & Nầo Tónsico & & Agudo & & Crónico & \\
\hline
\end{tabular}

\begin{tabular}{|c|c|c|c|c|c|c|c|c|c|c|c|c|}
\hline \multicolumn{13}{|l|}{ CALCULODOIVA } \\
\hline \multirow{2}{*}{\multicolumn{13}{|c|}{ GRUPO DE PAR. ESSENCIAIS }} \\
\hline & 1 & & & & & & 1 & & 3 & & 2 & \\
\hline \multirow{3}{*}{$\begin{array}{l}\text { Teste de Toxicidade } \\
\text { pH } \\
\text { OD } \\
\text { PE }\end{array}$} & 1 & & 2 & & 1 & & 1 & & 3 & & 2 & \\
\hline & 2 & & 2 & & 1 & & 1 & & 1 & & 1 & \\
\hline & $\frac{2}{2}$ & & $\frac{2}{2}$ & & 1 & & 1 & & 3 & & 2 & \\
\hline \multicolumn{13}{|l|}{ GRUPO DE SUEST. TOXICAS } \\
\hline \multirow{10}{*}{$\begin{array}{l}\text { Cádmio } \\
\text { Cromo } \\
\text { Cobre } \\
\text { Chumbo } \\
\text { Mercúrio } \\
\text { Niquel } \\
\text { Fenois } \\
\text { Surfactantes } \\
\text { Zinco } \\
\text { si }\end{array}$} & 1 & & & & 1 & & 1 & & & & 1 & \\
\hline & $\frac{1}{1}$ & & & & $\frac{1}{1}$ & & $\frac{1}{1}$ & & & & 1 & \\
\hline & 1 & & & & 1 & & 1 & & & & 1 & \\
\hline & 1 & & & & 2 & & 1 & & & & 1 & \\
\hline & 1 & & & & 1 & & 1 & & & & 3 & \\
\hline & 1 & & & & 1 & & 1 & & & & 1 & \\
\hline & $\frac{1}{2}$ & & & & $\frac{1}{1}$ & & 2 & & & & 1 & \\
\hline & 1 & & & & 1 & & 1 & & & & 1 & \\
\hline & 1 & & & & 1 & & 1 & & & & 1 & \\
\hline & 1 & & & & 1 & & 1 & & & & 2 & \\
\hline IPMCA & 2 & & 2 & & 1 & & 1 & & 3 & & 4 & \\
\hline IET(P) & 83 & 112 & 116 & 142 & 132 & 85 & 95 & 99 & 112 & 102 & 86 & 83 \\
\hline \multicolumn{13}{|l|}{ IET(CL) } \\
\hline IET & 83 & 112 & 116 & 142 & 132 & 85 & 95 & 99 & 112 & 102 & 86 & 83 \\
\hline PONDERAÇĀO DO IET & 4 & 4 & 4 & 4 & 4 & 4 & 4 & 4 & 4 & 4 & 4 & 4 \\
\hline PONDERACĀO DOIVA & 6,4 & & 6,4 & & 5,2 & & 5,2 & & 7.6 & & 8.8 & \\
\hline \multirow{2}{*}{$\begin{array}{l}\text { IVA } \\
\text { CLASSIFICAC,AOO } \\
\end{array}$} & 4 & & 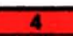 & & 4 & & $\overline{4}$ & & 5 & & 5 & \\
\hline & Ruim & & Ruim & & Ruim & & Ruim & & & & & \\
\hline \multirow{2}{*}{$\begin{array}{l}\text { IOA-INDICE DE QUAL. ÁGUAS } \\
\text { CLASSIFICACACAOO }\end{array}$} & 22 & & 40 & $\overline{27}$ & 45 & 66 & 45 & 42 & 40 & 36 & 51 & 49 \\
\hline & $80 a$ & 80 & Aceitive & Ruim & Aceitínel & 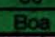 & Aceitivel & Acentiten & Acoitituel & Ruim & \begin{tabular}{|l|} 
Aceitituel \\
\end{tabular} & Aceitita \\
\hline
\end{tabular}


Tabela A23 - Resultados dos parâmetros analisados pela Rede de Monitoramento e cálculo do IVA no ponto MOGI02800, no ano de 1999.

\section{ANO: 1900}

PONTO DE COLTTA: RIO MOGI, PONTE NA RODOVIA PIAGAGUERA - GUARUA, QUE LIGA CUBATAO A GUARUAA

CODICO DO PONTO DE COLETA: MOC102390

CLases: 2

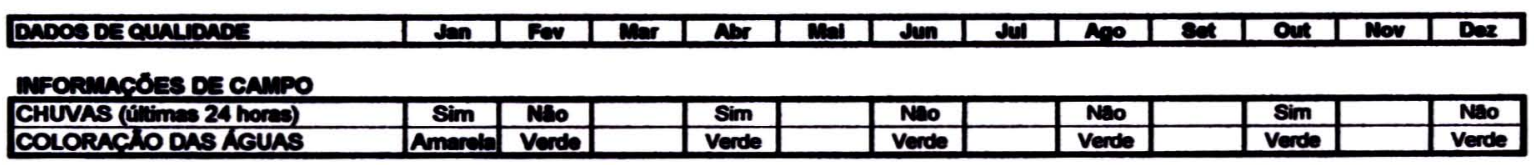

PARtnemes Fincocoulnucos

\begin{tabular}{|c|c|c|c|c|c|c|c|}
\hline TEMPERATURA DOAR ( C) & 28 & 28 & 25 & 24 & 24 & 24 & 30 \\
\hline TEMPERATURA DA AGUA (C) & 22 & 25 & 23 & 22 & 17 & 21 & 28 \\
\hline PH & 5,2 & 5,3 & 5,4 & 6,3 & 5,4 & 6,8 & 6,0 \\
\hline OXIGENIO DISSOLVIDO (mgorl) & 6,2 & 5,0 & 6,0 & 6,6 & 5,9 & $\mathbf{5 , 6}$ & 5,9 \\
\hline FÓSFORO TOTAL (m:PN) & 0,60 & 2,90 & 16,50 & 0,27 & 0,58 & 5,75 & 1,90 \\
\hline SURFACTANTES (mol) & $<0,04$ & 0,04 & 0.08 & 0,06 & 0,05 & 0.11 & 0,04 \\
\hline ALUMINIO (mol) & 15,50 & & 0,36 & 0,31 & 0,56 & 0,41 & 0,63 \\
\hline BÁRIO (mpl) & $<0,08$ & & $<0,40$ & $<0,40$ & $<0,40$ & $<0,40$ & $<0,40$ \\
\hline CADMIO (mol) & $<0,010$ & & $<0,010$ & $<0,010$ & $<0,001$ & $<0,010$ & $<0,010$ \\
\hline CHUMBO (mol) & $<0,02$ & & $<0,03$ & $<0,03$ & $<0,03$ & $<0,02$ & $<0,02$ \\
\hline COBRE (mol) & $<0,02$ & & $<0,02$ & 0,01 & $<, 02$ & 0,03 & $<0,02$ \\
\hline CROMO TOTAL (mol) & 0,02 & & $\infty, 02$ & $<0,02$ & $<0,02$ & 0,01 & 0,01 \\
\hline NIQUEL (mol) & $<0,020$ & & $<0,040$ & $<0,040$ & 0,040 & $\infty, 020$ & 0,020 \\
\hline MERCÚRIO (mol) & $<0,0002$ & & $<0,0003$ & $<0,0002$ & $<0,0002$ & $<0,0002$ & $<0,0003$ \\
\hline ZINCO (mol) & 0,09 & & 0,08 & $<0,03$ & $<0,03$ & 0,07 & 0,04 \\
\hline FENOIS $(m \cdot 1)$ & $<0,002$ & & 0.003 & 0.004 & 0.120 & $<0.002$ & $<0,002$ \\
\hline \multicolumn{8}{|l|}{ CLOROFILA- (nol) } \\
\hline TESTE DE TOXICIDAOE CRONICA & Aoudo & & Nio Tóloc & & Nibotóniox & Motónex & Niso Tóio \\
\hline
\end{tabular}

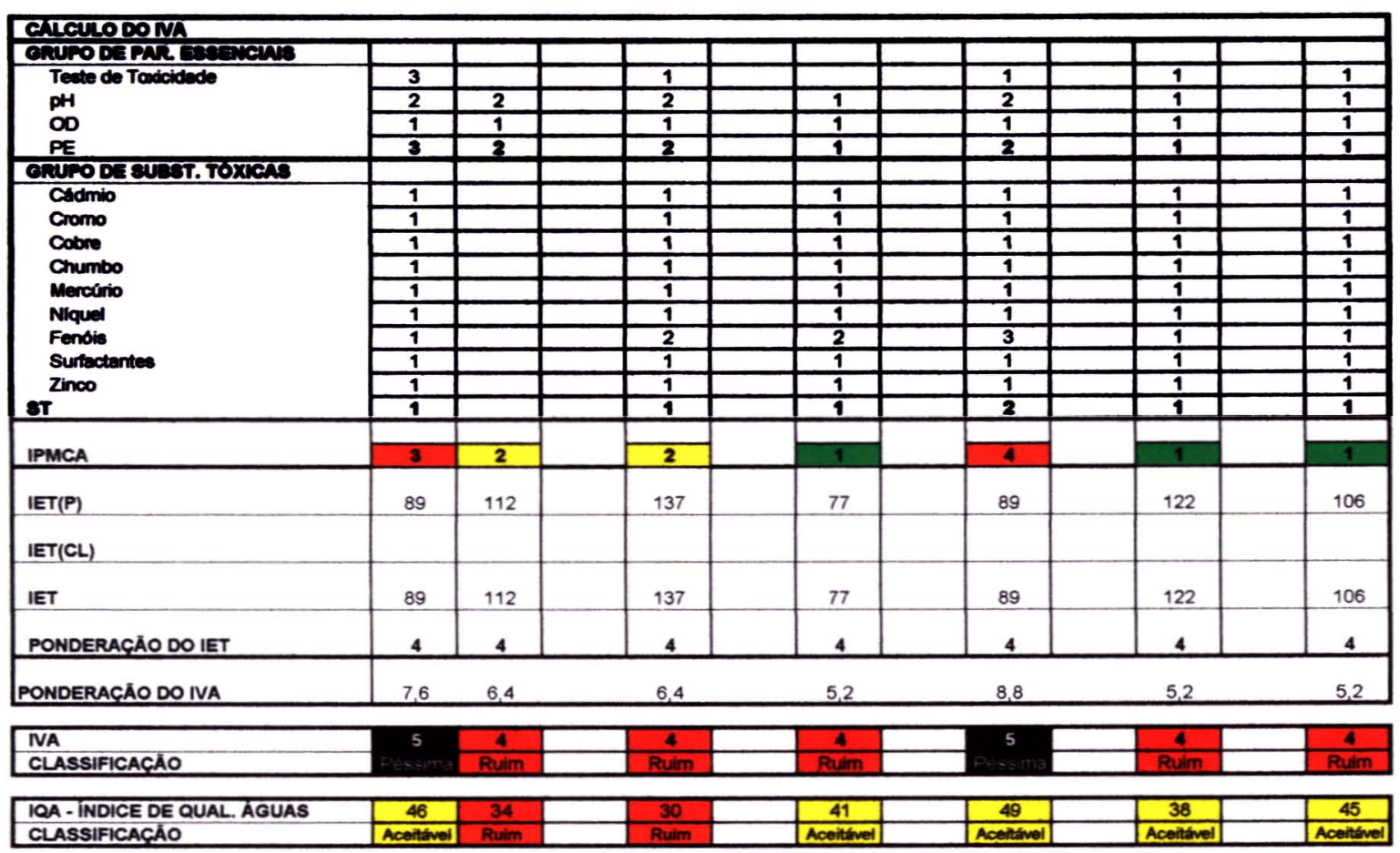


Tabela A25 - Resultados dos parâmetros analisados pela Rede de Monitoramento e cálculo do IVA no ponto PIAC02700, no ano de 1995.

\section{ANO: 1995}

PONTO DE COLETA: RIO PIAÇAGUERA, PONTE LOCALIZADA NA AREA DA COSIPA, EM VILA PARISI, $300 \mathrm{~m}$ A JUSANTE DA ADUBOS TREVO CODICO DO PONTO DE COLETA: PIAC02700

CLASSE: 2

\begin{tabular}{|c|c|c|c|c|c|c|c|c|c|c|c|c|}
\hline DADOS DE QUALIDADE & $\operatorname{Jan}$ & Fev & Mar & Abr & $\mathrm{Mal}$ & Jun & Jul & A.0 & set & Out & Nov & Dez \\
\hline & & & & & & & & & & & & \\
\hline CHUVAS (últimas 24 horas) & $\operatorname{sim}$ & Sim & Sim & Nao & Sim & Năo & Năo & Nao & Sim & Sim & Näo & NaO \\
\hline COLORACAO DAS AGUAS & Verde & Cinza & Cinza & Amarela & Cinza & Cinze & Cinza & Limpida & Cinza & Verde & Cinza & Cinze \\
\hline
\end{tabular}

PARAMETROS FISICO-QUimicos

\begin{tabular}{|c|c|c|c|c|c|c|c|c|c|c|c|c|}
\hline TEMPERATURA DO AR ( C) & 28 & 28 & 27 & 26 & 27 & 23 & 23 & 22 & 23 & 25 & 28 & 25 \\
\hline TEMPERATURA DA ÁGUA ( C) & 27 & 23 & 25 & 23 & 23 & 23 & 17 & 19 & 23 & 24 & 26 & 24 \\
\hline $\mathrm{pH}$ & 6,5 & 6,0 & 3,8 & 4,8 & 5,6 & 6,0 & 5,9 & 6,0 & 6,0 & 5,3 & 6,0 & 6,4 \\
\hline OXIGÉNIO DISSOLVIDO (mgO $/ 2)$ & 5,2 & 1,4 & 3,1 & 2,6 & 2,9 & 1,3 & 5,0 & 3,7 & 5,9 & 2,7 & 2,1 & 4,8 \\
\hline SURFACTANTES (mgl) & 0,04 & & 0,05 & & 0,09 & & 0,13 & & 0,08 & & $<0,02$ & \\
\hline \multicolumn{13}{|l|}{ ALUMINIO (mg/L) } \\
\hline BÁRIO (mgh) & 0,06 & & 0,04 & & $<0,02$ & & $<0,02$ & & $<0,02$ & & $<0,02$ & \\
\hline CROMO TOTAL (mg/L) & $<0,05$ & & $<0,05$ & & $<0,05$ & & $<0,05$ & & $<0,05$ & & $<0,05$ & \\
\hline NIQUEL (mgl) & 0,020 & & 0,030 & & 0,090 & & $<0,01$ & & $<0,01$ & & 0,020 & \\
\hline MERCÚRIO (mg/l) & & & & & & & & & & & 0,0002 & \\
\hline ZINCO (mg/l) & 0,14 & & 0,08 & & 0,11 & & 0,08 & & 0,07 & & 0,58 & \\
\hline FENÓIS (mgl) & 0.007 & & 0,013 & & 0,002 & & 0,008 & & 0.006 & & 0.017 & \\
\hline
\end{tabular}

\begin{tabular}{|c|c|c|c|c|c|c|c|c|c|c|c|c|}
\hline \multirow{2}{*}{\multicolumn{13}{|c|}{$\begin{array}{l}\text { CALCULODONA } \\
\text { GRUPO DE PAR ESSENCANS }\end{array}$}} \\
\hline & & & & & & & & & & & & \\
\hline \multirow{4}{*}{$\begin{array}{l}\text { Teste de Toxicidade } \\
\text { PH } \\
\text { OD } \\
\text { PE }\end{array}$} & 1 & & 3 & & 3 & & & & 1 & & 1 & \\
\hline & 1 & & 3 & & 2 & & 2 & & 1 & & 1 & \\
\hline & 1 & & 2 & & 3 & & 1 & & 1 & & 3 & \\
\hline & 1 & & 3 & & 3 & & 2 & & 1 & & 3 & \\
\hline \multicolumn{13}{|l|}{ GRUPO DE SUBST. TOXICAS } \\
\hline \multirow{10}{*}{$\begin{array}{l}\text { Cádmio } \\
\text { Cromo } \\
\text { Cobre } \\
\text { Chumbo } \\
\text { Mercúrio } \\
\text { Niquel } \\
\text { Fenois } \\
\text { Surfactantes } \\
\text { Zinco } \\
\text { sT } \\
\end{array}$} & 1 & & 1 & & 2 & & 1 & & 1 & & 3 & \\
\hline & 1 & & 1 & & 1 & & 1 & & 1 & & 1 & \\
\hline & 1 & & 1 & & 1 & & 1 & & 1 & & 3 & \\
\hline & 1 & & 9 & & 9 & & 1 & & 1 & & 1 & \\
\hline & & & & & & & & & & & 1 & \\
\hline & 1 & & 2 & & 2 & & 1 & & 1 & & 1 & \\
\hline & 2 & & 2 & & 2 & & 2 & & 2 & & 2 & \\
\hline & $\frac{1}{1}$ & & 9 & & 9 & & $\frac{1}{1}$ & & $\overline{1}$ & & 1 & \\
\hline & 1 & & 9 & & 1 & & 1 & & 1 & & 2 & \\
\hline & 1 & & 2 & & 2 & & 1 & & 1 & & 3 & \\
\hline \multicolumn{13}{|l|}{ IPMCA } \\
\hline IET(P) & 169 & 130 & 103 & 175 & 172 & 122 & 155 & 168 & 154 & 153 & 171 & 179 \\
\hline \multicolumn{13}{|l|}{ IET(CL) } \\
\hline IET & 169 & 130 & 103 & 175 & 172 & 122 & 155 & 168 & 154 & 153 & 171 & 179 \\
\hline PONDERAÇĀO DO IET & 4 & 4 & 4 & 4 & 4 & 4 & 4 & 4 & 4 & 4 & 4 & 4 \\
\hline PONDERACÃO DO IVA & 5,2 & & 11,2 & & 11,2 & & 6,4 & & 5,2 & & 14.8 & \\
\hline IVA & 4 & & 5 & & 5 & & 4 & & 4 & & 5 & \\
\hline CLASSIFICACĀOO & Ruim & & 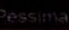 & & sin & & Ruim & & Ruim & & ssi & \\
\hline IQA - INDICE DE QUAL. AGUAS & 35 & 29 & 31 & 24 & 27 & 1, & 37 & 30 & 40 & 34 & & \\
\hline CLASSIFICAC̄ÃO & Ruim & Ruim & Ruim & Ruim & Ruim & Pessim & Aceitśvel & Ruim & Aceitível & Ruim & & \\
\hline
\end{tabular}


Tabela A26 - Resultados dos parâmetros analisados pela Rede de Monitoramento e cálculo do IVA no ponto PIAC02700, no ano de 1996.

ANO: 1996

PONTO dE COLETA: RIO PIAÇAGUERA, PONTE LOCALIZADA NA ÁREA DA COSIPA, EM VILA PARISI, $300 \mathrm{~m}$ A JUSANTE DA ADUBOS TREVO CODIGO DO PONTO DE COLETA: PIAC02700

CLASSE: 2

\begin{tabular}{|c|c|c|c|c|c|c|c|c|c|c|c|c|}
\hline DADOS DE QUALIDADE & Jan & Fev & Mar & $\mathrm{Abr}$ & Mal & Jun & Jul & Ago & Set & Out & Nov & Dez \\
\hline & & & & & & & & & & & & \\
\hline CHUVAS (ültimas 24 horas) & Năo & $\operatorname{sim}$ & Sim & Sim & Năo & NaO & Nâo & Náo & Sim & Sim & Năo & Nao \\
\hline COLORACAAO DAS AGUAS & Cinza & Cinza & Cinza & Amarela & Cinza & Cinza & Cinza & Preta & Cinza & Verde & Cinza & Verde \\
\hline
\end{tabular}

\begin{tabular}{|c|c|c|c|c|c|c|c|c|c|c|c|c|}
\hline TEMPERATURA DO AR ( C) & 32 & 30 & 29 & 26 & 27 & 20 & 23 & 20 & 22 & 25 & 24 & 25 \\
\hline TEMPERATURA DA ÁGUA ( C) & 23 & 27 & 23 & 22 & 23 & 19 & 21 & 19 & 21 & 24 & 23 & 26 \\
\hline $\mathrm{pH}$ & 6,5 & 6,0 & 6,5 & 5,2 & 6,2 & 5,9 & 5,7 & 5,8 & 5,6 & 6,5 & 6,2 & 6,1 \\
\hline OXIGÉNIO DISSOLVIDO $\left(\mathrm{mgO}_{2} \mathrm{~h}\right)$ & 5,5 & 4,0 & 3,3 & 6,2 & 2,4 & 5,2 & 3,2 & 3,5 & 4,6 & 5,4 & 5,1 & 0,0 \\
\hline FÓSFORO TOTAL (mgPR) & 138,0 & 38,0 & 80,0 & 15,0 & 40,0 & 94,0 & 90,0 & 150,0 & 80,0 & 21,5 & 41,5 & 46,0 \\
\hline SURFACTANTES (mgl) & 0,05 & & 0,13 & & $<0,02$ & & 0,11 & & 0,03 & & 0,10 & \\
\hline \multicolumn{13}{|l|}{ ALUMINIO (mg/L) } \\
\hline BÁRIO (mg/l) & $<0,02$ & & $<0,02$ & & $<0,02$ & & $<0,02$ & & $<0,08$ & & $<0,08$ & \\
\hline CÁDMIO (mg/L) & $<0,001$ & & $<0,001$ & & 0,004 & & 0,012 & & 0,004 & & 0,002 & \\
\hline CHUMBO (mg/) & $<0,05$ & & $<0,05$ & & $<0,05$ & & $<0,05$ & & $<0,05$ & & $<0,05$ & \\
\hline COBRE (mg/l) & $<0,004$ & & 0,04 & & $<0,004$ & & 0,034 & & $<0,004$ & & 0,006 & \\
\hline CROMO TOTAL (mg/L) & $<0,05$ & & $<0,05$ & & $<0,05$ & & $<0,05$ & & $<0,05$ & & $<0,05$ & \\
\hline NÍQUEL $(\mathrm{mg} / \mathrm{L})$ & 0,030 & & 0,050 & & 0,040 & & 0,110 & & 0,080 & & 0,030 & \\
\hline MERCÚRIO (mg/L) & 0,0015 & & $<0,0001$ & & $<0,0001$ & & $<0,0001$ & & $<0,0001$ & & $<0,0002$ & \\
\hline ZINCO (mg/L) & 0,05 & & 0,11 & & 0,06 & & 0,08 & & 0,10 & & 0,02 & \\
\hline FENÓIS (mgl) & $<0,001$ & & 0,004 & & 0,011 & & 0,048 & & 0,009 & & 0,011 & \\
\hline \multicolumn{13}{|l|}{ PARÁMETROS HIDROBIOLÓGICOS } \\
\hline CLOR & & & & & & & & & & & & \\
\hline TESTE DE TOXICIDADE CRÓNICA & Cronico & & & & Năo Tóxico & & \begin{tabular}{|l|} 
Agudo \\
\end{tabular} & & Agudo & & Nắo Tóxico & \\
\hline
\end{tabular}

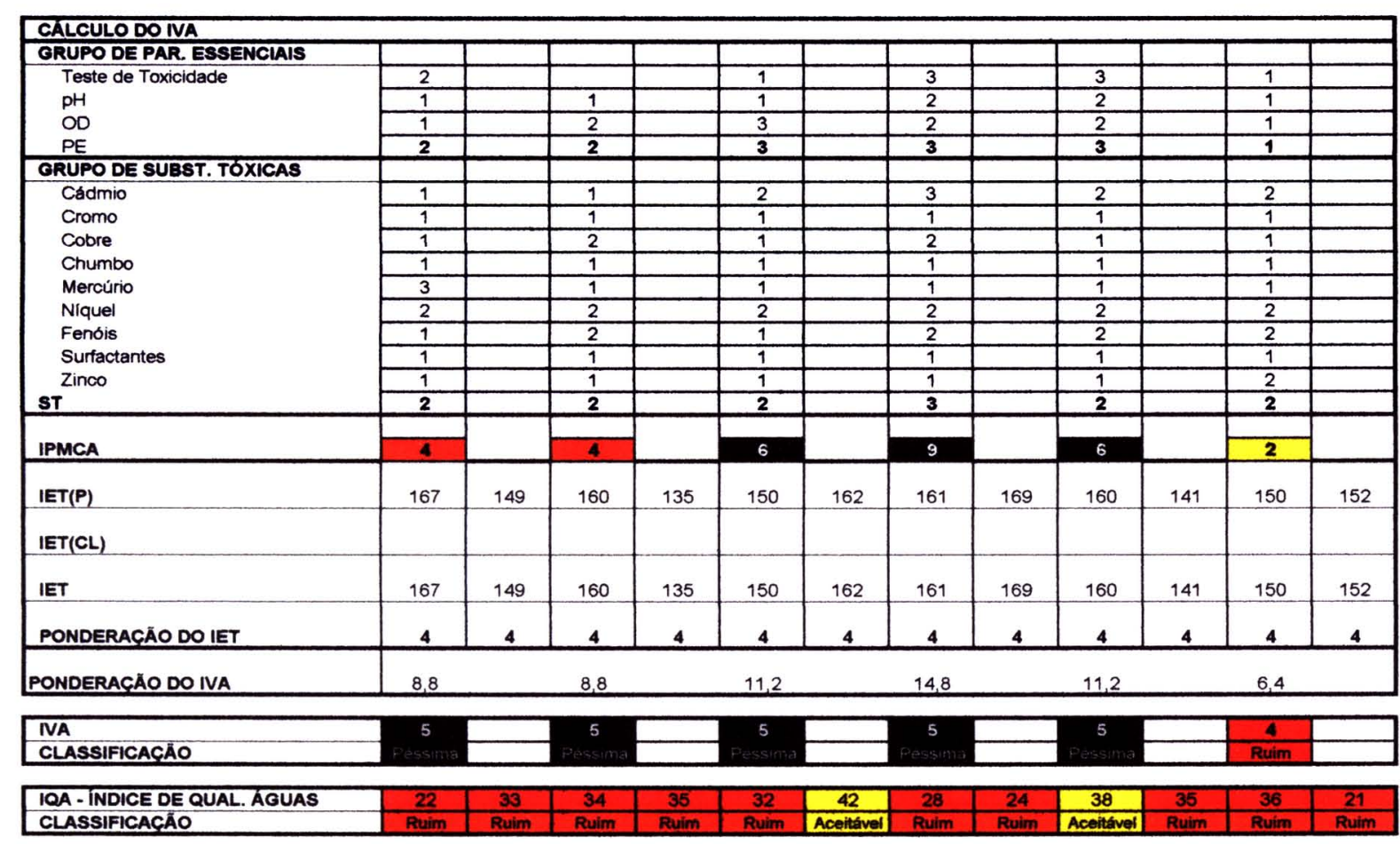


Tabela A27 - Resultados dos parâmetros analisados pela Rede de Monitoramento e cálculo do IVA no ponto PIAC02700, no ano de 1997.

ANO: 1997

PONTO dE COLETA: RIO PIAÇAGUERA, PONTE LOCALIZADA NA ÁREA DA COSIPA, EM VILA PARISI, 300 m A JUSANTE DA ADUBOS TREVO CÓDIGO DO PONTO DE COLETA: PIAC02700

CLASSE: 2

\begin{tabular}{|c|c|c|c|c|c|c|c|c|c|c|c|c|}
\hline DADOS DE QUALIDADE & $\operatorname{Jan}$ & Fev & Mar & Abr & Mai & Jun & Jul & A90 & Set & Out & Nov & Dez \\
\hline & & & & & & & & & & & & \\
\hline s24 horas) & Năo & Năo & Năo & Sim & Năo & Sim & Năo & Sim & Năo & Sim & Năo & Năo \\
\hline COLORAC̨ÃO DAS ÁGUAS & Verde & Cinzea & Cinza & Cinza & Cinza & Cinza & Cinza & Preta & Preta & Preta & Cinza & Cinza \\
\hline
\end{tabular}

\begin{tabular}{|c|c|c|c|c|c|c|c|c|c|c|c|c|}
\hline TEMPERATURA DO AR ( C) & 26 & 28 & 28 & 25 & 30 & 23 & 26 & 24 & 28 & 23 & 28 & 26 \\
\hline TEMPERATURA DA ÁGUA ( C) & 24 & 25 & 25 & 24 & 27 & 23 & 20 & 20 & 26 & 21 & 27 & 22 \\
\hline $\mathrm{pH}$ & 6,5 & 6,1 & 6,5 & 5,5 & 5,7 & 6,3 & 6,5 & 6,5 & 5,7 & 6,0 & 6,3 & 5,5 \\
\hline OXIGÉNIO DISSOLVIDO ( $\left.\mathrm{mgO}_{2} / \mathrm{L}\right)$ & 0,6 & 0,7 & 0,0 & 0,0 & 1,8 & 4,1 & 8,0 & 6,6 & 3,0 & 5,2 & 3,4 & 3,9 \\
\hline FÓSFORO TOTAL (mgPR) & 71,00 & 21,50 & 84,00 & 52,50 & 70,00 & 56,00 & 84,00 & 21,00 & 52,00 & 68,00 & 82,50 & 28,00 \\
\hline SURFACTANTES (mg/) & 0,03 & & 0,04 & & 0,07 & & 0,07 & & 0,09 & & $<0,02$ & \\
\hline \multicolumn{13}{|l|}{ ALUMINIO (mg/) } \\
\hline BÁRIO (mg/l) & $<0,08$ & & $<0,08$ & & $<0,08$ & & $<0,08$ & & $<0,08$ & & $<0,08$ & \\
\hline CÁDMIO (mg/L) & $<0,001$ & & $<0,001$ & & $<0,001$ & & $<0,001$ & & 0,005 & & $<0,001$ & \\
\hline CHUMBO (mg $/$ ) & $<0,05$ & & $<0,05$ & & $<0,05$ & & $<0,05$ & & $<0,05$ & & $<0,05$ & \\
\hline COBRE (mg/l) & 0,01 & & $<0,004$ & & 0,01 & & $<0,004$ & & 0,01 & & $<0,004$ & \\
\hline CROMO TOTAL (mgl) & $<0,05$ & & $<0,05$ & & $<0,05$ & & $<0,05$ & & $<0,05$ & & $<0,05$ & \\
\hline NIQUEL (mg/l) & 0,040 & & 0,040 & & 0,040 & & $<0,010$ & & 0,030 & & 0,080 & \\
\hline MERCÚRIO (mg/L) & $<0,0002$ & & 0,0003 & & $<0,0002$ & & $<0,0002$ & & $<0,0002$ & & $<0,0002$ & \\
\hline ZINCO (mg/) & 0,03 & & 0,05 & & 0,15 & & $<0,01$ & & 0,05 & & 0,09 & \\
\hline FENÓIS (mgl) & 0,010 & & 0,016 & & 0,004 & & 0.006 & & 0,029 & & 0,003 & \\
\hline \multicolumn{13}{|l|}{ ARÂMETROS HIDROBIOLÓOICOS } \\
\hline CLOROFILA-a $(\mu \mathrm{g} / \mathrm{L})$ & & & & & & & & & & & & \\
\hline TESTE DE TOXICIDADE CRC & Crônico & & Crónico & & Cronico & & Agudo & & Agudo & \multicolumn{3}{|c|}{ Năo Toxico } \\
\hline
\end{tabular}

\begin{tabular}{|c|c|c|c|c|c|c|c|c|c|c|c|c|}
\hline \multirow{2}{*}{\multicolumn{13}{|c|}{\begin{tabular}{|l|} 
CALCULODOIVA \\
GRUPO DE PAR. ESSENCIAIS
\end{tabular}}} \\
\hline & & & & & & & & & & & & \\
\hline \multirow{4}{*}{$\begin{array}{l}\text { Teste de Toxicidade } \\
\mathrm{pH} \\
\mathrm{OD} \\
\mathrm{PE}\end{array}$} & 2 & & 2 & & 2 & & 3 & & 3 & & 1 & \\
\hline & 1 & & 1 & & 2 & & 1 & & 2 & & 1 & \\
\hline & 3 & & 3 & & 3 & & 1 & & 2 & & 2 & \\
\hline \multirow{2}{*}{\multicolumn{13}{|c|}{ GRUPO DE SUBST. TOXICAS }} \\
\hline & & & & & & & & & & & & \\
\hline \multirow{10}{*}{$\begin{array}{l}\text { Cádmio } \\
\text { Cromo } \\
\text { Cobre } \\
\text { Chumbo } \\
\text { Mercúrio } \\
\text { Niquel } \\
\text { Fendis } \\
\text { Surfactantes } \\
\text { Zinco } \\
\text { sT }\end{array}$} & 1 & & 1 & & 1 & & 1 & & 2 & & 1 & \\
\hline & 1 & & 1 & & 1 & & 1 & & 1 & & 1 & \\
\hline & 1 & & 1 & & 1 & & 2 & & 1 & & 1 & \\
\hline & 1 & & 1 & & 1 & & 1 & & 1 & & 1 & \\
\hline & 1 & & 2 & & 1 & & 1 & & 1 & & 1 & \\
\hline & 2 & & 2 & & 2 & & 1 & & 2 & & 2 & \\
\hline & 2 & & 2 & & 2 & & 2 & & 2 & & 2 & \\
\hline & 1 & & 1 & & 1 & & 1 & & 1 & & 1 & \\
\hline & 1 & & 1 & & 1 & & 1 & & 1 & & 1 & \\
\hline & 2 & & 2 & & 2 & & 2 & & 2 & & 2 & \\
\hline \multicolumn{13}{|l|}{ IPMCA } \\
\hline \multicolumn{13}{|l|}{ IET(P) } \\
\hline (2) & 158 & 141 & 160 & 154 & 158 & 154 & 160 & 140 & 154 & 157 & 160 & 144 \\
\hline IET(CL) & & & & & & & & & & & & \\
\hline IET & 158 & 141 & 160 & 154 & 158 & 154 & 160 & 140 & 154 & 157 & 160 & 144 \\
\hline PONDERAÇÃO DO IET & 4 & 4 & 4 & 4 & 4 & 4 & 4 & 4 & 4 & 4 & 4 & 4 \\
\hline PONDERAC̨ÃO DO IVA & 11,2 & & 11,2 & & 11,2 & & 11,2 & & 11,2 & & 8,8 & \\
\hline IVA & 5 & & 5 & & 5 & & 5 & & 5 & & 5 & \\
\hline CLASSIFICACĀO & & & & & & & & & & & & \\
\hline IOA - INDICE DE QUAL. AGUAS & 26 & 21 & 24 & & $\overline{26}$ & 27 & $\overline{36}$ & $\overline{34}$ & & $\overline{23}$ & 28 & 28 \\
\hline $\begin{array}{l}\text { CLASSIFICACÁO } \\
\end{array}$ & Ruim & $\frac{21}{\text { Ruim }}$ & Ruim & & Ruim & Ruim & Ruim & Ruim & 10 & Ruim & Ruim & Ruim \\
\hline
\end{tabular}


Tabela A28 - Resultados dos parâmetros analisados pela Rede de Monitoramento e cálculo do IVA no ponto PIAC02700, no ano de 1998.

ANO: 1998

PONTO dE COLETA: RIO PIAÇAGUERA, PONTE LOCALIZADA NA ÁREA DA COSIPA, EM VILA PARISI, $300 \mathrm{~m}$ A JUSANTE DA ADUBOS TREVO CODIOO DO PONTO DE COLETA: PIAC02700

CLASSE: 2

\begin{tabular}{|c|c|c|c|c|c|c|c|c|c|c|c|c|}
\hline ADOS DE QUALLDADE & $\operatorname{Jan}$ & Fev & Mar & $\overline{\mathrm{Abr}}$ & Mal & Jun & JuII & Ano & set & Out & Nov & $\overline{D \text { Dez }}$ \\
\hline & & & & & & & & & & & & \\
\hline CHUVAS (ültimas 24 horas) & Năo & Naso & Sim & Nao & Sim & Năo & Náo & Năo & Sim & Sim & Náo & Ná \\
\hline COLORACAO DAS AGUAS & Verde & Cinza & Verde & Cinza & Preta & Verde & Verde & Verde & Cinza & Turva & Cinza & Verde \\
\hline
\end{tabular}

PARAMETROS FISICO-QUimICOS

\begin{tabular}{|c|c|c|c|c|c|c|c|c|c|c|c|c|}
\hline TEMPERATURA DO AR ( C) & 31 & 34 & 32 & 32 & 24 & 26 & 26 & 24 & 24 & 21 & 25 & 27 \\
\hline TEMPERATURA DA ÁGUA ( C) & 25 & 29 & 26 & 25 & 23 & 23 & 23 & 25 & 18 & 22 & 23 & 23 \\
\hline $\mathrm{PH}^{-}$ & 5,0 & 6,3 & 5,2 & 6,3 & 6,3 & 6,0 & 7,3 & 4,2 & 5,8 & 6,3 & 6,4 & 5,5 \\
\hline OXIGÉNIO DISSOLVIDO $\left(\mathrm{mgO}_{2} / \mathrm{L}\right)$ & 4,8 & 3,0 & 4,9 & 2,9 & 4,4 & 6,0 & 3,7 & 3,9 & 2,9 & 4,0 & 5,9 & 3,9 \\
\hline FOSFORO TOTAL (mgPR) & 410,0 & 50,00 & 23,00 & 4,00 & 32,00 & 0,02 & 120,00 & 193,70 & 78,00 & 46,00 & 65,00 & 20,00 \\
\hline SURFACTANTES (mgl) & $<0,02$ & $<0,04$ & $<0,04$ & $<0,04$ & $<0,04$ & $<0,04$ & \begin{tabular}{|l|}
0,05 \\
\end{tabular} & 0,04 & 0,05 & 0,10 & $<0,04$ & $<0,04$ \\
\hline ALUMINIO (mgl) & 0,41 & & & & 2,74 & & 2,41 & & & & 113,00 & \\
\hline BÁRIO (mgl) & $<0,08$ & & & & & & & & & & $<0,08$ & \\
\hline CADDMIO (mg/) & $<0,001$ & & $<0,001$ & & $<0,010$ & & $<0,010$ & & & & $<0,010$ & \\
\hline CHUMBO (mgl) & $<0,05$ & & & & 0,07 & & 0,03 & & & & $<0,02$ & \\
\hline COBRE (mgh) & $<0,004$ & & & & $<0,02$ & & 0,05 & & & & $<0,02$ & \\
\hline CROMO TOTAL (mgl) & $<0,05$ & & & & $<0,01$ & & 0,01 & & & & $<0,01$ & \\
\hline NIQQUEL (mgl) & $<0,01$ & & & & 0,050 & & 0,030 & & & & 0,030 & \\
\hline MERCÚRIO $(m g h)$ & $<0,0002$ & & & & & & $<0,0002$ & & & & $<0,0002$ & \\
\hline ZINCO (mgl) & 0,04 & & & & 0,08 & & 0,07 & & & & 0,06 & \\
\hline FENOIS (mg/L) & 0,008 & & & & $<0,001$ & & 0,003 & & & & $<0,001$ & \\
\hline \multicolumn{13}{|l|}{ PARAMETROS HIOROBOLOGICOS } \\
\hline \multicolumn{13}{|l|}{ 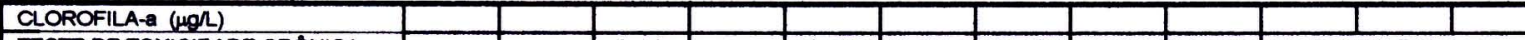 } \\
\hline TESTE DE TOXICIDADE CRÓNIC & & & Aqudo & & Agudo & & Aqudo & & Agudo & & Náo TOXXic & \\
\hline
\end{tabular}

\begin{tabular}{|c|c|c|c|c|c|c|c|c|c|c|c|c|}
\hline $\begin{array}{l}\text { CALCULODOIVA } \\
\text { ORUPO DE PAR. ESSENCUAIS }\end{array}$ & & & & & & & & & & & & \\
\hline Teste de Toxicidade & & & 3 & & 3 & & 3 & & 3 & & 1 & \\
\hline $\mathrm{pH}$ & 2 & & $\frac{x^{1}}{1}$ & & $\frac{5}{1}$ & & $\frac{\pi}{1}$ & & $\frac{\pi}{2}$ & & $\frac{1}{1}$ & \\
\hline$O D$ & 2 & & 2 & & 2 & & 2 & & 3 & & 1 & \\
\hline & 2 & & 3 & & $\frac{5}{3}$ & & 3 & & 3 & & 1 & \\
\hline GRUPO DE SUBST. TOXICAS & & & & & & & & & & & & \\
\hline Cadmio & 1 & & & & 1 & & $\overline{1}$ & & & & 1 & \\
\hline Cromo & 1 & & & & $\frac{1}{1}$ & & $\frac{1}{1}$ & & & & $\frac{1}{1}$ & \\
\hline Cobre & 1 & & & & $\frac{1}{1}$ & & 2 & & & & 1 & \\
\hline Chumbo & 1 & & & & 2 & & $\frac{\pi}{1}$ & & & & $\frac{1}{1}$ & \\
\hline Mercúrio & 1 & & & & $\frac{1}{1}$ & & 1 & & & & $\frac{1}{1}$ & \\
\hline Niquel & 1 & & & & $\frac{1}{2}$ & & $\frac{1}{2}$ & & & & 2 & \\
\hline Fenois & 2 & & & & 1 & & 2 & & & & 1 & \\
\hline Surfactantes & 1 & & & & 1 & & 1 & & & & 1 & \\
\hline Zinco & 1 & & & & 1 & & 1 & & & & 1 & \\
\hline & 1 & & & & 2 & & 2 & & & & 1 & \\
\hline IPMCA & 2 & & 3 & & 6 & & 6 & & 3 & & 1 & \\
\hline IET(P) & 183 & 153 & 142 & 116 & 146 & 40 & 165 & 172 & 159 & 152 & 157 & 140 \\
\hline IET(CL) & & & & & & & & & & & & \\
\hline IET & 183 & 153 & 142 & 116 & 146 & 40 & 165 & 172 & 159 & 152 & 157 & 140 \\
\hline PONDERACCAOO DO IET & 4 & 4 & 4 & 4 & 4 & 1 & 4 & 4 & 4 & 4 & 4 & 4 \\
\hline VALOR DOIVA & 6,4 & & 7,6 & & 11.2 & & 11,2 & & 7,6 & & 5,2 & \\
\hline IVA & 4 & & 5 & & 5 & & 5 & & 5 & & $\frac{4}{4}$ & \\
\hline CLASSIFICACĀO & Ruim & & & & & & & & & & $\frac{4}{\text { Ruim }}$ & \\
\hline $\begin{array}{l}\text { IOA-INDICE DE QUAL. AGUAS } \\
\text { CASSIFICACAOO }\end{array}$ & 800 & $\mathrm{Bn}$ & $\frac{40}{400 i t \text { ve }}$ & $\frac{27}{\text { Ruim }}$ & $\frac{45}{4 c e i t a v e l}$ & Boa & $\frac{45}{\text { Aceitive }}$ & $\frac{42}{A c e i t a v}$ & $\frac{40}{\text { Aceitivive }}$ & $\frac{36}{\text { Ruim }}$ & $\frac{51}{\text { Acoitaver }}$ & $\frac{49}{\text { Aceitave }}$ \\
\hline
\end{tabular}


Tabela A29 - Resultados dos parâmetros analisados pela Rede de Monitoramento e cálculo do IVA no ponto PIAC02700, no ano de 1999.

ANO: 1999

PONTO de COLETA: RIO PIAÇAGUERA, PONTE LOCALIZADA NA ÁREA DA COSIPA, EM VILA PARISI, $300 \mathrm{~m}$ A JUSANTE DA ADUBOS TREVO CODICO DO PONTO DE COLETA: PIAC02700

CLASSE: 2

\begin{tabular}{|c|c|c|c|c|c|c|c|c|c|c|c|c|}
\hline DADOS DE QUALIDADE & $\operatorname{Jan}$ & Fev & Mar & $\overline{A b r}$ & Mal & Jun & JuI & Ano & Set & Out & Nov & Dez \\
\hline INFOF & & & & & & & & & & & & \\
\hline CHUVAS (últimas 24 horas) & $\operatorname{sim}$ & Năo & & Sim & & Năo & & Nấo & & Sim & & Năo \\
\hline COLORACÁO DAS ÁGUAS & Preta & Verde & & Cinza & & Verde & & Cinza & & Cinza & & Cinza \\
\hline
\end{tabular}

PARÁmETROS FísICO-QUIMICOS

\begin{tabular}{|c|c|c|c|c|c|c|c|}
\hline TEMPERATURA DO AR ( C) & 28 & 28 & 25 & 24 & 19 & 22 & 29 \\
\hline TEMPERATURA DA ÁGUA ( C) & 23 & 24 & 24 & 23 & 22 & 21 & 25 \\
\hline $\mathrm{pH}$ & 5,3 & 5,8 & 5,6 & 6,2 & 6,5 & 6,5 & 5,8 \\
\hline OXIGÉNIO DISSOLVIDO (mgO $/ 2$ ) & 5,6 & 4,2 & 5,1 & 5,9 & 4,2 & 3,9 & 5,6 \\
\hline SURFACTANTES (mg/l) & $<0,04$ & 0,05 & 0,05 & 0,08 & 0,08 & 0,04 & $<0,04$ \\
\hline ALUMINIO (mg/L) & 13,40 & & 1,07 & 0,75 & 2,00 & 2,98 & 1,22 \\
\hline BÁRIO (mg/) & 0,26 & & $<0,40$ & $<0,040$ & $<0,040$ & $<0,040$ & $<0,040$ \\
\hline CADMIO (mg/L) & $<0,010$ & & $<0,010$ & $<0,010$ & $<0,010$ & $<0,010$ & $<0,010$ \\
\hline CROMO TOTAL (mg/) & 0,02 & & $<0,02$ & $<0,02$ & $<0,02$ & 0,01 & 0,02 \\
\hline NÍQUEL (mg/l) & 0,020 & & $<0,040$ & 0,090 & 0,080 & $<0,020$ & 0,020 \\
\hline MERCÚRIO (mg/L) & $<0,0002$ & & $<0,0003$ & $<0,0002$ & $<0,0002$ & $<0,0002$ & $<0,0003$ \\
\hline ZINCO (mg/L) & 0,13 & & 0,06 & 0,04 & 0,08 & 0,12 & 0,06 \\
\hline FENÓIS (mg/L) & 0,003 & & 0,003 & 0,005 & 0,012 & $<0,002$ & $<0,002$ \\
\hline
\end{tabular}

PARÁMETROS HIDROBIOLÓGICOS

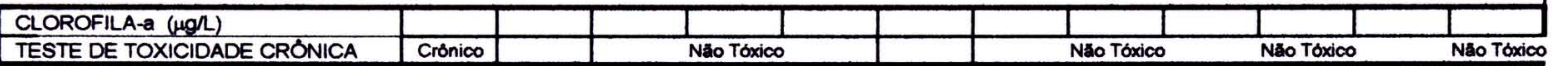

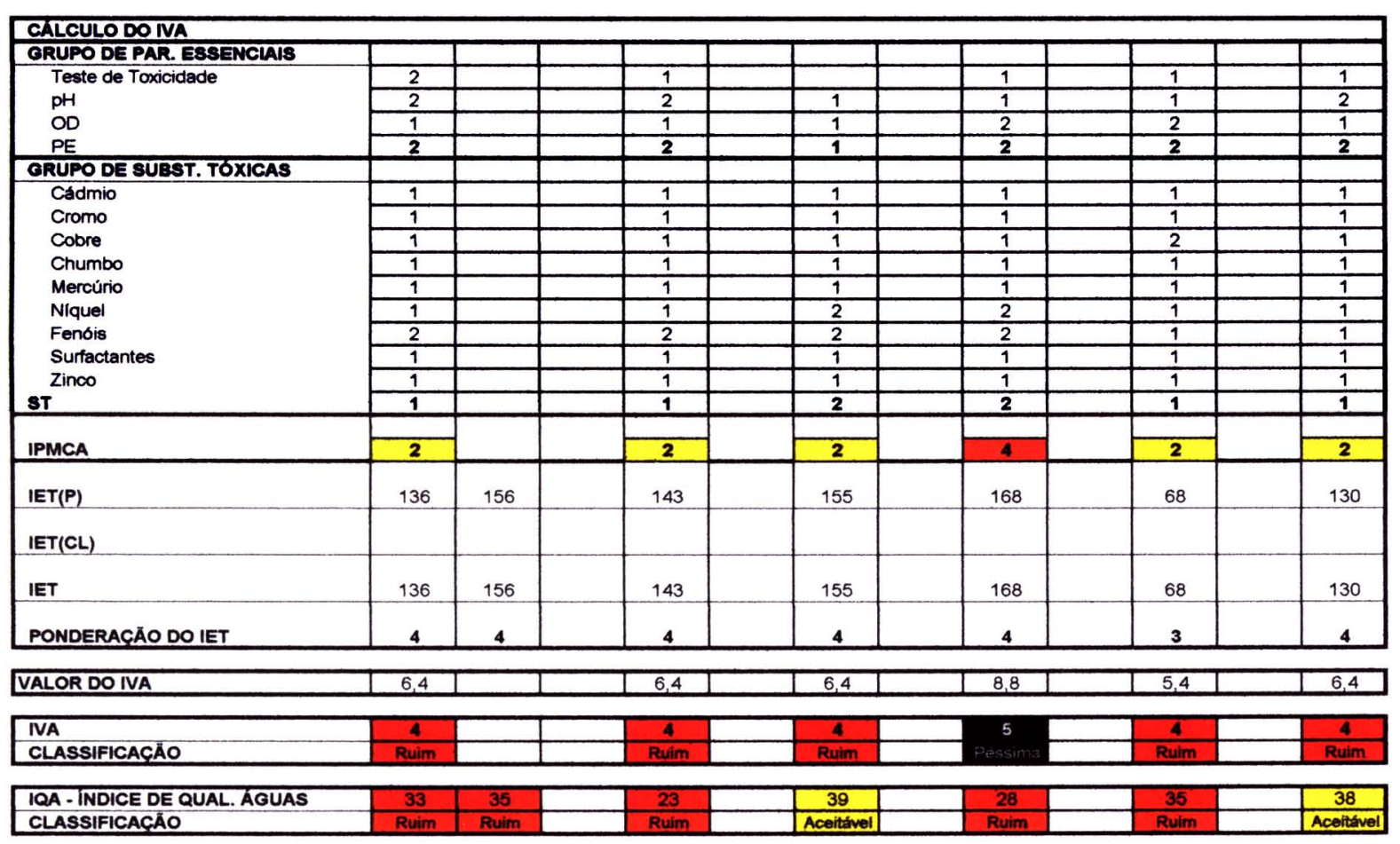


Tabela A30 - Resultados dos parâmetros analisados pela Rede de Monitoramento e cálculo do IVA no ponto PIAC02700, no ano de 2000.

ANO: 2000

PONTO dE COLETA: RIO PIAÇAGUERA, PONTE LOCALIZADA NA ÁREA DA COSIPA, EM VILA PARISI, 300 m A JUSANTE DA ADUBOS TREVO CODIGO DO PONTO DE COLETA: PIAC02700

CLASSE: 2

\begin{tabular}{|c|c|c|c|c|c|c|c|c|c|c|c|c|}
\hline DADOS DE QUALIDADE & $\operatorname{Jan}$ & Fev & Mar & Abr & Mai & Jun & Jul & Ago & Set & Out & Nov & Dez \\
\hline INEO & & & & & & & & & & & & \\
\hline CHUVAS (últimas 24 horas) & & Sim & & Năo & & Nao & & Năo & & Năo & & Năo \\
\hline COLORAČÃ DAS ÁGUAS & & Cinza & & Cinza & & Cinza & & Verde & & Cinza & & Verde \\
\hline
\end{tabular}

\section{PARÂMETROS FISICO-QUIMICOS}

\begin{tabular}{|c|c|c|c|c|c|c|}
\hline TEMPERATURA DO AR ( C) & 29 & 27 & 23 & 24 & 27 & 29 \\
\hline TEMPERATURA DA ÁGUA ( C) & 25 & 24 & 21 & 21 & 25 & 25 \\
\hline $\mathrm{pH}$ & 5,7 & 7,0 & 6,1 & 6,5 & 6,5 & 6,8 \\
\hline OXIGÉNIO DISSOLVIDO (mgO $/ \mathrm{L})$ & 5,0 & 6,1 & 3,8 & 2,6 & 2,3 & 5,4 \\
\hline SURFACTANTES (mg/) & 0,04 & 0,03 & 0,06 & 0,09 & 0,15 & 0,07 \\
\hline ALUMINIO (mg/L) & 1,79 & 3,50 & 1,37 & 1,39 & 1,88 & 1,59 \\
\hline BÁRIO (mg/) & $<0,40$ & $<0,40$ & $<0,08$ & $<0,08$ & $<0,40$ & $<0,08$ \\
\hline COBRE (mg/) & $<0,02$ & 0,02 & 0,03 & 0,06 & 0,04 & 0,04 \\
\hline CROMO TOTAL (mg/L) & $<0,01$ & $<0,01$ & $<0,01$ & $<0,01$ & $<0,01$ & $<0,01$ \\
\hline NÍQUEL (mg/L) & $<0,020$ & $<0,020$ & $<0,020$ & $<0,020$ & $<0,020$ & $<0,020$ \\
\hline MERCÚRIO (mg/) & $<0,0003$ & $<0,0003$ & $<0,0003$ & $<0,0010$ & $<0,0010$ & 0,0011 \\
\hline ZINCO (mg/L) & 0,08 & 0,04 & 0,10 & 0,04 & 0,06 & 0,08 \\
\hline FENÓIS (mg/) & $<0,002$ & $<0,002$ & 0,015 & $<0,002$ & $<0,002$ & $<0,002$ \\
\hline \multicolumn{7}{|l|}{ PARÂMETROS HIDROBIOLOGGICOS } \\
\hline
\end{tabular}

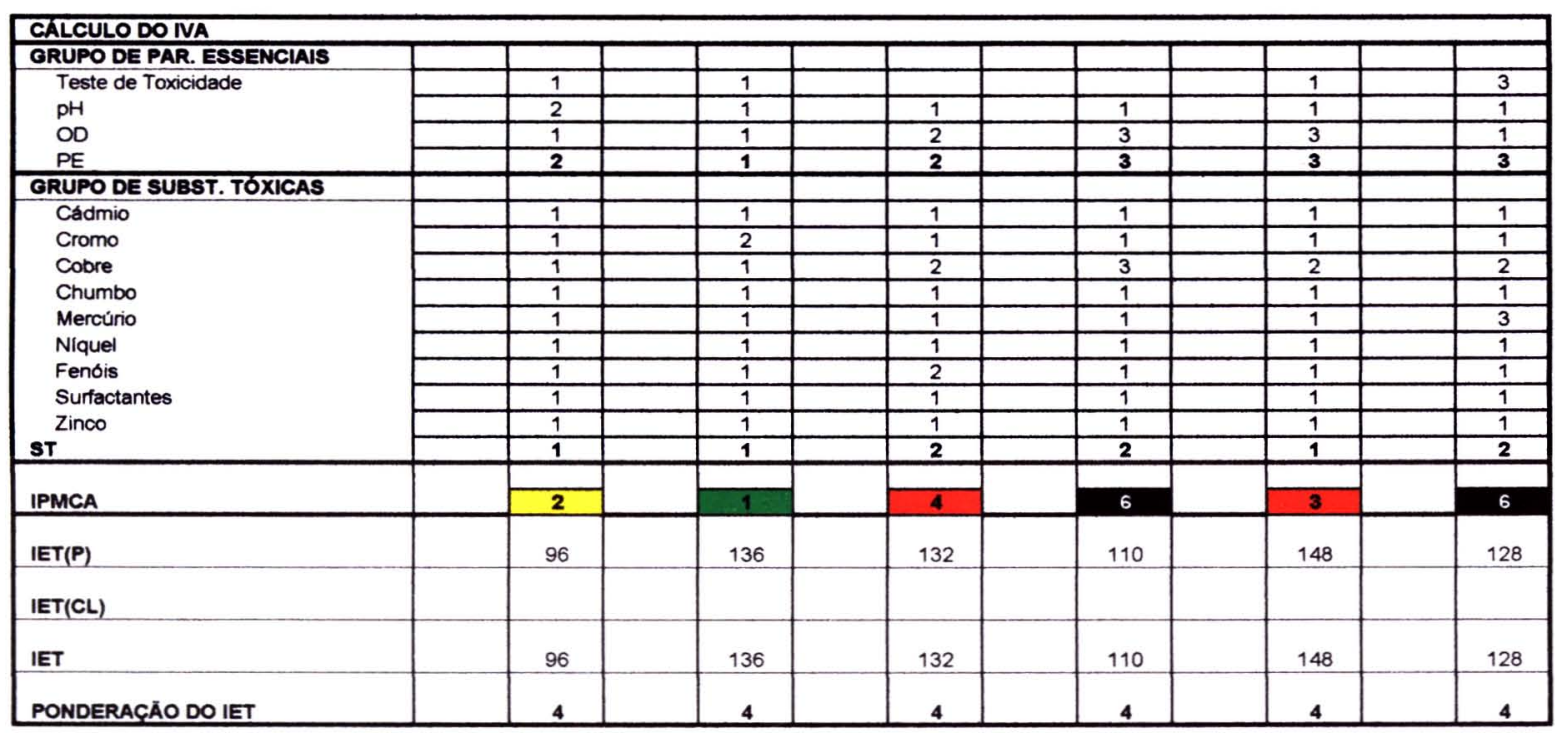

\begin{tabular}{|l|l|l|l|l|l|l|l|l|l|l|l|}
\hline VALOR DOIVA & & 6,4 & & 5,2 & & 8,8 & & 11,2 & & 7,6 & \\
\hline
\end{tabular}

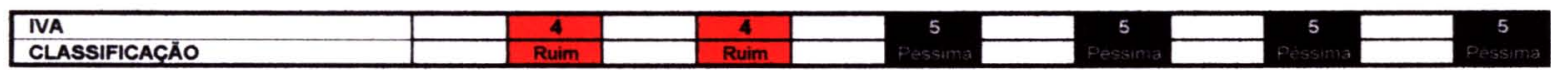

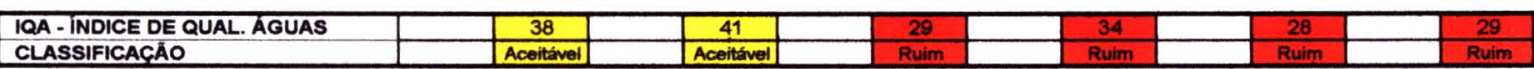


Tabela A31 - Parâmetros que influenciaram na qualidade das águas classificadas pelo IVA como Regular, Ruim e Péssima, no ponto CUBA02700, no período de 1995 a 2000.

\begin{tabular}{c|c|c|c|c|c|c|c|c}
\hline \multicolumn{1}{c}{ Ponto: CUBA02700 } \\
\hline Parámetros & $\mathbf{1 9 9 5}$ & $\mathbf{1 9 9 6}$ & $\mathbf{1 9 9 7}$ & $\mathbf{1 9 9 8}$ & $\mathbf{1 9 9 9}$ & $\mathbf{2 0 0 0}$ & $\begin{array}{c}\mathbf{1 9 9 5 -} \\
\mathbf{2 0 0 0}\end{array}$ & $\begin{array}{c}\text { \% } \\
\text { influéncia }\end{array}$ \\
\hline Total & 4 & 10 & 8 & 6 & 5 & 5 & 38 & \\
\hline Toxicidade & 1 & 4 & 2 & 4 & 3 & 1 & 15 & 39,5 \\
\hline $\mathrm{pH}$ & - & - & - & - & 2 & - & 2 & 5,3 \\
\hline OD & - & - & - & - & - & - & 0 & 0,0 \\
\hline Cádmio & 1 & 1 & - & - & - & - & 2 & 5,3 \\
\hline Cobre & 1 & 1 & - & - & - & 1 & 3 & 7,9 \\
\hline Chumbo & - & 1 & 1 & - & - & 1 & 3 & 7,9 \\
\hline Cromo & - & - & 1 & 1 & - & - & 2 & 5,3 \\
\hline Mercúrio & - & 1 & - & - & - & - & 1 & 2,6 \\
\hline Níquel & - & 1 & - & - & - & - & 1 & 2,6 \\
\hline Fenóis & - & 1 & 2 & 1 & - & 2 & 6 & 15,8 \\
\hline Zinco & - & - & 1 & - & - & - & 1 & 2,6 \\
\hline IET (P) & 1 & - & 1 & - & - & - & 2 & 5,3 \\
\hline
\end{tabular}

Tabela A32 - Parâmetros que influenciaram na qualidade das águas classificadas pelo IVA como Regular, Ruim e Péssima, no ponto CUBA03900, no período de 1995 a 2000.

\begin{tabular}{c|c|c|c|c|c|c|c|c}
\hline \multicolumn{1}{c}{ Ponto: CUBA03900 } \\
\hline Parámetros & 1995 & $\mathbf{1 9 9 6}$ & $\mathbf{1 9 9 7}$ & $\mathbf{1 9 9 8}$ & $\mathbf{1 9 9 9}$ & $\mathbf{2 0 0 0}$ & $\begin{array}{c}\mathbf{1 9 9 5 -} \\
\mathbf{2 0 0 0}\end{array}$ & $\begin{array}{c}\text { \% } \\
\text { influéncia }\end{array}$ \\
\hline Total & 7 & 11 & 8 & 7 & 12 & 2 & 47 & \\
\hline Toxicidade & - & 1 & 1 & 1 & 1 & 1 & 5 & 10,6 \\
\hline pH & - & - & - & - & 3 & - & 3 & 6,4 \\
\hline OD & - & - & - & - & - & - & - & - \\
\hline Cádmio & 1 & 2 & - & - & - & - & 3 & 6,4 \\
\hline Cobre & 1 & 1 & - & - & 1 & - & 3 & 6,4 \\
\hline Chumbo & - & - & - & 1 & - & - & 1 & 2,1 \\
\hline Cromo & - & - & - & - & - & - & - & - \\
\hline Mercúrio & - & - & - & - & - & - & - & - \\
\hline Níquel & - & 1 & 1 & - & 1 & - & 3 & 6,4 \\
\hline Fenóis & - & 3 & 2 & - & 2 & - & 7 & 14,9 \\
\hline Zinco & - & - & 1 & - & - & - & 1 & 2,1 \\
\hline IET $(\mathrm{P})$ & 5 & 3 & 3 & 5 & 4 & 1 & 21 & 44,7 \\
\hline
\end{tabular}


Tabela A33 - Parâmetros que influenciaram na qualidade das águas classificadas pelo IVA como Regular, Ruim e Péssima, no ponto CFUG02900, no período de 1995 a 2000.

\begin{tabular}{c|c|c|c|c|c|c|c|c}
\hline \multicolumn{10}{c}{ Ponto: CFUG02900 } \\
\hline Parâmetros & $\mathbf{1 9 9 5}$ & $\mathbf{1 9 9 6}$ & $\mathbf{1 9 9 7}$ & $\mathbf{1 9 9 8}$ & $\mathbf{1 9 9 9}$ & $\mathbf{2 0 0 0}$ & $\begin{array}{c}\mathbf{1 9 9 5 -} \\
\mathbf{2 0 0 0}\end{array}$ & $\begin{array}{c}\% \\
\text { influência }\end{array}$ \\
\hline Total & 5 & 4 & 9 & 6 & 8 & 5 & 37 & \\
\hline Toxicidade & - & - & 4 & 4 & 3 & 2 & 13 & 35,1 \\
\hline pH & 1 & - & 2 & - & 1 & - & 4 & 10,8 \\
\hline OD & - & - & - & 1 & - & - & 1 & 2,7 \\
\hline Cádmio & 1 & 1 & 1 & - & - & - & 3 & 8,2 \\
\hline Cobre & 1 & - & - & - & - & - & 1 & 2,7 \\
\hline Chumbo & - & - & - & 1 & - & 1 & 2 & 5,4 \\
\hline Cromo & - & - & - & - & - & - & - & - \\
\hline Mercúrio & - & - & - & - & - & - & - & - \\
\hline Niquel & - & 1 & - & - & 1 & 1 & 3 & 8,1 \\
\hline Fenóis & - & - & - & - & 1 & - & 1 & 2,7 \\
\hline Zinco & - & - & - & - & - & - & - & - \\
\hline IET (P) & 2 & 2 & 2 & - & 2 & 1 & 9 & 24,3 \\
\hline
\end{tabular}

Tabela A34 - Parâmetros que influenciaram na qualidade das águas classificadas pelo IVA como Regular, Ruim e Péssima, no ponto MOGI02800, no período de 1995 a 2000

\begin{tabular}{c|c|c|c|c|c|c|c|c}
\hline \multicolumn{10}{c}{ Ponto: MOG102800 } \\
\hline Parámetros & $\mathbf{1 9 9 5}$ & $\mathbf{1 9 9 6}$ & $\mathbf{1 9 9 7}$ & $\mathbf{1 9 9 8}$ & $\mathbf{1 9 9 9}$ & $\mathbf{2 0 0 0}$ & $\begin{array}{c}\mathbf{1 9 9 5 -} \\
\mathbf{2 0 0 0}\end{array}$ & $\begin{array}{c}\text { \% } \\
\text { influência }\end{array}$ \\
\hline Total & 16 & 16 & 12 & 14 & 13 & 9 & 80 & \\
\hline Toxicidade & 2 & 2 & 3 & 2 & 1 & 1 & 11 & 13,7 \\
\hline $\mathrm{pH}$ & 2 & 2 & 1 & 3 & 4 & 2 & 14 & 17,5 \\
\hline OD & - & - & - & 2 & - & - & 2 & 2,5 \\
\hline Cádmio & 2 & 2 & 1 & - & - & - & 5 & 6,2 \\
\hline Cobre & 1 & 1 & - & - & - & - & 2 & 2,5 \\
\hline Chumbo & - & - & - & - & - & - & - & - \\
\hline Cromo & - & - & - & - & - & - & - & - \\
\hline Mercúrio & - & - & - & 1 & - & - & 1 & 1,2 \\
\hline Niquel & 1 & - & - & - & - & - & 1 & 1,2 \\
\hline Fenóis & 2 & 3 & 1 & - & 1 & - & 7 & 8,7 \\
\hline IET (P) & 6 & 6 & 6 & 6 & 7 & 6 & 37 & 46,2 \\
\hline
\end{tabular}


Tabela A35 - Parâmetros que influenciaram na qualidade das águas classificadas pelo IVA como Regular, Ruim e Péssima, no ponto PIAC02700, no período de 1995 a 2000.

Ponto: PIAC02700

\begin{tabular}{c|c|c|c|c|c|c|c|c}
\hline Parâmetros & $\mathbf{1 9 9 5}$ & $\mathbf{1 9 9 6}$ & $\mathbf{1 9 9 7}$ & $\mathbf{1 9 9 8}$ & $\mathbf{1 9 9 9}$ & $\mathbf{2 0 0 0}$ & $\begin{array}{c}\mathbf{1 9 9 5 -} \\
\mathbf{2 0 0 0}\end{array}$ & $\begin{array}{c}\% \\
\text { influéncia }\end{array}$ \\
\hline Total & 23 & 33 & 32 & 22 & 16 & 16 & 142 & \\
\hline Toxicidade & 2 & 3 & 5 & 4 & 1 & 1 & 16 & 11,3 \\
\hline $\mathrm{pH}$ & 3 & 2 & 2 & 2 & 3 & 1 & 13 & 9,1 \\
\hline OD & 3 & 4 & 5 & 5 & 2 & 3 & 22 & 15,5 \\
\hline Cádmio & 2 & 4 & 1 & - & - & - & 7 & 4,9 \\
\hline Cobre & 1 & 2 & 1 & 1 & - & 3 & 8 & 5,6 \\
\hline Chumbo & - & - & - & 1 & - & - & 1 & 0,7 \\
\hline Cromo & - & - & - & - & - & - & - & - \\
\hline Mercúrio & - & 1 & 1 & - & - & 1 & 3 & 2,1 \\
\hline Niquel & 2 & 6 & 5 & 2 & 2 & - & 17 & 12,0 \\
\hline Fenóis & 3 & 4 & 6 & 1 & 2 & 1 & 17 & 12,0 \\
\hline Zinco & 1 & 1 & - & - & - & & 2 & 1,4 \\
\hline IET (P) & 6 & 6 & 6 & 6 & 6 & 6 & 36 & 25,3 \\
\hline & & & & & & & &
\end{tabular}


Tabela A 36 - Sumário da análise estatística da média móvel do IVA realizada para o ponto CUBA 02700

Analysis Summary

Data variable: MMCUBA02700

Number of observations $=61$

Start index $=1,0$

Sampling interval $=1,0$

Forecast Summary

Nonseasonal differencing of order: 1

Forecast model selected: $\operatorname{ARIMA}(1,1,0)$ with constant

Number of forecasts generated: 12

Number of periods withheld for validation: 0

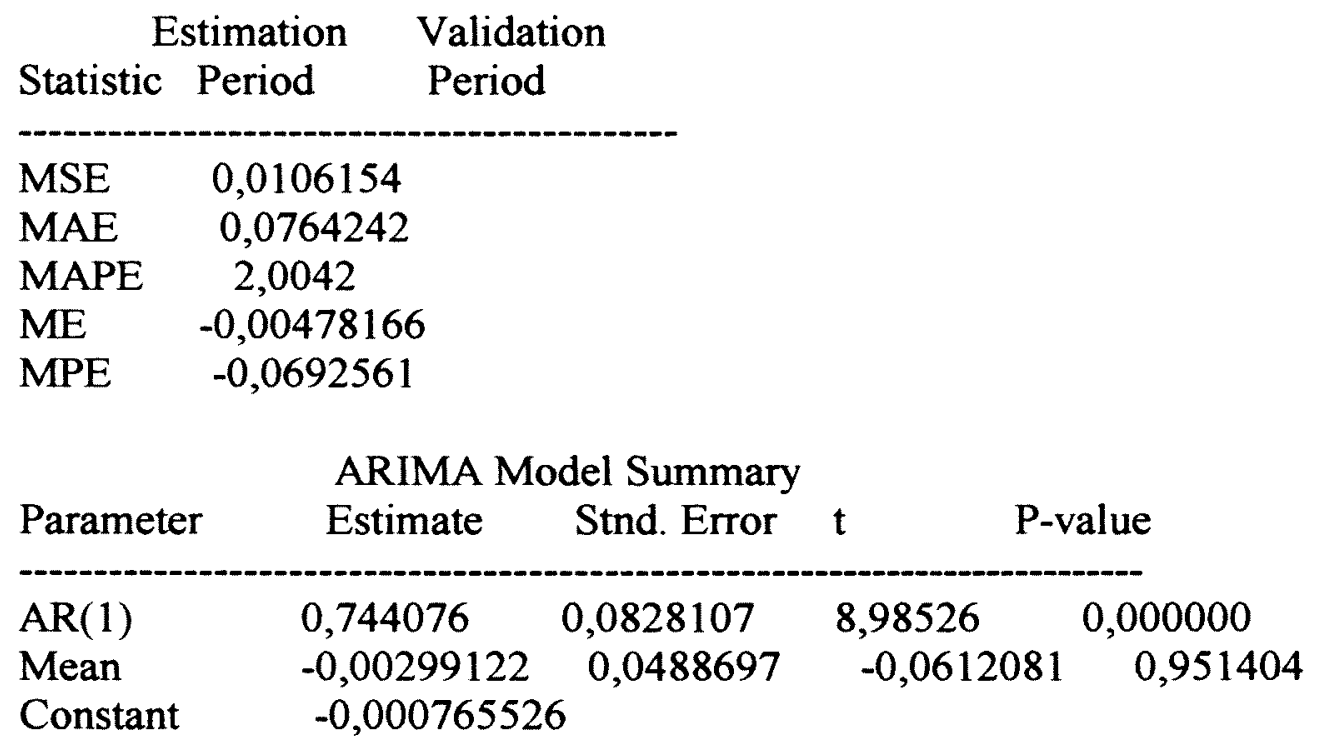


Tabela A 37 - Sumário da análise estatística da média móvel do IVA realizada para o ponto CUBA 03900

Analysis Summary

Data variable: MMCUBA03900

Number of observations $=61$

Start index $=1,0$

Sampling interval $=1,0$

Forecast Summary

Nonseasonal differencing of order: 1

Forecast model selected: $\operatorname{ARIMA}(1,1,0)$ with constant Number of forecasts generated: 12

Number of periods withheld for validation: 0

$\begin{array}{ll}\text { Estimation } & \text { Validation } \\ \text { Statistic Period } & \text { Period }\end{array}$

$\begin{array}{lc}\text { MSE } & 0,00672485 \\ \text { MAE } & 0,0654784 \\ \text { MAPE } & 1,51389 \\ \text { MPE } & -0,000304713\end{array}$

\begin{tabular}{llccc} 
& \multicolumn{2}{c}{ ARIMA Model Summary } & \\
Parameter & Estimate & Stnd. Error & $t$ & \multicolumn{1}{c}{ P-value } \\
\hline AR(1) & 0,722458 & 0,0906891 & 7,96632 & 0,000000 \\
Mean & $-0,0157625$ & 0,0369592 & $-0,426484$ & 0,671334 \\
Constant & $-0,00437474$ & & &
\end{tabular}


Tabela A 38 - Sumário da análise estatística da média móvel do IVA realizada para o ponto CFUG 02900

Analysis Summary

Data variable: MMCFUG02900

Number of observations $=61$

Start index $=1,0$

Sampling interval $=1,0$

Forecast Summary

Nonseasonal differencing of order: 1

Forecast model selected: $\operatorname{ARIMA}(1,1,0)$ with constant

Number of forecasts generated: 12

Number of periods withheld for validation: 0

\begin{tabular}{lc}
\multicolumn{2}{c}{ Estimation } \\
Statistic & Period \\
\hline MSE & 0,0105814 \\
MAE & 0,0791733 \\
MAPE & 1,90851 \\
ME & 0,000317726 \\
MPE & 0,00363504
\end{tabular}

\begin{tabular}{llccc} 
& \multicolumn{2}{c}{ ARIMA Model Summary } & \\
Parameter & Estimate & Stnd. Error & $t$ & P-value \\
\hline AR(1) & 0,476744 & 0,116057 & 4,10785 & 0,000127 \\
Mean & $-0,00451741$ & 0,0246557 & $-0,18322$ & 0,855265 \\
Constant & $-0,00236376$ & & &
\end{tabular}


Tabela A 39 - Sumário da análise estatística da média móvel do IVA realizada para o ponto MOGI 02800

Analysis Summary

Data variable: MMMOGI02800

Number of observations $=61$

Start index $=1,0$

Sampling interval $=1,0$

Forecast Summary

Nonseasonal differencing of order: 1

Forecast model selected: ARIMA(1,1,0) with constant

Number of forecasts generated: 12

Number of periods withheld for validation: 0

Estimation Validation

Statistic Period Period

$\begin{array}{lc}\text { MSE } & 0,0268687 \\ \text { MAE } & 0,12103 \\ \text { MAPE } & 1,74388 \\ \text { ME } & -0,0012068 \\ \text { MPE } & 0,000991032\end{array}$

\begin{tabular}{llccc} 
& \multicolumn{2}{c}{ ARIMA Model Summary } & \\
Parameter & Estimate & Stnd. Error & $t$ & P-value \\
\hline AR(1) & 0,6584 & 0,0984939 & 6,68468 & 0,000000 \\
Mean & $-0,0159076$ & 0,0600358 & $-0,264969$ & 0,791973 \\
Constant & $-0,00543405$ & & &
\end{tabular}


Tabela A 40 - Sumário da análise estatística da média móvel do IVA realizada para o ponto PIAC 02700

\author{
Analysis Summary \\ Data variable: MMPIAC02700 \\ Number of observations $=61$ \\ Start index $=1,0$ \\ Sampling interval $=1,0$ \\ Forecast Summary
}

Nonseasonal differencing of order: 1

Forecast model selected: ARIMA(1,1,0) with constant

Number of forecasts generated: 12

Number of periods withheld for validation: 0

\begin{tabular}{|c|c|c|c|c|c|}
\hline & timatic & Validat & ion & & \\
\hline Statistic I & Period & Period & & & \\
\hline MSE & 0,033 & 1452 & & & \\
\hline MAE & 0,130 & 049 & & & \\
\hline MAPE & 1,42 & 247 & & & \\
\hline $\mathrm{ME}$ & $-0,003$ & 04397 & & & \\
\hline MPE & 0,000 & 737155 & & & \\
\hline & & ARIMA Mc & del Summary & & \\
\hline Parameter & & Estimate & Stnd. Error & $\mathrm{P}$ & -value \\
\hline $\operatorname{AR}(1)$ & & 0,732286 & 0,091647 & 7,99029 & 0,000000 \\
\hline Mean & & 0,00371188 & 0,0809601 & 0,0458483 & 0,963589 \\
\hline Constant & & 0,000993723 & & & \\
\hline
\end{tabular}

